Keywords: DWPF Glass, Melt

Rate Model, X-Ray Computed

Tomography

Retention: Permanent

\title{
Determination of HLW Glass Melt Rate Using X-Ray Computed Tomography (CT)
}
A. S. Choi
D. H. Miller
D. M. Immel

October 2011

Savannah River National Laboratory Savannah River Nuclear Solutions, LLC Aiken, SC 29808

Prepared for the U.S. Department of Energy under

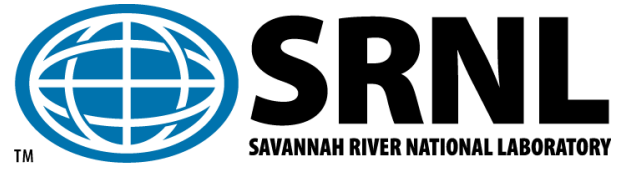
contract number DE-AC09-08SR22470. 
SRNL-STI-2010-00767

Revision 0

\section{DISCLAIMER}

This work was prepared under an agreement with and funded by the U.S. Government. Neither the U.S. Government or its employees, nor any of its contractors, subcontractors or their employees, makes any express or implied:

1. warranty or assumes any legal liability for the accuracy, completeness, or for the use or results of such use of any information, product, or process disclosed; or

2. representation that such use or results of such use would not infringe privately owned rights; or

3. endorsement or recommendation of any specifically identified commercial product, process, or service.

Any views and opinions of authors expressed in this work do not necessarily state or reflect those of the United States Government, or its contractors, or subcontractors.

\section{Printed in the United States of America \\ Prepared for \\ U.S. Department of Energy}




\section{REVIEWS AND APPROVALS}

\section{AUTHORS:}

A. S. Choi, Engineering Process Development

Date

D. H. Miller, Engineering Process Development

Date

D. M. Immel, Imaging \& Radiation Systems

Date

TECHNICAL REVIEW:

K. M. Fox, Process Technology Programs

Date

D. K. Peeler, Process Technology Programs

Date

APPROVAL:

A. B. Barnes, Manager

Date

Engineering Process Development

S.L. Marra, Manager

Date

Environmental \& Chemical Process Technology Research Programs 


\section{ACKNOWLEDGEMENTS}

The authors acknowledge the EM-31 Technology Development \& Deployment (TDD) Program (WP-4.2.3) at the U.S. Department of Energy Office of Environmental Management for financial support of this work. 


\section{EXECUTIVE SUMMARY}

A new technique has been developed that can be used to accurately determine the relative melt rates of simulated high-level waste (HLW) blended with glass forming frits or chemicals. It involves X-ray scanning and computed tomography (CT) to build three-dimensional (3-D) volumetric data of a heat-treated sample and performing an adaptive segmentation analysis of CT data to not only identify morphologically distinct regions in the sample matrix but quantify the relative amounts of material in each region based on the CT density scale.

Bench-scale melt rate testing to confirm the applicability of X-ray CT to the HLW glasses began with relatively simple frit-only feeds containing no gas generators and progressed to the fullblown HLW glass compositions. A 2"-diameter stainless steel beaker containing enough feed to make approximately $60 \mathrm{~g}$ of glass (when fully melted) was heated from the bottom, thus simulating the 1-D heating that the feed undergoes in the cold cap of actual melters. The resulting $\mathrm{X}$-ray images of heat-treated blended feeds revealed the presence of three distinct layers or zones: melt, froth, and un-melted. The froth layer is defined as where melted material is interspersed among gas bubbles. As expected, heat-treated frit-only feeds showed only the melt and un-melt layers and no froth layer, since they did not contain any gas generators.

The amount of material in each of the melt, froth and un-melt layers was calculated by finding the area under their respective CT histogram peaks, and the resulting material counts were used as the basis for ranking various feeds for their relative melt rates. It turns out that of several different CT-based material rankings, the one based on the total amount of material in the melt and froth layers combined would give the most robust measure of relative melt rates for the entire range of

feed compositions tested in this work. Furthermore, it seems prudent from the standpoint of continuously-fed melter operation to add the froth material in the relative melt rate determination. The relative melt rates of the same feeds were also determined visually using the X-ray images taken of a randomly-picked center-cut plane of each heat-treated sample and the resulting relative melt rate rankings were then compared to those based on the CT method.

A total of 32 melt rate runs were made using 10 frit-only and 22 blended feed compositions. Of the 22 blended feed runs, 4 runs were made with the sludge feeds containing four different combinations of bounding concentrations of $\mathrm{Al}, \mathrm{Fe}, \mathrm{Ca}, \mathrm{Mn}, \mathrm{Mg}$, and $\mathrm{Ni}$ each coupled with Frit 418 at 36\% waste loading; 6 runs were made with Sludge Batch 6 (SB6) simulant coupled with Frit 418 at six different targeted waste loadings ranging from 30 to $43 \%$ in $3 \%$ increments; and 12 additional SB6 runs were made with 12 different frit compositions each at 36\% waste loading. Some of the key findings from these runs include:

- Besides the alkali modifiers, the primary factors affecting the melt rate were:

1. concentration of gas generators such as nitrate and $\mathrm{Mn}^{4+}$ (negative impact the higher the concentration of gas generators, the lower the melt rate),

2. concentration of non-alkali modifiers such as $\mathrm{MnO}$ and $\mathrm{CaO}$ particularly at $\mathrm{B}_{2} \mathrm{O}_{3}$ concentrations $>10 \mathrm{wt} \%$ (positive impact - the higher the concentrations of $\mathrm{MnO}$ and $\mathrm{CaO}$, the higher the melt rate),

3. concentration of high field-potential modifiers such as $\mathrm{MgO}$ (negative impact the higher the concentration of $\mathrm{MgO}$, the lower the melt rate),

4. melt viscosity (negative impact - the higher the melt viscosity, the lower the melt rate). 
- Of the ten frit-only feeds tested, those containing $>12$ mol\% $\mathrm{Li}_{2} \mathrm{O}$ and $>11 \mathrm{~mol} \% \mathrm{~B}_{2} \mathrm{O}_{3}$ coupled with $<7 \mathrm{~mol} \% \mathrm{Na}_{2} \mathrm{O}$ melted significantly slower likely due to the tightening of the network structure as a result of higher field-strength modifier $\mathrm{Li}^{+}$coupling with $\mathrm{BO}_{4}{ }^{-}$ and NBO more easily than lower field-strength modifier $\mathrm{Na}^{+}$.

- Had the CT-based melt rate of the 33\% WL feed of SB6/Frit 418 been $\sim 10 \%$ higher, the CT-based melt rate profile would have shown the trend of monotonically decreasing melt rate with increasing WL throughout the WL range tested. On the other hand, the visual method-based melt rate profile did not show the same trend, although it did earlier with SB2/3 feeds.

- Of the twelve frits tested in conjunction with SB6 at 36\% WL, Frit CEF-10 that contains an additional $8 \mathrm{wt} \% \mathrm{~B}_{2} \mathrm{O}_{3}$ at the expense of $\mathrm{SiO}_{2}$ and $\mathrm{Na}_{2} \mathrm{O}$ at $4 \mathrm{wt} \%$ each (thus resulting in the highest relative concentration of $\mathrm{Li}_{2} \mathrm{O}$ ) was ranked last or the slowest melting frit.

- Frit CEF-9 that contains the highest concentration of modifiers including $4 \% \mathrm{MnO}$ and $2 \% \mathrm{CaO}$ added at the expense of $\mathrm{SiO}_{2}$ and $\mathrm{Na}_{2} \mathrm{O}$ in Frit 418, respectively, was ranked first or the fastest melting frit for SB6.

- Frit CEF-1 that contains an additional $3 \mathrm{wt} \% \mathrm{~B}_{2} \mathrm{O}_{3}$ added at the expense of $\mathrm{SiO}_{2}$ in Frit 418 increased the melt rate of SB6 only by 3\% from that of Frit 418.

- Frit 510 that contains an additional $6 \mathrm{wt} \% \mathrm{~B}_{2} \mathrm{O}_{3}$ added at the expense of $\mathrm{SiO}_{2}$ in Frit 418 decreased the melt rate of SB 6 by $9 \%$ from that of Frit 418 .

The glass samples from the twelve SB6/varying frit runs were sent to SIA Radon in Russia to perform structural characterization and analysis using high-resolution spectroscopic tools such as XPS, XANES, EXAFS, EPR, IR and Raman Spectroscopy. One of the key findings from the study was that the main structural units of the SB6 glass samples were metasilicate chains and rings, which confirms the current basis for the silicate phase used in the DWPF cold cap model. Unfortunately, the study could not provide quantitative information on the boron coordination which is essential to the understanding of the melting behavior of aluminoborosilicate HLW glasses. Additional findings are summarized later in this report and the final report by SIA Radon is also attached at the end of this report.

As a result, an attempt was made in this work to theoretically predict the boron coordination of a known glass system found in the literature by applying the field strengths of modifier ions to the modified Dell-Bray model for aluminoborosilicate glasses. The fractions of 4-coordinated boron $\left(\mathrm{N}_{4}\right)$ and non-bridging oxygen (NBO) thus predicted were found to be in good qualitative agreement with their respective measured values for the $\mathrm{Na}_{2} \mathrm{O}-\mathrm{CaO}-\mathrm{Al}_{2} \mathrm{O}_{3}-\mathrm{B}_{2} \mathrm{O}_{3}-\mathrm{SiO}_{2}$ system. When the same approach was next extended to the frit-only glass compositions studied in this work, it was found that the weighted sum of modifier concentrations alone could be used to predict the relative melt rate trends determined by the CT method reasonably well. These results suggest that the theoretical approach taken in this work is on the right track to improve the predictability of the existing DWPF melt rate model and the X-ray CT technique could provide necessary data for the calibration and validation of the model.

This report documents both experimental and theoretical studies performed to improve the existing DWPF melt rate model under the EM-31 funding. Since the original scope of work has not been completed due to lack of funding, the contents of this report do not represent the final set of data and analysis necessary for the model improvement. Furthermore, although there are some significant differences between SRS and Hanford waste chemistry, the same experimental and theoretical approaches taken in this work could potentially be applied to the WTP Hanford melters, since the underlying principles of optimization of frit or glass-forming chemicals are the same. 


\section{TABLE OF CONTENTS}

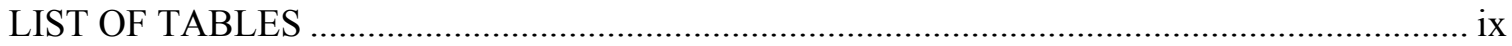

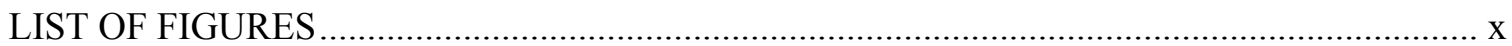

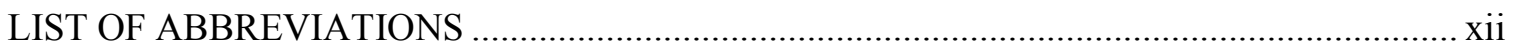

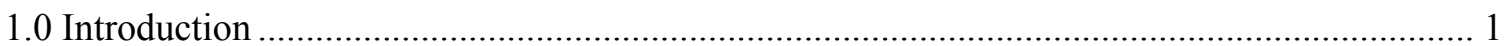

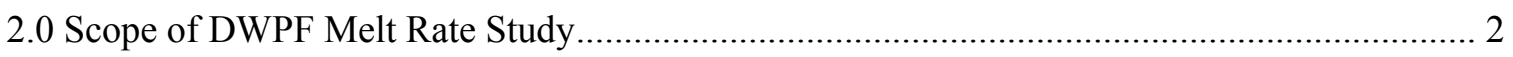

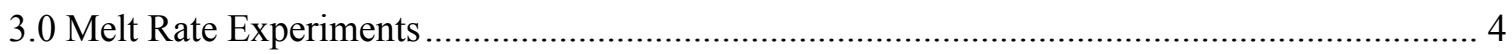

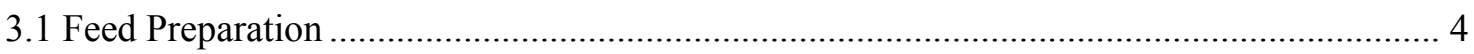

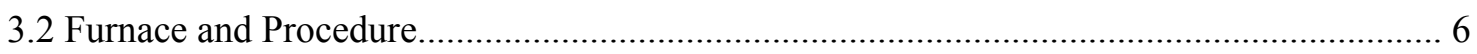

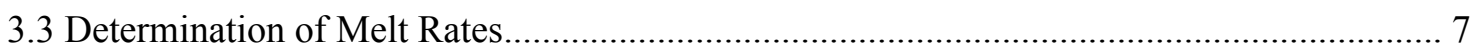

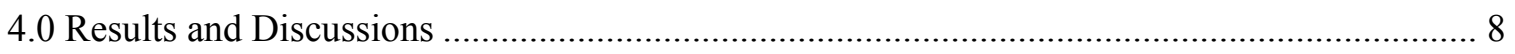

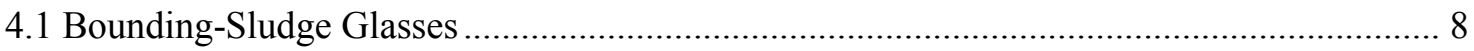

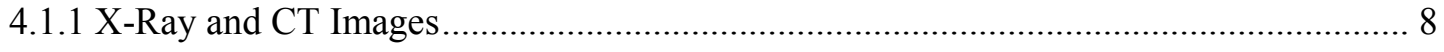

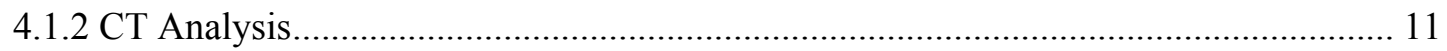

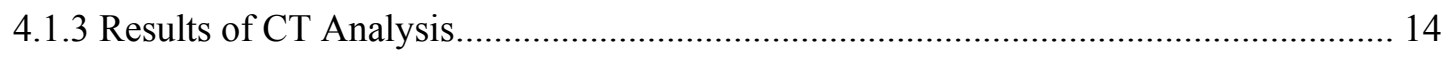

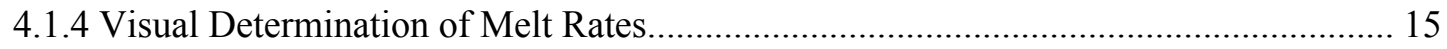

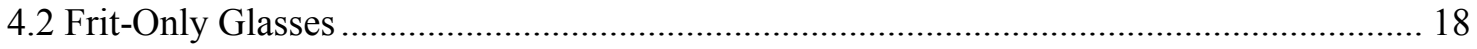

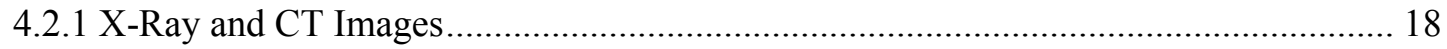

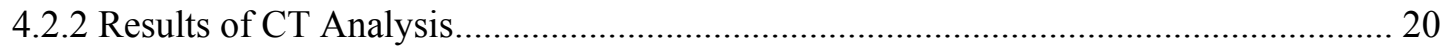

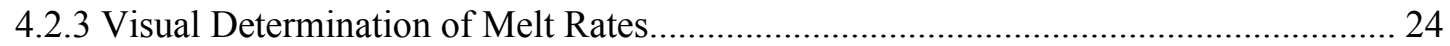

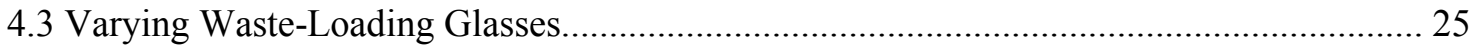

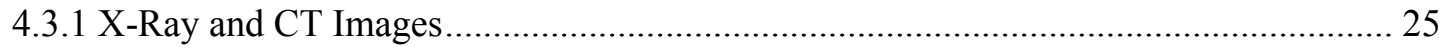

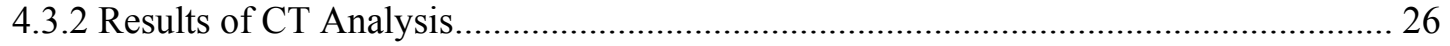

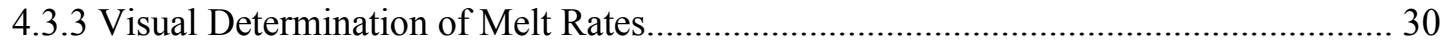

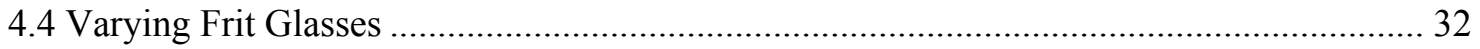

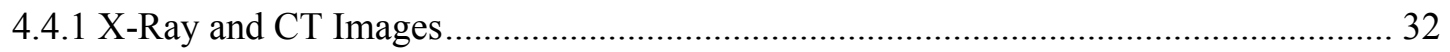

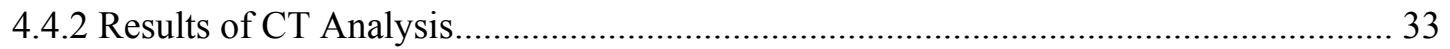

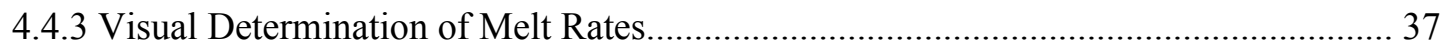

4.4.4 High-Resolution Spectroscopy Studies of SB6/Varying Frit Series Glasses................ 38

4.5 Theoretical Treatment of Frit-Only Glass Melt Rates ...................................................... 39

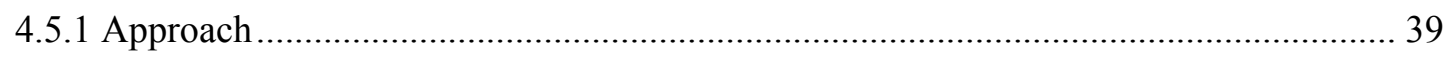

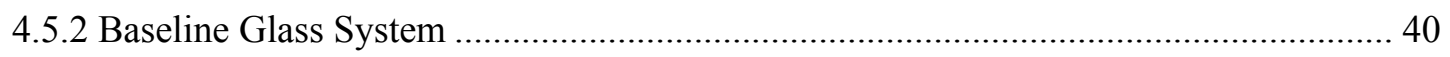

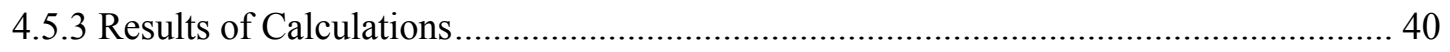

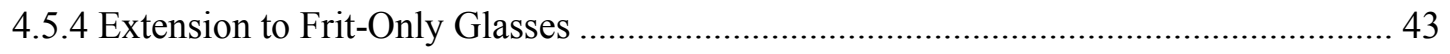


SRNL-STI-2010-00767

Revision 0

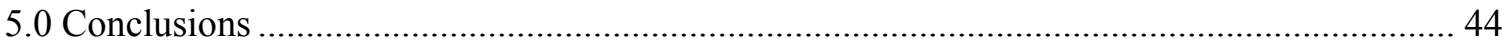

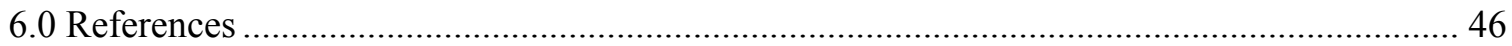

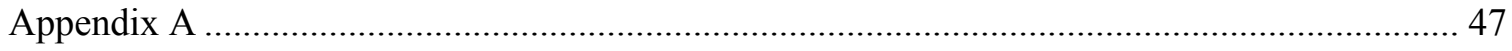




\section{LIST OF TABLES}

Table 3-1. Design Matrix of Bounding-Sludge Glasses............................................................... 4

Table 3-2. Compositions of Bounding-Sludge SRAT Products [Ref. 6] ..................................... 5

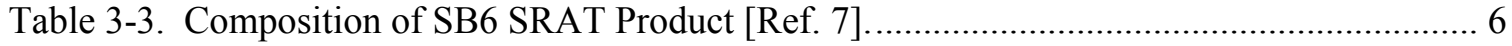

Table 4-1. Concentrations of Key Elements in Bounding Sludge SRAT Product...................... 10

Table 4-2. CT-Calculated Distribution of Material and Density of Bounding-Sludge Feeds...... 15

Table 4-3. CT-Based Melt Rate Rankings of Bounding-Sludge/Frit 418 Feeds......................... 15

Table 4-4. Measured Melt Rates of Bounding-Sludge/Frit 418 Using Visual Method................ 16

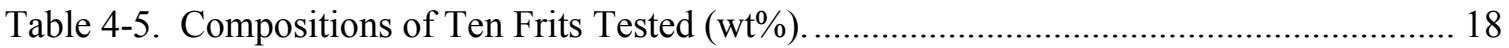

Table 4-6. CT-Calculated Distribution of Material and Density of Frit-Only Feeds. ................... 22

Table 4-7. CT-Based Melt Rate Rankings of Frit-Only Feeds................................................... 23

Table 4-8. Melt Rate Rankings vs. Frit Compositions (rounded to the nearest 1 mol\%)............. 23

Table 4-9. Visual vs. CT-Based Melt Rate Rankings and Frit Compositions (mol\%).................. 24

Table 4-10. CT-Calculated Distribution of Material and Density of SB6/Frit 418 WL Feeds. .... 29

Table 4-11. CT-Based Melt Rate Rankings of SB6/Frit 418 WL Feeds (\% WL)........................ 30

Table 4-12. Measured Linear Melt Rates of SB6/Frit 418 WL Feeds Using Visual Method....... 31

Table 4-13. Comparison of 12 Frit Compositions Used in Varying Frit Glass Study (wt\%)....... 32

Table 4-14. CT-Calculated Distribution of Material and Density of SB6/Varying Frit Feeds. .... 35

Table 4-15. CT-Based Melt Rate Rankings of SB6/Varying Frit Feeds (\% WL)........................ 36

Table 4-16. Measured Linear Melt Rates of SB6/Varying Frit Feeds Using Visual Method....... 37

Table 4-17. Shannon Ionic Radii [Ref. 11] and Calculated Field Strengths. ............................... 39

Table 4-18. Measured $\mathrm{N}_{4}$ and NBO Fractions - Compositions in mol\% [Ref. 5]....................... 40 


\section{LIST OF FIGURES}

Figure 1-1. Determination of Linear Melt Rates Using Visual Method....................................... 1

Figure 3-1. A Cross-Sectional View of the MRF....................................................................... 7

Figure 4-1. X-Ray Images of Bounding-Sludge Feeds after Heat Treatment. .............................. 9

Figure 4-2. Comparison of CT Histopics vs. X-Ray Images of Bounding-Sludge Feeds............ 11

Figure 4-3. A Histogram of CT Density vs. Material Amount for SB6/Frit 418 at 30\% WL...... 12

Figure 4-4. A Histogram of CT Density vs. Material Amount for SMEM-1 ............................... 13

Figure 4-5. A Histogram of CT Density vs. Material Amount for SMEM-3 ............................... 13

Figure 4-6. Comparison of Histograms of Four Bounding Sludge/Frit 418 Feeds. ..................... 14

Figure 4-7. Comparison of CT vs. Visual Melt Rates of Bounding-Sludge Feeds. ...................... 17

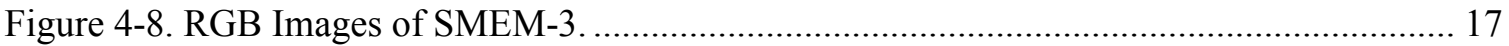

Figure 4-9. X-Ray Images of Heat-Treated Frit-Only Samples. ….......................................... 19

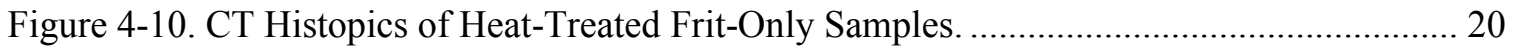

Figure 4-11. A Histogram of CT Density vs. Material Amount for Frit 418 .............................. 21

Figure 4-12. A Histogram of CT Density vs. Material Amount for Frit 519............................. 21

Figure 4-13. A Histogram of CT Density vs. Material Amount for Unfired Frit 418................. 21

Figure 4-14. Relative Melt Rate and Overall Density Profiles of Frit-Only Samples.................. 25

Figure 4-15. X-Ray Images of Heat-Treated SB6/Frit 418 Samples............................................ 26

Figure 4-16. A Histogram of CT Density vs. Material Amount for SB6/Frit 418 @ 43\% WL... 27

Figure 4-17. Comparison of Histograms of SB6/Frit 418 WL Series Feeds................................ 28

Figure 4-18. Colored X-Ray Images of Heat-Treated SB6/Frit 418 WL Samples....................... 28

Figure 4-19. Comparison of CT vs. Visual Based Melt Rates Relative to 36\% WL. ................... 31

Figure 4-20. X-Ray Images of Heat-Treated SB6/Varying Frit Feeds........................................ 33

Figure 4-21. RGB Images of Heat Treated SB6/Varying Frit Feeds. .......................................... 34

Figure 4-22. Histograms of 12 Heat-Treated SB6/Varying Frit Feeds. ....................................... 34

Figure 4-23. Comparison of CT vs. Visual Based Melt Rates Relative to SB6/Frit 418............. 38

Figure 4-24. Calculated vs. Measured $\mathrm{N}_{4}$ for $7 \mathrm{wt} \% \mathrm{~B}_{2} \mathrm{O}_{3}$ Glasses............................................ 41 
Figure 4-25. Calculated vs. Measured $\mathrm{N}_{4}$ for $21 \mathrm{wt} \% \mathrm{~B}_{2} \mathrm{O}_{3}$ Glasses......................................... 41

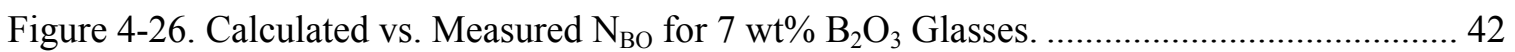

Figure 4-27. Calculated vs. Measured $\mathrm{N}_{\mathrm{BO}}$ for $21 \mathrm{wt} \% \mathrm{~B}_{2} \mathrm{O}_{3}$ Glasses. ...................................... 42

Figure 4-28. Adjusted Modifier Concentration vs. Relative Melt Rates of Varying Frit Feeds... 43 


\section{LIST OF ABBREVIATIONS}

$\begin{array}{ll}\text { ACTL } & \text { Aiken County Technical Laboratory } \\ \text { CN } & \text { Coordination Number } \\ \text { CT } & \text { Computed Tomography } \\ \text { DWPF } & \text { Defense Waste Processing Facility } \\ \text { EPR } & \text { Electron Paramagnetic Resonance } \\ \text { EXAFS } & \text { Extended X-ray Absorption Fine Structure } \\ \text { HLW } & \text { High Level Waste } \\ \text { IR } & \text { Infrared } \\ \text { IRS } & \text { Imaging and Radiation Systems } \\ \text { LLNL } & \text { Lawrence Livermore National Laboratory } \\ \text { LMR } & \text { Linear Melt Rate } \\ \text { MRF } & \text { Melt Rate Furnace } \\ \text { MRI } & \text { Melt Rate Indicator } \\ \text { NBO } & \text { Non-bridging oxygen } \\ \text { NMR } & \text { Nuclear Magnetic Resonance } \\ \text { SB } & \text { Sludge Batch } \\ \text { SRAT } & \text { Sludge Receipt and Adjustment Tank } \\ \text { SRNL } & \text { Savannah River National Laboratory } \\ \text { SRS } & \text { Savannah River Site } \\ \text { SS } & \text { Stainless steel } \\ \text { XANES } & \text { X-ray Absorption Near Edge Structure } \\ \text { WL } & \text { Waste oxide Loading in glass } \\ \text { WTP } & \text { Waste Treatment Plant } \\ \text { XPS } & \text { X-ray Photoelectron Spectroscopy } \\ & \end{array}$




\subsection{Introduction}

The purpose of the high-level waste (HLW) glass melt rate study is two-fold: (1) to gain a better understanding of the impact of feed chemistry on melt rate through bench-scale testing, and (2) to develop a predictive tool for melt rate in support of the on-going frit development efforts for the Defense Waste Processing Facility (DWPF). ${ }^{1}$ In particular, the focus is on predicting relative melt rates, not the absolute melt rates, of various HLW glass formulations solely based on feed chemistry, i.e., the chemistry of both waste and glass-forming frit for DWPF.

Critical to the successful melt rate modeling is the accurate determination of the melting rates of various HLW glass formulations. The baseline procedure being used at the Savannah River National Laboratory (SRNL) is to; (1) heat a 4 inch-diameter stainless steel beaker containing a mixture of dried sludge and frit in a furnace for a preset period of time, (2) section the cooled beaker along its diameter, and (3) measure the average glass height across the sectioned face using a ruler. As illustrated in Figure 1-1, the glass height is measured for each of the 16 horizontal segments up to the red lines where relatively large-sized bubbles begin to appear. The linear melt rate (LMR) is determined as the average of all 16 glass height readings divided by the time during which the sample was kept in the furnace. ${ }^{2}$

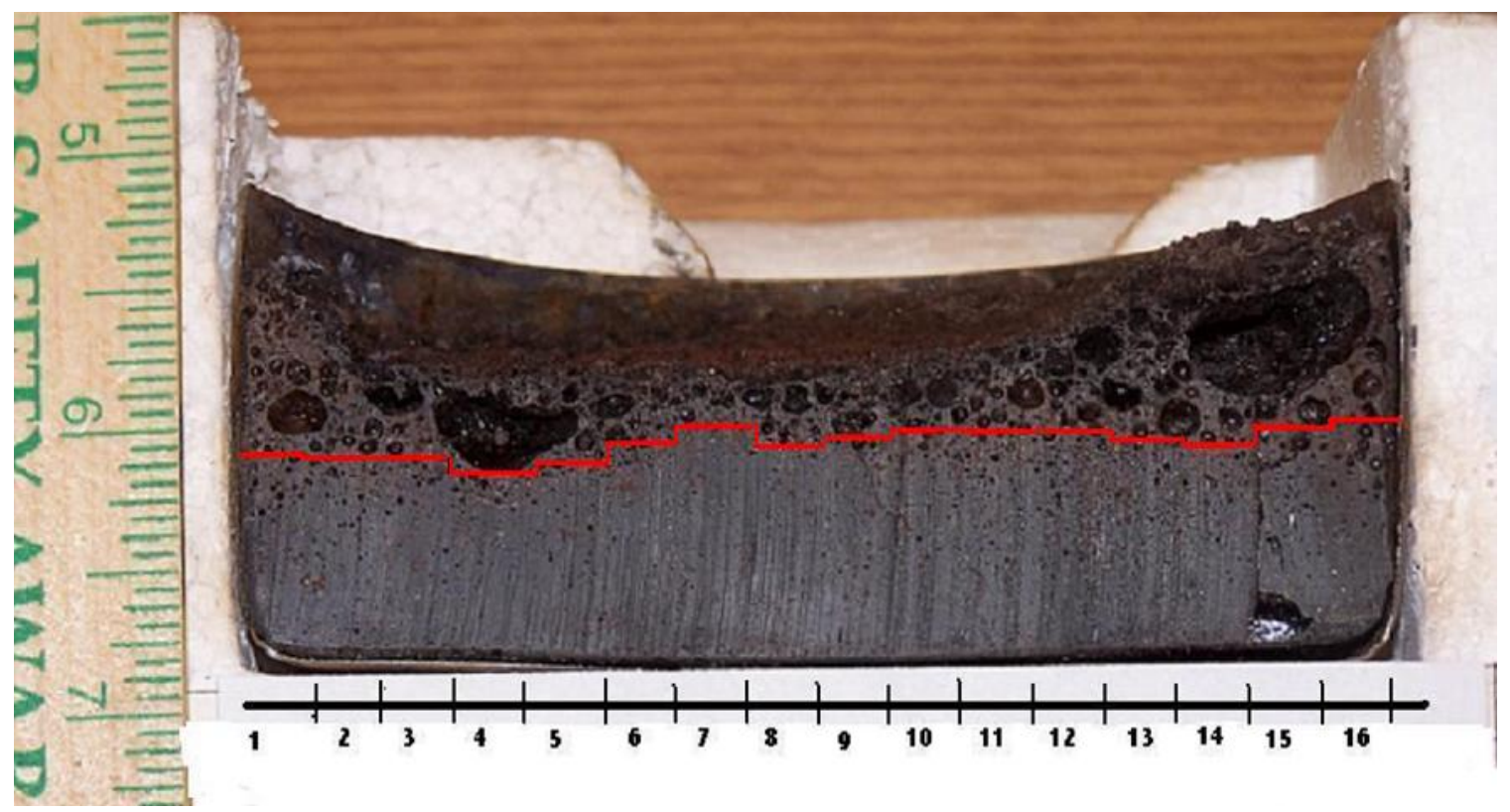

Figure 1-1. Determination of Linear Melt Rates Using Visual Method.

This "visual" method has proved useful in identifying melting accelerants such as alkalis and sulfate and further ranking the relative melt rates of candidate frits for a given sludge batch. However, one of the inherent technical difficulties of this method is to determine the glass height in the presence of numerous gas bubbles of varying sizes, which is prevalent especially for the higher-waste-loading glasses. That is, how the red lines are drawn in Figure 1-1 can be subjective and, therefore, may influence the resulting melt rates significantly. For example, if the red lines are drawn too low, a significant amount of glassy material interspersed among the gas bubbles will be excluded, thus underestimating the melt rate. Likewise, if they are drawn too high, many large voids will be counted as glass, thus overestimating the melt rate. 
As will be shown later in this report, there is also no guarantee that a given distribution of glass and gas bubbles along a particular sectioned plane will always be representative of the entire sample volume. Poor reproducibility seen in some LMR data may be related to these difficulties of the visual method. In addition, further improvement of the existing melt rate model requires that the overall impact of feed chemistry on melt rate be reflected on measured data at a greater quantitative resolution on a more consistent basis than the visual method can provide.

An alternate method being pursued is X-ray computed tomography (CT). It involves X-ray scanning of glass samples, performing CT on the 2-D X-ray images to build 3-D volumetric data, and adaptive segmentation analysis of CT results to not only identify but quantify the distinct regions within each sample based on material density and morphologies. The main advantage of this new method is that it can determine the relative local density of the material remaining in the beaker after the heat treatment regardless of its morphological conditions by selectively excluding all the voids greater than a given volumetric pixel (voxel) size, thus eliminating much of the subjectivity involved in the visual method. As a result, the melt rate data obtained from CT scan will give quantitative descriptions not only on the fully-melted glass, but partially-melted and unmelted feed materials. Therefore, the CT data are presumed to be more reflective of the actual melt rate trends in continuously-fed melters than the visual data.

In order to test the applicability of X-ray CT scan to the HLW glass melt rate study, several new series of HLW simulant/frit mixtures were melted in the Melt Rate Furnace (MRF) and the contents of each cooled but un-sectioned beaker were CT scanned and analyzed. For comparison purposes, a cross-sectional X-ray image of each sample was used to estimate the melt rate using the visual method. In order to see the impact of feed chemistry on melt rate more clearly, a total of ten frit-only glasses (i.e., no waste) were also made, CT scanned and analyzed. In addition, two historical glass series which were previously sectioned were re-joined and CT scanned; the results were then compared to the visual data obtained earlier. All the work performed on these historical samples will be documented separately in another report.

This report describes the methodologies used to interpret and apply the results of X-ray CT scans to the HLW melt rate study and further highlights some of the key results on the compositional dependence of melt rate and the cross-comparison of the visual and CT results. There is evidence that the CT results may get distorted due to X-ray beam hardening effects near the walls of the stainless steel beakers containing glass samples. In this study, the CT results for the ten frit-only glass samples were re-analyzed by correcting for the X-ray beam hardening effects and it was found that the difference between corrected and uncorrected CT results was small enough to have no impact on various relative melt rate rankings derived in this work.

\subsection{Scope of DWPF Melt Rate Study}

The melting rate of HLW glasses is impacted by a host of variables, including the chemistry of waste and frit (or glass forming chemicals) and their relative proportions (e.g., waste loading), the bulk properties of the slurry feed (e.g., solids content and viscosity), and melter design/operating variables (e.g., melt temperature, feed rate or cold cap coverage, air purge, dome heater power, bubbling rate, and configuration of bubblers). The goal of the DWPF melt rate modeling task is to quantify the impact of feed chemistry on relative melt rates, ${ }^{1}$ and the approach taken to achieve that goal is to develop a correlation for the melt rate indicator (MRI), which is the measure of relative melt rates of various glass formulations in the following form: ${ }^{3}$ 


$$
M R I=M R I_{\text {frit }} \cdot M R I_{\text {glass }}
$$

where $M R I_{\text {frit }}=R^{\prime} / K$

$$
R^{\prime}=\left(\left[\mathrm{Na}_{2} \mathrm{O}\right]+0.7\left[\mathrm{Li}_{2} \mathrm{O}\right]-\left[\mathrm{Al}_{2} \mathrm{O}_{3}\right]\right) /\left[\mathrm{B}_{2} \mathrm{O}_{3}\right]
$$

$\mathrm{K}=\left[\mathrm{SiO}_{2}\right] /\left[\mathrm{B}_{2} \mathrm{O}_{3}\right]$

$$
M R I_{\text {glass }}=\frac{\Delta G_{f, m}(\text { sludge } N a-A l-B)^{0.9} \cdot \Delta G_{f, m}(\text { frit } N a-A l-B)^{0.1} \cdot \Delta G_{f, m}(S)^{0.2}}{\Delta G_{f, m}(A l+B) \cdot \Delta G_{f, c g}}
$$

In Eq. (2), the concentrations of oxides are in molar. In Eq. (5), $\Delta G_{f, m}($ sludge $N a-A l-B)$ and $\Delta G_{f, m}($ frit $N a-A l-B)$ are the total free energies of formation of all melt species, excluding those containing aluminum and boron ions as well as the sodium that originated from the frit and sludge, respectively; $\Delta G_{f, m}(A l+B)$ is the total free energy of formation of all melt species containing aluminum or boron ions; $\Delta G_{f, m}(S)$ is the total free energies of formation of all melt species that contain sulfate ion; and $\Delta G_{f, c g}$ is the total free energy of formation of all calcine gas species. The speciation for the melt and spinel phases of the final glass are predicted using the existing DWPF cold cap model, ${ }^{4}$ and all the free energy terms in Eq. (5) are then calculated based on that equilibrium speciation.

The logic behind splitting the overall $M R I$ into the contributions by the frit $\left(M R I_{\text {frit }}\right)$ and glass $\left(M R I_{\text {glass }}\right)$ in Eq. (1) is simply that the faster a given frit melts, the faster it would make contact with the waste species to initiate various solid-liquid and liquid-liquid reactions, resulting in a higher inclusion rate of waste oxides into the glass. This situation can be considered somewhat unique for DWPF since it uses frits instead of glass-forming chemicals along with $\mathrm{SiO}_{2}$. The question is then what factors determine how fast a frit melts. One such factor could be the number of non-bridging oxygen (NBO) per formula weight of frit. This is because the higher the NBO concentration is, the lower the network connectivity is and, therefore, the more easily the network structure would soften upon heating. The calculation of NBO concentration is straightforward if $\mathrm{Si}$ were the only network former. However, the prediction of NBO concentration becomes more complicated when the intermediate oxides and other network formers such as Al and B are present, as in the aluminoborosilicate HLW glasses.

For example, each trigonally-coordinated boron $\left(\mathrm{B}^{3}\right)$ will become tetrahedrally-coordinated $\left(\mathrm{B}^{4}\right)$ by consuming one NBO up to a certain modifier-to-boron oxide ratio and then the trend reverses upon further increase in the modifier-to-boron oxide ratio; $\mathrm{B}^{4}$ reverts back to $\mathrm{B}^{3}$ with an NBO. A recent study also showed that the boron coordination chemistry and the NBO concentration are both affected by the field strength of a given modifier ion. ${ }^{5}$ For example, $\mathrm{Ca}^{2+}$ has a higher field strength than $\mathrm{Na}^{+}$and, therefore, the former would incur the formation of $\mathrm{NBO}$ over $\mathrm{BO}$. When the sum of $\mathrm{Na}_{2} \mathrm{O}$ and $\mathrm{CaO}$ molar concentrations was kept constant, measured NBO concentration decreased with decreasing $\mathrm{CaO} /\left(\mathrm{Na}_{2} \mathrm{O}+\mathrm{CaO}\right)$ ratio, while measured fraction of $\mathrm{B}^{4}\left(\mathrm{~N}_{4}\right)$ increased.

The current melt rate model given in Eq. (1) has at least two major deficiencies. One is the fact that all the terms containing B in Eq. (3) to (5) represent the total B, and the inability to partition the total $\mathrm{B}$ into $\mathrm{B}^{3}$ and $\mathrm{B}^{4}$ makes the model essentially incomplete. The other is the fact that the model has been calibrated using the visual melt rate data only, which can be subjective with sometimes questionable repeatability. The task plan outlines a three-step approach to overcome 
these problems. ${ }^{1} \quad$ The first is to expand the existing thermodynamic database by importing relevant data for borates from the literature and run the DWPF cold cap model using the expanded database to predict boron partitioning in select glass formulations. The second is to perform a high-resolution spectroscopic study to quantify boron partitioning in the same glass formulations used in the first step and use the results to validate model predictions. The third is to perform bench-scale tests to: (1) generate additional melt rate data by employing new glass formulations and the CT technique, (2) validate the adequacy of the visual melt rate data, and (3) improve the existing melt rate model based on the additional insights gained from the modeling, spectroscopic and bench-scale test results. This report summarizes the results obtained so far from Step \#2 and part of Step \#3. The expansions of the thermodynamic database as well as further improvement of the DWPF melt rate model have been suspended due to lack of funding.

\subsection{Melt Rate Experiments}

\subsection{Feed Preparation}

A total of five Sludge Receipt and Adjustment Tank (SRAT) products were used in this study. Four of those were based on the sludge simulants with bounding concentrations of six most abundant metals. ${ }^{6}$ The fifth was the same Sludge Batch 6 (SB6) simulant used in the pilot-scale DWPF melter bubbler tests. ${ }^{7}$ Each SRAT product was blended with a select glass-forming frit according to a mass ratio set by the targeted waste oxide loading in glass and measured calcination ratio of each SRAT product. The blended feed was dried in an oven at $\sim 100{ }^{\circ} \mathrm{C}$ overnight and the dried feed was screened through a 10-mesh $(1.7 \mathrm{~mm})$ screen before being poured into a 2 -inch diameter stainless steel beaker. The purpose of using a 2-inch beaker in lieu of 4-inch was to allow better penetration by X-ray into the entire sample volume using a narrower band and, therefore, at a higher intensity. This yielded higher-resolution images for better distinction between different phases of material remaining in the beaker and eliminated the need for sectioning the beaker. The smaller beaker also required much less feed, which made multiple replications possible with the same amount of feed used in 4-inch beaker tests.

The compositions of the five SRAT products used are shown in Table 3-2 and Table 3-3. The compositions of various frits tested in conjunction with these SRAT products are given later in the Results section. The four SRAT product simulants in Table 3-2 were designed by bounding the concentrations of the six most abundant insoluble metals as follows:

Table 3-1. Design Matrix of Bounding-Sludge Glasses.

\begin{tabular}{||c|c|c|c|c||}
\hline SRAT Product & SMEM-1 & SMEM-2 & SMEM-3 & SMEM-4 \\
\hline $\mathrm{Fe}$ & High & High & Low & Low \\
\hline $\mathrm{Al}$ & Low & Low & High & High \\
\hline $\mathrm{Mn}$ & High & Low & High & Low \\
\hline $\mathrm{Ca}$ & High & Low & High & Low \\
\hline $\mathrm{Mg}$ & Low & High & Low & High \\
\hline $\mathrm{Ni}$ & Low & High & Low & High \\
\hline
\end{tabular}

So, SMEM-1 and SMEM-2 had high Fe/low Al, while SMEM-3 and SMEM-4 had low Fe/high Al. Then, $\mathrm{Mn}$ and $\mathrm{Ca}$ were varied together between high and low as a pair and so were $\mathrm{Mg}$ and $\mathrm{Ni}$ but in the opposite direction of Mn and Ca. Indeed, the composition of the SB6 SRAT product shown in Table 3-3 has the concentrations of the two most abundant insoluble species (Fe and $\mathrm{Al}$ ) that fall near the midpoint of their respective bounding ranges given in Table 3-2. However, the concentrations of Mn and Ca of SB6 are shown to fall outside their respective bounds, while $\mathrm{Mg}$ and $\mathrm{Ni}$ are at their lower and upper bounds, respectively. 
Table 3-2. Compositions of Bounding-Sludge SRAT Products [Ref. 6].

\begin{tabular}{|c|c|c|c|c|}
\hline SRAT Product & $\begin{array}{l}\text { SMEM-1 } \\
\end{array}$ & SMEM-2 & SMEM-3 & SMEM-4 \\
\hline Elements & $\begin{array}{r}(w t \%) \\
\text { Calcined }\end{array}$ & $\begin{array}{r}(w t \%) \\
\text { calcined }\end{array}$ & $\begin{array}{r}(w t \%) \\
\text { calcined }\end{array}$ & $\begin{array}{r}(\mathrm{wt} \%) \\
\text { calcined }\end{array}$ \\
\hline $\mathrm{Fe}$ & 32.000 & 31.600 & 11.150 & 12.300 \\
\hline $\mathrm{Al}$ & 8.990 & 9.140 & 23.150 & 23.750 \\
\hline $\mathrm{Mn}$ & 4.035 & 0.698 & 3.500 & 0.699 \\
\hline $\mathrm{Ca}$ & 3.875 & 2.050 & 3.270 & 1.810 \\
\hline $\mathrm{Mg}$ & 0.376 & 2.645 & 0.309 & 2.505 \\
\hline $\mathrm{P}$ & $<0.100$ & $<0.100$ & $<0.100$ & $<0.100$ \\
\hline $\mathrm{Ni}$ & 0.231 & 2.610 & 0.199 & 2.285 \\
\hline $\mathrm{Cr}$ & 0.025 & 0.295 & 0.017 & 0.269 \\
\hline $\mathrm{Cu}$ & 0.066 & 0.065 & 0.054 & 0.059 \\
\hline $\mathrm{Ti}$ & 0.026 & 0.026 & 0.025 & 0.025 \\
\hline $\mathrm{Si}$ & 1.500 & 1.510 & 1.420 & 1.325 \\
\hline $\mathrm{Na}$ & 13.800 & 14.800 & 16.750 & 15.900 \\
\hline $\mathrm{Zn}$ & $<0.010$ & 0.015 & $<0.010$ & $<0.010$ \\
\hline $\mathrm{K}$ & $<0.100$ & $<0.100$ & 0.618 & $<0.100$ \\
\hline $\mathrm{Ce}$ & 0.112 & 0.113 & 0.099 & 0.104 \\
\hline $\mathrm{Sn}$ & 0.033 & 0.030 & 0.031 & 0.032 \\
\hline $\mathrm{Ba}$ & 0.079 & 0.096 & 0.063 & 0.064 \\
\hline $\mathrm{Pb}$ & 0.109 & 0.075 & 0.092 & 0.086 \\
\hline $\mathrm{La}$ & 0.055 & 0.053 & $<0.010$ & 0.050 \\
\hline $\mathrm{Zr}$ & 0.062 & 0.122 & 0.067 & 0.056 \\
\hline $\mathrm{S}$ & 0.310 & 0.312 & 0.372 & 0.413 \\
\hline Total & 65.681 & 66.253 & 61.183 & 61.729 \\
\hline Anions & (mg/kg) & (mg/kg) & (mg/kg) & (mg/kg) \\
\hline $\mathrm{F}$ & $<100$ & $<100$ & $<100$ & $<100$ \\
\hline $\mathrm{Cl}$ & 125 & 130 & 1,125 & 133 \\
\hline $\mathrm{NO}_{2}$ & $<100$ & $<100$ & 112 & $<100$ \\
\hline $\mathrm{NO}_{3}$ & 22,100 & 27,150 & 22,700 & 25,450 \\
\hline $\mathrm{SO}_{4}$ & 204 & $<100$ & 772 & $<100$ \\
\hline $\mathrm{COOH}$ & 51,400 & 48,900 & 51,100 & 47,300 \\
\hline $\mathrm{C}_{2} \mathrm{O}_{4}$ & $<100$ & $<100$ & $<100$ & $<100$ \\
\hline $\mathrm{PO}_{4}$ & $<100$ & $<100$ & $<100$ & $<100$ \\
\hline Solids & $(w t \%)$ & $(w t \%)$ & $(w t \%)$ & $(w t \%)$ \\
\hline total & 27.1 & 26.1 & 24.9 & 25.9 \\
\hline insoluble & 16.3 & 15.1 & 13.1 & 15.0 \\
\hline calcine & 18.1 & 16.9 & 15.3 & 15.7 \\
\hline Density & $(\mathrm{g} / \mathrm{ml})$ & $(\mathrm{g} / \mathrm{ml})$ & $(\mathrm{g} / \mathrm{ml})$ & $(\mathrm{g} / \mathrm{ml})$ \\
\hline Slurry* & 1.185 & 1.175 & 1.165 & 1.173 \\
\hline pH & 6.89 & 6.76 & 6.98 & 6.83 \\
\hline
\end{tabular}

* No data was available thus estimated. 
Table 3-3. Composition of SB6 SRAT Product [Ref. 7].

\begin{tabular}{|c|c|c|c|c|c|}
\hline Calcined & wt\% & Oxides & wt\% & Anions & $\mathrm{mg} / \mathrm{kg}$ \\
\hline $\mathrm{Fe}$ & 18.9 & $\mathrm{Fe}_{2} \mathrm{O}_{3}$ & 27.0218 & $\mathrm{~F}$ & $<100$ \\
\hline $\mathrm{Al}$ & 15.9 & $\mathrm{Al}_{2} \mathrm{O}_{3}$ & 29.9505 & $\mathrm{Cl}$ & 701 \\
\hline $\mathrm{Mn}$ & 5.92 & $\mathrm{MnO}$ & 7.6441 & $\mathrm{NO}_{2}$ & $<100$ \\
\hline $\mathrm{Ca}$ & 0.949 & $\mathrm{CaO}$ & 1.3271 & $\mathrm{NO}_{3}$ & 45,550 \\
\hline $\mathrm{Mg}$ & 0.454 & $\mathrm{MgO}$ & 0.7526 & $\mathrm{SO}_{4}$ & 931 \\
\hline $\mathrm{P}$ & $<0.100$ & $\mathrm{P}_{2} \mathrm{O}_{5}$ & 0.0000 & $\mathrm{COOH}$ & 88,950 \\
\hline $\mathrm{Ni}$ & 2.54 & $\mathrm{NiO}$ & 3.2318 & $\mathrm{C}_{2} \mathrm{O}_{4}$ & 399 \\
\hline $\mathrm{Cr}$ & - & $\mathrm{Cr}_{2} \mathrm{O}_{3}$ & - & $\mathrm{PO}_{4}$ & $<100$ \\
\hline $\mathrm{Cu}$ & 0.181 & $\mathrm{CuO}$ & 0.2266 & & \\
\hline $\mathrm{Ti}$ & 0.014 & $\mathrm{TiO}_{2}$ & 0.0234 & Density & $\mathrm{g} / \mathrm{ml}$ \\
\hline $\mathrm{Si}$ & 0.141 & $\mathrm{SiO}_{2}$ & 0.3006 & slurry & 1.209 \\
\hline $\mathrm{Na}$ & 15.4 & $\mathrm{Na}_{2} \mathrm{O}$ & 20.7589 & & \\
\hline $\mathrm{Zn}$ & 0.00 & $\mathrm{ZnO}$ & 0.0000 & Solids & wt\% \\
\hline $\mathrm{K}$ & 0.07 & $\mathrm{~K}_{2} \mathrm{O}$ & 0.0843 & total & 27.26 \\
\hline $\mathrm{Ce}$ & $<0.010$ & $\mathrm{Ce}_{2} \mathrm{O}_{3}$ & - & insoluble & 12.8 \\
\hline $\mathrm{Sr}$ & 0.049 & $\mathrm{SrO}$ & 0.0579 & calcine & 16.1 \\
\hline $\mathrm{Ba}$ & $<0.010$ & $\mathrm{BaO}$ & - & & \\
\hline $\mathrm{Pb}$ & $<0.010$ & $\mathrm{PbO}$ & - & pH & 3.51 \\
\hline $\mathrm{La}$ & $<0.010$ & $\mathrm{La}_{2} \mathrm{O}_{3}$ & - & & \\
\hline $\mathrm{Zr}$ & 0.217 & $\mathrm{ZrO}_{2}$ & 0.2924 & & \\
\hline $\mathrm{S}$ & 0.37 & $\mathrm{SO}_{3}$ & 0.9240 & & \\
\hline Total & 61.054 & Total & 92.5959 & & \\
\hline
\end{tabular}

\subsection{Furnace and Procedure}

The MRF installed at the Aiken County Technical Laboratory (ACTL) was utilized to compare the melting behavior of different sludge and frit formulations. The furnace has a cylindrical inner chamber with heating coils winding along the side wall. The chamber is $7 \frac{1 / 2}{2}$ in diameter and its bottom 8 " is heated (see Figure $3-1$ ). The furnace is heated to $\sim 1,150{ }^{\circ} \mathrm{C}$ with the top opening covered. Once it reaches the set point temperature, the cover is removed and the beaker containing a sufficient quantity of dried feed to produce $\sim 60 \mathrm{~g}$ of glass is lowered into the furnace. The 2"-diameter stainless steel beaker was placed in an insulating sleeve and covered with a vented insulating cover. When inserted, the bottom of the 2 " beaker was recessed approximately 3.5 " from the bottom of the insulating sleeve, which was flush with the top of the uppermost chamber coil. A layer of $1 / 8$ " thick insulating felt is wrapped around each beaker to reduce the chance of side heating by filling any gap between the beaker and the interior side wall of the sleeve. The goal of this setup is to impose a vertical temperature profile within the beaker that is similar to the one-dimensional heating from the melt pool that the feed is experiencing in the cold cap of actual melters.

The beaker was removed from the furnace after a pre-determined period of time, usually 20 to 22 minutes. This firing duration was found to be long enough to melt a significant portion of most feeds tested but still short enough to leave a good portion of the fresh feed partially melted or completely un-melted. This approach ensures that the relative melt rates for a broad range of candidate glass formulations are clearly differentiated. The furnace temperature was monitored during each firing to ensure that the conditions are the same for each sample. It was necessary to 
have a 20-minute wait period between successive tests for the furnace to return to a stable temperature. A beaker containing a Frit 418 standard was also fired along with each series of test beakers to ensure that furnace conditions were similar between firing dates.

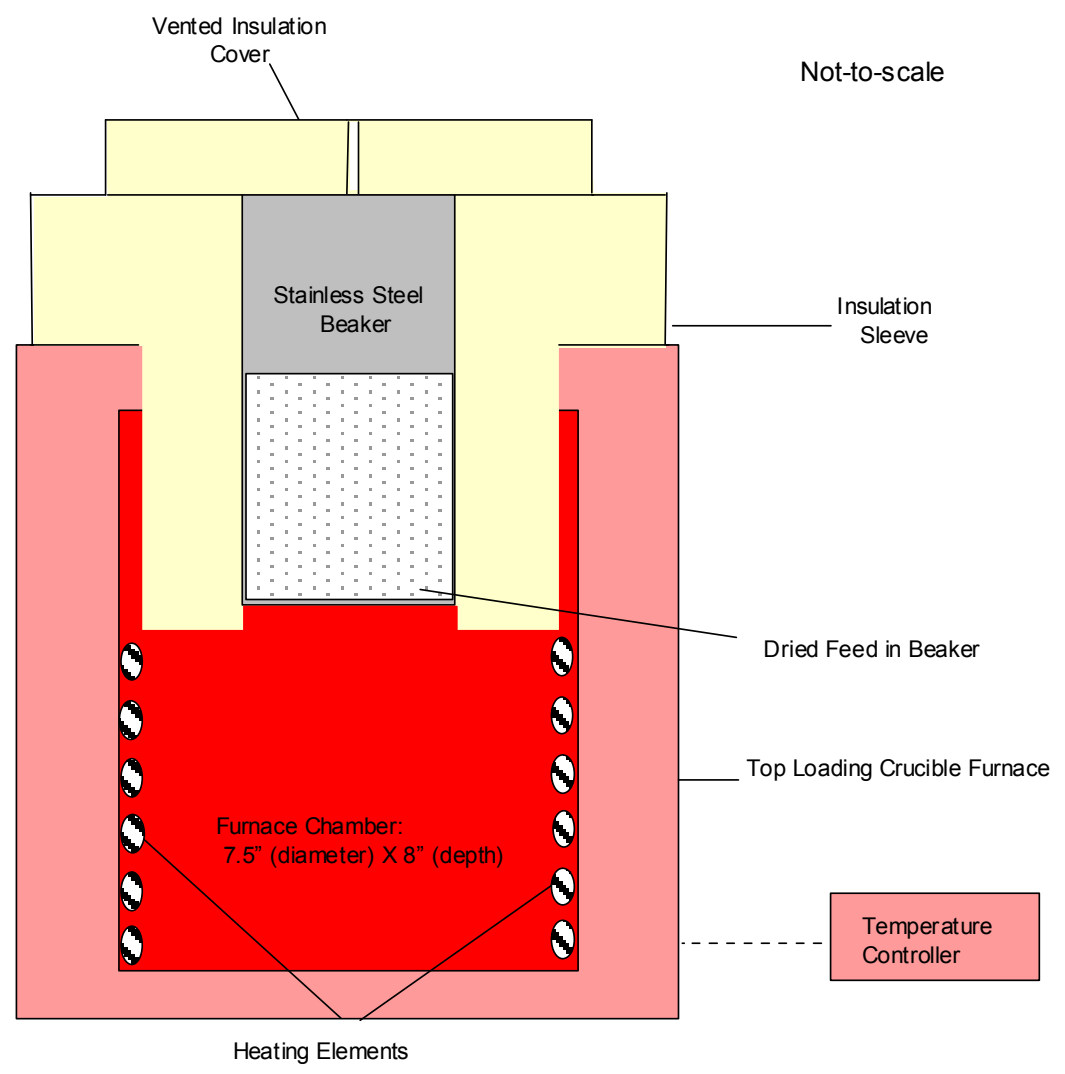

Figure 3-1. A Cross-Sectional View of the MRF.

\subsection{Determination of Melt Rates}

Once beakers were removed from the furnace after each firing, they were cooled in ambient air. The cooled beakers containing both melted glass and loose feed material were taken to the Imaging and Radiation Systems (IRS) Lab in SRNL for X-ray CT scan. X-ray images of the beaker contents were taken using an in-house developed lens-coupled digital radiography system consisting of a GE/Seifert 420 Isovolt X-ray generator, a Hamamatsu CsI scintillation screen and a Roper Scientific, Quantix CCD camera fitted with a Nikon Nikkor $105 \mathrm{~mm}$ lens. A four-axis motion control system from New England Affiliated Technologies was used for sample positioning. Control and processing software was written in-house, using National Instruments Labview programming language.

For each sample, 360 digital radiographs were taken at an angular increment of 1 degree. After several trials, the potential at the X-ray source was set at $300 \mathrm{KV}$. A $1.25 \mathrm{~mm}$ stainless steel filter was used at the X-ray source to harden the source beam and a $0.13 \mathrm{~mm}$ lead filter was used at the scintillator to attenuate X-ray scatter. Feldkamp cone-beam reconstruction was performed on the sample data using Imgrec software developed at Lawrence Livermore National Laboratory (LLNL) to produce a 3-D volumetric data set at a resolution of $0.0033 \mathrm{~mm}^{3}$ voxel. 
For cross-comparison purposes, melt rates were also measured by the visual method using a cross-sectional X-ray image of each sample instead of sectioning the beakers, as was done previously with 4-inch beakers. For that, the X-ray images were first re-sized to match the size of a sectioned 4-inch beaker. As illustrated in Figure 1-1, glass heights were then measured on the re-sized X-ray image at 0.25 -inch intervals along the bottom of the beaker. The height measurements were then averaged and divided by the time that the beaker was left in the furnace. This yielded an average linear melt rate expressed as inches per hour.

\subsection{Results and Discussions}

\subsection{Bounding-Sludge Glasses}

Although the chemistry of frit-only glasses is considerably simpler and therefore easier to analyze, the results of MRF runs with the bounding-sludge SRAT products are presented first in order to illustrate the full capabilities of CT and its application to the HLW glass melting. Frit 418 that has the targeted composition of $8 \mathrm{wt} \% \mathrm{~B}_{2} \mathrm{O}_{3}, 8 \mathrm{wt} \% \mathrm{Li}_{2} \mathrm{O}, 8 \mathrm{wt} \% \mathrm{Na}_{2} \mathrm{O}$, and $76 \mathrm{wt} \% \mathrm{SiO}_{2}$ was blended with SRAT Products \#25 to 28 shown in Table 3-2 at a targeted waste oxide loading of $36 \mathrm{wt} \%$ in glass and heat treated for 22 min according to the procedures described in Section 3.2.

\subsubsection{X-Ray and CT Images}

The X-ray images of what remained in the beakers after the heat treatment are shown in Figure 4-1, in which those elements in a larger, bold font indicate that their concentrations were set at their respective upper bounds, while those elements in a smaller font size had their concentrations set at their respective lower bounds. These images were taken along the cross-section through the center axis perpendicular to the X-ray source. It is clearly seen that each sample consists of four distinctive morphological zones or layers. First, the large void in the middle of each image was created mainly by the generation of calcine gases and, to a lesser degree, by the pockets of air that were present in the fresh feed. The bottom layer below the large void represents fully-melted glass relatively free of large gas bubbles, while the top layer contains not-yet-melted material in or near its original form. Lastly, the middle layer between the top layer and the large void in the middle contains more melted material interspersed among numerous bubbles of differing sizes.

Another interesting observation to be made regarding Figure 4-1 is that the SMEM-2 simulant is shown to have expanded the most and the resulting large void in the middle could have been even larger than shown, had it not been for the $\sim 1 / 3$ " opening in the center. Although SMEM-2 was loaded with high concentrations of $\mathrm{Fe}, \mathrm{Mg}$ and $\mathrm{Ni}$, the large expansion cannot be attributed to their high concentrations, since all metals except for Mn were fed as hydroxides that decompose early on, i.e., below $\sim 350{ }^{\circ} \mathrm{C}$, so their impact on the cold cap expansion will be small. It is more likely that the highest concentration of nitrate in SMEM-2 was responsible for the largest expansion since the complete decomposition of nitrate extends beyond $900{ }^{\circ} \mathrm{C}$. This is evidenced by the presence of a significant amount of bubbles still remaining in the bottom melt layer.

A significant expansion of the feed batch is also shown to have occurred in SMEM-1, despite the fact that its nitrate concentration was $5,000 \mathrm{ppm}$ lower than that of SMEM-2. It is likely that the high concentration of Mn in SMEM-1 was responsible for the second largest expansion of feed, since unreduced $\mathrm{Mn}$ enters the cold cap as $\mathrm{MnO}_{2}$, which later decomposes to $\mathrm{MnO}$ and/or $\mathrm{Mn}_{3} \mathrm{O}_{4}$ in the lower regions of the cold cap, thereby releasing $\mathrm{O}_{2}$ in the process. It is also shown that the melt layer of SMEM-1 contains significantly less gas bubbles than SMEM-2 most likely due to the fact that one mole of $\mathrm{MnO}_{2}$ generates 0.5 mole of $\mathrm{O}_{2}$, whereas each mole of nitrate generates at least 1.5 moles of gases consisting of $\mathrm{N}_{2}, \mathrm{O}_{2}, \mathrm{NO}$, and $\mathrm{NO}_{2}$. 


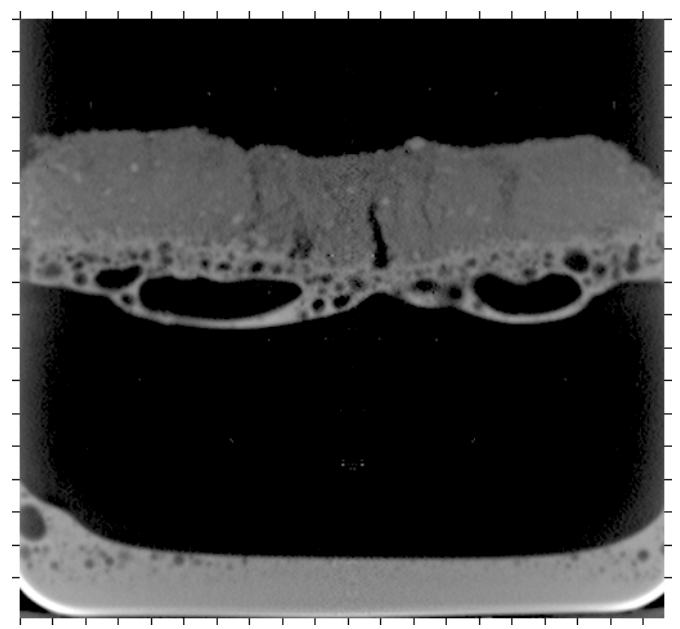

(A) SMEM-1 (Al, Fe, Ca, Mn, Mg, Ni)

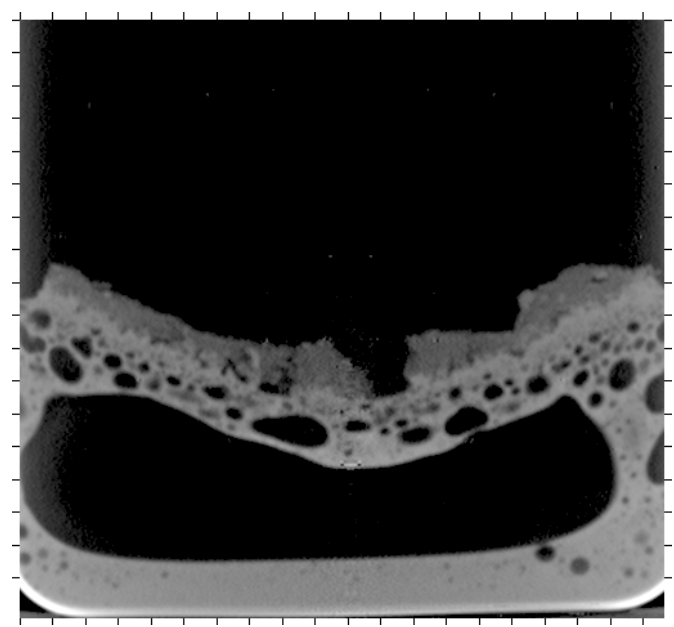

(C) SMEM-3 (Al, Fe, Ca, Mn, Mg, Ni)

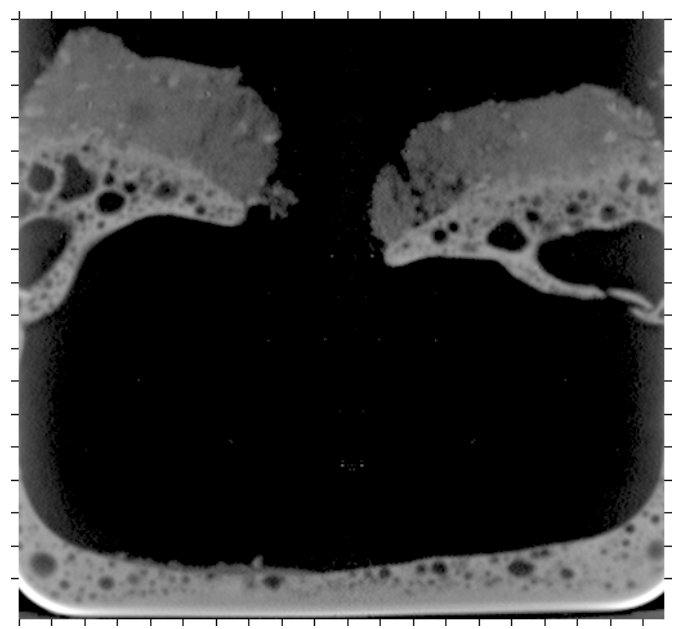

(B) SMEM-2 (Al, Fe, Ca, Mn, Mg, Ni)

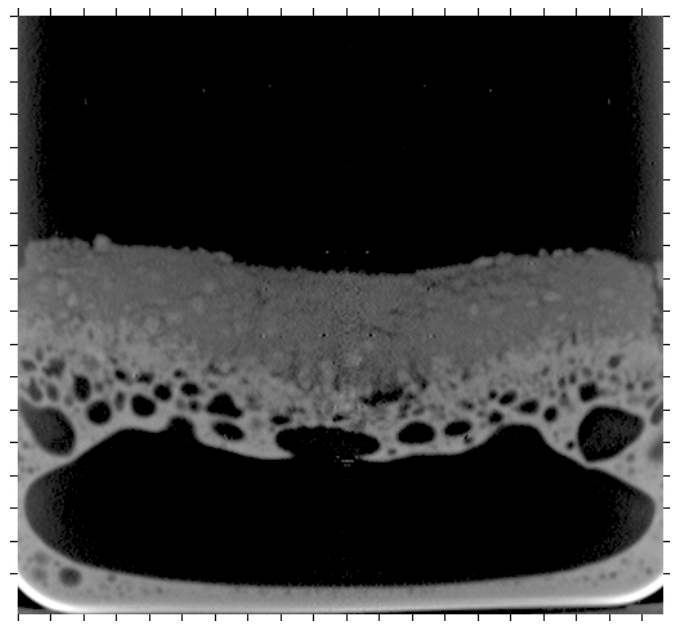

(D) SMEM-4 (Al, Fe, Ca, Mn, Mg, Ni)

Figure 4-1. X-Ray Images of Bounding-Sludge Feeds after Heat Treatment.

However, despite its relatively high concentration of Mn, the volume expansion of SMEM-3 is shown to be considerably less than that of SMEM-1. Since the nitrate levels are nearly the same in both feeds, the reduced expansion of SMEM-3 may be attributed to the fact that $56 \%$ of its Mn was reduced to $\mathrm{Mn}^{2+}$ during the SRAT processing compared to $25 \%$ for SMEM- $1 ;^{6}$ reduced $\mathrm{Mn}^{2+}$ acts as a modifier without releasing $\mathrm{O}_{2}$. As shown in Table 4-1, SMEM-1 thus had twice as much un-dissolved $\mathrm{Mn}^{4+}$ as SMEM-3 that contributes to the feed expansion by releasing $\mathrm{O}_{2}$ to become $\mathrm{Mn}^{2+}$ in the glass matrix.

SMEM-4 appears to have the least melted material of all the samples and thus has the most unmelted material. This was expected since SMEM-4 was low on non-alkali modifiers such as $\mathrm{Ca}$ and $\mathrm{Mn}$ but high in $\mathrm{Al}$; each $\mathrm{Al}$ atom consumes one existing NBO. Furthermore, SMEM-4 was also high in $\mathrm{Mg}$, whose high field potential makes it couple more tightly with NBO than either $\mathrm{Ca}$ or $\mathrm{Mn}$. Therefore, $\mathrm{Mg}$ makes the glass more refractory compared to $\mathrm{Ca}$ and $\mathrm{Mn}$ and thus more viscous, which then lowers the melt rate. The field potential of an ion is commonly defined as the charge divided by its ionic radius in angstroms squared. 
SRNL-STI-2010-00767

Revision 0

Table 4-1. Concentrations of Key Elements in Bounding Sludge SRAT Product.

\begin{tabular}{||c|c|c|c|c||}
\hline $\begin{array}{c}\text { SRAT } \\
\text { Product }\end{array}$ & SMEM-1 & SMEM-2 & SMEM-3 & SMEM-4 \\
\hline Elements & $\begin{array}{c}\text { Mole/100g } \\
\text { Calcined } \\
\text { Solids }\end{array}$ & $\begin{array}{c}\text { Mole/100g } \\
\text { Calcined } \\
\text { Solids }\end{array}$ & $\begin{array}{c}\text { Mole/100g } \\
\text { Calcined } \\
\text { Solids }\end{array}$ & $\begin{array}{c}\text { Mole/100g } \\
\text { Calcined } \\
\text { Solids }\end{array}$ \\
\hline $\mathrm{Fe}$ & 0.57301 & 0.56585 & 0.19966 & 0.22025 \\
\hline $\mathrm{Al}$ & 0.33319 & 0.33874 & 0.85798 & 0.88022 \\
\hline $\mathrm{Mn}(+4)$ & 0.05508 & 0.00953 & 0.02803 & 0.00547 \\
\hline $\mathrm{Mn}(+2)$ & 0.01836 & 0.00318 & 0.03568 & 0.00725 \\
\hline $\mathrm{Ca}$ & 0.09669 & 0.05115 & 0.08159 & 0.04516 \\
\hline $\mathrm{Mg}$ & 0.01547 & 0.10883 & 0.01271 & 0.10307 \\
\hline $\mathrm{Ni}$ & 0.00394 & 0.04447 & 0.00339 & 0.03893 \\
\hline $\mathrm{Na}$ & 0.60026 & 0.64376 & 0.72858 & 0.69161 \\
\hline \hline
\end{tabular}

The CT histogram pictures, called histopics, of the bounding-sludge/Frit 418 samples are shown in Figure 4-2 each paired with their respective X-ray images. Each histopic has been colored for better definition; the color correlates to the count in the histogram bin from blue (low count) to red (highest count). It is noted that the distribution and shape of gas bubbles including the large voids in the middle of these X-ray images are shown to be somewhat different from those shown in Figure 4-1, since the two sets of images represent two different cross-sections. This confirms the fact that a 2-D center-cut image shot at a particular rotational angle cannot be considered to be representative of the entire $360^{\circ}$ sample volume.

Each histopic represents a vertical profile of material or CT density count; the y-axis represents the elevation within the beaker, while the x-axis represents the CT density. So, the farther the green-colored region extends to the right, the higher the sample density is at a given elevation. As expected, the green areas shift to the right as the elevation decreases, since the material compacts as it melts, i.e., the material density increases with decreasing elevation. Furthermore, as more and more material is found at a given elevation and CT density, its color changes from green to yellow and to red.

For example, both SMEM-1 and SMEM-4 show patches of red at the elevation of the un-melted layer, which means that these samples contain more un-melted material than either SMEM-2 or SMEM-3. Likewise, SMEM-1 and SMEM-3 both show patches of yellow in the middle of lower green areas, more so in the latter, which means that these feeds produced more melted material than either SMEM-2 or SMEM-4. The CT histopics also show large "zero" material regions that separate the upper (un-melted and partially-melted) and lower (melted) green areas, confirming that the large voids in the middle of X-ray images on the right indeed consist only of low-density gases. However, when there is a significant amount of materials found near the walls as shown in SMEM-3 and SMEM-4, the upper and lower green areas are shown to almost touch each other and, moreover, their CT densities are shown to be right in the middle of those of melted material, thus confirming that these materials found near the walls are indeed melted. 

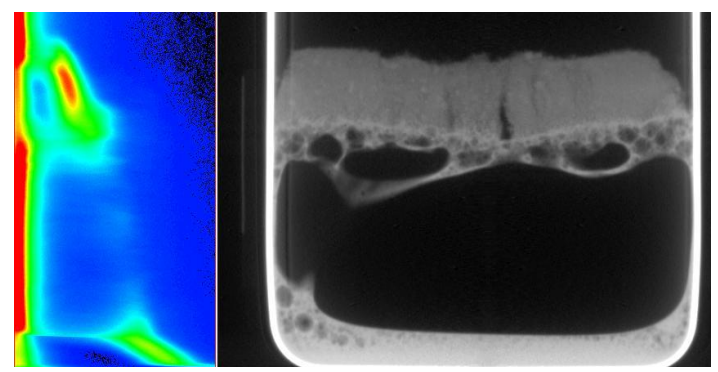

(A) SMEM-1 (Al, Fe, Ca, Mn, Mg, Ni)

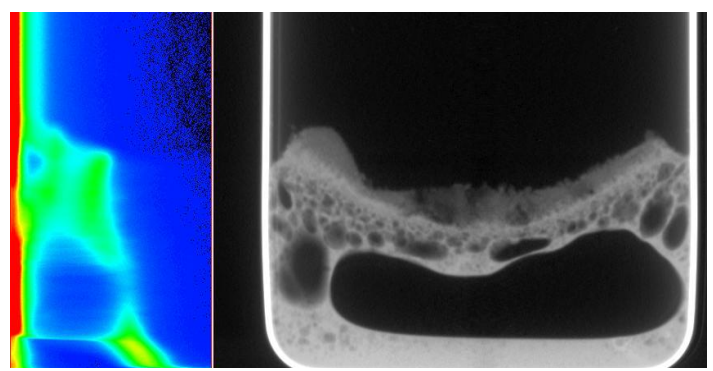

(C) SMEM-3 (Al, Fe, Ca, Mn, Mg, Ni)

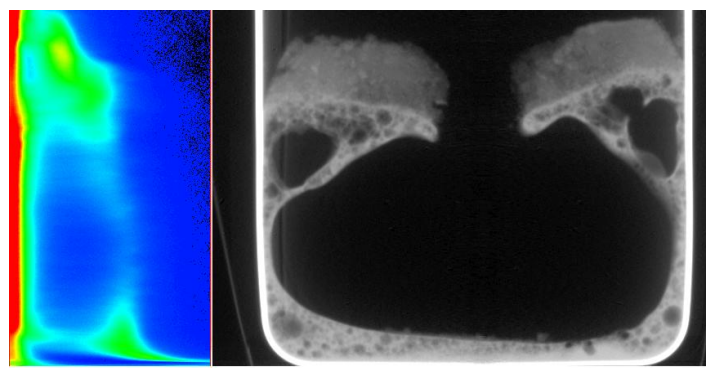

(B) SMEM-2 (Al, Fe, Ca, Mn, Mg, Ni)

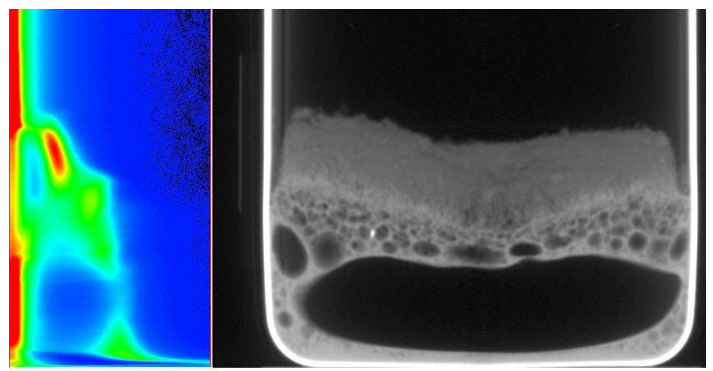

(D) SMEM-4 (Al, Fe, Ca, Mn, Mg, Ni)

Figure 4-2. Comparison of CT Histopics vs. X-Ray Images of Bounding-Sludge Feeds.

\subsubsection{CT Analysis}

A segmentation approach was adopted to analyze the MRF samples. First, the entire sample in a beaker was partitioned into typically $\sim 200$ horizontal slices and each $0.15-\mathrm{mm}$ thick slice or disk was scanned $360^{\circ}$ with X-ray. Some portion of the incident X-ray beam will be absorbed by the sample and the remaining portion not absorbed will be captured by a detector positioned on the other side. Since radiographic attenuation is proportional to material density, the denser a material is, the greater the attenuation will be as shown next:

$$
I=I_{0} e^{-\mu L}
$$

where $I_{0}$ and $I$ are the intensities of the incident and attenuated X-ray beams, respectively, $\mu$ is the "material frequency" unique to each type of material in $\mathrm{mm}^{-1}$, and $L$ the material dimension or the size of the volume pixel, called voxel, in $\mathrm{mm}$. Therefore, the exponent of Eq. (6) is dimensionless and the product of $\mu$ and $L$ is specifically called the CT density. By definition, the CT density of vacuum is zero because it contains no matter, so $I=I_{0}$. And the denser a material is, the greater its CT density is. So, voids of gas have a very small CT density that $I \approx I_{0}$. On the other hand, the SS beakers used in the MRF runs have a high enough CT density that $I<<I_{0}$. Therefore, the product of a given CT density and the number of voxels of material having the same CT density will yield a relative measure of the total amount of material of that density. Since the CT density is dimensionless, the amount of material thus obtained is also dimensionless.

Each voxel of the material remaining in the beaker was categorized into one of the four zones or layers in the order from the most to least dense as follows: 
Melt: $\quad$ Fully melted glass with little or no gas bubbles.

Froth: $\quad$ Melted material interspersed among gas bubbles.

Un-melt: $\quad$ Feed material which may have begun to soften but is still fundamentally in its original, loose granular form.

Bellow: $\quad$ Material of very low but non-zero density arising from voids of gas or the artifacts of radiography (x-ray beam-hardening, shadowing, etc.).

A histogram of CT density vs. material amount of each sample was next created from the 3-D volumetric data, and the integration of the resulting histogram over the CT density interval for a given layer gave the amount of material present in that layer. The threshold boundaries between two adjacent layers were determined by finding significant negative-to-positive zero crossings of the $3^{\text {rd }}$ derivative of the histogram, which was generated by repeated shifting and smoothing of the derivatives. It turns out that the zero-crossing points are at or near the midpoint between two adjacent histogram peaks produced by different material types, as shown in Figure 4-3. It is noted that Figure 4-3 actually represents the SB6/Frit 418 feed at 30\% waste oxide loading (WL), which will be discussed later in the report and is shown here as an example, since it has three distinct peaks of melt, froth and un-melt layers. The material amount on the vertical axis was calculated by multiplying a given CT density by the number of voxels having that CT density.

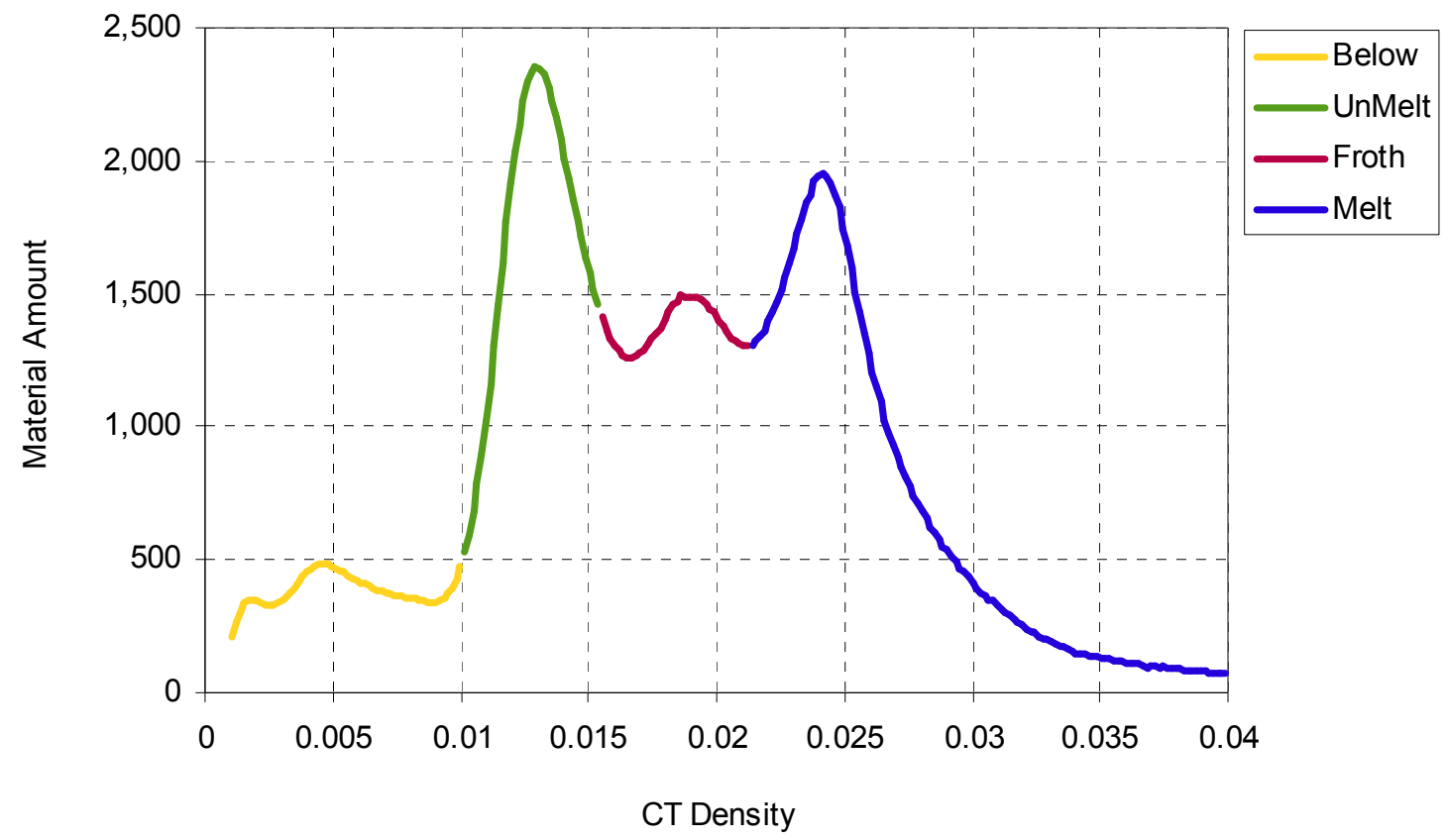

Figure 4-3. A Histogram of CT Density vs. Material Amount for SB6/Frit 418 at 30\% WL.

As a comparison, the histogram of SMEM-1 shown in Figure 4-4 lacks a distinct peak for the froth layer; instead, the peak is replaced by an inflection point at the CT density of $\sim 0.018$. As a result, the threshold boundary or interface between the un-melt and froth layers is the midpoint between the peak of the former and the inflection point of the latter. The peak for the SMEM-1 un-melt layer is high and well-developed because a significant amount of un-melt material still remained after the heat treatment, as shown in Figure 4-1. On the other hand, the histogram of SMEM-3 shown in Figure 4-5 has an almost-indistinguishable un-melt peak, since it has much less un-melt material above the froth layer than SMEM-1. Instead, SMEM-3 is shown to have a much larger melt layer peak than SMEM-1. 


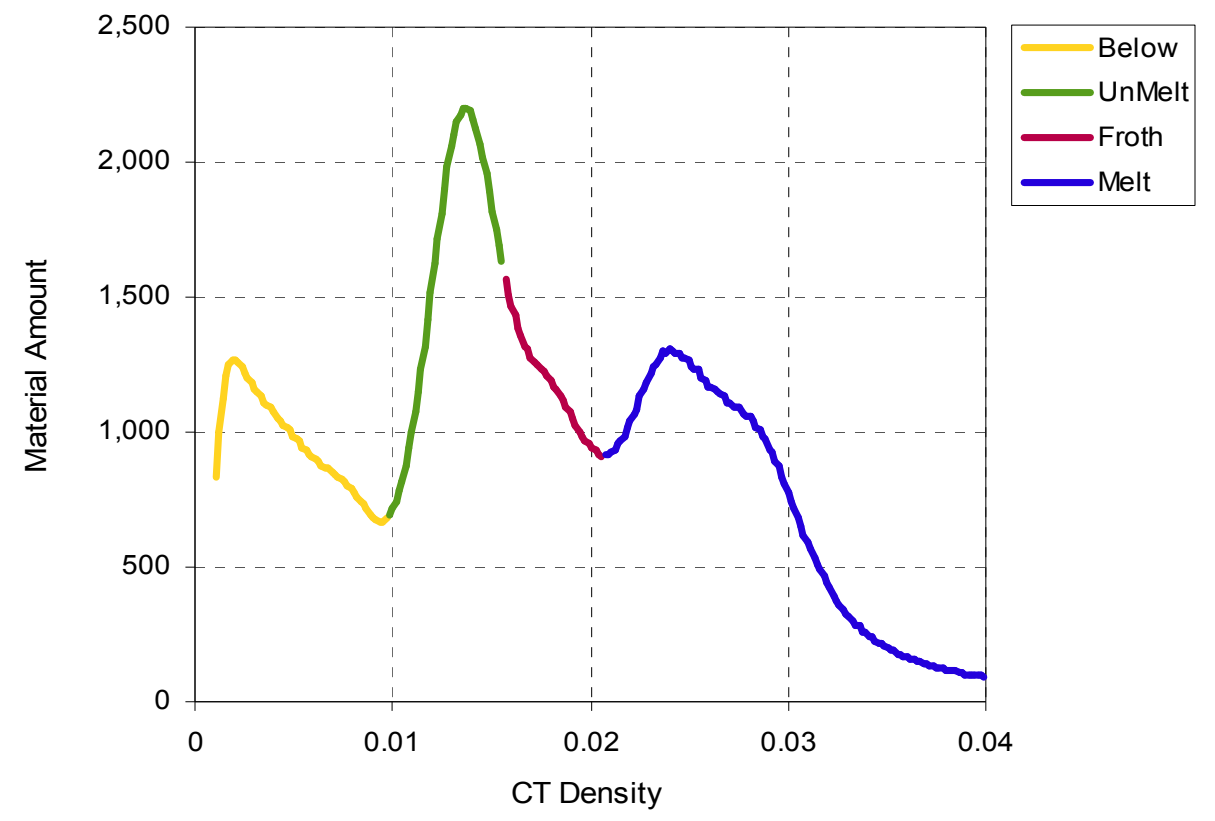

Figure 4-4. A Histogram of CT Density vs. Material Amount for SMEM-1.

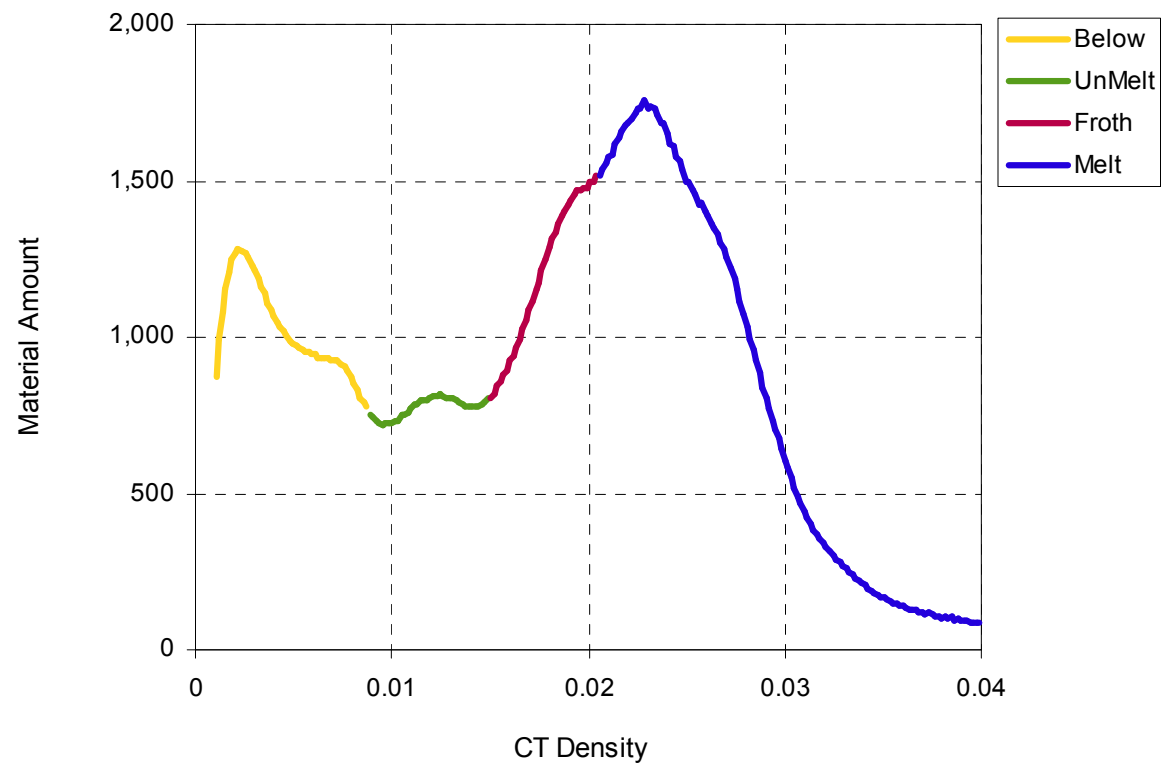

Figure 4-5. A Histogram of CT Density vs. Material Amount for SMEM-3.

The histograms of all four bounding sludge/Frit 418 heat-treated samples are compared in Figure 4-6. SMEM-1 is shown to contain the most glass with CT density $>0.028$ but its remaining melt $(0.02<$ CT density $<0.028)$ and froth layer $(0.016<$ CT density $<0.02)$ profiles are lower than those of either SMEM-3 or SMEM-2. On the other hand, SMEM-4 is shown to contain the least glass with CT density $>0.023$ and thus has the highest froth layer peak and the second-highest un-melt layer peak of all samples. By contrast, the histogram of SMEM-2 is generally flat with no distinct peaks for either the melt or froth layer but its melt and froth-layer profiles appears to be higher than those of SMEM-1. The goal of CT analysis is to determine the amounts of material in the melt, froth, and un-melt layers to enable a quantitative comparison of relative melt rates. 


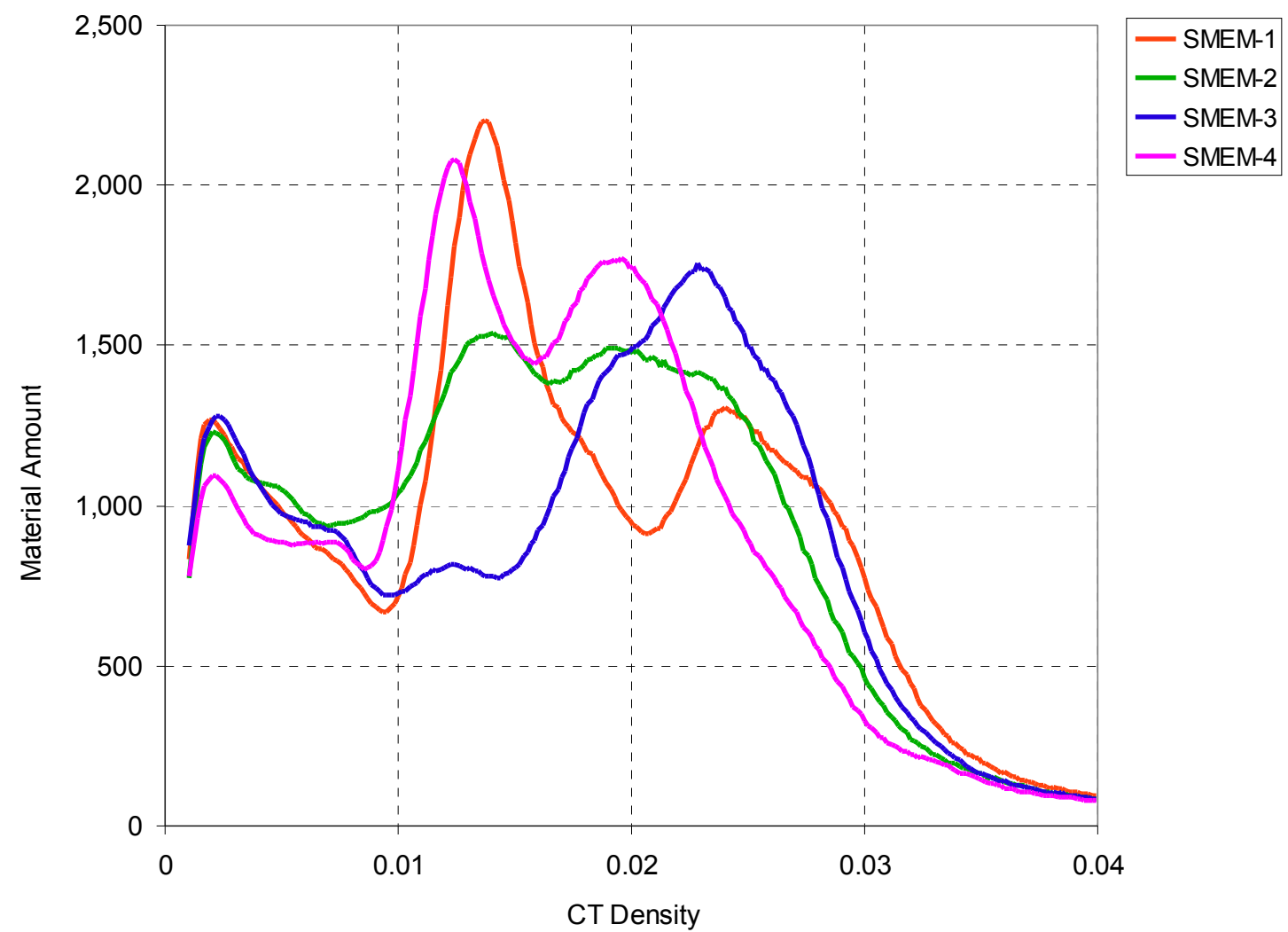

Figure 4-6. Comparison of Histograms of Four Bounding Sludge/Frit 418 Feeds.

\subsubsection{Results of CT Analysis}

The amount of material in each of the melt, froth and un-melt layers was calculated by finding the area under their respective CT histogram peaks and the results are tabulated in Table 4-2. Also included in the table are the material densities that were calculated as the material mass-tovolume ratio; the overall density represents the degree of compaction that occurred to the entire sample volume. Among the four samples, SMEM-3 was determined to contain the most melted material: more than twice that of SMEM-4. The latter contained the least melted and the most froth materials. Since the material in the froth layer is either fully-melted or well into the transition to the melted state, it seems prudent from the standpoint of continuous melter operation to include it in the overall melt rate determination. However, the combined amount of melted and froth materials was still the largest for SMEM-3, while SMEM-4 had the least. As a result, SMEM-3 is shown to have the least un-melt material remaining. This result was somewhat unexpected since a high concentration of $\mathrm{Al}$ would increase the network connectivity by removing NBOs and thus make the SMEM-3 melt more viscous:

$$
\mathrm{Al}_{2} \mathrm{O}_{3}+2 \mathrm{NBO}^{-} \rightarrow 2 \mathrm{AlO}_{4 / 2}^{-}
$$

where the subscript $4 / 2$ of the aluminate tetrahedra represents four bridging oxygen (BO) atoms shared by two cations, Al and Si. It appears that the highest combined total of melted and froth materials in SMEM-3 could be due to its high concentration of modifiers including $\mathrm{Na}, \mathrm{K}$ and $\mathrm{Ca}$ coupled with high $\mathrm{Mn}$, particularly $\mathrm{Mn}^{2+}$, and sulfate so as to provide enough fluxes to overcome increased viscosity due to high Al. 
Table 4-2 shows that the standard deviation of the calculated total amounts of material remaining in the beaker after the heat treatment was only $3.7 \%$ of the mean, and it could have been even smaller had it not been for the unexpectedly-large total mass of SMEM-1. This small variance was expected since the amount of each fresh feed batched in the beakers was set to make the same amount of glass at a constant waste oxide loading.

Table 4-2. CT-Calculated Distribution of Material and Density of Bounding-Sludge Feeds.

\begin{tabular}{||c|c|c|c|c|c|c|c|c|c|c||}
\hline \hline \multirow{2}{*}{$\begin{array}{c}\text { Sample } \\
\text { ID }\end{array}$} & \multicolumn{5}{|c|}{ Material Amount } & \multicolumn{4}{c||}{ Material Density } \\
\cline { 2 - 12 } & Total & $\begin{array}{c}\text { Un- } \\
\text { melt }\end{array}$ & $\begin{array}{c}\text { Melt/ } \\
\text { Froth }\end{array}$ & Froth & Melt & Overall & $\begin{array}{c}\text { Un- } \\
\text { melt }\end{array}$ & $\begin{array}{c}\text { Melt/ } \\
\text { Froth }\end{array}$ & Froth & Melt \\
\hline SMEM-1 & 174,012 & 57,499 & 116,513 & 36,410 & 80,103 & 5.453 & 3.866 & 6.838 & 5.314 & 7.863 \\
\hline SMEM-2 & 165,923 & 47,278 & 118,645 & 46,189 & 72,456 & 5.414 & 3.716 & 6.620 & 5.462 & 7.656 \\
\hline SMEM-3 & 161,430 & 27,064 & 134,366 & 40,805 & 93,562 & 5.784 & 3.417 & 6.722 & 5.347 & 7.572 \\
\hline SMEM-4 & 160,654 & 55,857 & 104,797 & 58,867 & 45,930 & 4.967 & 3.551 & 6.308 & 5.423 & 7.978 \\
\hline std dev & 6,129 & 13,978 & 12,158 & 9,726 & 20,052 & 0.336 & 0.195 & 0.227 & 0.068 & 0.186 \\
\hline $\begin{array}{c}\text { std dev/ } \\
\text { mean }\end{array}$ & $3.7 \%$ & $29.8 \%$ & $10.3 \%$ & $21.3 \%$ & $27.5 \%$ & $6.2 \%$ & $5.4 \%$ & $3.4 \%$ & $1.3 \%$ & $2.4 \%$ \\
\hline \hline
\end{tabular}

Based on the quantitative CT data given in Table 4-2, various melt rate rankings of the boundingsludge/Frit 418 feeds were derived in Table 4-3 from the fastest to slowest melting. The material rankings of the combined melt and froth layers and those of the melt-only layer show SMEM-3 and SMEM-4 as the fastest and slowest melting, respectively, which appears to be consistent with the X-ray images in Figure 4-1. On the other hand, the intermediate rankings of SMEM-1 and SMEM-2 are reversed for the melt/froth and melt-only layers. The overall material density rankings, which represent the degree of densification or compaction that has occurred to the entire sample, are identical to the material rankings of the melt-only layer. However, the other material density rankings do not correctly show SMEM-3 as the fastest melting, which means that the densification factor for each layer by itself is not a good indicator of the overall melt rate.

Table 4-3. CT-Based Melt Rate Rankings of Bounding-Sludge/Frit 418 Feeds.

\begin{tabular}{|c|c|c|c|c|c|c|c||}
\hline \multirow{2}{*}{ Rankings } & \multicolumn{3}{|c|}{ Material Amount } & \multicolumn{4}{c||}{ Material Density } \\
\cline { 2 - 8 } & Un-melt & Melt/Froth & Melt & Overall & Un-melt & Melt/Froth & Melt \\
\hline 1 & SMEM-1 & SMEM-3 & SMEM-3 & SMEM-3 & SMEM-1 & SMEM-1 & SMEM-4 \\
\hline 2 & SMEM-4 & SMEM-2 & SMEM-1 & SMEM-1 & SMEM-2 & SMEM-3 & SMEM-1 \\
\hline 3 & SMEM-2 & SMEM-1 & SMEM-2 & SMEM-2 & SMEM-4 & SMEM-2 & SMEM-2 \\
\hline 4 & SMEM-3 & SMEM-4 & SMEM-4 & SMEM-4 & SMEM-3 & SMEM-4 & SMEM-3 \\
\hline
\end{tabular}

\subsubsection{Visual Determination of Melt Rates}

The visual melt rate readings were taken from the X-ray images shown in Figure 4-1 using the procedures described in Section 3.3. The resulting LMR based on the visual method are shown in Table 4-4. Although it is clearly shown in the X-ray images that SMEM-3 has a much less unmelted material remaining than SMEM-1 and thus must be faster melting of the two, the visual method concludes that both feeds are tied as the fastest melting because it ignored the significant amount of melted material interspersed in the froth layer and along the walls of the SMEM-3 beaker. 
Table 4-4. Measured Melt Rates of Bounding-Sludge/Frit 418 Using Visual Method.

\begin{tabular}{|c|c|c|c|c||}
\hline \multirow{2}{*}{$\begin{array}{c}\text { Distance From } \\
\text { Center (in) }\end{array}$} & \multicolumn{4}{|c|}{ Glass Height (in) } \\
\cline { 2 - 5 } & SMEM-1 & SMEM-2 & SMEM-3 & SMEM-4 \\
\hline 1 & 0.2 & 0.17 & 0.2 & 0.15 \\
\hline 0.875 & 0.25 & 0.18 & 0.18 & 0.1 \\
\hline 0.75 & 0.2 & 0.15 & 0.16 & 0.1 \\
\hline 0.625 & 0.2 & 0.15 & 0.15 & 0.1 \\
\hline 0.5 & 0.19 & 0.12 & 0.16 & 0.09 \\
\hline 0.375 & 0.19 & 0.13 & 0.18 & 0.08 \\
\hline 0.25 & 0.18 & 0.11 & 0.18 & 0.07 \\
\hline 0.125 & 0.18 & 0.1 & 0.18 & 0.07 \\
\hline-0.125 & 0.17 & 0.11 & 0.19 & 0.075 \\
\hline-0.25 & 0.17 & 0.12 & 0.19 & 0.075 \\
\hline-0.375 & 0.17 & 0.12 & 0.19 & 0.075 \\
\hline-0.5 & 0.18 & 0.14 & 0.19 & 0.08 \\
\hline-0.625 & 0.18 & 0.09 & 0.2 & 0.07 \\
\hline-0.75 & 0.18 & 0.15 & 0.12 & 0.08 \\
\hline-0.875 & 0.19 & 0.2 & 0.15 & 0.1 \\
\hline-1 & 0.2 & 0.22 & 0.4 & 0.15 \\
\hline Average (in) & 0.19 & 0.14 & 0.19 & 0.09 \\
\hline Run Time (min) & 20 & 20 & 20 & 20 \\
\hline LMR (in/hr) & $\mathbf{0 . 5 7}$ & $\mathbf{0 . 4 2}$ & $\mathbf{0 . 5 7}$ & $\mathbf{0 . 2 7}$ \\
\hline \hline & & & & \\
\hline \hline
\end{tabular}

The relative melt rates determined by the CT and visual methods are compared in Figure 4-7, in which the lines are drawn for visualization-purposes only. As stated above, all three CT plots show SMEM-3 as the fastest melting, while the visual plot shows SMEM-1 and SMEM-3 tied as the fastest melting. When the X-ray images of SMEM-1 and SMEM-2 are compared, the melt layer of the former looks more uniform with a lot fewer voids than that of the latter and, therefore, SMEM-1 appears to be faster-melting than SMEM-2. This is indeed what the CT results show in Table 4-2. However, when the materials in the melt as well as froth layer are considered together, CT ranks SMEM-2 slightly higher than SMEM-1. This somewhat surprising result seems to make sense when un-melt materials remaining in both samples are compared, or it may be reflecting the fact that a center-cut X-ray image shot at a particular angle does not always accurately represent the morphology of a sample across its entire volume. However, the overall material densities of both samples, excluding voids larger than $0.15 \mathrm{~mm}$, are shown to be practically equal.

Figure 4-8 shows a pair of the Red-Green-Blue (RGB) images of SMEM-3; the melt, froth and un-melt layers are colored blue, red and green, respectively. Each RGB image represents a 2D projection of the 3D volumetric data on an orthogonal plane. Although they appear similar for this sample, a closer look generally reveals meaningful differences between them in terms of distribution of materials, which confirms that a 2D projection image across a particular center-cut plane does not always give an accurate quantitative measure of the entire sample. Furthermore, the interface between the froth and un-melt layers above the large void in the middle is highly diffuse in nature; there is a significant overlap of melt, froth and un-melt materials in the froth and part of un-melt layers. This illustrates a difficulty in obtaining consistent melt rate data using the visual method even in the absence of bubbles in the melt layer, since it ignores any melt material present in the froth and un-melt layer, as shown. 


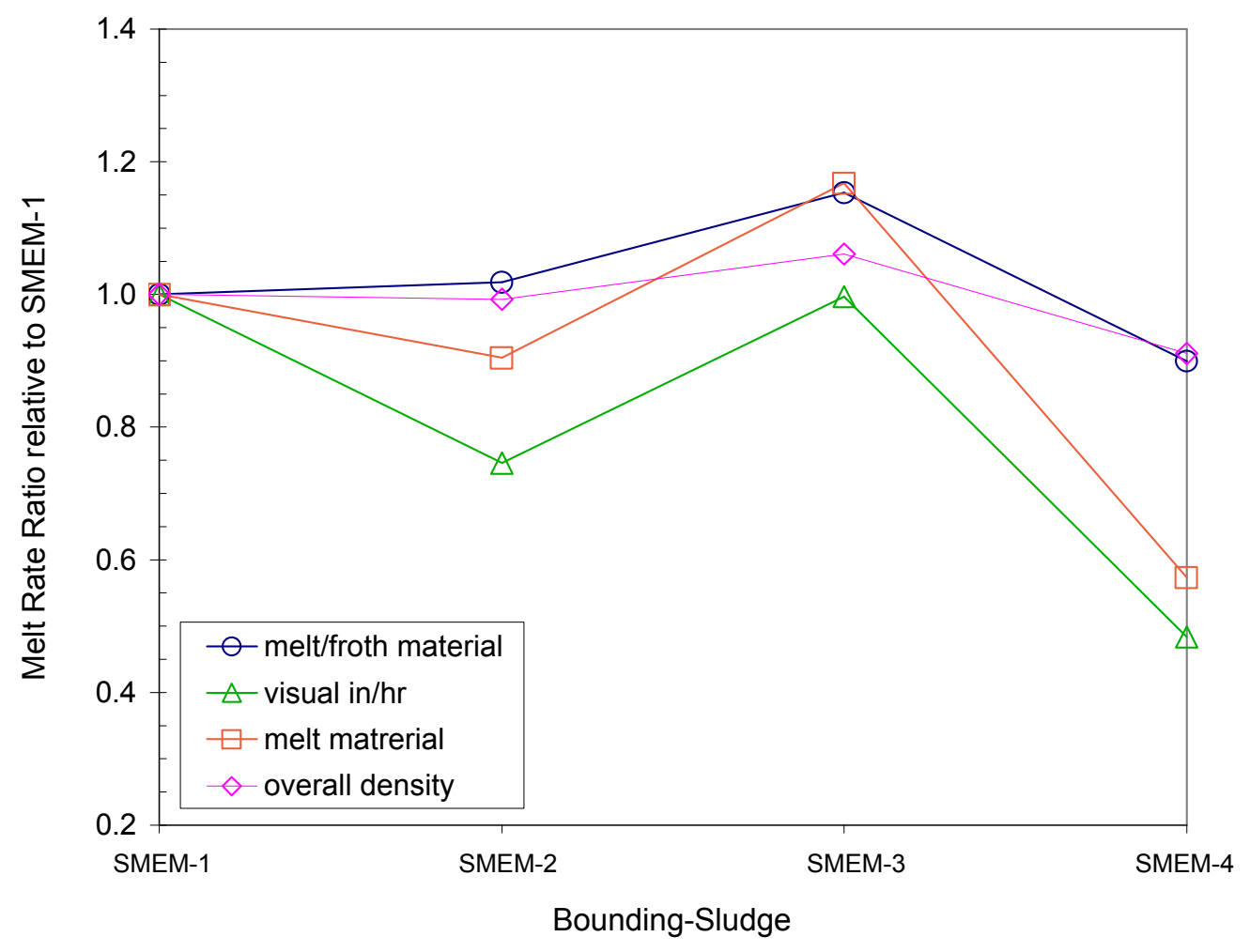

Figure 4-7. Comparison of CT vs. Visual Melt Rates of Bounding-Sludge Feeds.

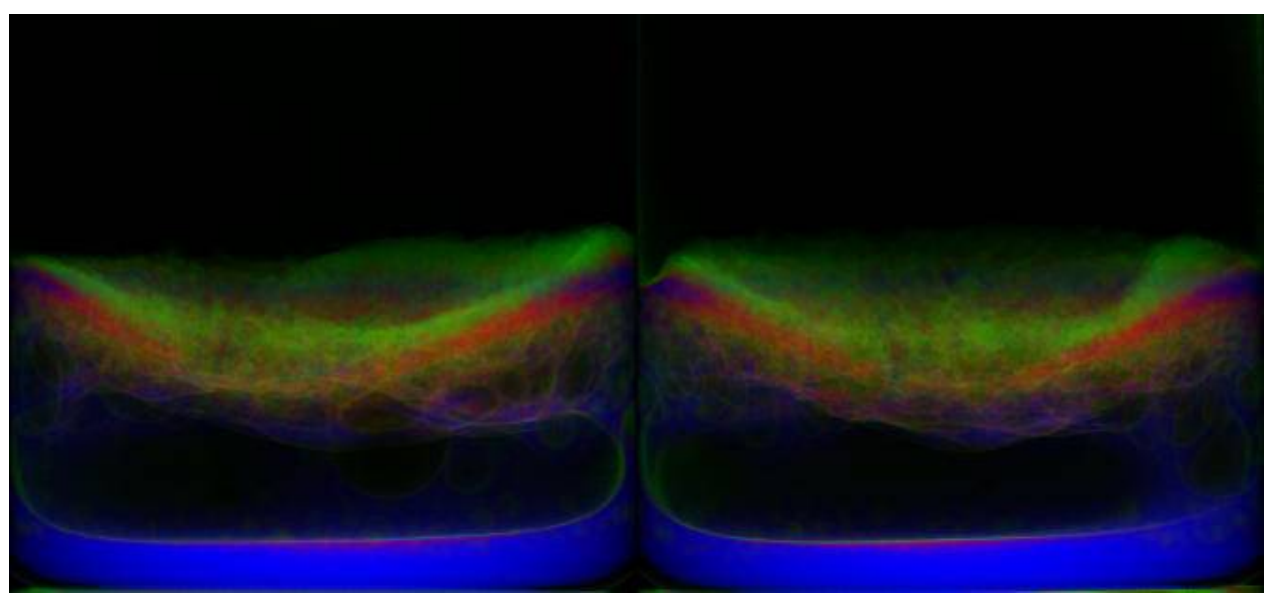

Figure 4-8. RGB Images of SMEM-3. 


\subsection{Frit-Only Glasses}

The purpose of running the frit-only melting tests was to simplify the feed chemistry and, therefore, see the compositional dependence of melt rate more clearly. The compositions of the ten frits tested, including the baseline Frit 418, are given in Table 4-5. These frits were the leftovers from previous tests, so their compositions are not seen to vary systematically, as they normally would in designed experiments. However, the value of this particular set is the fact that the boron content was varied widely from 8 to $20 \mathrm{wt} \%$ (or 6.5 to $16.1 \mathrm{~mol} \%$ ), while the $\mathrm{Li}_{2} \mathrm{O}$-to$\mathrm{Na}_{2} \mathrm{O}$ mole ratio was varied from 0.8 to over 21 at a more or less constant total alkali content of $20 \pm 3 \mathrm{~mol} \%$. The firing time for each frit-only feed was $15 \mathrm{~min}$.

Table 4-5. Compositions of Ten Frits Tested (wt\%).

\begin{tabular}{||c|c|c|c|c|c|c||}
\hline Frit & $\mathbf{B}_{\mathbf{2}} \mathbf{O}_{\mathbf{3}}$ & $\mathbf{C a O}$ & $\mathbf{L i}_{\mathbf{2}} \mathbf{O}$ & $\mathbf{N a}_{\mathbf{2}} \mathbf{O}$ & $\mathbf{S i O}_{\mathbf{2}}$ & Total \\
\hline 418 & 8 & 0 & 8 & 8 & 76 & 100 \\
\hline 503 & 14 & 0 & 8 & 4 & 74 & 100 \\
\hline 532 & 14 & 2 & 6 & 7 & 71 & 100 \\
\hline 533 & 16 & 0 & 5 & 8 & 71 & 100 \\
\hline 534 & 15 & 0 & 9 & 4 & 72 & 100 \\
\hline 540 & 12 & 2 & 6 & 8 & 72 & 100 \\
\hline 541 & 15 & 0 & 5 & 10 & 70 & 100 \\
\hline 542 & 18 & 0 & 4 & 10 & 68 & 100 \\
\hline 518 & 20 & 0 & 10 & 1 & 69 & 100 \\
\hline 519 & 20 & 0 & 9 & 3 & 68 & 100 \\
\hline \hline
\end{tabular}

\subsubsection{X-Ray and CT Images}

The X-ray images of ten heat-treated, frit-only samples are shown in Figure 4-9 along with that of the unfired Frit 418 as a comparison. One obvious difference between these images and those shown in Figure 4-1 is that the froth layer is completely missing from the former, since there are no gas-generators in the frits. Instead, a clear interface between the melt and un-melt layers is shown in each image, perhaps with the exception of Frit 518 and 519. The image of the unfired Frit 418 shows no voids, since all the frits used in this study were sieved to between 80 and 200 mesh $(74-177 \mu \mathrm{m})$, thus resulting in no interstitial voids larger than the preset CT voxel size of $0.15 \mathrm{~mm}$. Therefore, those voids shown in heat-treated Frit 418, 503, 534, 518 and 519 must have resulted from the agglomeration of air that was present interstitially among unfired frit granules but not vented out.

It will be shown in the results of CT analysis that Frit 418, 503, 534, 518 and 519 that contain large voids are also ranked as the five slowest-melting of all ten frits tested, while the remaining frits that contain little or no voids are ranked as the five fastest melting. These results essentially suggest that the rate of melting of these frits amounted to how many granules of each frit were fused together and how well the interstitial air that was trapped within the matrix of fused granules was released in the process. Since venting of gas is hindered by the fluid viscosity, it is clear that the viscosity of the resulting melt plays a significant role in the fusion process; the higher the viscosity of the resulting melts, the lower the melt rate. 


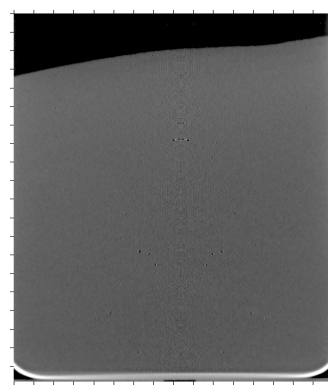

Un-fired 418

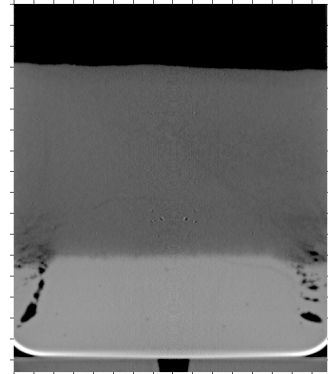

533

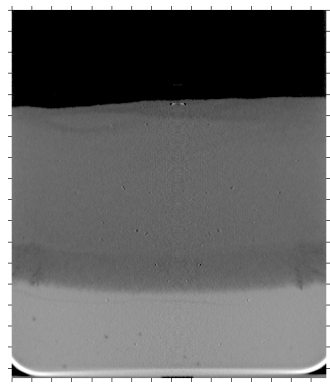

542

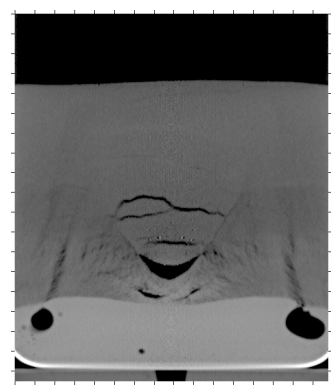

418

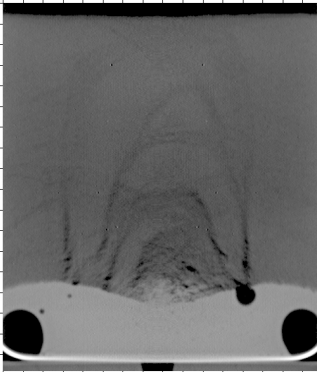

534

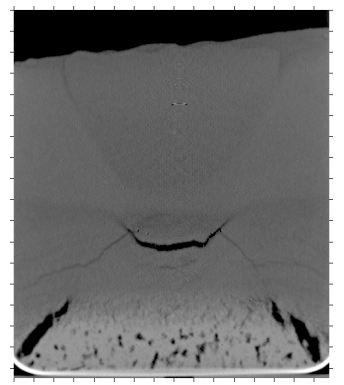

518

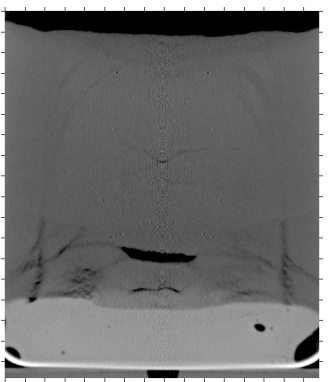

503

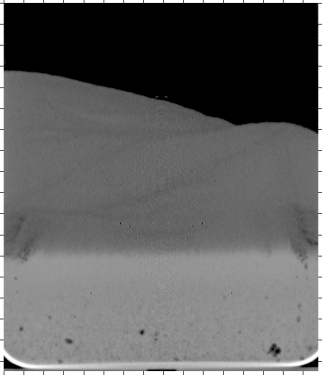

540

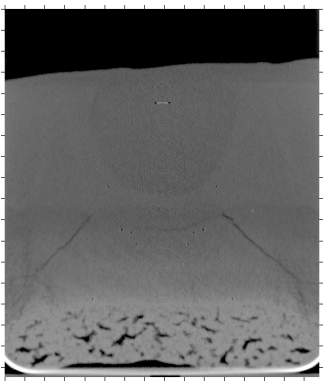

519

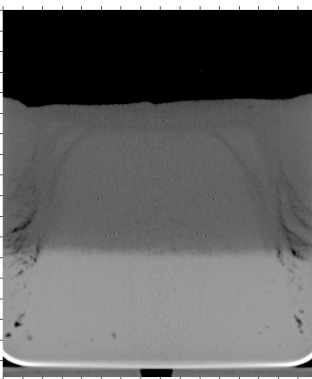

532

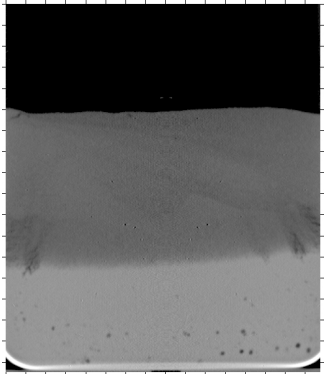

541

Figure 4-9. X-Ray Images of Heat-Treated Frit-Only Samples.

The CT histopics of the frit-only samples are shown in Figure 4-10. Note that the abrupt fall of $\mathrm{CT}$ density to near zero in the upper portion of each image represents the transition from sample to ambient air above, whereas the sharp increase at the bottom represents the transition from sample to the beaker bottom. As expected, the unfired Frit 418 shows a vertical line with no bends, since its CT density is the same everywhere in the sample. On the other hand, all heattreated samples except for Frit 518 and 519 show a sharp increase in CT density near the middle or lower half of each profile; this break represents the transition from the un-melt to melt layers. So, the elevation of this middle break point represents the height of the melt layer; however, it may not be used as a reliable melt rate indicator since the particular CT density at which the break occurs will likely vary from sample to sample and so does the color pattern of the CT density profile. By contrast, the breaks in the CT density profiles of Frit 518 and 519 are more gradual, which means that the transition from the un-melt to melt layers was more diffuse in these frits. 


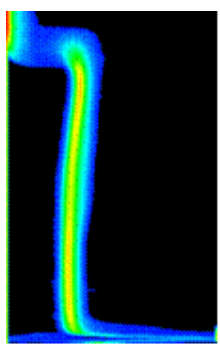

Unfired 418

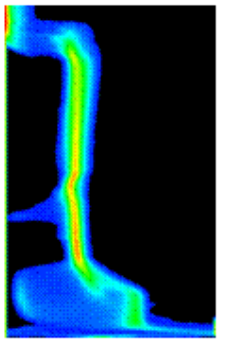

518

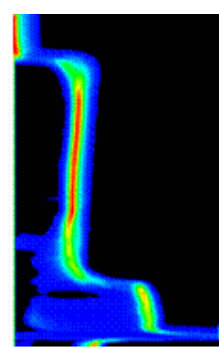

503

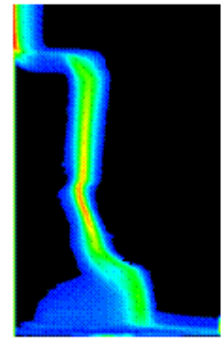

519

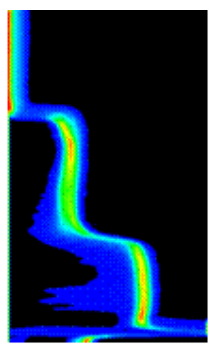

532

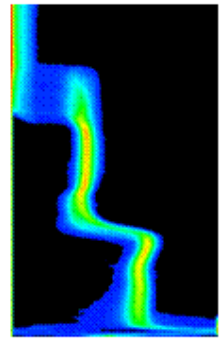

540

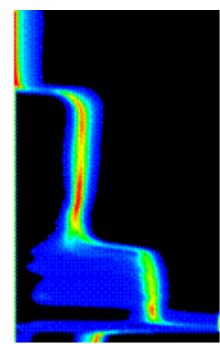

533

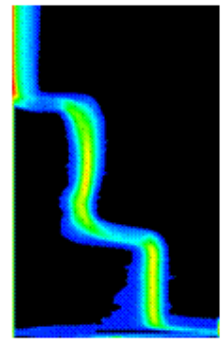

541

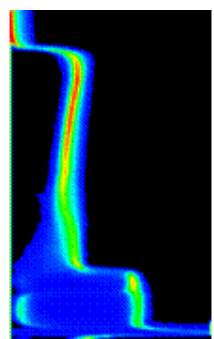

534

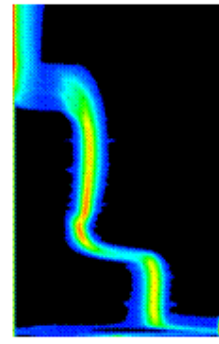

542

Figure 4-10. CT Histopics of Heat-Treated Frit-Only Samples.

\subsubsection{Results of CT Analysis}

The missing froth layers in the frit-only samples are confirmed by the histograms that lack the froth layer peaks. For example, it is shown in Figure 4-11 that the froth layer of the heat-treated Frit 418 not only lacks its peak but contains little material. Furthermore, Figure 4-12 shows that the froth layer of Frit 519 also lacks its peak but contains more material than Frit 418; not only the area under the froth layer curve but its relative proportion to that of the melt layer are both greater than the corresponding values of Frit 418. These results are indeed consistent with the trend shown by the Frit 519 histopics that the transition from the un-melt to melt layers was more diffusive.

As expected, the only peak shown in the histogram of the unfired Frit 418 is that of the un-melt layer (see Figure 4-13). However, Figure 4-13 also shows the froth-layer curve climbing up slightly toward the un-melt layer peak, which would give some small mass of froth material even for the unfired frit. Although small in magnitude, this is clearly an inherent error of the CT analysis caused by the method used to find the threshold boundaries between adjacent layers as described earlier; this method does not work well for the histogram regions that lack well-defined peaks with no significant mass of material.

The amount of material in each of the melt, froth, un-melt layers was calculated by integrating their respective portion of the CT histogram curve and the results are tabulated in Table 4-6. It is seen that although all froth layers lacked their peaks, the integration of their histogram curves still resulted in relatively small masses of material compared to those of the melt and un-melt layers of most samples; the exceptions were the slower-melting Frit 518 and 519, for which comparable masses of material were found in both the melt and froth layers. Also included in the table are the material densities that were calculated as the ratio of material mass-to-volume; the higher the overall density, the greater the degree of compaction or densification of the feed batch. 


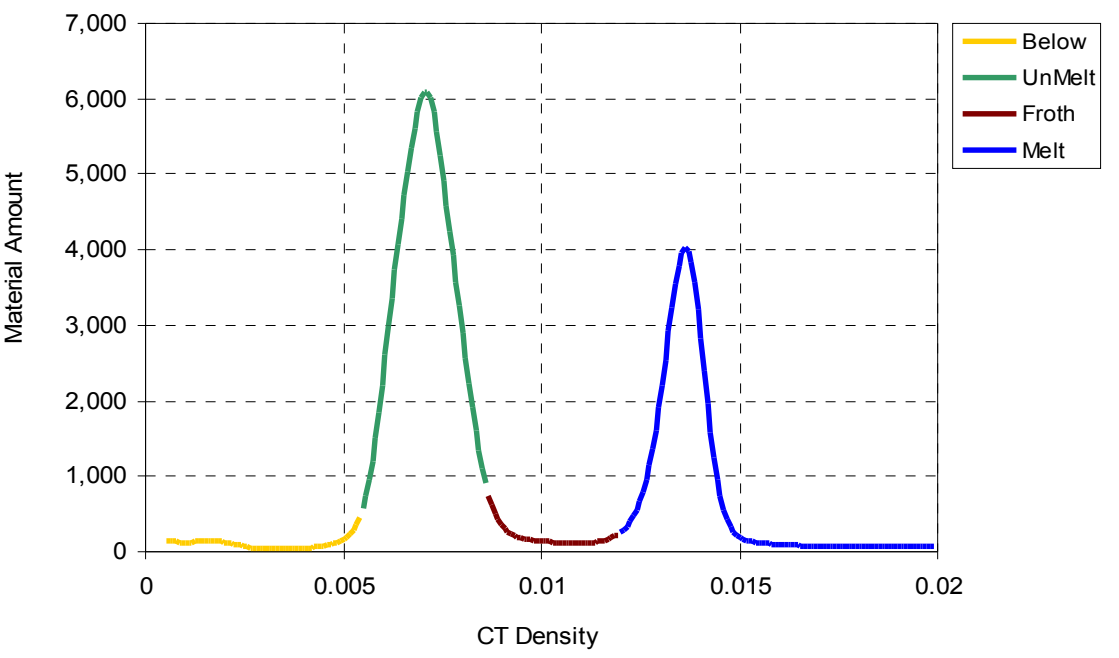

Figure 4-11. A Histogram of CT Density vs. Material Amount for Frit 418.

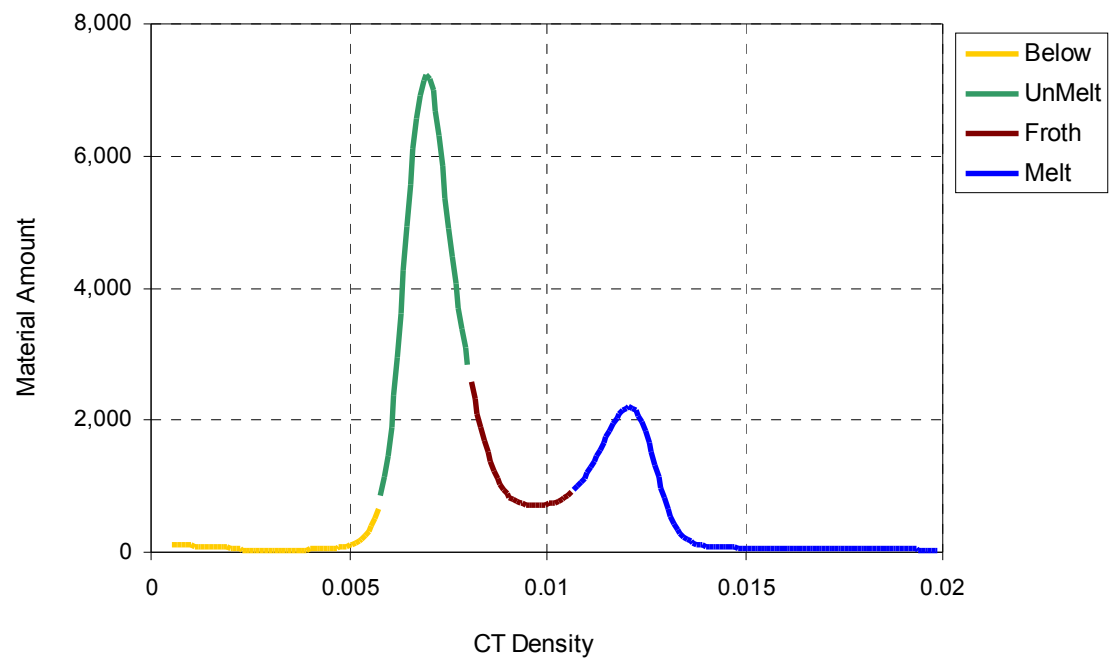

Figure 4-12. A Histogram of CT Density vs. Material Amount for Frit 519.

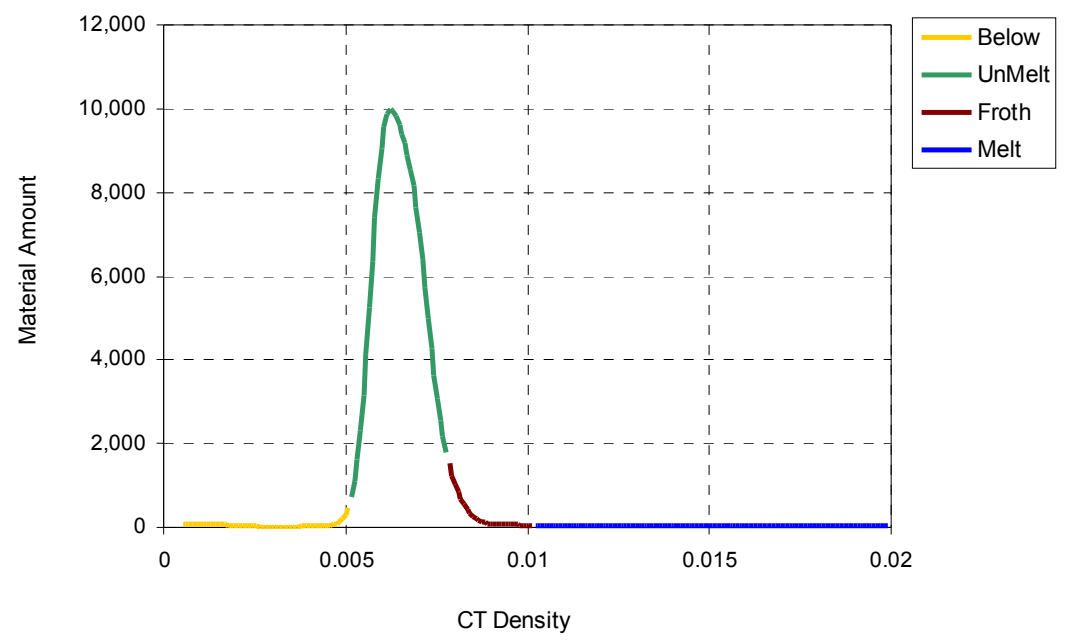

Figure 4-13. A Histogram of CT Density vs. Material Amount for Unfired Frit 418. 
Among the ten frits tested, Frit 541 was determined to contain the most melted material, slightly more than Frit 532. However, when the material in the froth layer was included, it was Frit 532 that contained the most material in the melt/froth layers. This is consistent with the result that Frit 532 also contained the least amount of un-melted material, since the total amount of material remaining in a beaker should be conserved with no gas generators in these frit-only feeds. With a variance of only $3.2 \%$ for the total amount of material remaining in each of the ten beakers, the conservation of mass was indeed satisfactorily achieved. Table 4-6 also shows that the degree of densification that occurred to Frit 532 was not the highest among the ten frits; it was the Frit 540 series that collapsed the most.

Table 4-6. CT-Calculated Distribution of Material and Density of Frit-Only Feeds.

\begin{tabular}{||c|c|c|c|c|c|c|c|c|c|c||}
\hline \multirow{3}{*}{ Frit } & \multicolumn{4}{|c|}{ Material Amount } & \multicolumn{5}{c||}{ Material Density } \\
\cline { 2 - 13 } & Total & $\begin{array}{c}\text { Un- } \\
\text { melt }\end{array}$ & $\begin{array}{c}\text { Melt/ } \\
\text { Froth }\end{array}$ & Froth & Melt & Overall & $\begin{array}{c}\text { Un- } \\
\text { melt }\end{array}$ & $\begin{array}{c}\text { Melt/ } \\
\text { Froth }\end{array}$ & Froth & Melt \\
\hline 418 & 215,351 & 136,760 & 78,591 & 8,336 & 70,255 & 2.545 & 2.111 & 3.966 & 2.946 & 4.136 \\
\hline 503 & 202,043 & 125,307 & 76,736 & 15,151 & 61,585 & 2.111 & 1.728 & 3.307 & 2.201 & 3.774 \\
\hline 532 & 208,248 & 70,457 & 137,791 & 14,026 & 123,765 & 2.692 & 1.773 & 3.663 & 2.361 & 3.907 \\
\hline 533 & 210,433 & 90,482 & 119,951 & 20,099 & 99,852 & 2.598 & 1.900 & 3.596 & 2.355 & 4.023 \\
\hline 534 & 197,092 & 137,247 & 59,844 & 4,738 & 55,107 & 2.085 & 1.764 & 3.580 & 2.622 & 3.697 \\
\hline 518 & 209,060 & 156,884 & 52,176 & 19,264 & 32,912 & 2.314 & 2.094 & 3.377 & 2.778 & 3.864 \\
\hline 519 & 216,087 & 127,906 & 88,181 & 34,094 & 54,087 & 2.500 & 2.143 & 3.299 & 2.771 & 3.749 \\
\hline 540 & 216,425 & 83,923 & 132,501 & 10,740 & 121,761 & 2.948 & 2.192 & 3.772 & 2.804 & 3.890 \\
\hline 541 & 217,800 & 84,968 & 132,832 & 8,431 & 124,400 & 3.039 & 2.167 & 4.093 & 2.974 & 4.200 \\
\hline 542 & 213,867 & 106,759 & 107,108 & 7,151 & 99,958 & 2.872 & 2.208 & 4.100 & 2.960 & 4.216 \\
\hline std dev & 6,772 & 28,733 & 31,674 & 8,667 & 33,624 & 0.33 & 0.19 & 0.30 & 0.28 & 0.19 \\
\hline $\begin{array}{c}\text { std dev/ } \\
\text { mean }\end{array}$ & $3.2 \%$ & $25.6 \%$ & $32.1 \%$ & $61.0 \%$ & $39.9 \%$ & $12.9 \%$ & $9.7 \%$ & $8.3 \%$ & $10.5 \%$ & $4.8 \%$ \\
\hline \hline
\end{tabular}

Based on the quantitative CT data given in Table 4-6, various melt rate rankings of the frit-only feeds were derived in Table 4-7. As discussed above, the material rankings of the combined melt and froth layers show Frits 532 and 518 as the fastest and slowest melting frits, respectively, which agrees with the inverse rankings of the un-melt materials. However, some differences are seen in the middle rankings of the melt/froth and un-melt materials mainly due to the closeness of their CT-based material counts. For example, the calculated material amounts in the melt/froth layers of Frits 540 and 541 are practically equal, while the corresponding differences among Frits 418,503 and 519 are less than $10 \%$. As discussed earlier, it is the material rankings based on both the melt and froth layers that are deemed most relevant to continuous melter operation.

In order to see the impact of frit composition on melt rate, the material rankings of the melt/froth layers are re-listed in Table 4-8 along with the corresponding targeted frit compositions in mole percent. Note that the given frit compositions are not exact; instead, they were rounded to the nearest $1 \mathrm{~mol} \%$ in order to facilitate quick comparisons. So, as written, they do not quite add up to $100 \%$ for Frit 532 and 418 . It is clearly seen that the five slowest-melting frits contain the five highest levels of $\mathrm{Li}_{2} \mathrm{O}$ and the five lowest levels $\mathrm{Na}_{2} \mathrm{O}$ among all ten frits tested. Particularly, when the two highest-boron containing Frits 518 and 519 are compared, the lowering of $\mathrm{Li}_{2} \mathrm{O}$ in Frit 518 by $2 \mathrm{~mol} \%$ and the counter-balancing increase in $\mathrm{Na}_{2} \mathrm{O}$ by the same amount so as to maintain a constant total alkali level resulted in a $70 \%$ higher melt rate for Frit 519 (see Table 4-6). 
Table 4-7. CT-Based Melt Rate Rankings of Frit-Only Feeds.

\begin{tabular}{||c|c|c|c|c|c|c|c||}
\hline \multirow{2}{*}{ Rankings } & \multicolumn{3}{|c|}{ Material Amount } & \multicolumn{4}{c||}{ Material Density } \\
\cline { 2 - 8 } & \multirow{2}{*}{ Un-melt } & Melt/Froth & \multirow{2}{*}{ Melt } & \multirow{2}{*}{ Overall } & Un-melt & Melt/Froth & \multirow{2}{*}{ Melt } \\
\hline 1 & 518 & 532 & 541 & 541 & 418 & 542 & 542 \\
\hline 2 & 534 & 541 & 532 & 540 & 542 & 541 & 541 \\
\hline 3 & 418 & 540 & 540 & 542 & 540 & 418 & 418 \\
\hline 4 & 519 & 533 & 542 & 532 & 541 & 540 & 533 \\
\hline 5 & 503 & 542 & 533 & 533 & 519 & 532 & 532 \\
\hline 6 & 542 & 519 & 418 & 418 & 518 & 533 & 540 \\
\hline 7 & 533 & 418 & 503 & 519 & 533 & 534 & 518 \\
\hline 8 & 541 & 503 & 534 & 518 & 532 & 518 & 503 \\
\hline 9 & 540 & 534 & 519 & 503 & 534 & 503 & 519 \\
\hline 10 & 532 & 518 & 518 & 534 & 503 & 519 & 534 \\
\hline \hline
\end{tabular}

When the $\mathrm{Li}_{2} \mathrm{O}$ level was further reduced from $17 \mathrm{~mol} \%$ in Frit 519 to $8 \mathrm{~mol} \%$ in Frit 542 with a counterbalancing increase in $\mathrm{Na}_{2} \mathrm{O}$ from 3 to $10 \mathrm{~mol} \%$, the corresponding relative increase in melt rate was less than that seen between Frits 518 and 519; the measured melt rate of Frit 542 was $21 \%$ higher than that of Frit 519. Part of the reason for the attenuated increase in melt rate despite greater swings in the $\mathrm{Li}_{2} \mathrm{O}$ and $\mathrm{Na}_{2} \mathrm{O}$ levels may be due to a higher $\mathrm{SiO}_{2}$ level in Frit 542 than that in Frit 519; 67 vs. $64 \mathrm{~mol}^{\%} \mathrm{SiO}_{2}$. These results suggest that the tightening of the network structure by smaller and therefore higher field-strength modifier ions and the increased network connectivity as a result of increased network former levels both have a large, negative impact on melt rate. It is interesting to note that the frit term in the existing MRI correlation shown in Eq. (3) has the concentration of $\mathrm{Li}_{2} \mathrm{O}$ empirically reduced by a factor of 0.7 to better match measured data.

Table 4-8. Melt Rate Rankings vs. Frit Compositions (rounded to the nearest $1 \mathrm{~mol} \%$ ).

\begin{tabular}{||c|c|c|c|c|c|c|c||}
\hline Rankings & Frit & $\mathbf{B}_{\mathbf{2}} \mathbf{O}_{\mathbf{3}}$ & $\mathbf{C a O}$ & $\mathbf{L i}_{\mathbf{2}} \mathbf{O}$ & $\mathbf{N a}_{\mathbf{2}} \mathbf{O}$ & $\mathbf{S i O}_{\mathbf{2}}$ & Total \\
\hline 1 & 532 & 12 & 2 & 12 & 7 & 68 & 101 \\
\hline 2 & 541 & 13 & 0 & 10 & 9 & 68 & 100 \\
\hline 3 & 540 & 10 & 2 & 12 & 7 & 69 & 100 \\
\hline 4 & 533 & 13 & 0 & 10 & 8 & 69 & 100 \\
\hline 5 & 542 & 15 & 0 & 8 & 10 & 67 & 100 \\
\hline 6 & 519 & 16 & 0 & 17 & 3 & 64 & 100 \\
\hline 7 & 418 & 6 & 0 & 15 & 7 & 71 & 99 \\
\hline 8 & 503 & 11 & 0 & 15 & 4 & 70 & 100 \\
\hline 9 & 534 & 12 & 0 & 17 & 4 & 67 & 100 \\
\hline 10 & 518 & 16 & 0 & 19 & 1 & 64 & 100 \\
\hline
\end{tabular}

The impact of $\mathrm{B}_{2} \mathrm{O}_{3}$ on melt rate can be seen by comparing Frits 418 and 503. The $\mathrm{Na}_{2} \mathrm{O}$ level in Frit 418 is $3 \mathrm{~mol} \%$ higher than that in Frit 503 at the same $\mathrm{Li}_{2} \mathrm{O}$ and nearly identical $\mathrm{SiO}_{2}$ levels. Based on these comparisons, the melt rate of Frit 418 should have been higher than that of Frit 503. However, the measured difference in melt rate between these two frits is only $\sim 2 \%$, which suggests that a $5 \mathrm{~mol} \%$ increase in $\mathrm{B}_{2} \mathrm{O}_{3}$ over that of Frit 418 was enough to counterbalance a 3 mol\% reduction in $\mathrm{Na}_{2} \mathrm{O}$ level in Frit 503. However, when Frits 503 and 534 are compared, the beneficial effect of $\mathrm{B}_{2} \mathrm{O}_{3}$ addition becomes unclear. When the $\mathrm{B}_{2} \mathrm{O}_{3}$ and $\mathrm{Li}_{2} \mathrm{O}$ levels in Frit 534 were increased by 1 and $2 \mathrm{~mol} \%$, respectively, at the expense of $\mathrm{SiO}_{2}$ over their counterparts in 
Frit 503, the resulting melt rate of Frit 534 fell by $28 \%$. This large reduction in melt rate may be attributed to the meager $1 \mathrm{~mol} \%$ increase in $\mathrm{B}_{2} \mathrm{O}_{3}$ in Frit 534, since it is presumed that increased $\mathrm{Li}_{2} \mathrm{O}$ at a constant $\mathrm{Na}_{2} \mathrm{O}$ level should help melt rate by creating additional NBO, thus reducing the network connectivity that is already reduced by the lower $\mathrm{SiO}_{2}$ level. It may also be hypothesized that the reduced melt rate was due to increases in both $\mathrm{B}_{2} \mathrm{O}_{3}$ and $\mathrm{Li}_{2} \mathrm{O}$, since $\mathrm{Li}^{+}$should couple with the $\mathrm{BO}_{4}{ }^{-}$tetrahedra more easily than $\mathrm{Na}^{+}$, thus resulting in a tighter network structure.

It is also clearly seen from Table 4-8 that the addition of $\mathrm{CaO}$ helps improve melt rate. Despite the lowering of $\mathrm{Na}_{2} \mathrm{O}$ in Frit 541 by $2 \mathrm{~mol} \%$ and the counter-balancing increase in $\mathrm{Li}_{2} \mathrm{O}$ by the same amount, the melt rate of Frit 532 was still 4\% higher than that of Frit 541 because of the presence of $\mathrm{CaO}$ in the former. Likewise, when Frit 540 and 541 are compared, the lower $\mathrm{Li}_{2} \mathrm{O}$ and higher $\mathrm{Na}_{2} \mathrm{O}$ in the latter should have resulted in a higher melt rate than the former. However, the measured melt rates of both frits were practically identical due to the presence of $\mathrm{CaO}$ in Frit 540. However, it is not clear whether the $3 \mathrm{~mol} \%$ lower $\mathrm{B}_{2} \mathrm{O}_{3}$ in Frit 540 had a compounding effect on its melt rate along with $\mathrm{CaO}$.

\subsubsection{Visual Determination of Melt Rates}

The visual melt rate readings were taken from the X-ray images shown in Figure 4-9 using the procedures described in Section 3.3. The resulting melt rate rankings based on the visual method are compared to those based on the CT method in Table 4-9. The lack of froth layers in the fritonly samples made the visual readings more straightforward and thus less subjective. As a result, the visual rankings are shown to be similar to the CT-based rankings. The main difference is that the visual method ranks Frit 519 as the second slowest melting, while the CT analysis ranks it higher than Frit 418. This discrepancy resulted from the fact that the CT analysis revealed a significant un-melt-to-melt transition region in Frit 519 that is not readily visible in the X-ray images. As shown in Figure 4-14, the visual and CT-based melt rate profiles indeed track each other well except for Frit 519. The overall density profile is also shown to track the melt rate profiles well except for Frit 518 for which the CT analysis ranks it as the third least dense sample. Interestingly, it is the same five slowest-melting frits that contain large voids in the X-ray images.

Table 4-9. Visual vs. CT-Based Melt Rate Rankings and Frit Compositions (mol\%).

\begin{tabular}{|c|c|c|c|c|c|c|c|c||}
\hline \hline Rankings & $\mathbf{C T}$ & Visual & $\mathbf{B}_{\mathbf{2}} \mathbf{O}_{\mathbf{3}}$ & $\mathbf{C a O}$ & $\mathbf{L}_{\mathbf{2}} \mathbf{O}$ & $\mathbf{N a}_{\mathbf{2}} \mathbf{O}$ & $\mathbf{S i O}_{\mathbf{2}}$ & Total \\
\hline 1 & 532 & 532 & 12 & 2 & 12 & 7 & 68 & 101 \\
\hline 2 & 541 & 540 & 10 & 2 & 12 & 7 & 69 & 100 \\
\hline 3 & 540 & 541 & 13 & 0 & 10 & 9 & 68 & 100 \\
\hline 4 & 533 & 533 & 13 & 0 & 10 & 8 & 69 & 100 \\
\hline 5 & 542 & 542 & 15 & 0 & 8 & 10 & 67 & 100 \\
\hline 6 & 519 & 418 & 6 & 0 & 15 & 7 & 71 & 99 \\
\hline 7 & 418 & 503 & 11 & 0 & 15 & 4 & 70 & 100 \\
\hline 8 & 503 & 534 & 12 & 0 & 17 & 4 & 67 & 100 \\
\hline 9 & 534 & 519 & 16 & 0 & 17 & 3 & 64 & 100 \\
\hline 10 & 518 & 518 & 16 & 0 & 19 & 1 & 64 & 100 \\
\hline
\end{tabular}




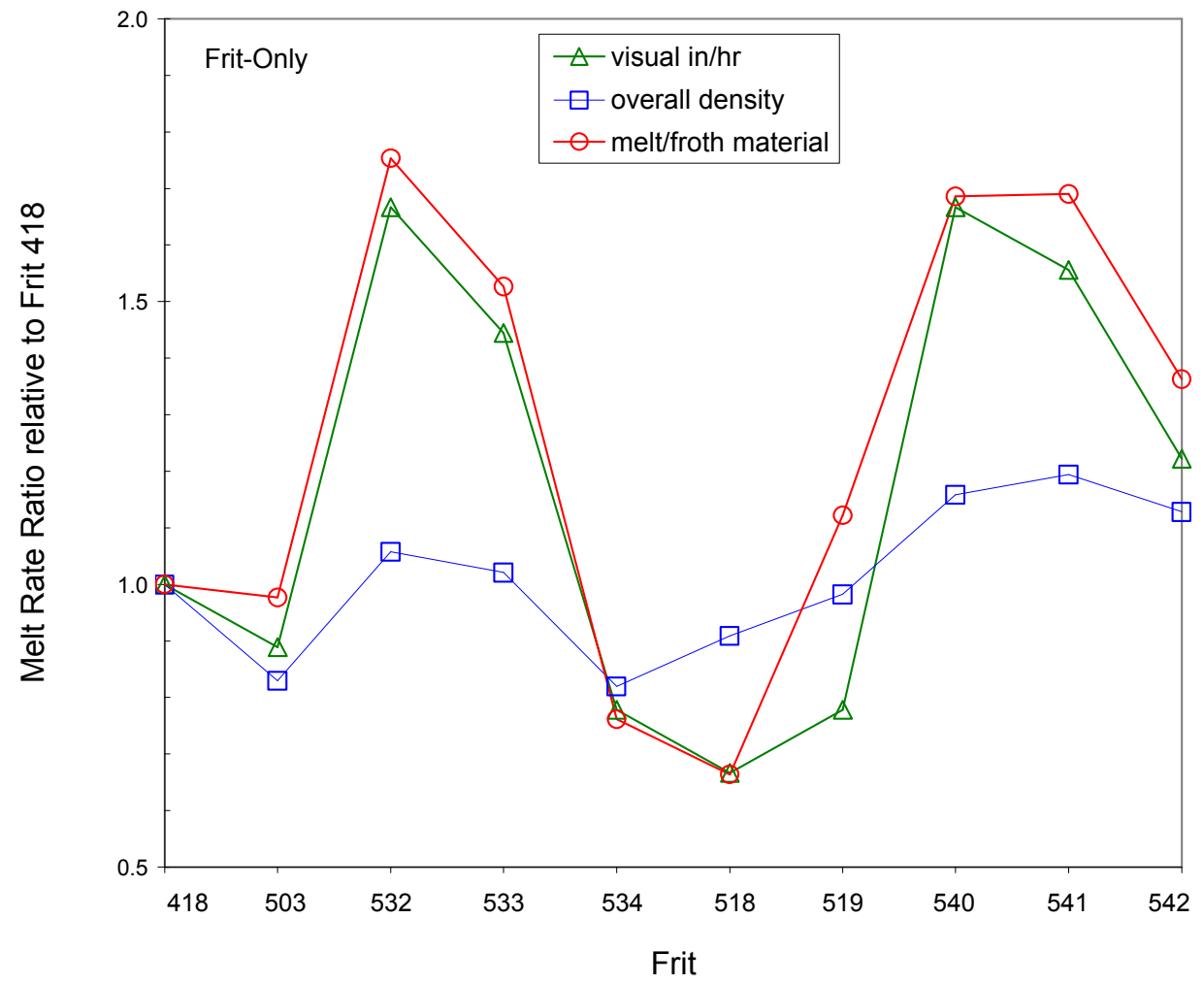

Figure 4-14. Relative Melt Rate and Overall Density Profiles of Frit-Only Samples.

\subsection{Varying Waste-Loading Glasses}

The SB6 SRAT product shown in Table 3-3 was blended with Frit 418 at varying waste oxide loadings ranging from 30 to $43 \mathrm{wt} \%$ in order to make a quantitative assessment of the impact of $\mathrm{WL}$ on melt rate. The firing time for each sample was $20 \mathrm{~min}$.

\subsubsection{X-Ray and CT Images}

The X-ray images of six SB6/Frit 418 heat-treated feeds are shown in Figure 4-15. In general, both the melt and un-melt layers appear to become more sluggish with increasing WL. This was expected since with increasing WL there are not only more waste oxides to be incorporated into the glass but more gases are generated from the decomposition of non-volatile feed components into their oxides. Furthermore, despite compositional differences, these samples lack the large voids that were present in the middle of the bounding sludge/Frit 418 heat-treated feeds shown in Figure 4-1. Since the SB6 SRAT product contained nearly twice as much nitrate as the bounding sludge feeds, the X-ray images shown in Figure 4-15 should have contained larger voids than those shown in Figure 4-1. Therefore, the missing large voids in the middle of these samples were likely due to a 2 -min shorter firing time compared to that of the bounding sludge feeds. A difference of $2 \mathrm{~min}$ or $10 \%$ reduction in firing time may not seem significant. However, it should be noted that the degree of fusion is not directly proportional to the firing time, since it takes at least several minutes for the samples to reach the decomposition and melting temperatures; according to the temperature data taken within the batch throughout the duration of a MRF run, it is during the final several minutes of the firing time when most fusion occurs to the feed. 


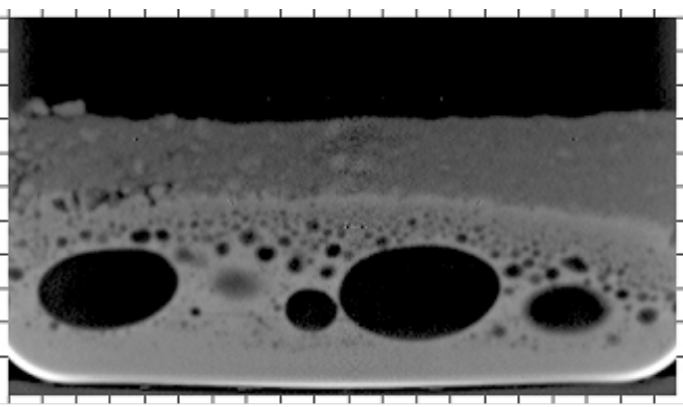

$30 \%$ WL

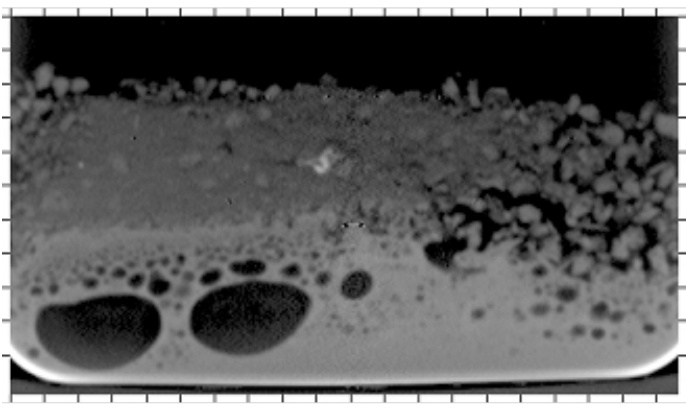

$36 \% \mathrm{WL}$

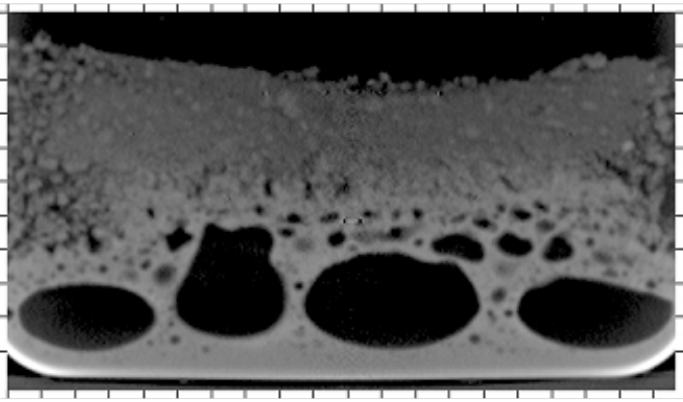

$42 \%$ WL

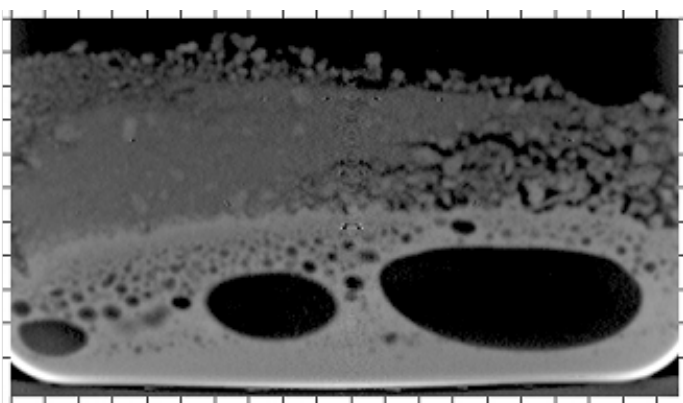

$33 \% \mathrm{WL}$

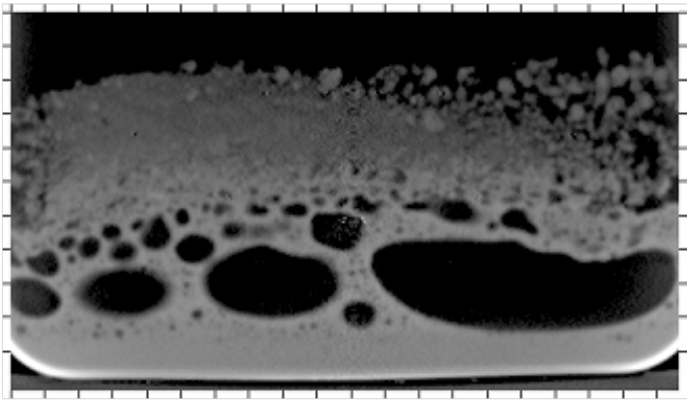

$39 \% \mathrm{WL}$

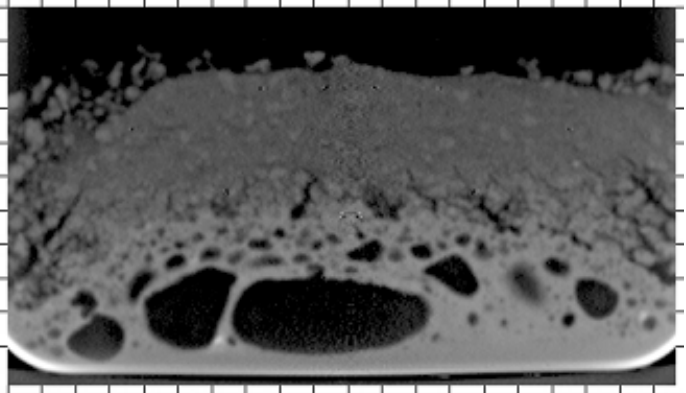

$45 \% \mathrm{WL}$

Figure 4-15. X-Ray Images of Heat-Treated SB6/Frit 418 Samples.

\subsubsection{Results of CT Analysis}

A histogram of CT density vs. material amount for the $30 \% \mathrm{WL}$ feed was shown earlier in Figure 4-3; its melt and froth-layer profiles peaked at near 2,000 and 1,500, respectively. By comparison, the melt-layer profile of the 45\% WL feed is shown in Figure 4-16 to peak at near 1,300, while no peak is present in the froth-layer profile. A gradual reduction of both melt and froth-layer peaks with increasing WL can be seen in Figure 4-17 except for the 36 and 39\% WL feeds, whose melt layer peaks are shown to be higher than that of the $33 \% \mathrm{WL}$ feed.

The results of the histogram analysis were next superimposed on the X-ray images, as shown in Figure 4-18, to clearly depict how different materials are spatially distributed. It is shown that the interfaces between the un-melt and froth layers and between the froth and melt layers are highly diffuse so there is a significant overlap of materials across the interfaces. It is also shown that larger-sized bubbles found exclusively in the melt layer are typically surrounded by the froth 
material at their peripheries, while smaller-sized bubbles found in the froth layer are surrounded by the un-melt material at their peripheries.

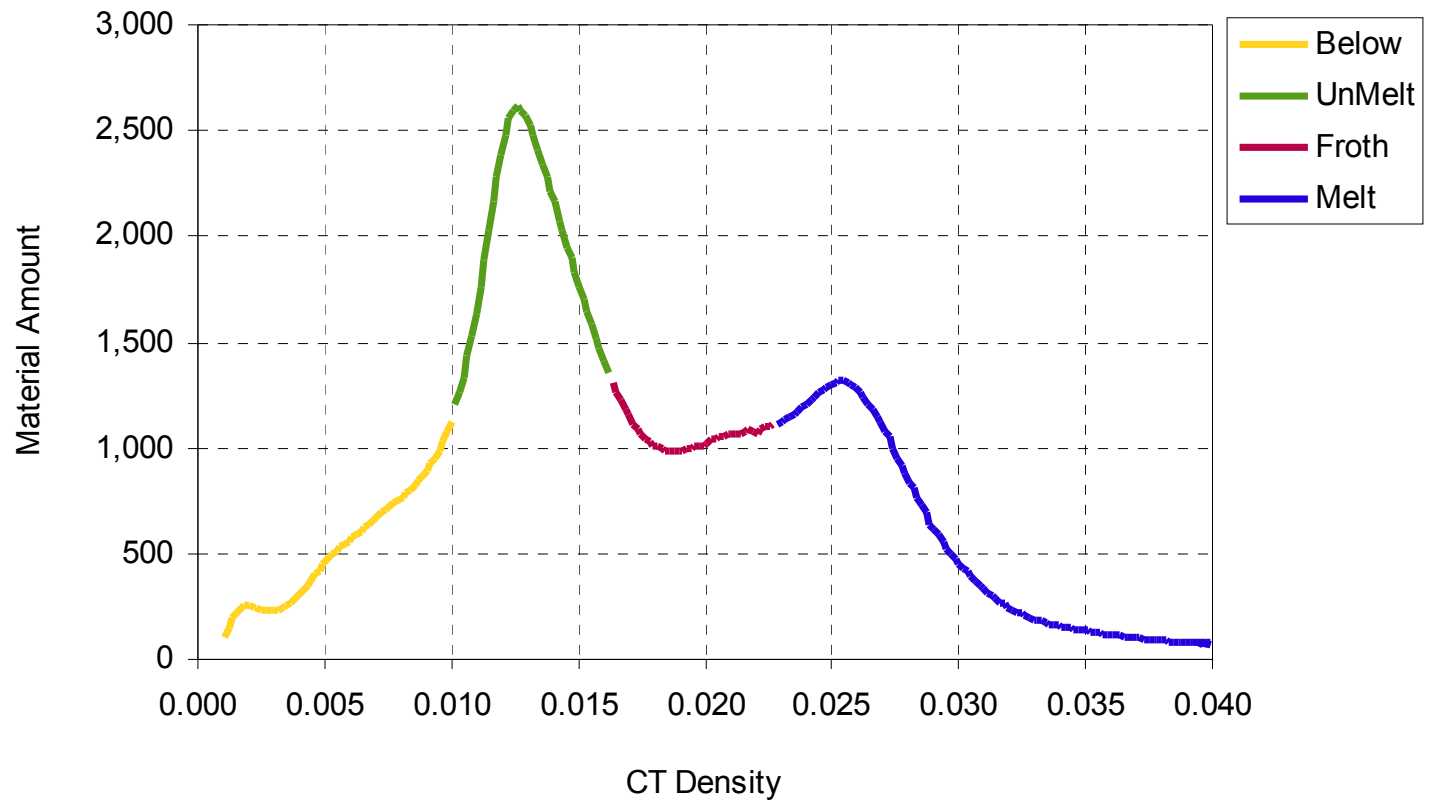

Figure 4-16. A Histogram of CT Density vs. Material Amount for SB6/Frit $418 @ 43 \%$ WL.

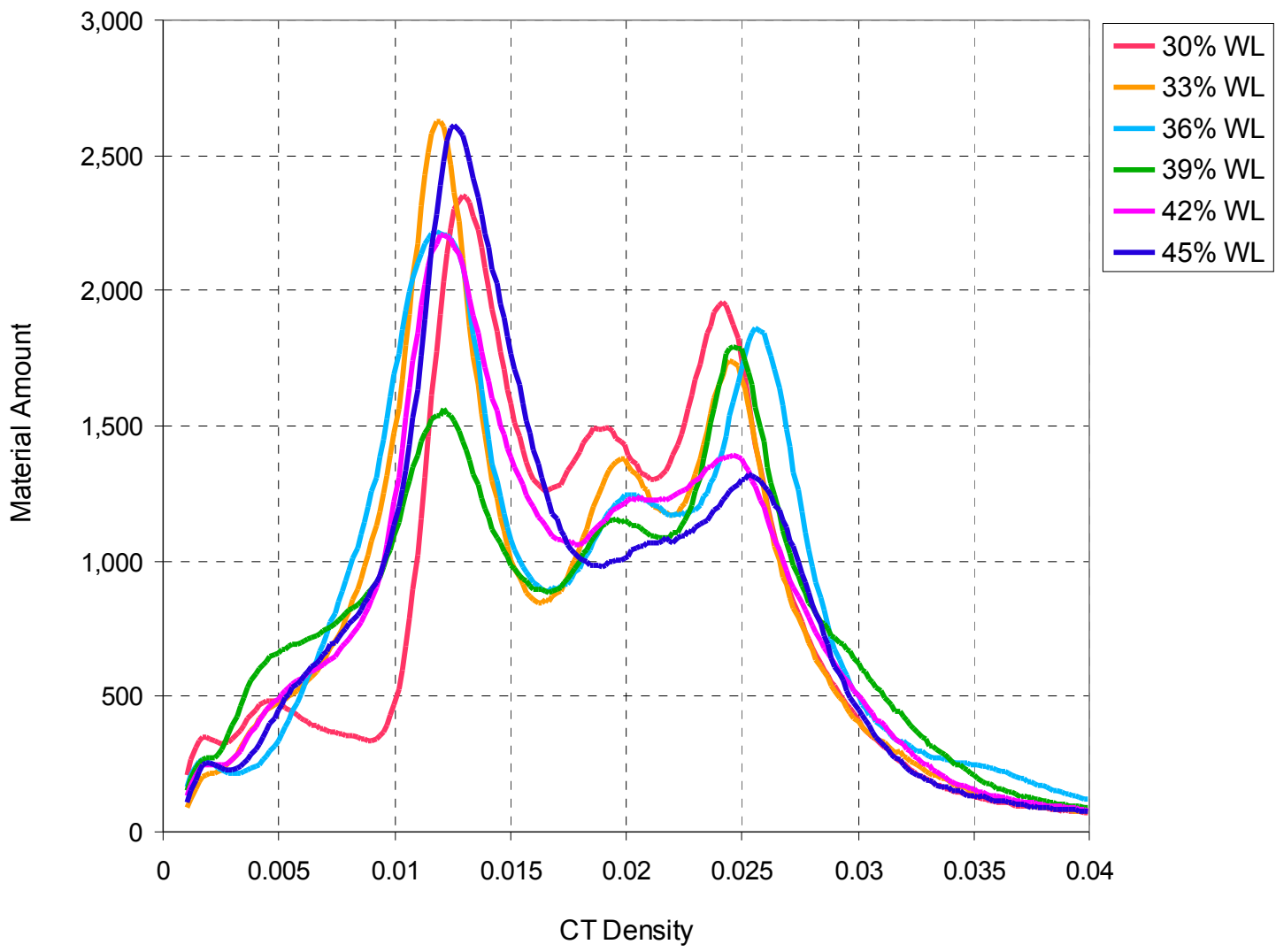


Figure 4-17. Comparison of Histograms of SB6/Frit 418 WL Series Feeds.

Since bubbles are produced as a result of decomposition and fusion reactions, it is expected to see some residual feed material in them. This is indeed what is shown in Figure 4-18; regardless of its size, each bubble including those in the melt layer contains a thin layer of un-melt material near its periphery. For the 36\% WL heat-treated feed, a rather modest amount of un-melt material is shown to be still present inside the bubbles. Therefore, when viewed from its center to the periphery, each developing bubble may be regarded as a small cold cap itself in that much of the inside volume of a bubble is made up of the "below" material, which is surrounded by a thin layer of un-melt material near the periphery, which is in turn surrounded by a layer of froth material. If the bubble is in the melt layer, the entire bubble assembly just described would be surrounded by an infinite layer of melt material.

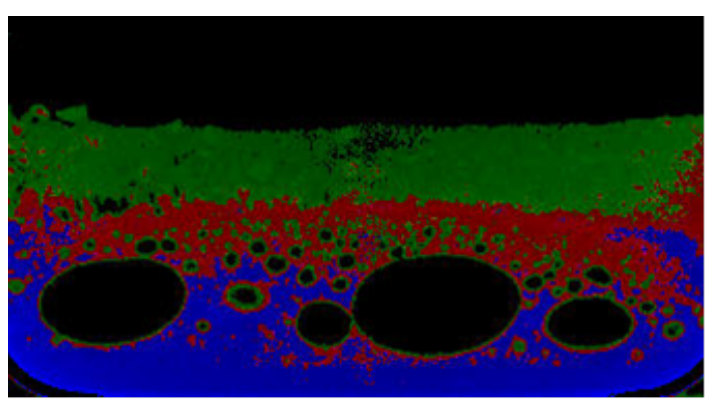

$30 \%$ WL

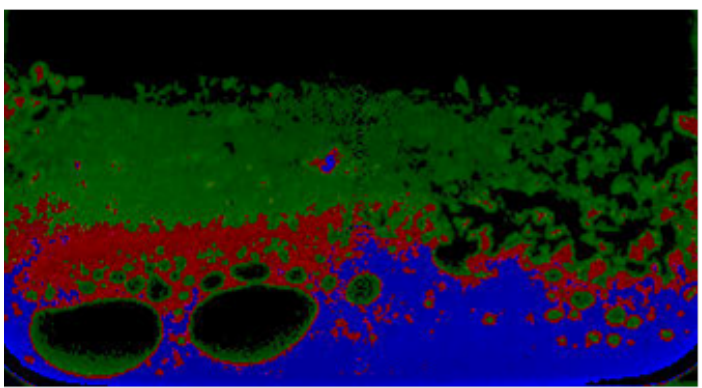

$36 \% \mathrm{WL}$

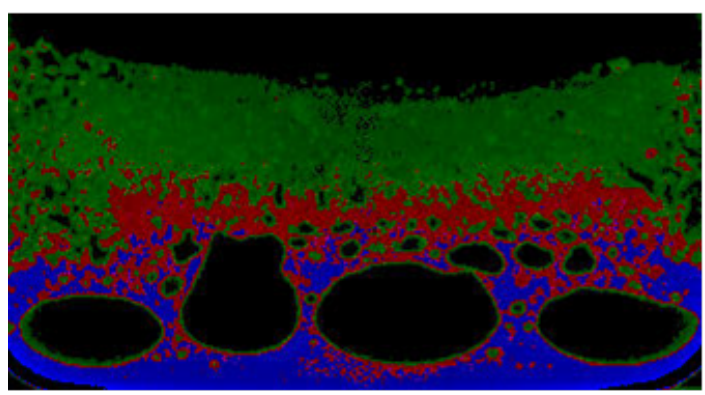

$42 \%$ WL

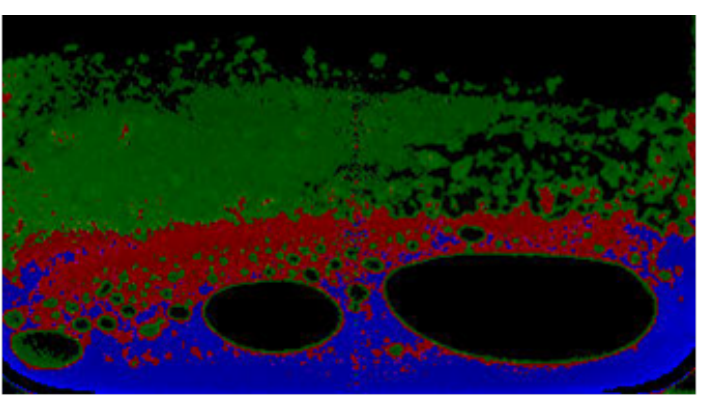

$33 \% \mathrm{WL}$

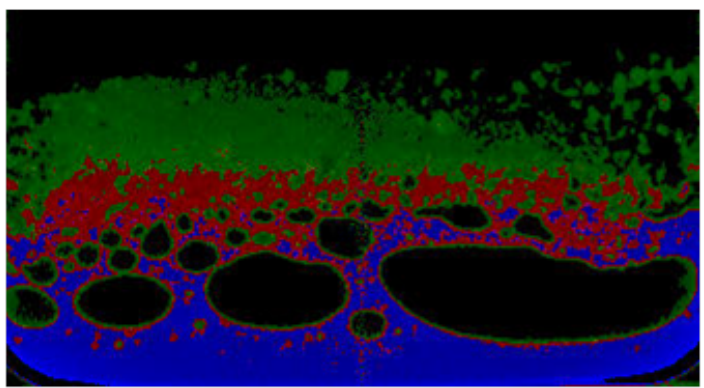

$39 \% \mathrm{WL}$

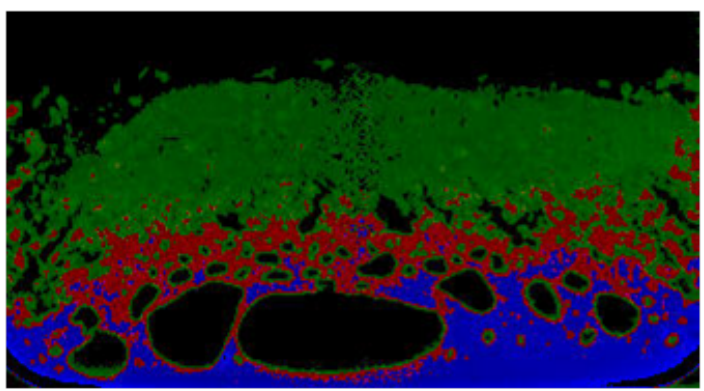

$45 \% \mathrm{WL}$

Figure 4-18. Colored X-Ray Images of Heat-Treated SB6/Frit 418 WL Samples. 
It may also be envisioned that the feed undergoes physical transformations similar to those shown by the images of Figure 4-18 as it moves downward caused by the eroding melt layer, which is in turn caused by the convective motion of the melt pool. By comparison, the large voids in the middle of each image in Figure 4-1 are not likely to be representative of the real cold cap, since such large voids resulting from the agglomeration of trapped bubbles could have been stabilized by the walls of the 2 "-diameter beaker.

For a quantitative assessment of the impact of waste loading on melt rate, the amount of material in each of the melt, froth, un-melt layers was calculated by integrating their respective portion of the CT histogram curve and the results are tabulated in Table 4-10. As expected, the amount of material in both the melt and froth layers combined decreased with increasing WL except for the $33 \% \mathrm{WL}$ heat-treated feed. It is not clear why the amount of melt material in the $33 \% \mathrm{WL}$ feed was less than either the $36 \%$ or $39 \%$ WL feed despite having more froth material. It is also noted that the variance in the total material amount remaining in each beaker was only $3.2 \%$ despite the fact that some high-melting feeds should have lost significant masses due to gas evolution.

Also included in Table 4-10 are the material densities that were calculated as the ratio of material mass-to-volume. The overall densities of the 30 and $39 \% \mathrm{WL}$ heat-treated feeds were practically identical, while those of the $33 \%$ and $36 \%$ WL heat-treated feeds were lower than either the $42 \%$ or $45 \% \mathrm{WL}$ feed. This means that a higher degree of compaction occurred to the slowest melting $45 \% \mathrm{WL}$ feed than either the $33 \%$ or $36 \%$ WL feed. This may seem counterintuitive at first but is entirely feasible when the expansion of feed batch due to the gas evolution during melting is considered, which means that the material density cannot be a good indicator of how fast a given feed batch melts when a significant gas evolution is involved, as shown in Figure 4-18.

Table 4-10. CT-Calculated Distribution of Material and Density of SB6/Frit 418 WL Feeds.

\begin{tabular}{|c|c|c|c|c|c|c|c|c|c|c|}
\hline \multirow{2}{*}{$\begin{array}{c}\text { WL } \\
(w t \%)\end{array}$} & \multicolumn{5}{|c|}{ Material Amount } & \multicolumn{5}{|c|}{ Material Density } \\
\hline & Total & $\begin{array}{l}\text { Un- } \\
\text { melt }\end{array}$ & $\begin{array}{l}\text { Melt/ } \\
\text { Froth }\end{array}$ & Froth & Melt & Overall & $\begin{array}{l}\text { Un- } \\
\text { melt }\end{array}$ & $\begin{array}{l}\text { Melt/ } \\
\text { Froth }\end{array}$ & Froth & Melt \\
\hline 30 & 180,710 & 55,996 & 124,714 & 49,417 & 75,297 & 5.399 & 3.854 & 6.584 & 5.451 & 7.623 \\
\hline 33 & 176,536 & 66,460 & 110,076 & 43,512 & 66,563 & 5.070 & 3.595 & 6.740 & 5.589 & 7.789 \\
\hline 36 & 195,145 & 75,999 & 119,146 & 43,380 & 75,766 & 5.015 & 3.474 & 6.993 & 5.690 & 8.048 \\
\hline 39 & 166,307 & 50,761 & 115,546 & 38,222 & 77,324 & 5.396 & 3.582 & 6.938 & 5.557 & 7.910 \\
\hline 42 & 177,440 & 68,310 & 109,130 & 45,327 & 63,803 & 5.106 & 3.662 & 6.778 & 5.624 & 7.935 \\
\hline 45 & 174,004 & 74,998 & 99,007 & 42,602 & 56,405 & 5.150 & 3.868 & 6.876 & 5.760 & 8.054 \\
\hline std dev & 6,772 & 28,733 & 31,674 & 8,667 & 33,624 & 0.167 & 0.158 & 0.149 & 0.107 & 0.165 \\
\hline $\begin{array}{c}\text { std dev/ } \\
\text { mean }\end{array}$ & $3.2 \%$ & $25.6 \%$ & $32.1 \%$ & $61.0 \%$ & $39.9 \%$ & $3.2 \%$ & $4.3 \%$ & $2.2 \%$ & $1.9 \%$ & $2.1 \%$ \\
\hline
\end{tabular}

Based on the quantitative CT data given in Table 4-10, various melt rate rankings of the SB6/Frit 418 WL feeds were derived in Table 4-11. As noted above, the material rankings of the melt and froth layers combined put both $36 \%$ and 39\% WL feeds higher than the 33\% WL feed despite the fact that it was the $39 \%$ WL feed that had the most un-melt material remaining after 20 min of heat treatment. Otherwise, the expected overall trend of decreasing melt rate with increasing WL would have been preserved throughout the WL range. The rankings based on the un-melt material only put the two highest WL feeds higher than the $36 \%$ WL feed, which clearly contradicts the other two material-based rankings. Of all the density-based rankings, only the overall density 
rankings show the $30 \% \mathrm{WL}$ feed as the fastest melting; however, the two highest WL feeds are also ranked as the third and fourth fastest melting feeds, which clearly is not in agreement with the X-ray images, thus confirming that the material ranking based on the melt and froth layers combined is still the best CT-based ranking even for such high-gas-generating feeds like the SB6 SRAT product studied here.

Table 4-11. CT-Based Melt Rate Rankings of SB6/Frit 418 WL Feeds (\% WL).

\begin{tabular}{||c|c|c|c|c|c|c|c||}
\hline \multirow{2}{*}{ Rankings } & \multicolumn{3}{|c|}{ Material Amount } & \multicolumn{4}{c||}{ Material Density } \\
\cline { 2 - 8 } & Un-melt & Melt/Froth & Melt & Overall & Un-melt & Melt/Froth & Melt \\
\hline 1 & 39 & 30 & 39 & 30 & 36 & 36 & 45 \\
\hline 2 & 30 & 36 & 36 & 39 & 39 & 39 & 36 \\
\hline 3 & 33 & 39 & 30 & 45 & 33 & 45 & 42 \\
\hline 4 & 42 & 33 & 33 & 42 & 42 & 42 & 39 \\
\hline 5 & 45 & 42 & 42 & 33 & 30 & 33 & 33 \\
\hline 6 & 36 & 45 & 45 & 36 & 45 & 30 & 30 \\
\hline \hline
\end{tabular}

\subsubsection{Visual Determination of Melt Rates}

The visual melt rate readings were taken from the X-ray images shown in Figure 4-15 using the procedures described in Section 3.3. Each image was magnified to a 4"-diameter scale and the glass heights were read at $1 / 4$ " intervals. The average height readings were then reduced back to a 2"-diameter scale in order to calculate the LMR given in Table 4-12. The relative LMR with respect to the 36\% WL feed are plotted in Figure 4-19 against WL along with the relative melt rates based on the CT method. As noted earlier, had the relative melt rate of the $33 \% \mathrm{WL}$ feed fallen near the dotted line shown, the CT-based relative melt rate profile would have shown the trend of monotonically decreasing melt rate with increasing WL throughout the WL range tested. The monotonic decrease in melt rate with increasing WL was also visually determined in an earlier melt rate study conducted with the SB2/3 feeds that contained a significantly lower concentration of gas generators than the SB6 feed tested in this study. ${ }^{8}$

On the other hand, the visual method ranks the $36 \%$ WL feed as the fastest melting by a wide margin followed by the $39 \% \mathrm{WL}$ feed. As a result, its overall melt rate profile does not show any sign of the decreasing melt rate trend with increasing WL. In order to exhibit such a trend, the visually-determined melt rates of the remaining feeds, particularly the lower WL feeds, would have to be raised up considerably higher, which suggests that the visual method cannot be used effectively especially in the presence of multitudes of bubbles of varying sizes like those shown in Figure 4-18. In addition, the effectiveness of the visual method could be reduced further since the spatial distribution of materials and bubbles is likely to vary more widely from one particular center-cut plane to another in the presence of multitudes of bubbles, thus rendering a particular set of visual data less representative of the entire sample volume. 
Table 4-12. Measured Linear Melt Rates of SB6/Frit 418 WL Feeds Using Visual Method.

\begin{tabular}{||c|c|c|c|c|c|c||}
\hline \multirow{2}{*}{$\begin{array}{c}\text { Distance from } \\
\text { Center } \\
\text { (inch) }\end{array}$} & \multicolumn{7}{|c||}{ WL } \\
\cline { 2 - 7 } & $30 \%$ & $33 \%$ & $36 \%$ & $39 \%$ & $42 \%$ & $45 \%$ \\
\cline { 2 - 7 } & \multicolumn{7}{|c|}{ Glass Height (inch) } \\
\hline 2 & 0.4 & 0.1 & 0.2 & 0.25 & 0.1 & 0.1 \\
\hline 1.75 & 0.28 & 0.16 & 0.05 & 0.5 & 0.1 & 0.03 \\
\hline 1.5 & 0.3 & 0.36 & 0.1 & 0.3 & 0.17 & 0.15 \\
\hline 1.25 & 0.45 & 0.36 & 0.3 & 0.35 & 0.4 & 0.2 \\
\hline 1 & 0.6 & 0.43 & 0.3 & 0.5 & 0.27 & 0.15 \\
\hline 0.75 & 0.5 & 0.34 & 0.2 & 0.4 & 0.25 & 0.2 \\
\hline 0.5 & 0.55 & 0.28 & 0.25 & 0.35 & 0.4 & 0.15 \\
\hline 0.25 & 0.32 & 0.32 & 0.6 & 0.45 & 0.25 & 0.13 \\
\hline-0.25 & 0.35 & 0.58 & 0.5 & 0.3 & 0.2 & 0.13 \\
\hline-0.5 & 0.27 & 0.38 & 0.85 & 0.45 & 0.2 & 0.2 \\
\hline-0.75 & 0.3 & 0.28 & 0.7 & 0.3 & 0.22 & 0.5 \\
\hline-1 & 0.35 & 0.2 & 0.85 & 0.25 & 0.5 & 0.55 \\
\hline-1.25 & 0.4 & 0.18 & 0.7 & 0.25 & 0.3 & 0.4 \\
\hline-1.5 & 0.27 & 0.18 & 0.5 & 0.25 & 0.2 & 0.3 \\
\hline-1.75 & 0.32 & 0.2 & 0.3 & 0.25 & 0.15 & 0.3 \\
\hline-2 & 0.28 & 0.4 & 0.6 & 0.25 & 0.15 & 0.25 \\
\hline Average & 0.37 & 0.30 & 0.44 & 0.34 & 0.24 & 0.23 \\
\hline Run Time (min) & 20 & 20 & 20 & 20 & 20 & 20 \\
\hline LMR (in/hr) & 0.56 & 0.45 & 0.66 & 0.51 & 0.36 & 0.35 \\
\hline \hline
\end{tabular}

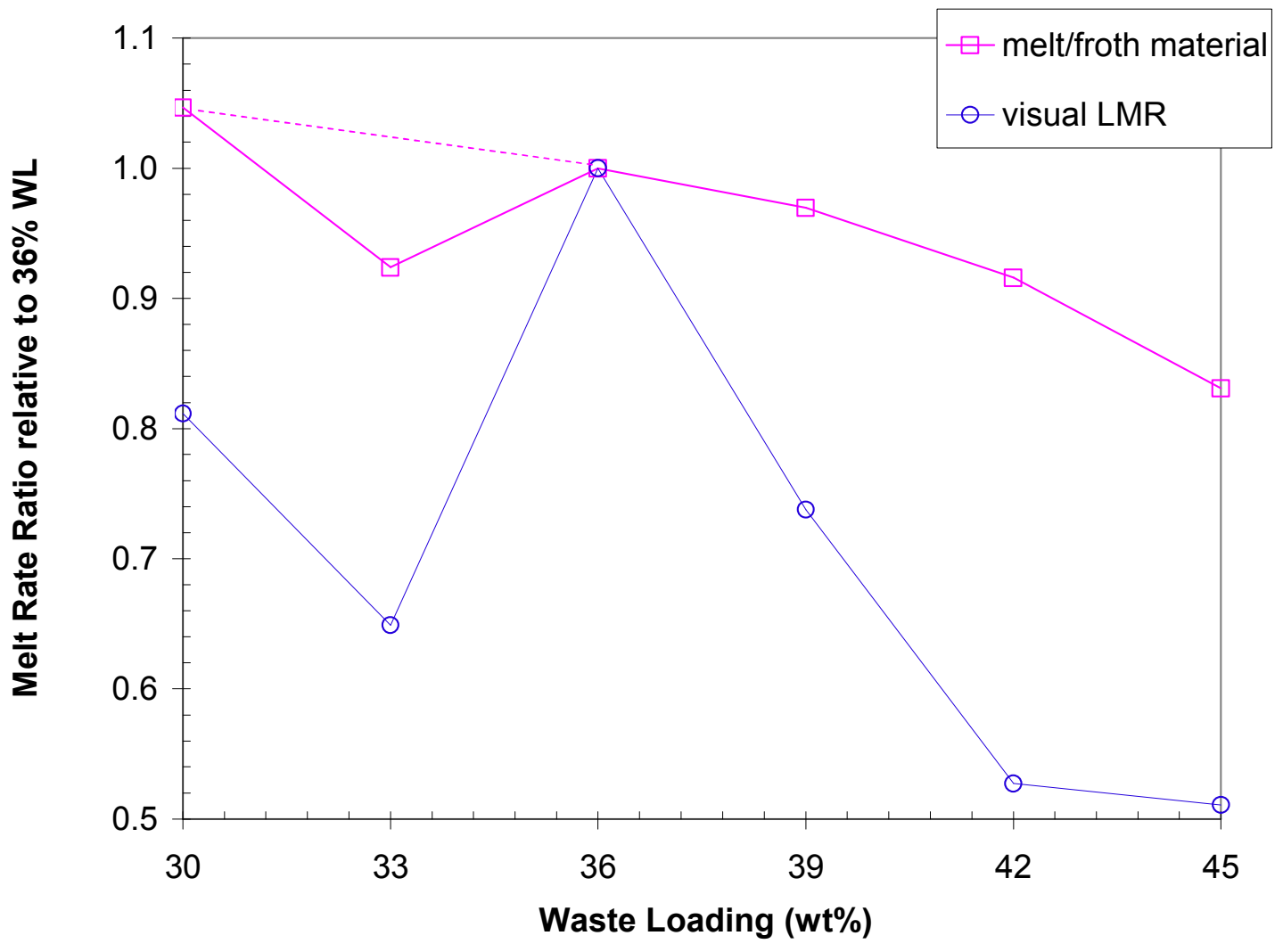

Figure 4-19. Comparison of CT vs. Visual Based Melt Rates Relative to 36\% WL. 


\subsection{Varying Frit Glasses}

The SB6 SRAT product shown in Table 3-3 was blended with 12 different frits, including Frits 418 and 510, at the target waste oxide loading of $36 \%$ in order to make a quantitative assessment of the impact of frit composition on melt rate. The firing time for each sample was $20 \mathrm{~min}$. The compositions of the 12 frits used are compared in Table 4-13. Of the four constituents of Frit 418, the concentration of $\mathrm{B}_{2} \mathrm{O}_{3}$ was varied from 8 to $16 \mathrm{wt} \%$, while that of $\mathrm{Na}_{2} \mathrm{O}$ was varied from 4 to $8 \mathrm{wt} \%$. $\mathrm{CaO}$ and $\mathrm{MnO}$ were added as additional modifiers at $2 \mathrm{wt} \%$ and up to $4 \mathrm{wt} \%$, respectively.

Table 4-13. Comparison of 12 Frit Compositions Used in Varying Frit Glass Study (wt\%).

\begin{tabular}{|l|c|c|c|c|c|c|c|c|c|c|c|c||}
\hline Frit & 418 & 510 & $\mathrm{CEF}$ & $\mathrm{CEF}$ & $\mathrm{CEF}$ & $\mathrm{CEF}$ & $\mathrm{CEF}$ & CEF & CEF & CEF & CEF & CEF \\
& & & 1 & 2 & 3 & 4 & 5 & 6 & 7 & 8 & 9 & 10 \\
\hline $\mathrm{B}_{2} \mathrm{O}_{3}$ & 8 & 14 & 11 & 11 & 11 & 8 & 8 & 8 & 8 & 8 & 8 & 16 \\
\hline $\mathrm{CaO}$ & 0 & 0 & 0 & 0 & 0 & 0 & 0 & 0 & 2 & 2 & 2 & 0 \\
\hline $\mathrm{Li}{ }_{2} \mathrm{O}$ & 8 & 8 & 8 & 8 & 9 & 8 & 8 & 8 & 8 & 8 & 8 & 8 \\
\hline $\mathrm{MnO}$ & 0 & 0 & 0 & 2 & 4 & 1 & 2 & 4 & 1 & 2 & 4 & 0 \\
\hline $\mathrm{Na}_{2} \mathrm{O}$ & 8 & 8 & 8 & 6 & 5 & 8 & 7 & 6 & 7 & 6 & 6 & 4 \\
\hline $\mathrm{SiO}_{2}$ & 76 & 70 & 73 & 73 & 71 & 75 & 75 & 74 & 74 & 74 & 72 & 72 \\
\hline Total & 100 & 100 & 100 & 100 & 100 & 100 & 100 & 100 & 100 & 100 & 100 & 100 \\
\hline
\end{tabular}

\subsubsection{X-Ray and CT Images}

The X-ray images of the SB6 fused with 12 different frits are shown in Figure 4-20. These images look very similar to those of the varying WL SB6 feeds in Figure 4-15; they all exhibit the melt, froth and un-melt layers with voids/bubbles scattered among them. The SB6/Frit CEF-10 feed appears to stand out as the slowest melting; its X-ray image shows a large void in the middle similar to that of SMEM-4 shown in Figure 4-1, with the most un-melt material on top. In fact, the upper middle melt and froth layers seem to have collapsed somewhat, due to the weight of unmelt material, resulting in the fall of some glassy material onto the lower part of the melt layer. Frit CEF-10 has the highest $\mathrm{B}_{2} \mathrm{O}_{3}$ concentration at $16 \mathrm{wt} \%$ and the highest $\mathrm{Li} /$ total modifier ratio, which seems to substantiate the hypothesis made earlier that $\mathrm{Li}^{+}$couples with the $\mathrm{BO}_{4}{ }^{-}$tetrahedra more easily than other modifiers including $\mathrm{Na}^{+}$and the resulting tighter network structure renders the melt more viscous, leading to reduced melt rates. The fact that SB6/Frit CEF-10 was the only feed batch that produced a large void encompassing nearly the entire diameter of the beaker may be explained by the high viscosity of its melt and thus restricted venting of gas bubbles.

Aside from Frit CEF-10, however, a visual inspection of the X-ray images shown in Figure 4-20 does not readily yield definitive information on how each frit affected the melt rate of SB6. As stated earlier, part of the reason for this is the presence of numerous bubbles having various sizes. One way to partially overcome this difficulty is to make melt rate assessment based on the extent of the un-melt layer since it is essentially bubble-free. It appears that Frit CEF-9 and CEF-2 runs resulted in two smallest un-melt layer volumes followed by CEF-1, CEF-4 and CEF-5. These qualitative visual rankings of the most and least un-melt materials remaining after the heat treatment are confirmed by the RGB images shown in Figure 4-21; as stated before, the melt, froth, and un-melt layers are colored blue, red, and green, respectively. These RGB images also show that the spatial distribution of the melt, froth, and un-melt layers of each feed is not quite the same when the 3-D volumetric data are projected on two orthogonal planes. This further illustrates that assessing the melting behavior of a given feed based on a particular center-cut view cannot always provide a representative picture across the entire sample volume. 


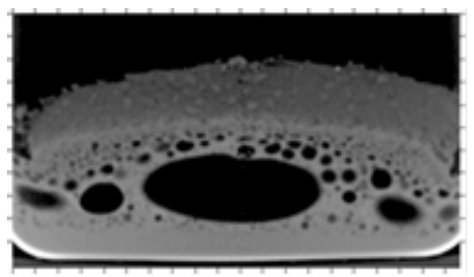

$35 \mathrm{~A} 418$

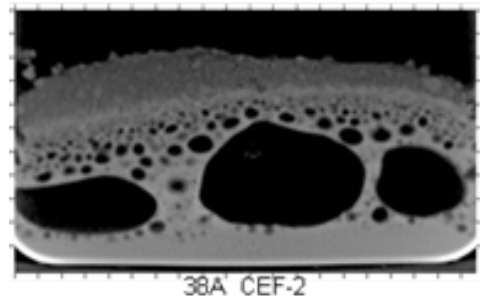

CEF-2

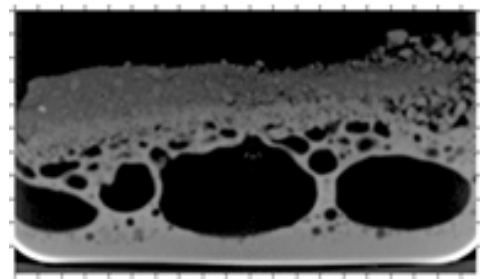

41A CEF-5

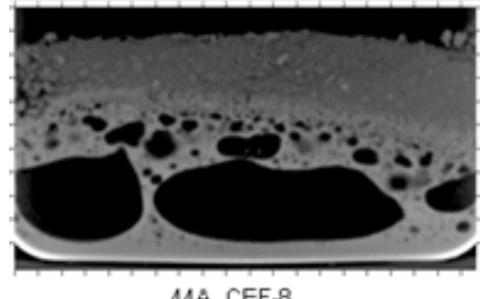

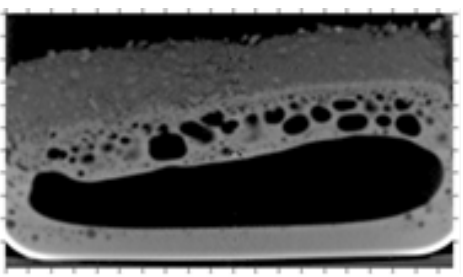

$36 \mathrm{~A} 510$
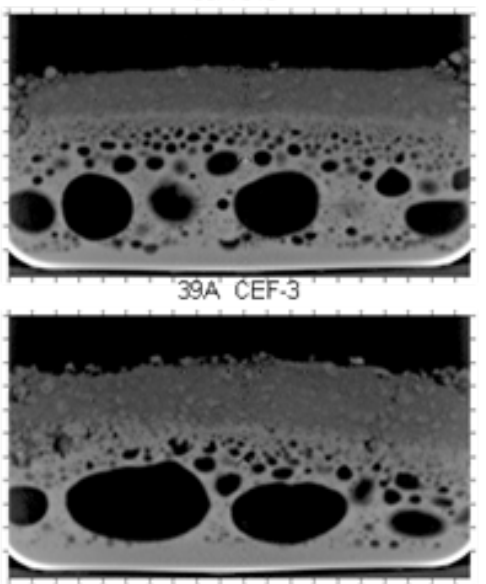

42A CEF-6

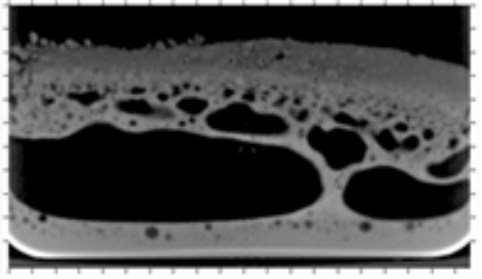

45A CEF.9

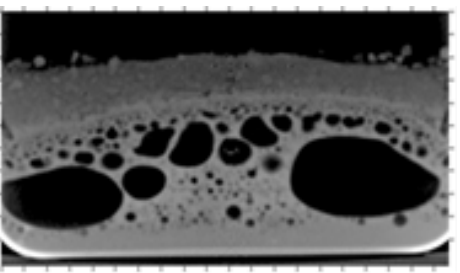

37A CEF-1

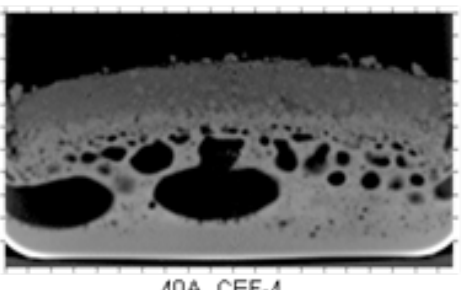

40A CEF -4

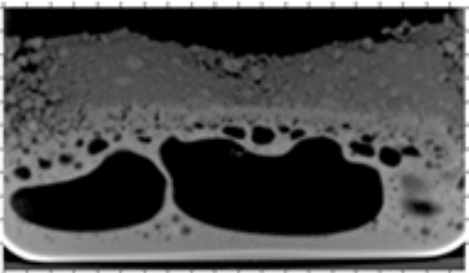

43A CEF-7

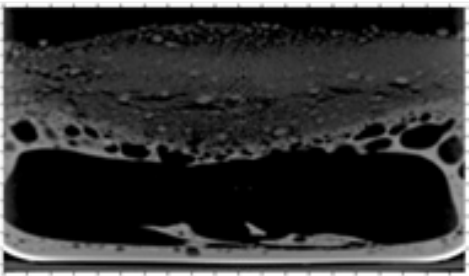

46A CEF-10

Figure 4-20. X-Ray Images of Heat-Treated SB6/Varying Frit Feeds.

\subsubsection{Results of CT Analysis}

Histograms of CT density vs. material amount for all 12 heat-treated SB6/varying frit feeds are compared in Figure 4-22. Again, it is the CT profile of CEF-10 that stands out most; its un-melt layer peak is not only considerably higher but at a much lower CT density than the rest, which shows how raw its large un-melted mass is. As shown in the RGB images, the un-melt layer peak of CEF-9 is the lowest of all, while the peak of its melt layer falls only in the middle of the group. However, the CEF-9 melt layer is shown to be denser; its profile is higher than the rest at $0.027<$ CT density $<0.032$, which more than compensated for its lower melt layer peak, as shown next.

The amount of material in each of the melt, froth, un-melt layers was calculated by integrating the CT histogram and the results are tabulated in Table 4-14. First, the variance of only $2.5 \%$ in the total material amount remaining in each beaker indicates a good overall mass balance for all cases. As expected, the CEF-10 feed is shown to have the most un-melt and least melt material; however, it has more froth material than five other frit feeds. As a result, the total material in the CEF-10 melt/froth layers was greater than that of either Frit 510 or CEF-7, which is clearly not in agreement with the X-ray images in Figure 4-20. This unexpected result is attributed to the overestimation of the froth material by the automatic routine used for finding the threshold points for each layer caused by the overall shift of CEF-10 un-melt and froth layer profiles to the left. 
CEF-10

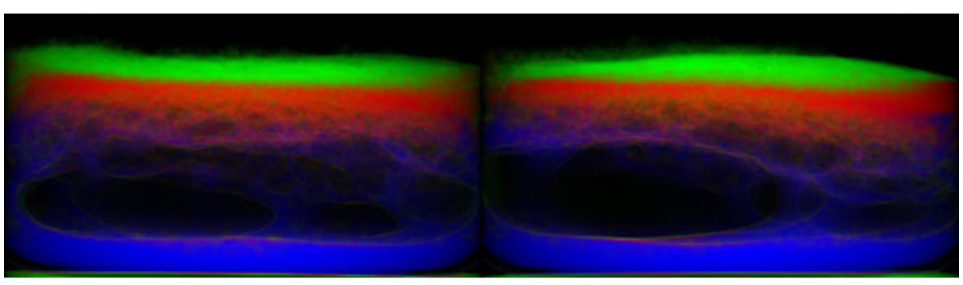

CEF-9

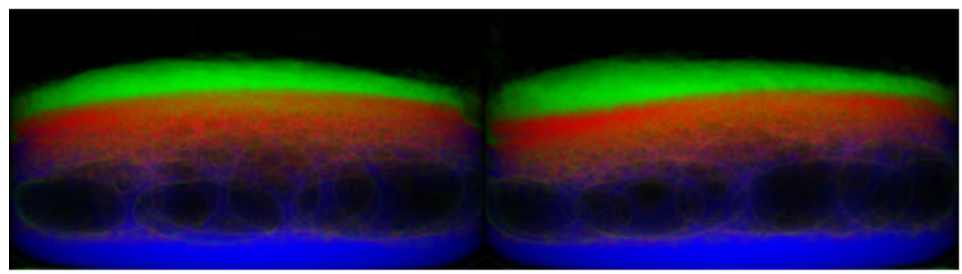

CEF-2

Figure 4-21. RGB Images of Heat Treated SB6/Varying Frit Feeds.

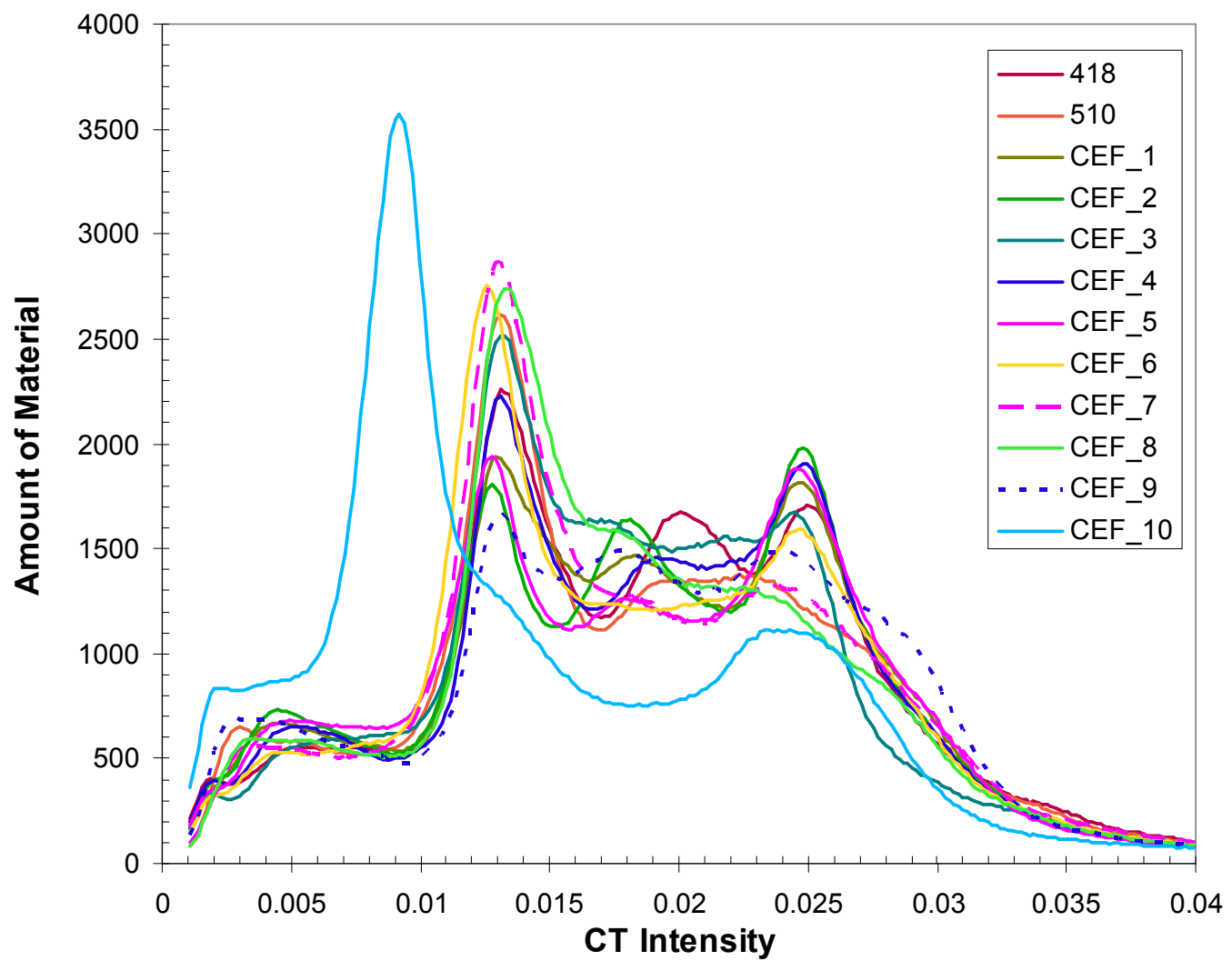

Figure 4-22. Histograms of 12 Heat-Treated SB6/Varying Frit Feeds. 
Table 4-14. CT-Calculated Distribution of Material and Density of SB6/Varying Frit Feeds.

\begin{tabular}{|c|c|c|c|c|c|c|c|c|c|c|}
\hline \multirow{2}{*}{ Frit } & \multicolumn{5}{|c|}{ Material Amount } & \multicolumn{5}{|c|}{ Material Density } \\
\hline & Total & $\begin{array}{l}\text { Un- } \\
\text { melt }\end{array}$ & $\begin{array}{l}\text { Melt/ } \\
\text { Froth }\end{array}$ & Froth & Melt & Overall & $\begin{array}{l}\text { Un- } \\
\text { melt }\end{array}$ & $\begin{array}{l}\text { Melt/ } \\
\text { Froth }\end{array}$ & Froth & Melt \\
\hline 418 & 183,242 & 53,588 & 129,654 & 54,171 & 75,483 & 5.580 & 3.906 & 6.781 & 5.640 & 7.933 \\
\hline 510 & 174,528 & 56,058 & 118,470 & 39,702 & 78,767 & 5.445 & 3.877 & 6.733 & 5.378 & 7.713 \\
\hline CEF-1 & 175,455 & 42,303 & 133,151 & 49,516 & 83,635 & 5.607 & 3.809 & 6.597 & 5.283 & 7.735 \\
\hline CEF-2 & 174,223 & 38,274 & 135,949 & 50,808 & 85,141 & 5.625 & 3.714 & 6.578 & 5.293 & 7.692 \\
\hline CEF-3 & 181,319 & 46,858 & 134,461 & 58,171 & 76,290 & 5.385 & 3.809 & 6.293 & 5.195 & 7.502 \\
\hline CEF-4 & 177,909 & 45,108 & 132,800 & 51,118 & 81,682 & 5.659 & 3.901 & 6.681 & 5.464 & 7.764 \\
\hline CEF-5 & 175,344 & 46,447 & 128,897 & 42,333 & 86,564 & 5.481 & 3.642 & 6.701 & 5.301 & 7.694 \\
\hline CEF-6 & 184,053 & 56,043 & 128,010 & 45,919 & 82,091 & 5.297 & 3.679 & 6.560 & 5.199 & 7.686 \\
\hline CEF-7 & 180,030 & 60,651 & 119,379 & 41,911 & 77,468 & 5.353 & 3.858 & 6.665 & 5.289 & 7.757 \\
\hline CEF-8 & 179,632 & 55,224 & 124,408 & 51,661 & 72,747 & 5.369 & 3.905 & 6.441 & 5.255 & 7.669 \\
\hline CEF-9 & 171,222 & 34,546 & 136,676 & 47,372 & 89,304 & 5.786 & 3.850 & 6.628 & 5.247 & 7.703 \\
\hline CEF-10 & 185,504 & 64,805 & 120,699 & 48,018 & 72,681 & 3.890 & 2.552 & 5.415 & 3.962 & 7.147 \\
\hline std dev & 4,478 & 9,185 & 6,474 & 5,358 & 5,431 & 0.49 & 0.38 & 0.37 & 0.41 & 0.19 \\
\hline $\begin{array}{c}\text { std dev/ } \\
\text { mean }\end{array}$ & $2.5 \%$ & $18.4 \%$ & $5.0 \%$ & $11.1 \%$ & $6.8 \%$ & $9.1 \%$ & $10.1 \%$ & $5.7 \%$ & $7.9 \%$ & $2.5 \%$ \\
\hline
\end{tabular}

Also included in Table 4-14 are the material densities that were calculated as the ratio of material mass-to-volume. Again, the overall density of the CEF-10 feed stands out as the lowest by a wide margin, while the CEF-9 feed has the highest overall density. Based on the CT data in Table 4-14, various melt rate rankings of the SB6/varying frit feeds were derived in Table 4-15. As expected, CEF-10 is ranked first and last in the material left in the un-melt and melt layers, respectively. As explained above, CEF-10 also should have been ranked last in the melt/froth material rankings, were it not for an inadvertent error introduced by the automatic routine used to find the threshold CT densities. In addition, CEF-10 is ranked last in all density rankings, which confirms it as the slowest melting frit for SB6. On the other hand, CEF-9 is ranked first in the melt/froth and meltonly material rankings as well as in the overall density rankings and last in the un-melt material rankings, which confirms it as the fastest melting frit for SB6.

Since the variance in the total amount of material in each beaker was only $2.5 \%$, a new ranking criterion was added to Table 4-15 based on the ratio of melt and froth materials combined to the total amount of material remaining in each beaker. The new rankings of all 12 frits are shown to be similar to the melt/froth material rankings except that the former correctly rank CEF-10 last. The likely reason for the CEF-10 being the slowest melting frit was attributed earlier to its highest $\mathrm{B}_{2} \mathrm{O}_{3}$ concentration coupled with the highest $\mathrm{Li}_{2} \mathrm{O}$ concentration among all modifiers. According to Table 4-13, Frit CEF-9 has the highest concentration of modifiers including $4 \% \mathrm{MnO}$ and $2 \%$ $\mathrm{CaO}$ added at the expense of $\mathrm{SiO}_{2}$ and $\mathrm{Na}_{2} \mathrm{O}$ in Frit 418, respectively. So, it is not surprising that Frit CEF-9 is determined to be the fastest melting frit for SB6.

Frit CEF-1 has an additional $3 \mathrm{wt} \% \mathrm{~B}_{2} \mathrm{O}_{3}$ added at the expense of $\mathrm{SiO}_{2}$ in Frit 418 and is ranked as the third fastest melting according to both the new and melt/froth material rankings. This clearly shows the benefit of substituting $\mathrm{Si}$ with $\mathrm{B}$ in the baseline Frit 418 . However, when an additional $3 \mathrm{wt} \% \mathrm{~B}_{2} \mathrm{O}_{3}$ was added at the expense of $\mathrm{SiO}_{2}$ in Frit CEF-1, the resulting Frit 510 was ranked next to the last, which demonstrates the adverse impact on melt rate of adding excess $\mathrm{B}_{2} \mathrm{O}_{3}$. 
Table 4-15. CT-Based Melt Rate Rankings of SB6/Varying Frit Feeds (\% WL).

\begin{tabular}{|c|c|c|c|c|c|c|c|c||}
\hline \hline \multirow{3}{*}{ Rankings } & \multicolumn{4}{|c|}{ Material Amount } & \multicolumn{3}{|c||}{ Material Density } & Fraction \\
\cline { 2 - 10 } & $\begin{array}{c}\text { Un- } \\
\text { melt }\end{array}$ & $\begin{array}{c}\text { Melt/ } \\
\text { Froth }\end{array}$ & $\begin{array}{c}\text { Revised } \\
\text { Melt/ } \\
\text { Froth }\end{array}$ & Melt & Overall & $\begin{array}{c}\text { Melt/ } \\
\text { Froth }\end{array}$ & Melt & $\begin{array}{c}\text { Melt/ } \\
\text { Froth }\end{array}$ \\
\hline 1 & CEF-10 & CEF-9 & CEF-9 & CEF-9 & CEF-9 & 418 & 418 & CEF-9 \\
\hline 2 & CEF-7 & CEF-2 & CEF-2 & CEF-5 & CEF-4 & 510 & CEF-4 & CEF-2 \\
\hline 3 & 510 & CEF-3 & CEF-3 & CEF-2 & CEF-2 & CEF-5 & CEF-7 & CEF-1 \\
\hline 4 & CEF-6 & CEF-1 & CEF-1 & CEF-1 & CEF-1 & CEF-4 & CEF-1 & CEF-4 \\
\hline 5 & CEF-8 & CEF-4 & CEF-4 & CEF-6 & 418 & CEF-7 & 510 & CEF-3 \\
\hline 6 & 418 & 418 & 418 & CEF-4 & CEF-5 & CEF-9 & CEF-9 & CEF-5 \\
\hline 7 & CEF-3 & CEF-5 & CEF-5 & 510 & 510 & CEF-1 & CEF-5 & 418 \\
\hline 8 & CEF-5 & CEF-6 & CEF-6 & CEF-7 & CEF-3 & CEF-2 & CEF-2 & CEF-6 \\
\hline 9 & CEF-4 & CEF-8 & CEF-8 & CEF-3 & CEF-8 & CEF-6 & CEF-6 & CEF-8 \\
\hline 10 & CEF-1 & CEF-10 & CEF-7 & 418 & CEF-7 & CEF-8 & CEF-8 & 510 \\
\hline 11 & CEF-2 & CEF-7 & 510 & CEF-8 & CEF-6 & CEF-3 & CEF-3 & CEF-7 \\
\hline 12 & CEF-9 & 510 & CEF-10 & CEF-10 & CEF-10 & CEF-10 & CEF-10 & CEF-10 \\
\hline
\end{tabular}

Frit CEF-2 has $2 \mathrm{wt} \% \mathrm{MnO}$ added at the expense of $\mathrm{Na}_{2} \mathrm{O}$ in Frit CEF-1 and is ranked as the second fastest melting above Frit CEF-1, which suggests that for the range of frit compositions tested, $\mathrm{MnO}$ was more effective than $\mathrm{Na}_{2} \mathrm{O}$ on an equal weight basis. However, when an additional $2 \mathrm{wt} \% \mathrm{MnO}$ was added at the expense of $\mathrm{SiO}_{2}$ in Frit CEF-2, the resulting Frit CEF-3 was ranked third below Frit CEF-2. It is not clear whether the slight drop in rankings was due to the increase in $\mathrm{MnO}$ or the increase in $\mathrm{Li}_{2} \mathrm{O}$ by $1 \mathrm{wt} \%$ at the expense of $\mathrm{Na}_{2} \mathrm{O}$. On the other hand, when $1 \mathrm{wt} \% \mathrm{MnO}$ was added at the expense of $\mathrm{SiO}_{2}$ in Frit 418, the resulting Frit CEF-4 was ranked higher than Frit 418, which clearly demonstrates the effectiveness of $\mathrm{MnO}$ as a modifier. However, when $1 \mathrm{wt} \% \mathrm{MnO}$ was added at the expense of $\mathrm{Na}_{2} \mathrm{O}$ in Frit CEF-4, the resulting Frit CEF-5 was ranked seventh below Frit 418. This result is in direct conflict with the CEF-2 results above, which showed a positive impact on melt rate of substituting $\mathrm{Na}_{2} \mathrm{O}$ with $\mathrm{MnO}$. Since the main compositional difference between Frit CEF-2 and CEF-5 is in the concentration of $\mathrm{B}_{2} \mathrm{O}_{3}$, it may be postulated that $\mathrm{MnO}$ is more effective as a modifier at higher $\mathrm{B}_{2} \mathrm{O}_{3}$ concentrations. A strong positive impact on melt rate of $\mathrm{Mn}$ from the sludge feed was demonstrated earlier during the analysis of the bounding sludge/Frit 418 runs.

When $2 \mathrm{wt} \% \mathrm{CaO}$ was added at the equal expense of $\mathrm{Na}_{2} \mathrm{O}$ and $\mathrm{SiO}_{2}$ in Frit CEF-4, the resulting Frit CEF-7 was ranked tenth; considerably below Frit CEF-4, which appears to suggest that the effectiveness of $\mathrm{CaO}$ as a modifier is at least questionable at a nominal $8 \mathrm{wt} \% \mathrm{~B}_{2} \mathrm{O}_{3}$ concentration. It is noted that the positive impact of $\mathrm{CaO}$ addition on melt rate was shown earlier when it was added to the frits containing 12 to $14 \mathrm{wt} \% \mathrm{~B}_{2} \mathrm{O}_{3}$. When an additional $1 \mathrm{wt} \%$ of $\mathrm{MnO}$ was added at the expense of $\mathrm{Na}_{2} \mathrm{O}$ in Frit CEF-7, the resulting Frit CEF-8 was ranked surprisingly slightly higher at ninth. When an additional $2 \mathrm{wt} \% \mathrm{MnO}$ was added at the expense of $\mathrm{SiO}_{2}$ in Frit CEF-8, the resulting Frit CEF-9 was ranked first and its total modifier concentration was the highest of all 12 frits at $20 \mathrm{wt} \%$. 


\subsubsection{Visual Determination of Melt Rates}

The visual melt rate readings were taken from the X-ray images shown in Figure 4-20 using the procedures described in Section 3.3, and the resulting LMR are given in Table 4-16. The relative LMR with respect to that of SB6/Frit 418 are plotted in Figure 4-23 along with the relative melt rates based on the CT method. The relative LMR is shown to vary more widely than the CTbased melt rates but the measured melt rate rankings of all frits are quite different from those by the CT method except for Frit CEF-10. For example, the visual method ranked CEF-4 as the fastest melting frit for SB6, while it was ranked fourth by the CT method. On the other hand, CEF-9 was ranked only fifth by the visual method, while it was ranked first by the CT method. It is also noted that although the visual melt rate rankings of the frit-only feeds were shown to track the CT-based rankings well in Figure 4-14, they do not track each other well even qualitatively with the SB6/varying WL feeds. This again seems to confirm that the presence of voids of gases could hinder the visual reading of glass heights significantly enough to render the resulting melt rate data less consistent and, therefore, less accurate.

Table 4-16. Measured Linear Melt Rates of SB6/Varying Frit Feeds Using Visual Method.

\begin{tabular}{||c|c|c|c|c|c|c|c|c|c|c|c|c|c|c||}
\hline $\begin{array}{c}\text { Distance } \\
\text { from } \\
\text { Center }\end{array}$ & $\mathbf{4 1 8}$ & $\mathbf{5 1 0}$ & $\begin{array}{c}\text { CEF } \\
\mathbf{1}\end{array}$ & $\begin{array}{c}\mathbf{C E F} \\
\mathbf{2}\end{array}$ & $\begin{array}{c}\mathbf{C E F} \\
\mathbf{3}\end{array}$ & $\begin{array}{c}\text { CEF } \\
\mathbf{4}\end{array}$ & $\begin{array}{c}\text { CEF } \\
\mathbf{5}\end{array}$ & $\begin{array}{c}\text { CEF } \\
\mathbf{6}\end{array}$ & $\begin{array}{c}\text { CEF } \\
\mathbf{7}\end{array}$ & $\begin{array}{c}\text { CEF } \\
\mathbf{8}\end{array}$ & $\begin{array}{c}\text { CEF } \\
\mathbf{9}\end{array}$ & $\begin{array}{c}\text { CEF } \\
\mathbf{1 0}\end{array}$ \\
\hline (inch) & \multicolumn{10}{|c|}{ Glass Height (inch) } \\
\hline 1 & 0.2 & 0.2 & 0.07 & 0.07 & 0.1 & 0.1 & 0.1 & 0.18 & 0.11 & 0.08 & 0.1 & 0.11 \\
\hline 0.875 & 0.22 & 0.18 & 0.1 & 0.1 & 0.1 & 0.1 & 0.11 & 0.2 & 0.1 & 0.07 & 0.15 & 0.1 \\
\hline 0.75 & 0.2 & 0.16 & 0.1 & 0.1 & 0.1 & 0.12 & 0.17 & 0.1 & 0.1 & 0.08 & 0.15 & 0.09 \\
\hline 0.625 & 0.18 & 0.15 & 0.12 & 0.11 & 0.1 & 0.15 & 0.13 & 0.1 & 0.11 & 0.1 & 0.15 & 0.05 \\
\hline 0.5 & 0.2 & 0.15 & 0.12 & 0.13 & 0.05 & 0.2 & 0.2 & 0.1 & 0.12 & 0.11 & 0.1 & 0.07 \\
\hline 0.375 & 0.18 & 0.15 & 0.15 & 0.15 & 0.11 & 0.18 & 0.12 & 0.11 & 0.11 & 0.1 & 0.1 & 0.06 \\
\hline 0.25 & 0.18 & 0.15 & 0.11 & 0.18 & 0.2 & 0.12 & 0.1 & 0.2 & 0.1 & 0.09 & 0.1 & 0.04 \\
\hline 0.125 & 0.15 & 0.15 & 0.11 & 0.15 & 0.08 & 0.14 & 0.1 & 0.15 & 0.08 & 0.07 & 0.11 & 0.06 \\
\hline-0.125 & 0.15 & 0.14 & 0.11 & 0.14 & 0.1 & 0.2 & 0.1 & 0.1 & 0.05 & 0.07 & 0.12 & 0.07 \\
\hline-0.25 & 0.15 & 0.14 & 0.16 & 0.15 & 0.1 & 0.25 & 0.15 & 0.09 & 0.05 & 0.07 & 0.13 & 0.07 \\
\hline-0.375 & 0.16 & 0.12 & 0.13 & 0.16 & 0.11 & 0.3 & 0.11 & 0.11 & 0.06 & 0.07 & 0.2 & 0.05 \\
\hline-0.5 & 0.2 & 0.13 & 0.14 & 0.2 & 0.1 & 0.3 & 0.15 & 0.18 & 0.07 & 0.08 & 0.2 & 0.05 \\
\hline-0.625 & 0.15 & 0.13 & 0.13 & 0.19 & 0.1 & 0.3 & 0.1 & 0.1 & 0.1 & 0.1 & 0.1 & 0.06 \\
\hline-0.75 & 0.12 & 0.14 & 0.13 & 0.2 & 0.05 & 0.3 & 0.1 & 0.09 & 0.2 & 0.12 & 0.1 & 0.07 \\
\hline-0.875 & 0.15 & 0.17 & 0.15 & 0.19 & 0.08 & 0.2 & 0.11 & 0.1 & 0.08 & 0.15 & 0.14 & 0.1 \\
\hline-1 & 0.1 & 0.2 & 0.16 & 0.12 & 0.08 & 0.15 & 0.11 & 0.11 & 0.08 & 0.05 & 0.14 & 0.1 \\
\hline Average & 0.17 & 0.15 & 0.12 & 0.15 & 0.10 & 0.19 & 0.12 & 0.13 & 0.10 & 0.09 & 0.13 & 0.07 \\
\hline $\begin{array}{c}\text { Run Time } \\
\text { (min) }\end{array}$ & 20 & 20 & 20 & 20 & 20 & 20 & 20 & 20 & 20 & 20 & 20 & 20 \\
\hline $\begin{array}{c}\text { Melt Rate } \\
\text { (in/hr) }\end{array}$ & 0.50 & 0.46 & 0.37 & 0.44 & 0.29 & 0.58 & 0.37 & 0.38 & 0.29 & 0.26 & 0.39 & 0.22 \\
\hline Rankings & 2 & 3 & 7 & 4 & 9 & 1 & 8 & 6 & 10 & 11 & 5 & 12 \\
\hline
\end{tabular}




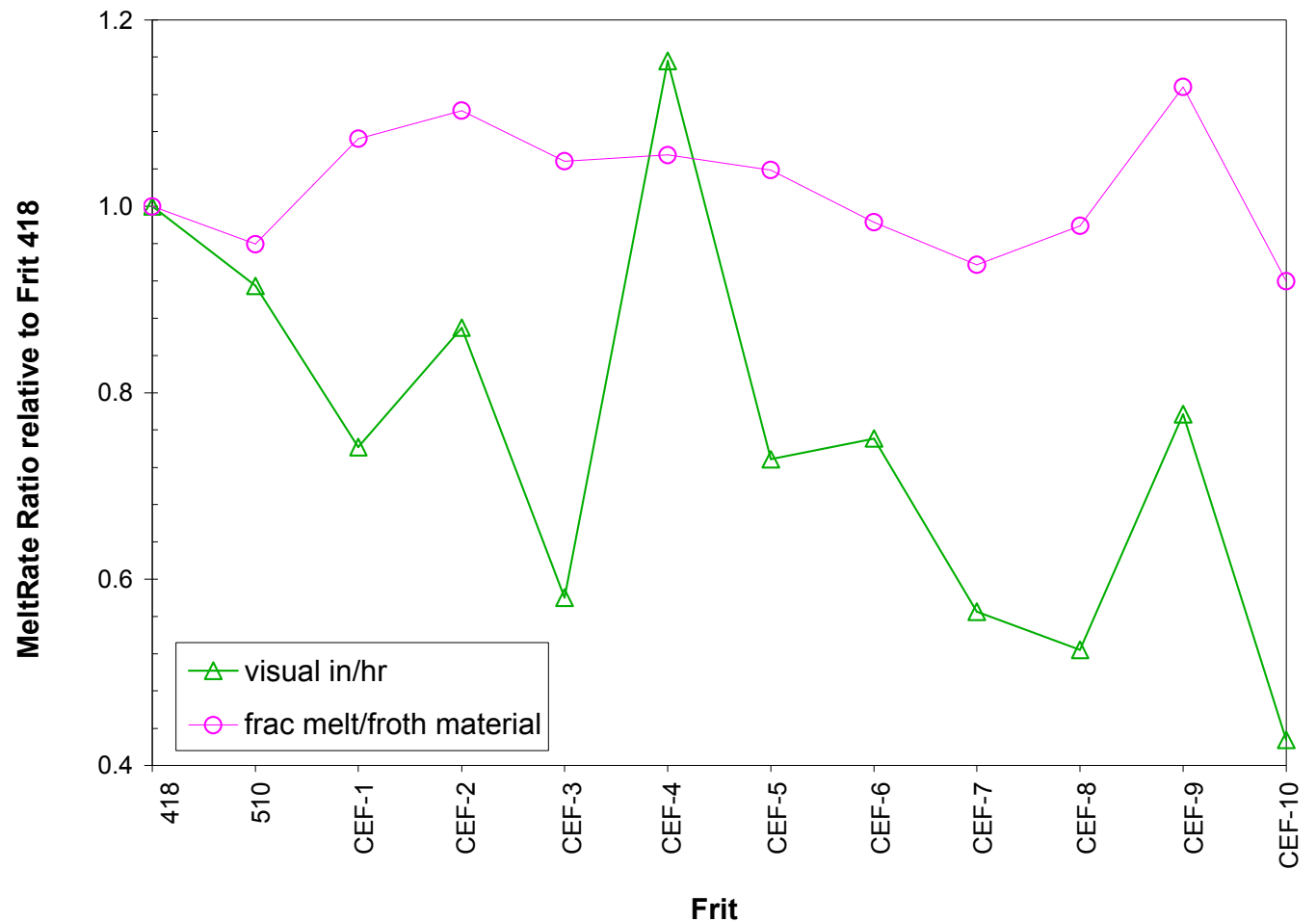

Figure 4-23. Comparison of CT vs. Visual Based Melt Rates Relative to SB6/Frit 418.

\subsubsection{High-Resolution Spectroscopy Studies of SB6/Varying Frit Series Glasses}

The glass samples from the SB6/varying frit runs were sent to SIA Radon in Russia to perform structural characterization and analysis using high-resolution spectroscopic tools. Although the partitioning of boron between trigonal and tetrahedral coordination in aluminoborosilicate glass systems can be determined quantitatively using the nuclear magnetic resonance (NMR) technique, the presence of iron in HLW glasses at concentrations greater than $5 \mathrm{wt} \%$ prevents the use of NMR. The objective of this task was to study the impact of varying levels of boron, alkali, and some additives such as $\mathrm{Ca}$ and $\mathrm{Mn}$ on the coordination chemistry of simulated HLW glasses using X-ray Photoelectron Spectroscopy (XPS), X-ray Absorption Near Edge Structure (XANES), Extended X-ray Absorption Fine Structure (EXAFS), Electron Paramagnetic Resonance (EPR), Infrared (IR) and Raman Spectroscopy. Some of the key findings from the study include:

1. All glass compositions were mainly amorphous with some spinel phases.

2. The main structural units were metasilicate chains and rings; this confirms the current basis for the silicate phase used in the DWPF cold cap model.

3. The coordination of $\mathrm{Al}$ and Fe was mainly tetrahedral, with some octahedral iron ions $\left(\mathrm{FeO}_{6}\right)$. Iron was mainly present as $\mathrm{Fe}^{3+}$.

4. Boron was present mainly in trigonal coordination with some tetrahedrally-coordinated boron forming complex borate units; however, no quantification of the boron partitioning between 3- and 4-coordination states was made.

The final report by SIA Radon is attached at the end of this report. 


\subsection{Theoretical Treatment of Frit-Only Glass Melt Rates}

One of the key underlying premises of the DWPF melt rate model is that the less the network connectivity of a glass is, the higher its melt rate becomes. There are three network formers in the aluminoborosilicate glass systems: $\mathrm{Si}, \mathrm{B}$, and Al. Since Al assumes tetrahedral coordination in most cases of relevance to the HLW glasses, it is primarily the coordination of B that determines the network connectivity. An attempt was made in this work to predict the boron coordination of a known glass system found in the literature by applying the field strengths of modifier ions to the modified Dell-Bray model. ${ }^{9}$ If successful, it will be further tested to see whether the same approach can be used to qualitatively predict the relative melt rate profile of the frit-only feeds shown in Figure 4-14.

\subsubsection{Approach}

The original Dell-Bray model is highly successful in predicting the boron coordination in a sodium borosilicate glass from its composition. ${ }^{10}$ Du and Stebbins have extended the applicability of the original Dell-Bray model to a sodium aluminoborosilicate glass by grouping $\mathrm{Al}$ and $\mathrm{B}$ in the same type of cations. The modified Dell-Bray model is based on the following parameters:

$$
\begin{aligned}
R^{s t b} & =R /\left(1+\left[\mathrm{Al}_{2} \mathrm{O}_{3}\right] /\left[\mathrm{B}_{2} \mathrm{O}_{3}\right]\right) \\
K^{s t b} & =K /\left(1+\left[\mathrm{Al}_{2} \mathrm{O}_{3}\right] /\left[\mathrm{B}_{2} \mathrm{O}_{3}\right]\right) \\
N_{4}^{s t b} & =\left(\mathrm{N}_{4}+\left[\mathrm{Al}_{2} \mathrm{O}_{3}\right] /\left[\mathrm{B}_{2} \mathrm{O}_{3}\right]\right) /\left(1+\left[\mathrm{Al}_{2} \mathrm{O}_{3}\right] /\left[\mathrm{B}_{2} \mathrm{O}_{3}\right]\right)
\end{aligned}
$$

where $\mathrm{R}=\left[\mathrm{Na}_{2} \mathrm{O}\right] /\left[\mathrm{B}_{2} \mathrm{O}_{3}\right]$ and $\mathrm{K}=\left[\mathrm{SiO}_{2}\right] /\left[\mathrm{B}_{2} \mathrm{O}_{3}\right]$ in the $\mathrm{RNa}_{2} \mathrm{O}-\mathrm{B}_{2} \mathrm{O}_{3}-\mathrm{KSiO}_{2}$ ternary system. $\mathrm{N}_{4}$ is the fraction of 4-coordinated $\mathrm{B}$. The value of $\mathrm{N}_{4}$ is calculated as a function of $\mathrm{R}$ according to the original Dell-Bray model. ${ }^{10}$

In this work, the effect of additional modifiers besides $\mathrm{Na}^{+}$on $\mathrm{N}_{4}$ and $\mathrm{NBO}$ was accounted for by using the weighted sum of modifier concentrations according to their field strengths. Therefore, the underlying assumption of this approach is that the original Dell-Bray is also applicable to the non-sodium modifiers as long as the weighted sum of modifier concentrations is used. Table 4-17 lists the Shannon radius of the modifiers of interest to the HLW glass and their calculated field strengths.

Table 4-17. Shannon Ionic Radii [Ref. 11] and Calculated Field Strengths.

\begin{tabular}{||c|c|c|c||}
\hline Modifiers & $\mathrm{CN}$ & $\begin{array}{c}\text { Shannon } \\
\text { Ionic Radius } \\
(\AA)\end{array}$ & $\begin{array}{c}\text { Field Strength } \\
\text { (charge/ } / \AA 2)\end{array}$ \\
\hline $\mathrm{Li}^{+}$ & IV & 0.59 & 2.87 \\
\hline $\mathrm{Na}^{+}$ & IV & 0.99 & 1.02 \\
\hline $\mathrm{K}^{+}$ & IV & 1.37 & 0.53 \\
\hline $\mathrm{Mg}^{2+}$ & IV & 0.57 & 6.16 \\
\hline $\mathrm{Ca}^{2+}$ & VI & 1 & 2.00 \\
\hline $\mathrm{Cu}^{2+}$ & IV & 0.57 & 6.16 \\
\hline $\mathrm{Mn}^{2+}$ & IV & 0.66 & 4.59 \\
\hline $\mathrm{Fe}^{3+}$ & IV & 0.49 & 12.49 \\
\hline $\mathrm{Fe}^{2+}$ & IV & 0.63 & 5.04 \\
\hline
\end{tabular}




\subsubsection{Baseline Glass System}

The $\mathrm{Na}_{2} \mathrm{O}-\mathrm{CaO}-\mathrm{Al}_{2} \mathrm{O}_{3}-\mathrm{B}_{2} \mathrm{O}_{3}-\mathrm{SiO}_{2}$ system recently studied by $\mathrm{Wu}$ and Stebbins was taken as the baseline system for this work. ${ }^{5}$ The sum of $\mathrm{Na}_{2} \mathrm{O}$ and $\mathrm{CaO}$ concentrations was held constant at 25 mol\%, while the molar ratio of $\mathrm{Na}_{2} \mathrm{O} /\left(\mathrm{Na}_{2} \mathrm{O}+\mathrm{CaO}\right)$ was varied from 0 to 1 in 0.25 increments. Two series of experiments were conducted each at a fixed $\mathrm{B}_{2} \mathrm{O}_{3}$ concentration: 7 and $21 \mathrm{~mol} \%$. The sum of $\mathrm{SiO}_{2}$ and $\mathrm{B}_{2} \mathrm{O}_{3}$ concentrations was held constant at $72 \mathrm{~mol} \%$, while the $\mathrm{Al}_{2} \mathrm{O}_{3}$ concentration was fixed at $8 \mathrm{~mol} \%$. The magic angle spinning (MAS) NMR was used to measure $\mathrm{N}_{4}$ and NBO fractions for each glass, as shown in Table 4-18. As expected, the fraction of NBO decreases with increasing $\mathrm{N}_{4}$, since it takes a modifier ion to charge balance the $\mathrm{BO}_{4}{ }^{-}$tetrahedra.

Table 4-18. Measured $\mathrm{N}_{4}$ and NBO Fractions - Compositions in mol\% [Ref. 5].

\begin{tabular}{||c|c|c|c|c|c|c|c||}
\hline \hline Glass & $\mathrm{Na}_{2} \mathrm{O}$ & $\mathrm{CaO}$ & $\mathrm{B}_{2} \mathrm{O}_{3}$ & $\mathrm{Al}_{2} \mathrm{O}_{3}$ & $\mathrm{SiO}_{2}$ & $\mathrm{~N}_{4}$ & $\mathrm{NBO}$ \\
\hline B7N20 & 20 & 0 & 7 & 8 & 65 & 0.15 & 0.117 \\
\hline B7N15 & 15 & 5 & 7 & 8 & 65 & 0.19 & 0.111 \\
\hline B7N10 & 10 & 10 & 7 & 8 & 65 & 0.28 & 0.103 \\
\hline B7N05 & 5 & 15 & 7 & 8 & 65 & 0.44 & 0.092 \\
\hline B7N00 & 0 & 20 & 7 & 8 & 65 & 0.62 & 0.080 \\
\hline B21N20 & 20 & 0 & 21 & 8 & 51 & 0.21 & 0.084 \\
\hline B21N15 & 15 & 5 & 21 & 8 & 51 & 0.27 & 0.064 \\
\hline B21N10 & 10 & 10 & 21 & 8 & 51 & 0.32 & 0.053 \\
\hline B21N05 & 5 & 15 & 21 & 8 & 51 & 0.36 & 0.044 \\
\hline B21N00 & 0 & 20 & 21 & 8 & 51 & 0.51 & 0.014 \\
\hline
\end{tabular}

\subsubsection{Results of Calculations}

The key steps involved in the calculation of $\mathrm{N}_{4}$ and NBO for each glass are as follows:

1. The value of $\mathrm{R}$ was calculated as the ratio of the weighted sum of $\mathrm{Na}_{2} \mathrm{O}$ and $\mathrm{CaO}$ to $\mathrm{B}_{2} \mathrm{O}_{3}$.

2. The value of $\mathrm{R}^{\mathrm{stb}}$ was calculated using Eq. (8).

3. The value of $\mathrm{K}$ was calculated as the ratio of $\mathrm{SiO}_{2}$ to $\mathrm{B}_{2} \mathrm{O}_{3}$.

4. The value of $K^{\mathrm{stb}}$ was calculated using Eq. (9).

5. The value of $\mathrm{N}_{4}{ }^{\text {stb }}$ was calculated using the original Dell-Bray model.

6. The value of $\mathrm{N}_{4}$ was calculated from $\mathrm{N}_{4}$ stb using Eq. (10).

7. The fraction of NBO was calculated from the general formula for NBO after reducing the boron concentration by the factor of $\mathrm{N}_{4}$ in the numerator:

$$
\mathrm{NBO}=\frac{2\left(\left[\mathrm{Li}_{2} \mathrm{O}\right]+\left[\mathrm{Na}_{2} \mathrm{O}\right]+[\mathrm{CaO}]-\left[\mathrm{Al}_{2} \mathrm{O}_{3}\right]-\mathrm{N}_{4}\left[\mathrm{~B}_{2} \mathrm{O}_{3}\right]\right)}{\left[\mathrm{Li}_{2} \mathrm{O}\right]+\left[\mathrm{Na}_{2} \mathrm{O}\right]+[\mathrm{CaO}]+3\left[\mathrm{Al}_{2} \mathrm{O}_{3}\right]+3\left[\mathrm{~B}_{2} \mathrm{O}_{3}\right]+2\left[\mathrm{SiO}_{2}\right]}
$$

The values of $\mathrm{N}_{4}$ and NBO thus calculated are compared to the measured values in Figure 4-24 to Figure 4-27. Although the calculated values are in general not close enough to the measured data, they are shown to track each other well qualitatively. It is certainly encouraging to see that such a simple weighted approach to accommodate a non-sodium modifier has resulted in a reasonably good outcome. Although not confirmed yet, the qualitative agreements between calculated and measured $\mathrm{N}_{4}$ and NBO fractions shown in these figures should immediately improve the current model's capability to assess the relative impact of different modifiers on melt rate. It will also be interesting to see whether any additional improvement could be achieved by taking a similar weighted approach to account for the effects of different formers and anion complexes such as $\mathrm{BO}_{4}{ }^{-}$tetrahedra on the boron coordination. 
SRNL-STI-2010-00767

Revision 0

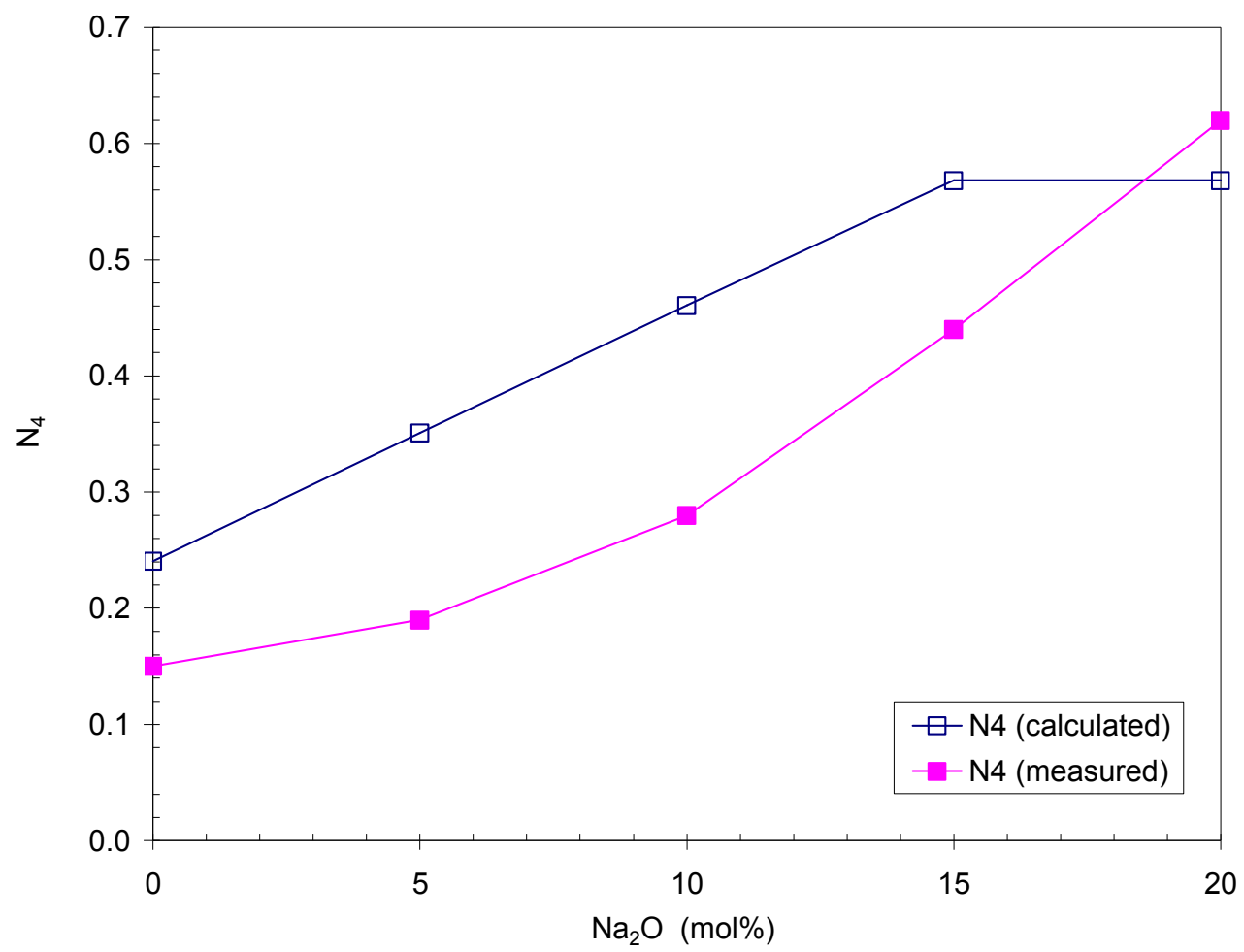

Figure 4-24. Calculated vs. Measured $\mathrm{N}_{4}$ for $7 \mathrm{wt} \% \mathrm{~B}_{2} \mathrm{O}_{3}$ Glasses.

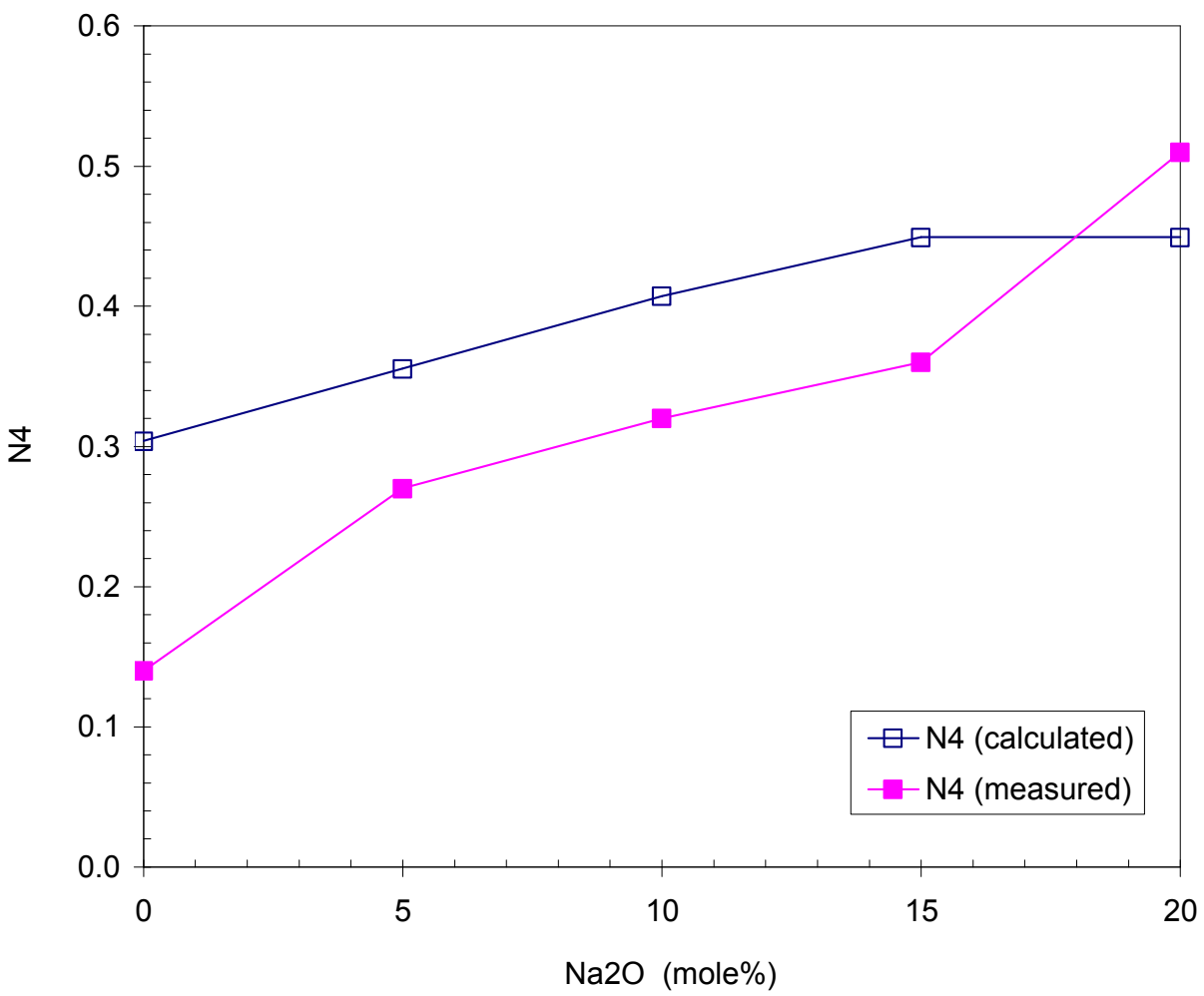

Figure 4-25. Calculated vs. Measured $\mathrm{N}_{4}$ for $21 \mathrm{wt} \% \mathrm{~B}_{2} \mathrm{O}_{3}$ Glasses. 
SRNL-STI-2010-00767

Revision 0

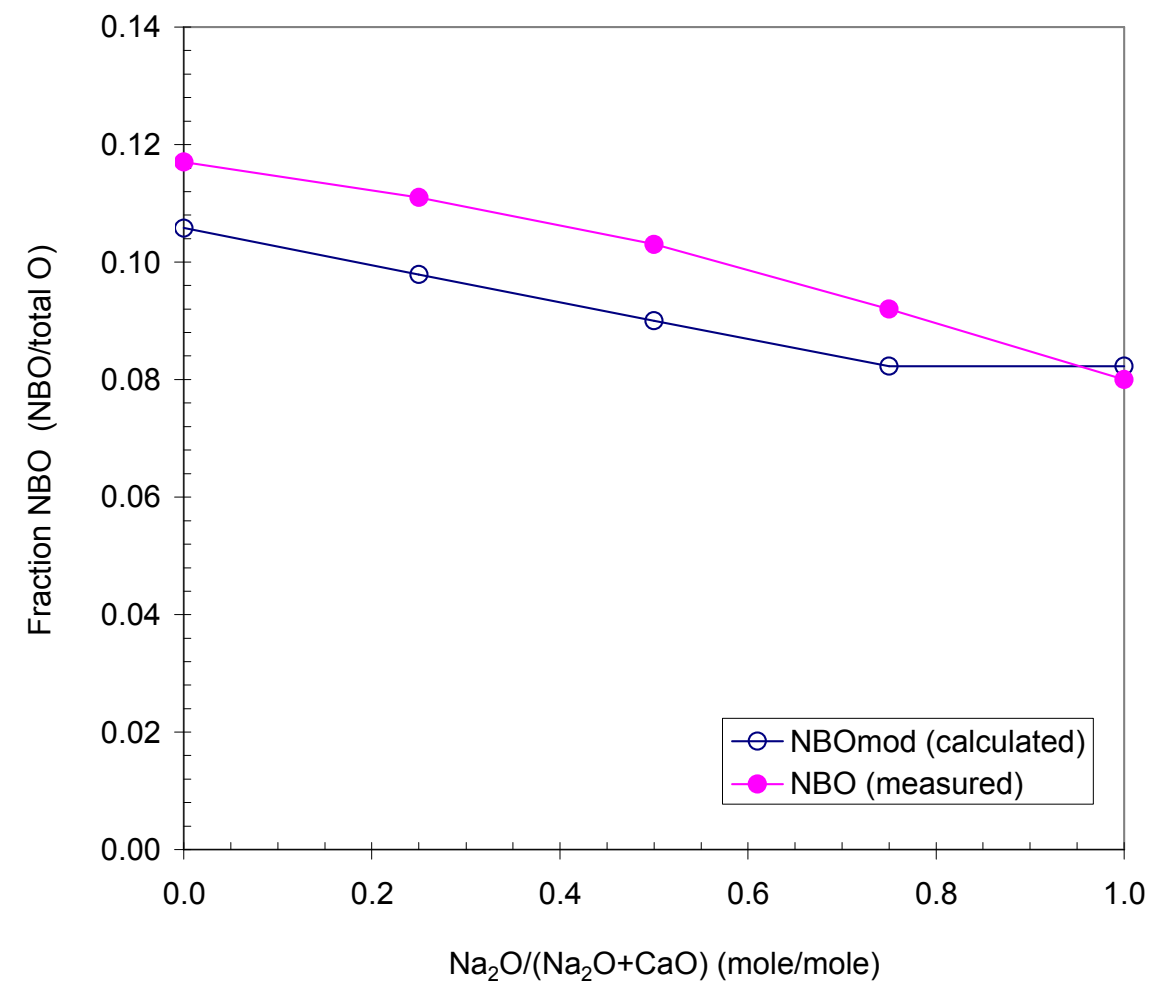

Figure 4-26. Calculated vs. Measured $\mathrm{N}_{\mathrm{BO}}$ for $7 \mathrm{wt} \% \mathrm{~B}_{2} \mathrm{O}_{3}$ Glasses.

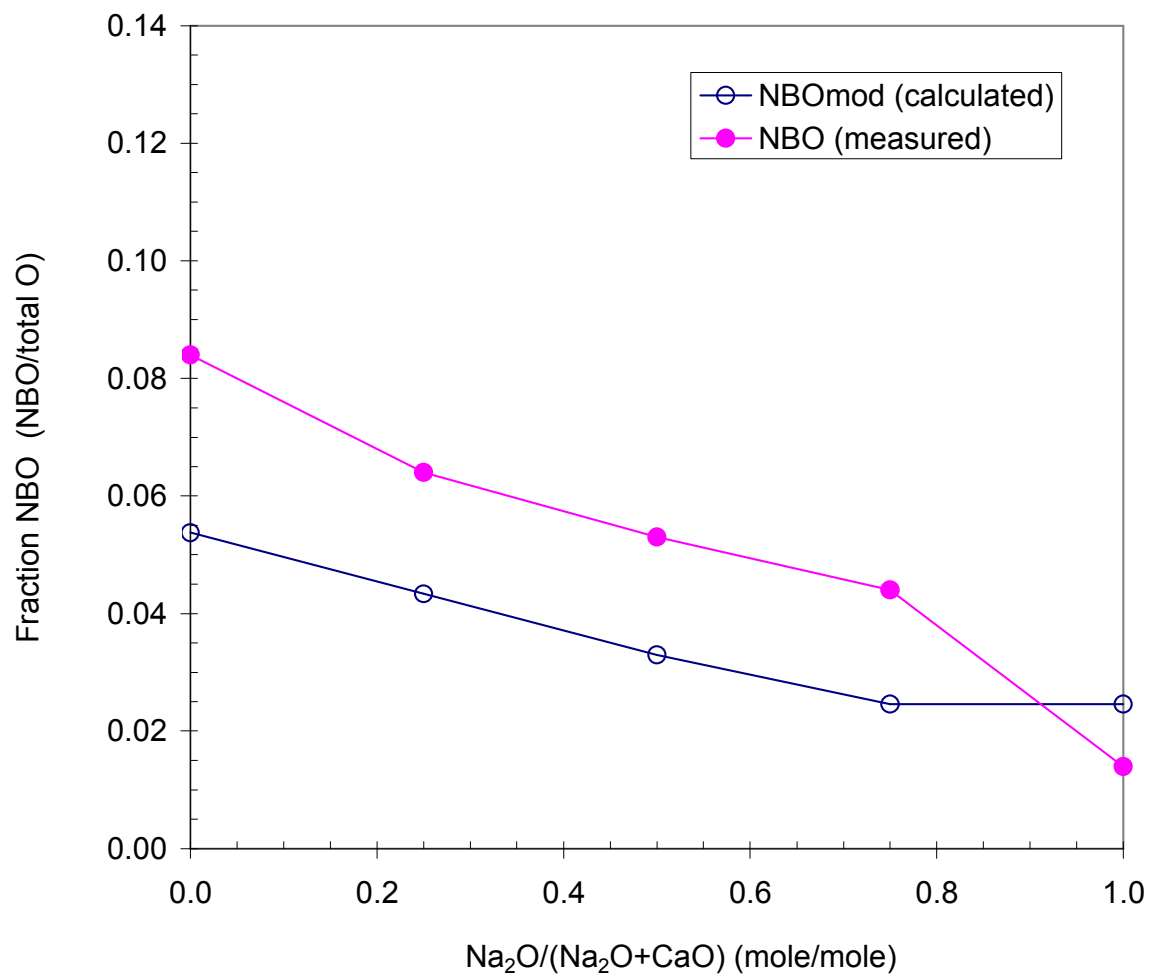

Figure 4-27. Calculated vs. Measured $\mathrm{N}_{\mathrm{BO}}$ for $21 \mathrm{wt} \% \mathrm{~B}_{2} \mathrm{O}_{3}$ Glasses. 


\subsubsection{Extension to Frit-Only Glasses}

The weighted approach to accommodate non-sodium modifiers was next extended to the frit-only glass compositions shown in Table 4-5. However, the goal of doing so was not to predict $\mathrm{N}_{4}$ or NBO fractions but to predict the qualitative melt rate trends shown in Figure 4-14. The additional modifier to consider besides $\mathrm{Na}^{+}$and $\mathrm{Ca}^{2+}$ is $\mathrm{Li}^{+}$, which was shown earlier to have such a strong impact on melt rate especially at high $\mathrm{B}_{2} \mathrm{O}_{3}$ concentrations. To do so, the weighted approach was applied to Eq. (1), specifically the modifier terms only.

The results of the weighted modifier approach applied to the frit-only glasses are shown in Figure 4-28. It is seen that the adjusted or weighted modifier concentrations track the relative melt rates very well. That is, every increase or decrease in the relative melt rate from one frit to the next is matched by the corresponding increase or decrease in the weighted modifier concentration, although the rates of such increase or decrease do not match quantitatively for all frits, particularly for Frit 418. This confirms that Eq. (1) can be improved upon immediately and applied to frit formulation when the addition of different modifiers other than alkali metals are being considered.

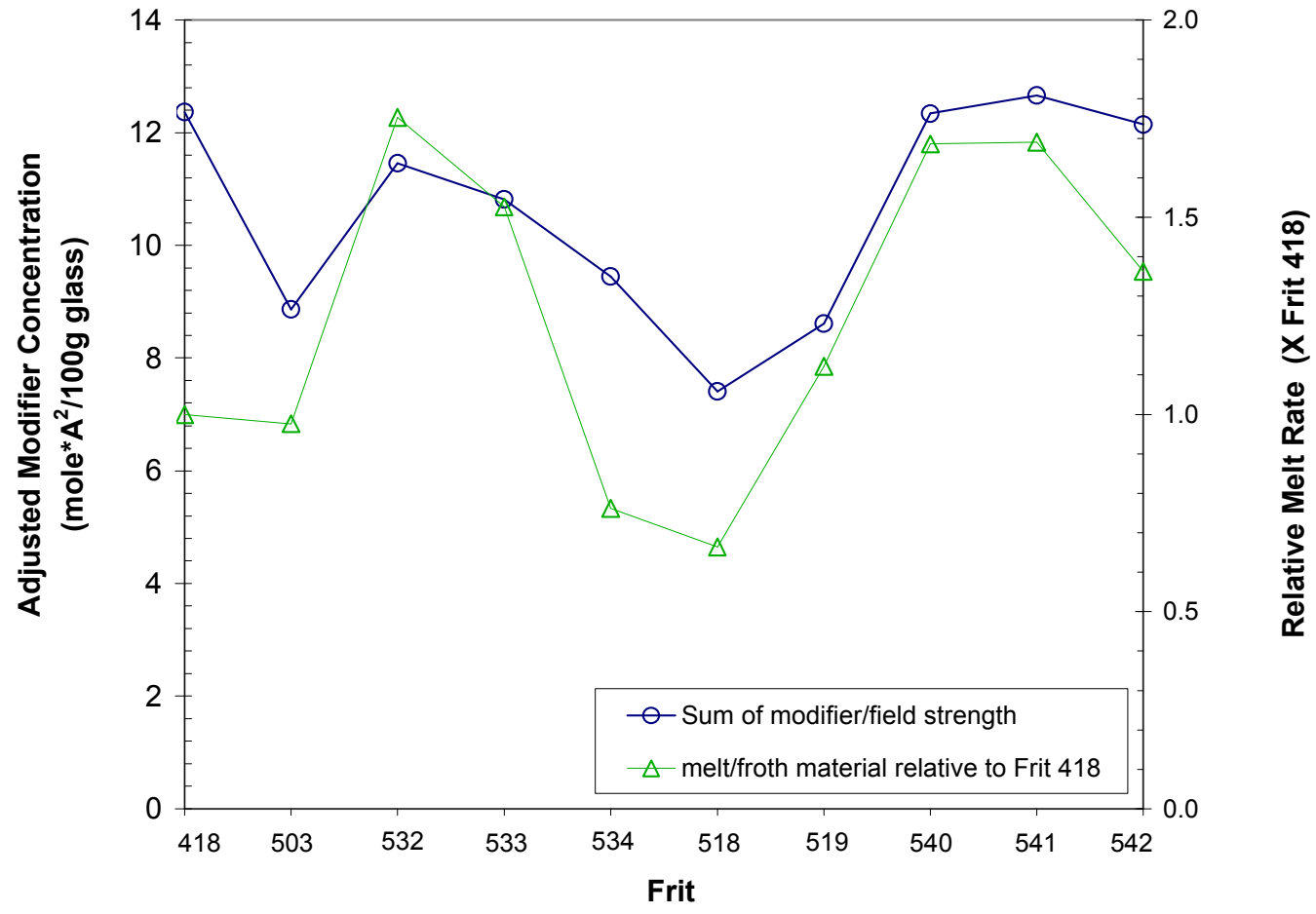

Figure 4-28. Adjusted Modifier Concentration vs. Relative Melt Rates of Varying Frit Feeds. 


\subsection{Conclusions}

The X-ray scanning and CT technique has been developed as a tool for accurately determining the relative melt rates of HLW glasses in a consistent manner. A total of 32 bench-scale melt rate runs were performed to optimize the $\mathrm{CT}$ parameters and confirm the applicability of X-ray $\mathrm{CT}$ to the HLW glass melting study. The feed for the bench-scale melt rate testing was formulated from by 5 different sludge and 21 different frit compositions and 6 different WL. Some of the key conclusions of this study include:

- The total amount of material present in both the melt and froth layers as determined by the $\mathrm{CT}$ analysis gives the most robust measure of relative meltability of a given feed.

- The accuracy of visually-determined melt rates decreases with increasing concentration of gas bubbles in the sample matrix.

- Melt rate decreases with increasing concentration of gas generators such as $\mathrm{NO}_{3}$ and $\mathrm{Mn}^{4+}$ in the feed.

- The melt rate of a given feed decreases with increasing viscosity of the resulting melt.

- $\mathrm{MnO}$ and $\mathrm{CaO}$ are more effective as modifiers at $\mathrm{B}_{2} \mathrm{O}_{3}$ concentrations $>10 \mathrm{wt} \%$.

- Melt rate decreases with increasing concentration of high field-potential modifiers such as $\mathrm{Mg}^{2+}$.

- Frits containing $>12$ mol $\% \mathrm{Li}_{2} \mathrm{O}$ and $>11 \mathrm{~mol} \% \mathrm{~B}_{2} \mathrm{O}_{3}$ coupled with $<7 \mathrm{~mol} \% \mathrm{Na}_{2} \mathrm{O}$ melts significantly slower likely due to the tightening of the network structure as a result of higher field-strength modifier $\mathrm{Li}^{+}$coupling with $\mathrm{BO}_{4}{ }^{-}$and $\mathrm{NBO}$ more easily than lower field-strength modifier $\mathrm{Na}^{+}$.

- Had the CT-based melt rate of the 33\% WL feed of SB6/Frit 418 been $\sim 10 \%$ higher, the CT-based melt rate profile would have shown the trend of monotonically decreasing melt rate with increasing WL throughout the WL range tested. On the other hand, the visual method-based melt rate profile did not show the same trend, although it did earlier with SB2/3 feeds.

- Of the twelve frits tested in conjunction with SB6 at 36\% WL, Frit CEF-10 that contains an additional $8 \mathrm{wt} \% \mathrm{~B}_{2} \mathrm{O}_{3}$ at the expense of $\mathrm{SiO}_{2}$ and $\mathrm{Na}_{2} \mathrm{O}$ at $4 \mathrm{wt} \%$ each (thus resulting in the highest relative concentration of $\mathrm{Li}_{2} \mathrm{O}$ ) was ranked last (i.e., the slowest melting frit for SB6).

- Frit CEF-9 that contains the highest concentration of modifiers including 4\% $\mathrm{MnO}$ and $2 \% \mathrm{CaO}$ added at the expense of $\mathrm{SiO}_{2}$ and $\mathrm{Na}_{2} \mathrm{O}$ in Frit 418 , respectively, was ranked first (i.e., the fastest melting frit for SB6).

- Frit CEF-1 that contains an additional $3 \mathrm{wt} \% \mathrm{~B}_{2} \mathrm{O}_{3}$ added at the expense of $\mathrm{SiO}_{2}$ in Frit 418 increased the melt rate of SB6 only by 3\% from that of Frit 418.

- Frit 510 that contains an additional $6 \mathrm{wt} \% \mathrm{~B}_{2} \mathrm{O}_{3}$ added at the expense of $\mathrm{SiO}_{2}$ in Frit 418 decreased the melt rate of SB 6 by $9 \%$ from that of Frit 418 .

- High-resolution spectroscopic analyses of the twelve SB6/varying frit glass samples revealed that the main structural units of the SB6 glass samples were metasilicate chains and rings, which confirms the current basis for the silicate phase used in the DWPF cold cap model.

- The application of the weighted sum of modifier concentrations based on their field strengths to the modified Dell-Bray model for aluminoborosilicate glasses enabled prediction of 4-coordinated boron $\left(\mathrm{N}_{4}\right)$ and non-bridging oxygen $(\mathrm{NBO})$ fractions that were in good qualitative agreement with their respective measured values for the $\mathrm{Na}_{2} \mathrm{O}$ $\mathrm{CaO}-\mathrm{Al}_{2} \mathrm{O}_{3}-\mathrm{B}_{2} \mathrm{O}_{3}-\mathrm{SiO}_{2}$ system. 
- The same approach to substitute the sum of weighted concentrations of both alkali and non-alkali modifiers for $\mathrm{Na}^{+}$was found to work reasonably well in predicting the relative melt rate trends of frit-only feeds tested in this work.

These results suggest that the theoretical approach taken in this work is on the right track to improve the predictability of the existing DWPF melt rate model and the X-ray CT technique could provide necessary data for the calibration and validation of the model. However, the original scope of work to improve the existing DWPF melt rate model has not been completed due to lack of funding; therefore, the contents of this report do not represent the final set of data and analysis necessary for the model improvement.

Furthermore, although there are some significant differences between SRS and Hanford waste chemistry, the same experimental and theoretical approaches taken in this work could potentially be applied to the WTP Hanford melters, since the underlying principles of optimization of frit or glass-forming chemicals are the same. 
SRNL-STI-2010-00767

Revision 0

\subsection{References}

1. DOE EM-31 Technology Development \& Deployment (TDD) Program Task Plan: Advanced Process Understanding and Predictive Tools for Cold-Cap Melting Rate, WP-4.2-2010-01, Revision 0, March 31, 2010.

2. Miller, D. H., Fox, K. M., Pickenheim, B. R., and Stone, M. E., "Melter Rate Furnace Testing for Sludge Batch 5 Frit Optimization," SRNS-STI-2008-00092, Rev. 0, Savannah River National Laboratory, Aiken, SC (2008).

3. Choi, A. S., "Thermodynamic Modeling of Comparative Melt Rates: FY08 Summary," SRNL-PSE-2008-00178, Savannah River National Laboratory, Aiken, SC (2008).

4. Choi, A. S., Peeler, D. K., and Edwards, T. B., "Modeling Melt Rate for DWPF: a Preliminary Assessment," Ceramic Transactions, 176, pp 179-190, 2006.

5. Wu, J., and Stebbins, J. F., "Effects of Cation Field Strength on the Structure of Aluminoborosilicate Glasses: High-Resolution ${ }^{11} \mathrm{~B},{ }^{27} \mathrm{Al}$, and ${ }^{23} \mathrm{Na}$ MAS NMR," J. Non-Cryst. Solids, 355 (2009) 556.

6. Koopman, D. C., and Lambert, D. P., "Initial Characterizations and SRAT Simulations of Four Sludge Matrix Study Simulants," SRNL-STI-2009-00606, Revision 0, Savannah River National Laboratory, Aiken, SC (2009).

7. Choi, A. S., "DWPF Melter Off-Gas Flammability Assessment," X-CLC-S-00164, Rev. 4, Savannah River National Laboratory, Aiken, SC (2009).

8. Lorier, T.H., and Smith, M.E., "Melt Rate Assessment of SB2/3 with Frit 418 - Effects of Waste Loading and Acid Addition," WSRC-TR-2004-00098, Rev. 0, Westinghouse Savannah River Company, Aiken, South Carolina (2004).

9. Du, L-S, and Stebbins, J. F., "Network Connectivity in Aluminoborosilicate Glasses: A High-Resolution ${ }^{11} \mathrm{~B},{ }^{27} \mathrm{Al}$ and ${ }^{17} \mathrm{O}$ NMR Study," J. Non-Cryst. Solids, 351 (2005) 3508.

10. Dell, W. J., Bray, P. J., and Xiao, S. Z., "'11B NMR Studies and Structural Modeling of $\mathrm{Na}_{2} \mathrm{O}-\mathrm{B}_{2} \mathrm{O}_{3}-\mathrm{SiO}_{2}$ Glasses of High Soda Content," J. Non-Cryst. Solids, 58 (1983) 1.

11. Ionic Radii in Crystals, Handbook of Chemistry and Physics, 91st Ed., CRC Press, 2010-2011 
SRNL-STI-2010-00767

Revision 0

Appendix A 
Designing-Constructing and Industrial-Inculcating Enterprise

$$
\text { «Daymos, Ltd.» }
$$

Office: \#9 Kurchatova Street, Room 340, St.Petersburg, Russia

Telephone Number: (812) 550-41-59; (812) 550-41-64 Facsimile Number: (812) 550-41-59

E-Mail Address: daymos@mail.wplus.net

FINAL REPORT

Glass Structural Characterization and Analysis

Subcontract Number AC69549N together with Change Notice Number 1

Task 3: Chemistry and Structure of Simulated HLW Glass Systems

3.2. Provide interim data report on analyses completed on glass samples

3.3. Provide final report describing analytical techniques utilized, measurement results and data interpretation for glass samples studied 


\section{INTRODUCTION}

The partitioning of boron between trigonal and tetrahedral coordination in aluminoborosilicate glass systems can be determined quantitatively using the nuclear magnetic resonance (NMR) technique. However, the presence of iron in HLW glasses at concentrations greater than $5 \mathrm{wt} \%$ prevents the use of NMR. The objective of this task is to apply the insight gained from Task 1 in studying the impact of varying levels of boron, alkali, and some additives such as $\mathrm{Ca}$ and $\mathrm{Mn}$ on the coordination chemistry of simulated HLW glass systems using XPS, XANES, EXAFS, EPR, IR and Raman spectroscopy.

Sample glasses have been made using SB6 simulant (high in both Al and Fe) with 12 different frit compositions at a constant waste loading of $36 \mathrm{wt} . \%$ (Tables I and II). The baseline frit composition is Frit 418 and the remaining frit compositions contain 8-16 wt $\% \mathrm{~B}_{2} \mathrm{O}_{3}, 4-8 \mathrm{wt} \%$ $\mathrm{Na}_{2} \mathrm{O}, 0-4 \mathrm{wt} \% \mathrm{MnO}$ and $0-2 \mathrm{wt} \% \mathrm{CaO}$. Glasses were delivered by customer (SRNL).

Table I. Glass compositions, wt.\%

\begin{tabular}{|c|c|c|c|c|c|c|c|c|c|c|c|c|}
\hline Oxides & 35 & 36 & 37 & 38 & 39 & 40 & 41 & 42 & 43 & 44 & 45 & 46 \\
\hline $\mathrm{Li}_{2} \mathrm{O}$ & 5.12 & 5.12 & 5.12 & 5.12 & 5.76 & 5.12 & 5.12 & 5.12 & 5.12 & 5.12 & 5.12 & 5.12 \\
\hline $\mathrm{B}_{2} \mathrm{O}_{3}$ & 5.12 & 8.96 & 7.04 & 7.04 & 7.04 & 5.12 & 5.12 & 5.12 & 5.12 & 5.12 & 5.12 & 10.24 \\
\hline $\mathrm{Na}_{2} \mathrm{O}$ & 12.59 & 12.59 & 12.59 & 11.31 & 10.67 & 12.59 & 11.95 & 11.31 & 11.95 & 11.31 & 11.31 & 10.03 \\
\hline $\mathrm{MgO}$ & 0.27 & 0.27 & 0.27 & 0.27 & 0.27 & 0.27 & 0.27 & 0.27 & 0.27 & 0.27 & 0.27 & 0.27 \\
\hline $\mathrm{Al}_{2} \mathrm{O}_{3}$ & 10.78 & 10.78 & 10.78 & 10.78 & 10.78 & 10.78 & 10.78 & 10.78 & 10.78 & 10.78 & 10.78 & 10.78 \\
\hline $\mathrm{SiO}_{2}$ & 48.75 & 44.91 & 46.83 & 46.83 & 45.55 & 48.11 & 48.11 & 47.47 & 47.47 & 47.47 & 46.19 & 46.19 \\
\hline $\mathrm{SO}_{3}$ & 0.33 & 0.33 & 0.33 & 0.33 & 0.33 & 0.33 & 0.33 & 0.33 & 0.33 & 0.33 & 0.33 & 0.33 \\
\hline $\mathrm{K}_{2} \mathrm{O}$ & 0.03 & 0.03 & 0.03 & 0.03 & 0.03 & 0.03 & 0.03 & 0.03 & 0.03 & 0.03 & 0.03 & 0.03 \\
\hline $\mathrm{CaO} 0.48$ & 0.48 & 0.48 & 0.48 & 0.48 & 0.48 & 0.48 & 0.48 & 1.76 & 1.76 & 1.76 & 0.48 \\
\hline $\mathrm{TiO}_{2}$ & 0.01 & 0.01 & 0.01 & 0.01 & 0.01 & 0.01 & 0.01 & 0.01 & 0.01 & 0.01 & 0.01 & 0.01 \\
\hline $\mathrm{MnO}$ & 2.75 & 2.75 & 2.75 & 4.03 & 5.31 & 3.39 & 4.03 & 5.31 & 3.39 & 4.03 & 5.31 & 2.75 \\
\hline $\mathrm{Fe} \mathrm{O}_{3}$ & 9.73 & 9.73 & 9.73 & 9.73 & 9.73 & 9.73 & 9.73 & 9.73 & 9.73 & 9.73 & 9.73 & 9.73 \\
\hline $\mathrm{NiO}$ & 1.16 & 1.16 & 1.16 & 1.16 & 1.16 & 1.16 & 1.16 & 1.16 & 1.16 & 1.16 & 1.16 & 1.16 \\
\hline $\mathrm{CuO}$ & 0.08 & 0.08 & 0.08 & 0.08 & 0.08 & 0.08 & 0.08 & 0.08 & 0.08 & 0.08 & 0.08 & 0.08 \\
\hline $\mathrm{SrO}$ & 0.02 & 0.02 & 0.02 & 0.02 & 0.02 & 0.02 & 0.02 & 0.02 & 0.02 & 0.02 & 0.02 & 0.02 \\
\hline $\mathrm{ZrO} 2$ & 0.11 & 0.11 & 0.11 & 0.11 & 0.11 & 0.11 & 0.11 & 0.11 & 0.11 & 0.11 & 0.11 & 0.11 \\
\hline $\mathrm{Sum}$ & 97.33 & 97.33 & 97.33 & 97.33 & 97.33 & 97.33 & 97.22 & 97.33 & 97.33 & 97.33 & 97.33 & 97.33 \\
\hline
\end{tabular}

Table II. Glass compositions, mol.\%

\begin{tabular}{|c|c|c|c|c|c|c|c|c|c|c|c|c|}
\hline Oxides & 35 & 36 & 37 & 38 & 39 & 40 & 41 & 42 & 43 & 44 & 45 & 46 \\
\hline $\mathrm{Li}_{2} \mathrm{O}$ & 11.41 & 11.47 & 11.44 & 11.46 & 12.83 & 11.42 & 11.43 & 11.45 & 11.41 & 11.42 & 11.44 & 11.49 \\
\hline $\mathrm{B}_{2} \mathrm{O}_{3}$ & 4.90 & 8.62 & 6.75 & 6.76 & 6.73 & 4.90 & 4.91 & 4.91 & 4.89 & 4.90 & 4.91 & 9.86 \\
\hline $\mathrm{Na}_{2} \mathrm{O}$ & 13.52 & 13.60 & 13.56 & 12.20 & 11.45 & 13.54 & 12.86 & 12.20 & 12.83 & 12.16 & 12.18 & 10.85 \\
\hline $\mathrm{MgO}$ & 0.45 & 0.45 & 0.45 & 0.45 & 0.45 & 0.45 & 0.45 & 0.45 & 0.45 & 0.45 & 0.45 & 0.45 \\
\hline $\mathrm{Al}_{2} \mathrm{O}_{3}$ & 7.04 & 7.08 & 7.06 & 7.07 & 7.03 & 7.05 & 7.05 & 7.07 & 7.04 & 7.04 & 7.06 & 7.09 \\
\hline $\mathrm{SiO}_{2}$ & 54.01 & 50.05 & 52.03 & 52.12 & 50.43 & 53.36 & 53.40 & 52.80 & 52.58 & 52.63 & 51.32 & 51.53 \\
\hline $\mathrm{SO}_{3}$ & 0.27 & 0.28 & 0.28 & 0.28 & 0.27 & 0.27 & 0.27 & 0.28 & 0.27 & 0.27 & 0.28 & 0.28 \\
\hline $\mathrm{K}_{2} \mathrm{O}$ & 0.02 & 0.02 & 0.02 & 0.02 & 0.02 & 0.02 & 0.02 & 0.02 & 0.02 & 0.02 & 0.02 & 0.02 \\
\hline
\end{tabular}




\begin{tabular}{|c|c|c|c|c|c|c|c|c|c|c|c|c|}
\cline { 2 - 14 } & 0.57 & 0.57 & 0.57 & 0.57 & 0.57 & 0.57 & 0.57 & 0.57 & 2.09 & 2.09 & 2.10 & 0.57 \\
\hline $\mathrm{TiO}_{2}$ & 0.01 & 0.01 & 0.01 & 0.01 & 0.01 & 0.01 & 0.01 & 0.01 & 0.01 & 0.01 & 0.01 & 0.01 \\
\hline $\mathrm{MnO}$ & 2.58 & 2.60 & 2.59 & 3.80 & 4.98 & 3.18 & 3.79 & 5.00 & 3.18 & 3.78 & 5.00 & 2.60 \\
\hline $\mathrm{Fe}_{2} \mathrm{O}_{3}$ & 4.06 & 4.08 & 4.07 & 4.07 & 4.05 & 4.06 & 4.06 & 4.07 & 4.06 & 4.06 & 4.07 & 4.08 \\
\hline $\mathrm{NiO}$ & 1.03 & 1.04 & 1.04 & 1.04 & 1.03 & 1.04 & 1.04 & 1.04 & 1.03 & 1.03 & 1.04 & 1.04 \\
\hline $\mathrm{CuO}$ & 0.07 & 0.07 & 0.07 & 0.07 & 0.07 & 0.07 & 0.07 & 0.07 & 0.07 & 0.07 & 0.07 & 0.07 \\
\hline $\mathrm{SrO}$ & 0.01 & 0.01 & 0.01 & 0.01 & 0.01 & 0.01 & 0.01 & 0.01 & 0.01 & 0.01 & 0.01 & 0.01 \\
\hline $\mathrm{ZrO}_{2}$ & 0.06 & 0.06 & 0.06 & 0.06 & 0.06 & 0.06 & 0.06 & 0.06 & 0.06 & 0.06 & 0.06 & 0.06 \\
\hline $\mathrm{Sum}^{100.00}$ & 100.00 & 100.00 & 100.00 & 100.00 & 100.00 & 100.00 & 100.00 & 100.00 & 100.00 & 100.00 & 100.00 \\
\hline$\psi_{\mathrm{B}}^{*}$ & 2,14 & 1.22 & 1.56 & 1.35 & 1.25 & 2.14 & 2.00 & 1.86 & 2.00 & 1.86 & 1.86 & 0.79 \\
\hline$\psi_{\mathrm{B}}(\mathrm{Fe})^{* *}$ & 1.89 & 1.08 & 1.37 & 1.17 & 1.07 & 1.89 & 1.75 & 1.61 & 1.75 & 1.61 & 1.61 & 0.66 \\
\hline
\end{tabular}

$* \psi_{\mathrm{B}}=\left\{\left(\mathrm{Na}_{2} \mathrm{O}+\mathrm{K}_{2} \mathrm{O}+\mathrm{BaO}\right)+\left[0.7(\mathrm{CaO}+\mathrm{SrO}+\mathrm{CdO}+\mathrm{PbO})+[0.3(\mathrm{Li} 2 \mathrm{O}+\mathrm{MgO}+\mathrm{ZnO})]-\mathrm{Al}_{2} \mathrm{O}_{3}\right\} / \mathrm{B}_{2} \mathrm{O}_{3}[1]\right.$

$* * \psi_{\mathrm{B}}(\mathrm{Fe})=\left\{\left(\mathrm{Na}_{2} \mathrm{O}+\mathrm{K}_{2} \mathrm{O}+\mathrm{BaO}\right)+\left[0.7(\mathrm{CaO}+\mathrm{SrO}+\mathrm{CdO}+\mathrm{PbO})+\left[0.3\left(\mathrm{Li}_{2} \mathrm{O}+\mathrm{MgO}+\mathrm{ZnO}\right)\right]-\mathrm{Al}_{2} \mathrm{O}_{3}-0.3 \mathrm{Fe}_{2} \mathrm{O}_{3}\right\}\right.$ $/ \mathrm{B}_{2} \mathrm{O}_{3}$

The $\psi_{\mathrm{B}}$ and $\psi_{\mathrm{B}}(\mathrm{Fe})$ values range between 0.79 and 2.14 and between 0.66 abd 1.89 , respectively at moderate silica contents (50-54 mol.\%) that points to significant fraction of trigonally coordinated boron. The glasses \#35 and \#40 should have th highest fraction of tetrahedrally coordinated boron, whereas the glass $\# 46$ - the lowest one.

\section{EXPERIMENTAL}

Samples were examined by X-ray diffraction (XRD) using a Rigaku D / Max 2200 diffractometer $(\mathrm{Cu} \mathrm{K} \alpha$ radiation, $40 \mathrm{keV}$ voltage, $20 \mathrm{~mA}$ current, stepwise 0.02 degrees $2 \theta)$. Glasses were studied by optical microscopy using an OLYMPUS BX51 polarizing microscope, infrared spectroscopy using a modernized IKS-29 spectrophotometer (compaction of powdered glasses in pellets with $\mathrm{KBr}$ ) within the range of $4000-400 \mathrm{~cm}^{-1}$ and Raman spectroscopy using a Jobin Yvon U1000 spectrophotometer operated at an excitation wavelength of $532 \mathrm{~nm}$.

X-ray absorption (XAS) spectra were recorded at the Structural Materials Science (STM) Beamline of the synchrotron source at RRC "Kurchatov Institute". The glass samples were measured at room temperature either as dispersed powder or as pellets pressed from powder mixed with sucrose in the transmission mode using a $\mathrm{Si}(220)$ channel-cut monochromator and two air-filled ionization chambers. Fluorescence spectra were also acquired. Powders of chemically pure $\mathrm{Fe}$ oxides $\mathrm{Fe}_{2} \mathrm{O}_{3}$ and $\mathrm{FeO}$ were used as standards and measured under identical conditions. Experimental XAFS spectra were fitted in R-space using an IFEFFIT package [2] and crystal structures of corresponding oxides and silicates. In the fitting, $a b$ initio photoelectron backscattering amplitudes and phases calculated self-consistently using FEFF8 [3] were used. Wavelet transform (WT) is commonly applied to evaluation of complex time-frequency signals. As shown in refs $[4,5]$, WT is easily adapted to EXAFS analysis, and the expression of the WT of the $\mathrm{k}^{\mathrm{n}}$-weighted EXAFS data takes the form: 


$$
W_{\chi}^{\psi}(k, r)=(2 r)^{1 / 2} \int_{-\infty}^{\infty} \chi\left(k^{\prime}\right) k^{\prime^{n}} \psi^{*}\left[2 r\left(k^{\prime}-k\right)\right] d k^{\prime}
$$

where $\chi(\mathrm{k})$ is the EXAFS signal and $\psi^{*}\left[2 r\left(k^{\prime}-k\right)\right]$ is the complex wavelet function.

The WT is able to resolve the $\mathrm{k}$ dependence of the absorption signal, which potentially allows separation of contributing backscattering atoms even situated at the same distances from the core. One of the advantages of the wavelet analysis is the visualization of the WT modulus in a k-R plot, which provides an easy way to interpret the results. Our analysis of EXAFS data for Pu and Hf were performed using the FORTRAN program HAMA employing Morlet wavelet algorithm [6]. The Morlet wavelet is well-suited for EXAFS signal since it consists of a slowly varying amplitude term and a fast oscillating phase term. Its mathematical description is broadly analogous to the Fourier transform. The Morlet wavelet is obtained by taking a complex sine wave with frequency $\eta$ (as in FT) and by confining it with a Gaussian envelope with the half width $\sigma$,

$$
\psi(k)=\frac{1}{(2 \pi)^{1 / 2} \sigma} \exp (i \eta k) \exp \left(-k^{2} / 2 \sigma^{2}\right)
$$

The choice of the $\eta$ and $\sigma$ parameters is important for data analysis since, besides other issues, it determines resolution in k-R space. Various combinations of these parameters were used in an attempt to resolve contributions from atoms at close distances from the central atom. As shown in ref.[5] use of higher k-weighting decreases resolution in the k-space, since backscattering amplitudes become flattened and shifted to higher values. Nevertheless, WT modulus plots for different $\mathrm{k}$ weights are shown to emphasize contributions of light and heavy backscatterers. Note, that in all plots of the WT modulus the interatomic distances are given without phase shift correction.

\section{RESULTS AND DISCUSSION}

\section{XRD study}

XRD patterns show that all the samples are composed of major glass and minor spinel structure phase (Figure 1). Because lattice parameter of the spinel phase is same in all the samples, it may be suggested that chemical composition of this phase is similar in all the samples as well. 


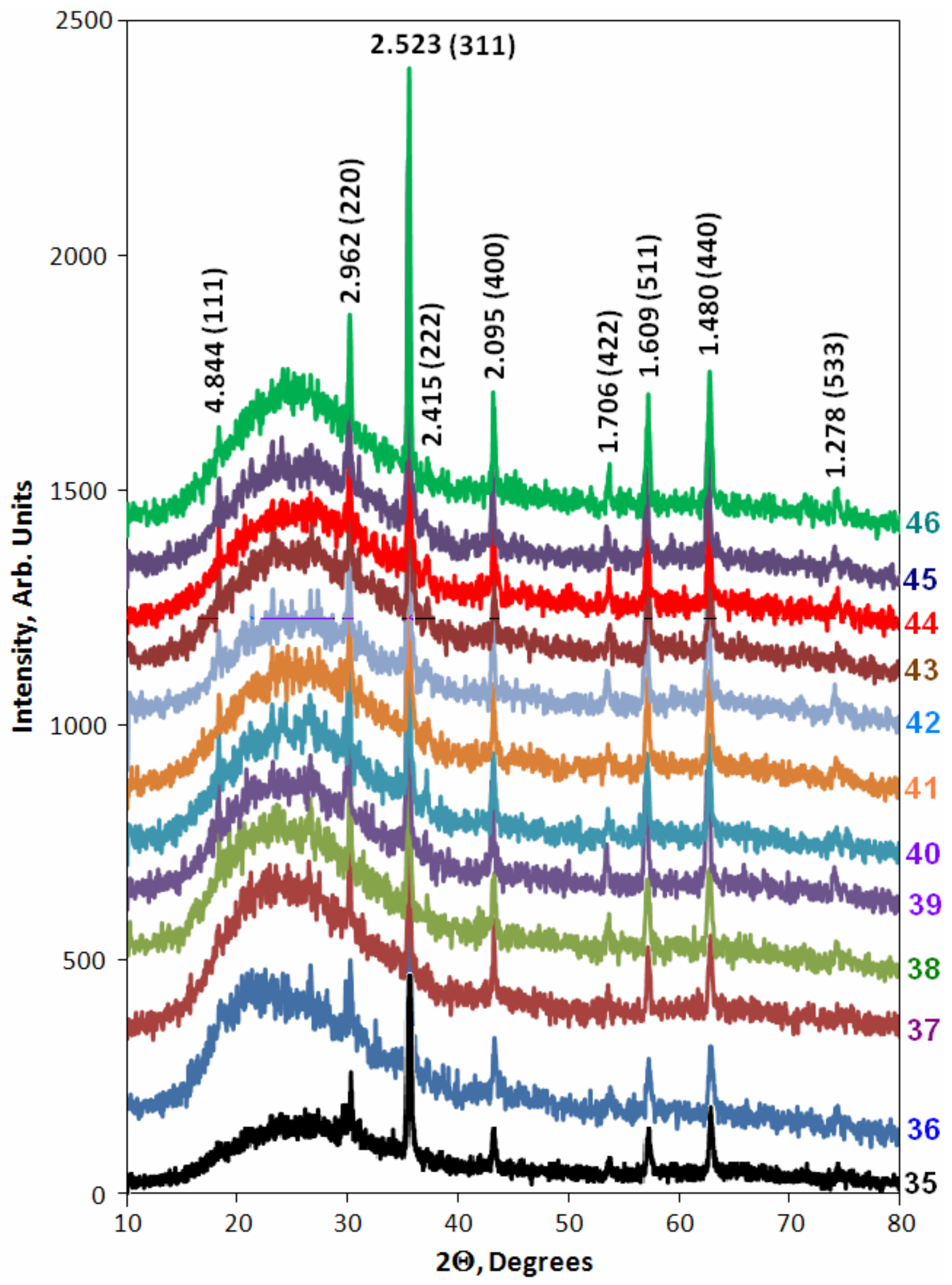

Figure 1. XRD patterns of the samples. 


\section{Optical Microscopy Study}

Microphotograph of the general view of sample \#35 (Figure 2a) shows dominance of light transparent glass containing spinel occurred as both isometric grains tens of microns in size and the finest crystals of about $1 \mu \mathrm{m}$ in size. Glass matrix contains wavy bands displaying features of melt flowing and differing in amount of fine crystals in glass. Wavy-banded distribution of microcrystals causes fluidal texture of the glass which is typical for glassy volcanic rocks. Moreover gas bubbles from tens to hundreds microns in diameter are seen well in the lapping.
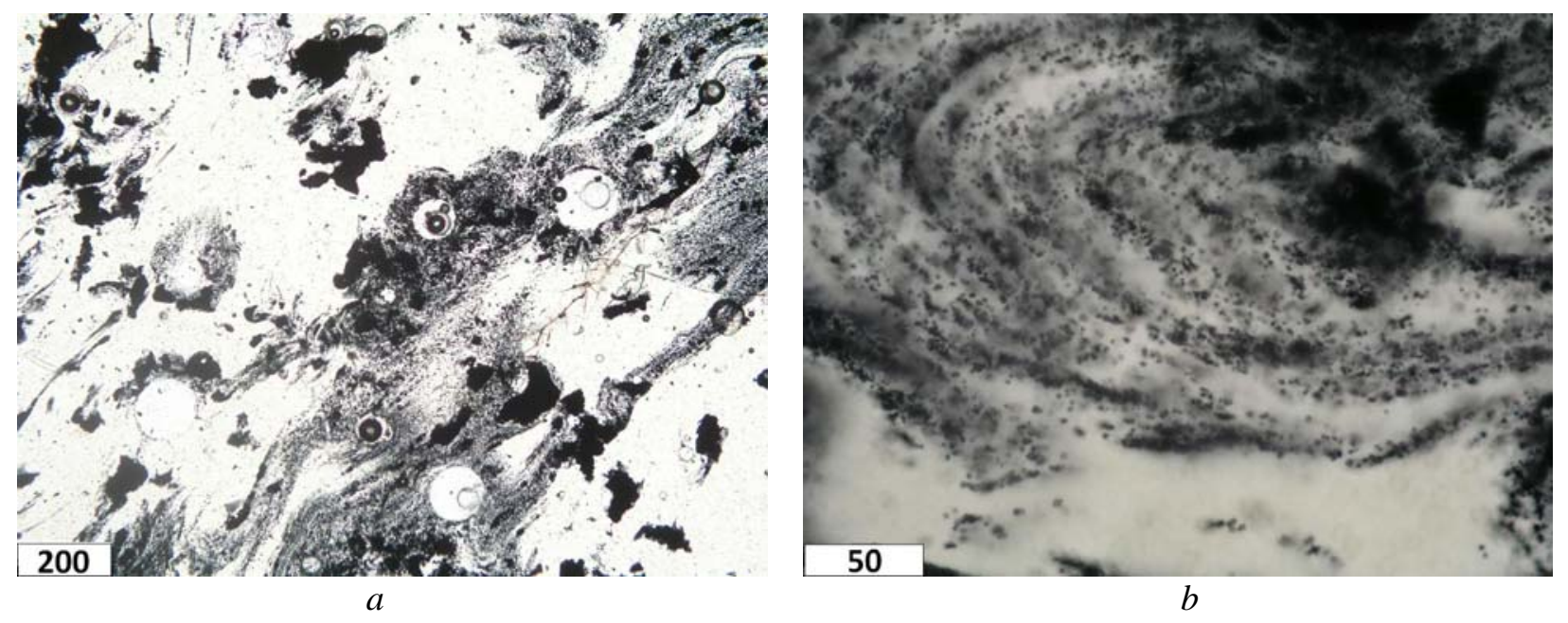

Figure 2. Microphotographs at single Nichol of the lapping of the sample \#35.

A detail of the lapping on Figure $2 a$ at higher magnification demonstrates that microcrystals of the spinel phase are the finest cubic crystals about $1 \mu \mathrm{m}$ in size. This microphotograph clearly characterizes features of distribution of microcrystals in glass.

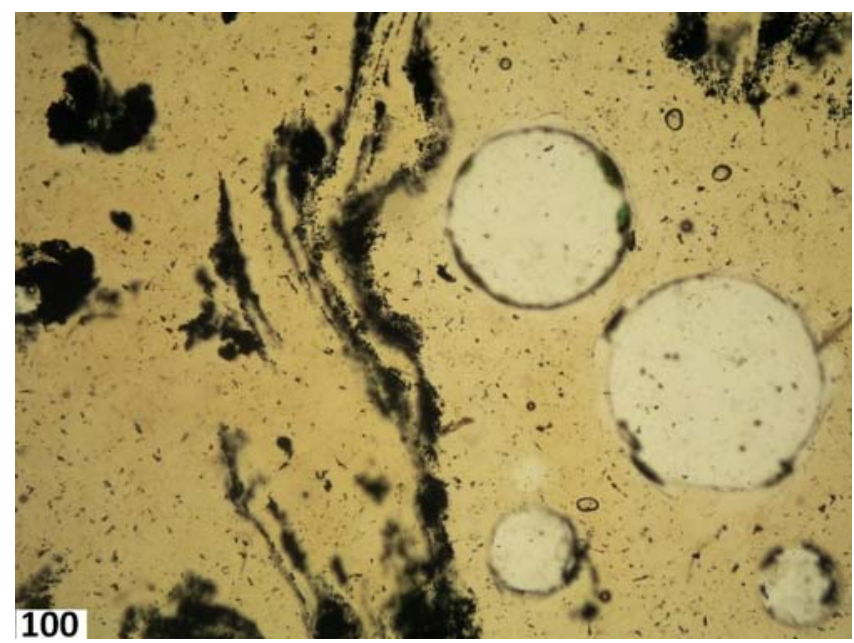

Figure 3. Microphotograph at single Nichol of the lapping of the sample \#36. 
Specific feature of the glassy matrix in the sample \#36 are light-brown coloring of glass and relatively low content of spinel (Figure 3). Spinel forms either irregular grains or elongated wavy-type grains emphasizing elements of the fluidal texture. Minor cubic microcrystals of spinel are also present. Gas bubbles 50-200 $\mu \mathrm{m}$ in diameter occurred in the vitreous and are nonuniformly distributed.

Figure 4a demonstrates general view of the lapping of sample \#37. Glassy matrix is characterized by clearly appeared fluidal texture and light-brown coloring. Spinel is rather nonuniformly distributed over the bulk and occurs predominantly as fine $(\sim 1 \mu \mathrm{m}$ in size $)$ crystals. Glass contains numerous gas bubbles up to $0.5 \mathrm{~mm}$ in diameter.
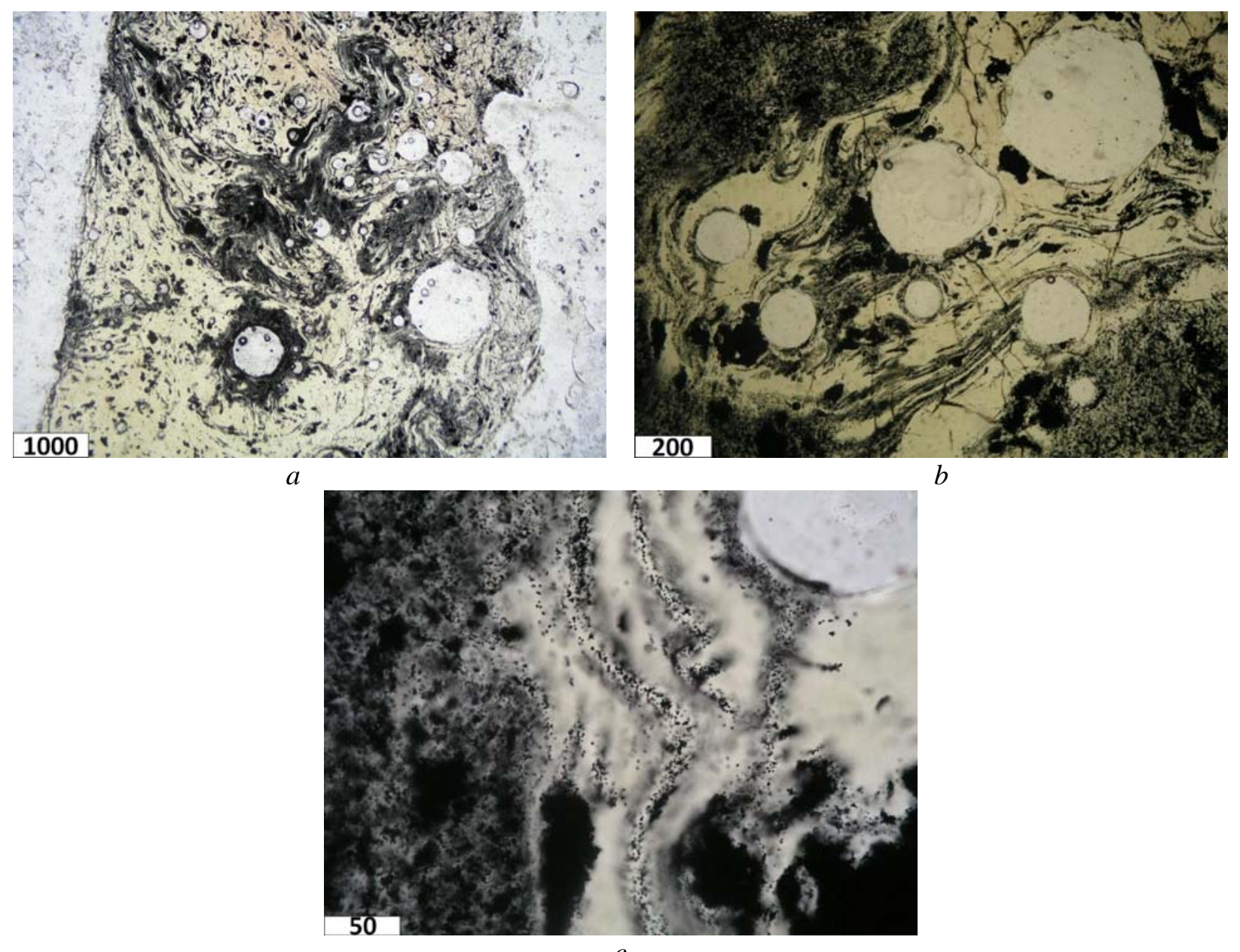

$C$

Figure 4. Microphotographs at single Nichol of the lapping of the sample \#37.

Figure $4 b$ demonstrates fragment of the same lapping enriched with spinel. It is seen well that fluidity is represented by alternation of wavy bands enriched and depleted with fine cubic spinel crystals. Dense aggregates of cubic spinel crystals are occasionally occur. As seen at higher magnification (Figure 4c) spinel occurs as both individual cubic crystals about $1 \mu \mathrm{m}$ in size and aggregates of fine crystals forming dense opaque areas. 
Glass in the lapping of the sample \#38 has light-brown coloring and is characterized by strong cracking showing high mechanical stress (Figure 5). Amount of spinel is rather minor. Major fraction of spinel is represented by isometric grains. Fine cubic crystals are concentrated at small area of the lapping. Wavy-banded distribution of cubic microcrystals determines fluidal texture of this area.

The lapping of the sample \#39 is a light-brown glass with high contents of spinel and gas bubbles (Figure 6). Spinel is present as both isometric grains and cubic microcrystals. There are areas both enriched with microcrystals and free of crystals. The first of them have clear fluidal texture. Cracking is negligible.

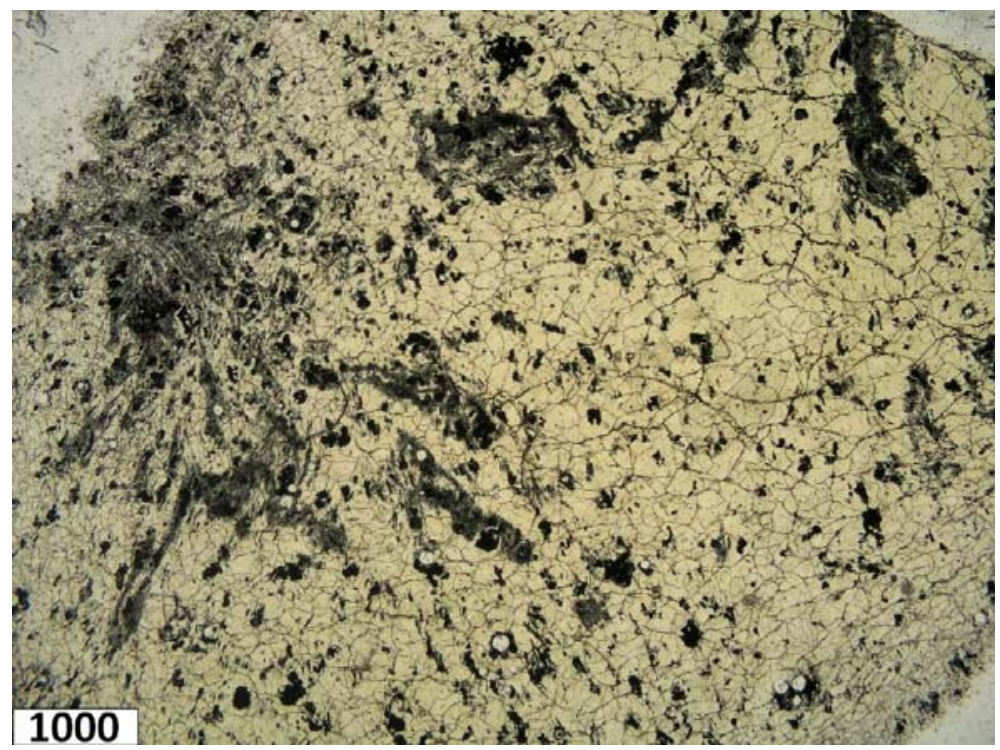

Figure 5. Microphotograph at single Nichol of the lapping of the sample \#38.

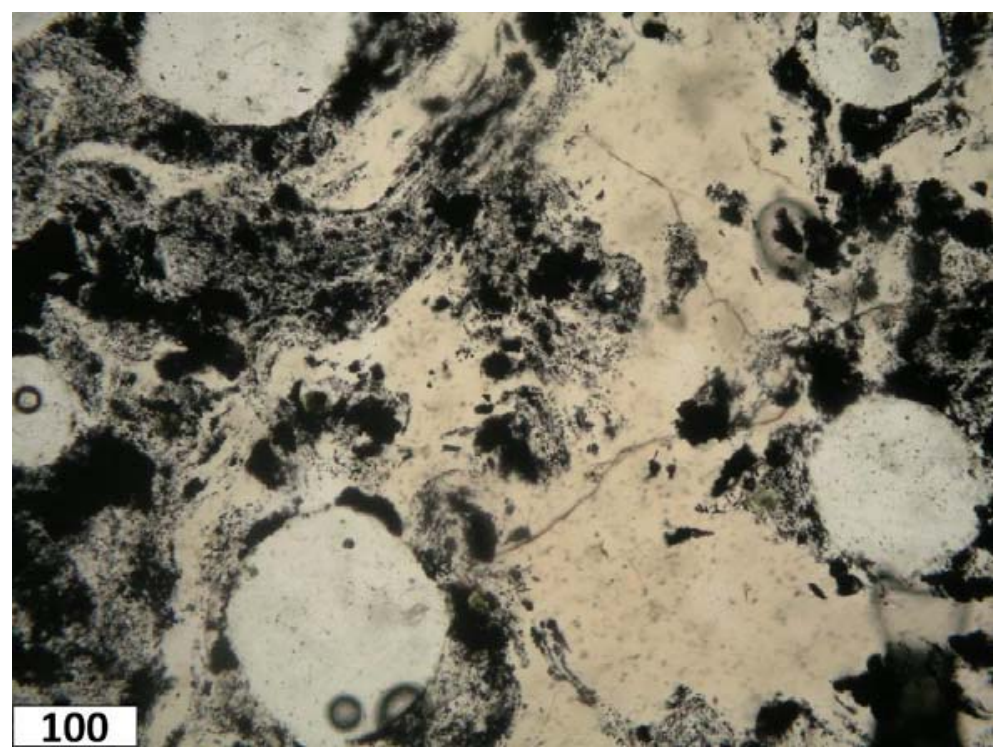

Figure 6. Microphotograph at single Nichol of the lapping of the sample \#39. 
Glassy matrix in the lapping of the sample \#40 is strongly enriched with spinel (Figure 7). Spinel occurs as both isometric grains and cubic microcrystals. Fluidity is appeared locally. Areas not containing spinel are small in size and occur rarely. In spite of high spinel content glass is light and transparent. This demonstrates absence of the dependence between iron oxides content in the glassy matrix and glass coloring. Microcracking of the glass is negligible.

Glassy matrix in the lapping of the sample \#41 (Figure 8) has low spinel content ( $<10 \mathrm{vol} \%$ ). Nearly all the spinel forms isometric grains. Amount of microcrystals is negligible. Glass has light brown-green coloring and numerous cracks due to mechanical stresses.

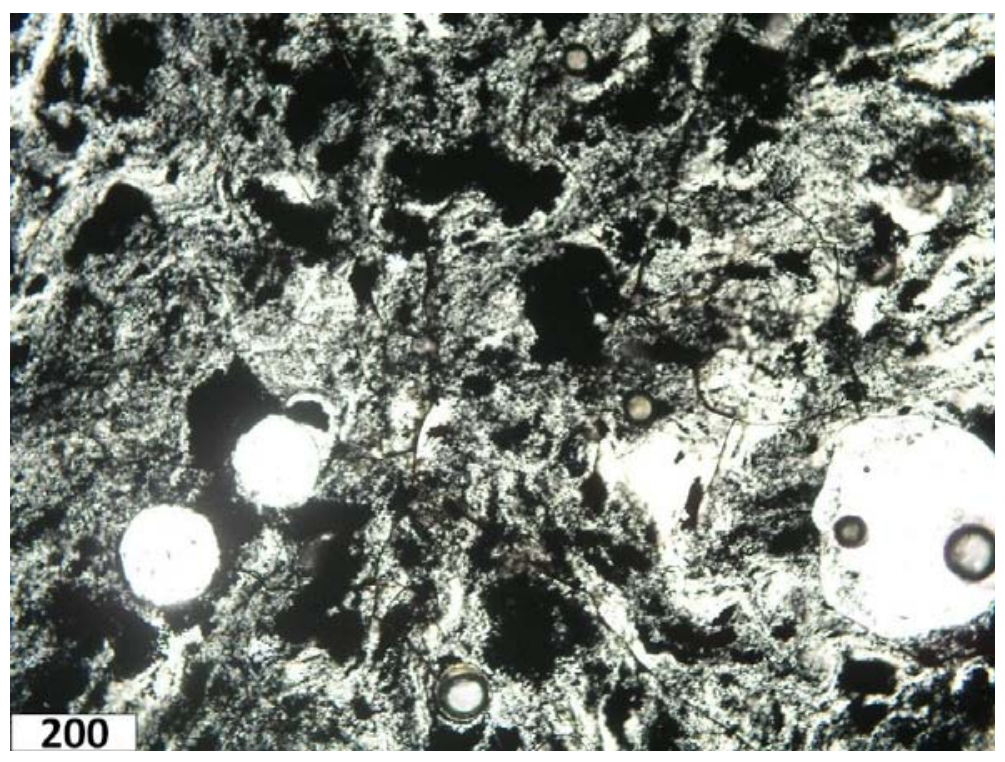

Figure 7. Microphotograph at single Nichol of the lapping of the sample \#40.

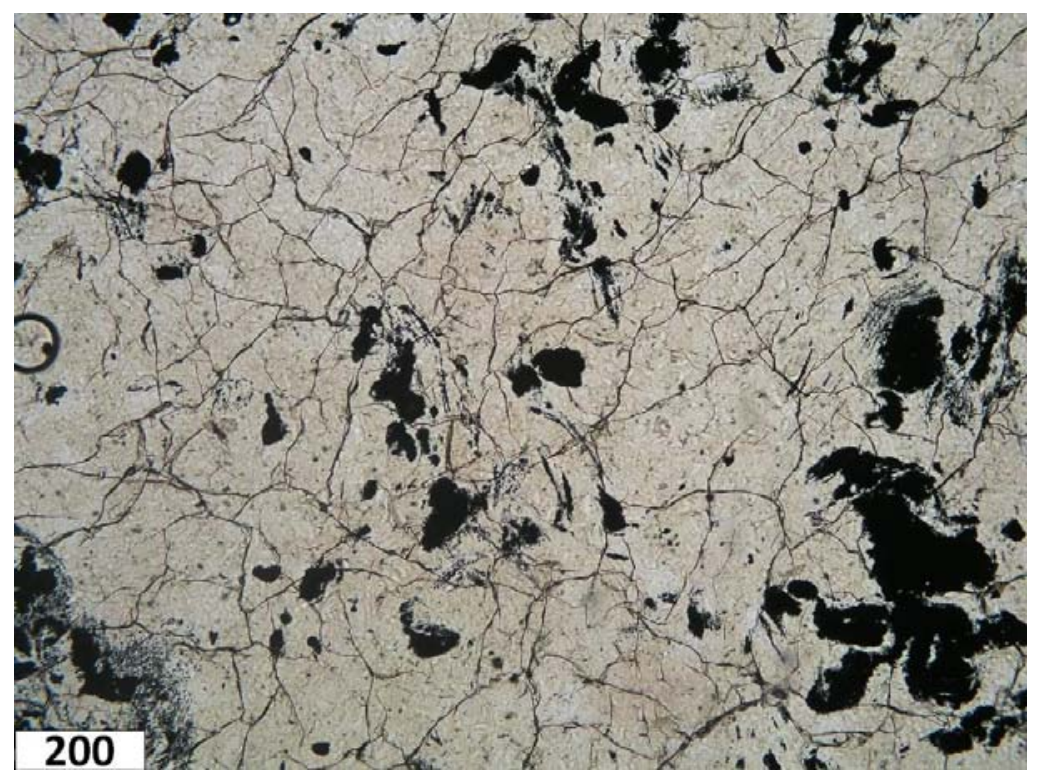

Figure 8. Microphotograph at single Nichol of the lapping of the sample \#41. 
The lapping of the sample \#42 is represented by glass with high content of spinel and gas bubbles (Figure 9). Bubbles are up to $200 \mu \mathrm{m}$ in size. Glass has brown color, fluidity is poorly appeared. Spinel forms predominantly isomeric grains. Content of cubic microcrystals is negligible.

The lapping of the sample \#43 is composed of poorly colored brown-green glass with minor spinel forming isometric grains (Figure 10). Spinel content may be evaluated as 6-8 vol.\%. Rare aggregates of microcrystals and gas bubbles up to $200 \mu \mathrm{m}$ in diameter also occur. Cracking is negligible.

The lapping of the sample \#44 is composed of green-brown glass with high spinel content (25-30 vol.\%). Major spinel is represented by isometric randomly distributed grains. Minor cubic microcrystals determine fluidal texture of the glassy matrix due to their wavy-banded distribution over the matrix. Large (up to $1.5 \mathrm{~mm}$ in diameter) gas bubbles are also present. Microcracking is nearly absent (Figure 11).

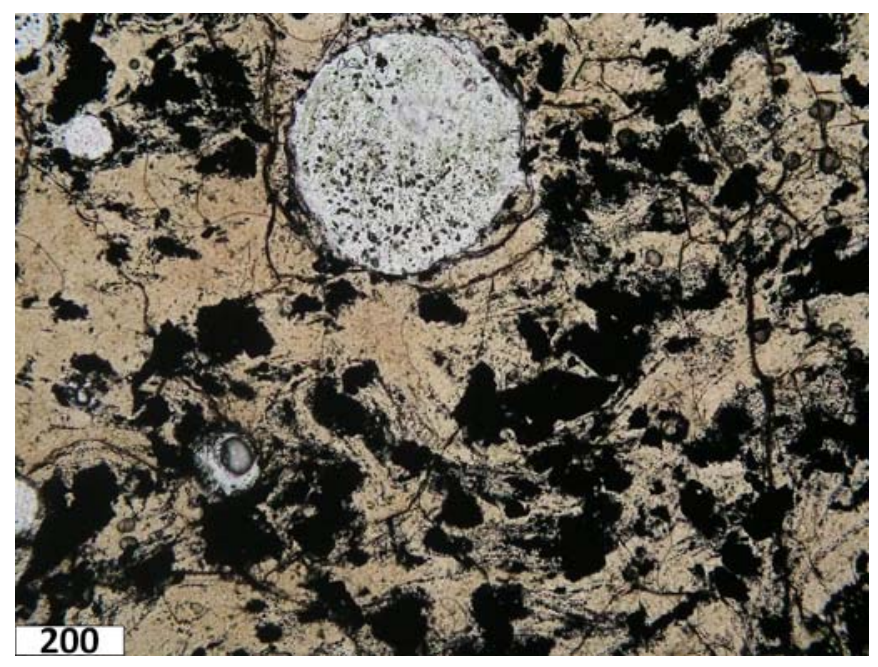

Figure 9. Microphotograph at single Nichol of the lapping of the sample \#42.

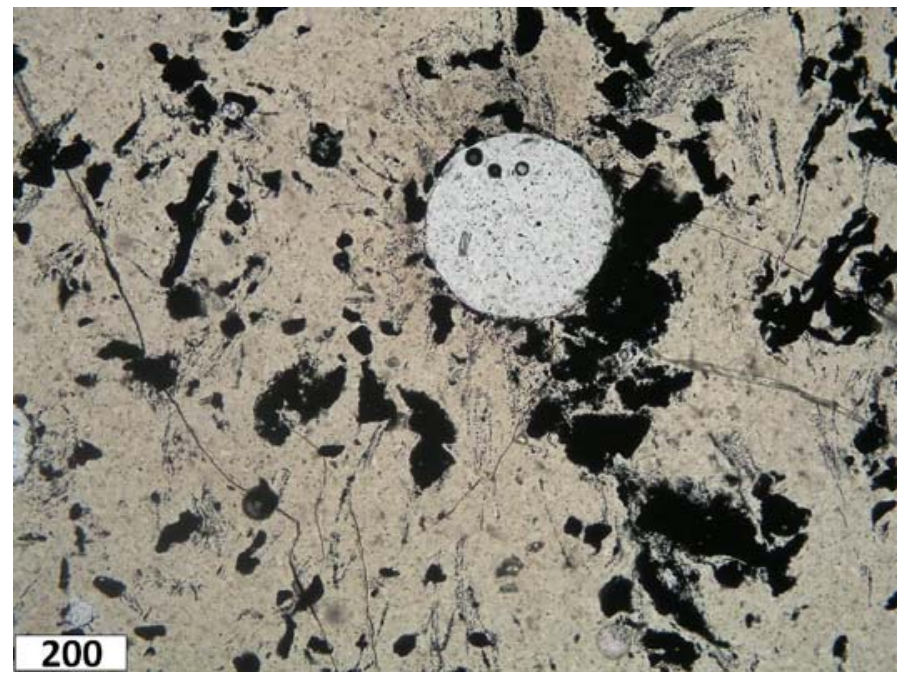

Figure 10. Microphotograph at single Nichol of the lapping of the sample \#43. 
The lapping of the sample \#45 is composed of yellow-green glass with minor spinel content ( $\sim 10$ vol.\%) - see Figure 12. Major spinel forms isomeric grains. Cubic microcrystals with wavybanded distribution are present in local areas. Isolated gas bubbles $10-20 \mu \mathrm{m}$ in diameter also occur. In crossed Nichols areas with weakly appeared double reflection probably due to initial stage of glass devitrification were found.

The lapping of the sample \#46 (Figure 13) is composed of non-uniformly colored (from clear transparent to light-yellow) glass with minor spinel (5-10 vol.\%). Major spinel is isometric randomly distributed grains. Minor spinel is is cubic microcrystals occurred in local areas. The latter forms short discontinuous bands. Glass contains numerous small gas bubbles. Most of them are $<20 \mu \mathrm{m}$ in diameter.

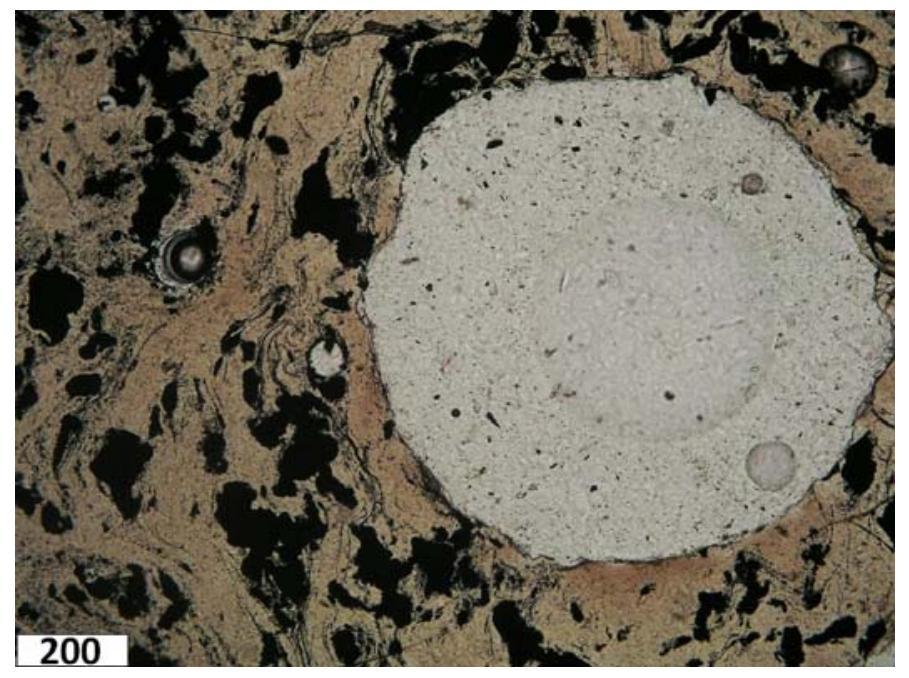

Figure 11. Microphotograph at single Nichol of the lapping of the sample \#44.

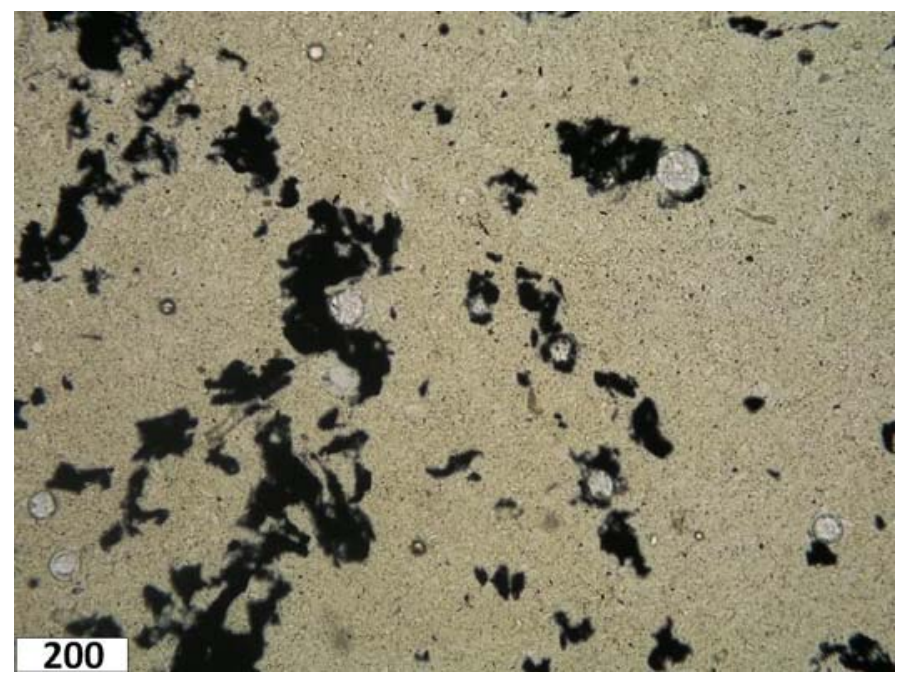

Figure 12. Microphotograph at single Nichol of the lapping of the sample \#45. 


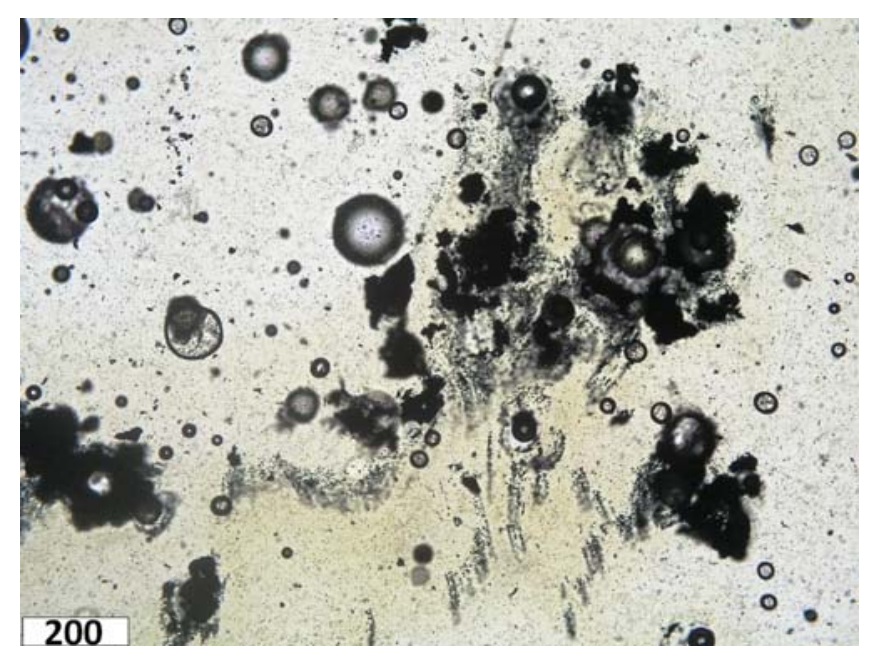

Figure 13. Microphotograph at single Nichol of the lapping of the sample \#46.

Major features of all the samples are as follows:

- All the samples are composed of major glass and minor spinel;

- All the samples contain gas bubbles with variable diameter (from $<10 \mu \mathrm{m}$ to $>1 \mathrm{~mm}$ );

- Coloring of glass varies from nearly clear to brown;

- Spinel forms both isometric grains and cubic microcrystals $(\sim 1 \mu \mathrm{m})$;

- Microcrystals are aggregated in bands with variable glass and spinel contents;

- Relative location of the bands is caused by flowing of various portion of glassmelt with various viscosity;

- Wavy profile of the bands is similar to that in volcanic glasses with fluidal texture;

- No devitrification of glass was found.

Major differences between the samples are as follows:

- The samples (possibly various parts of the same sample as well) are different in quantitative glass to spinel ratio;

- Significant differences was found in a ratio of isometric grains to cubic microcrystals;

- Fluidal texture is variably appeared; in some samples fluidity takes place only in local areas or absent at all;

- Degree of cracking in the lappings is widely varied.

\section{IR spectroscopic study}

IR spectra of all the samples are similar (Figures 14 and 15). IR spectra of glasses (Figure 16) consist of the bands due to stretching $\left(3100-3600 \mathrm{~cm}^{-1}\right)$ and bending modes $\left(1600-1800 \mathrm{~cm}^{-1}\right)$ in the molecules of absorbed and structurally bound water, weak bands due to hydrogen bonds in the structure of glasses and numerous bands lower $1600 \mathrm{~cm}^{-1}$ due to stretching and bending modes in the units forming anionic motif of the structure of glasses. 


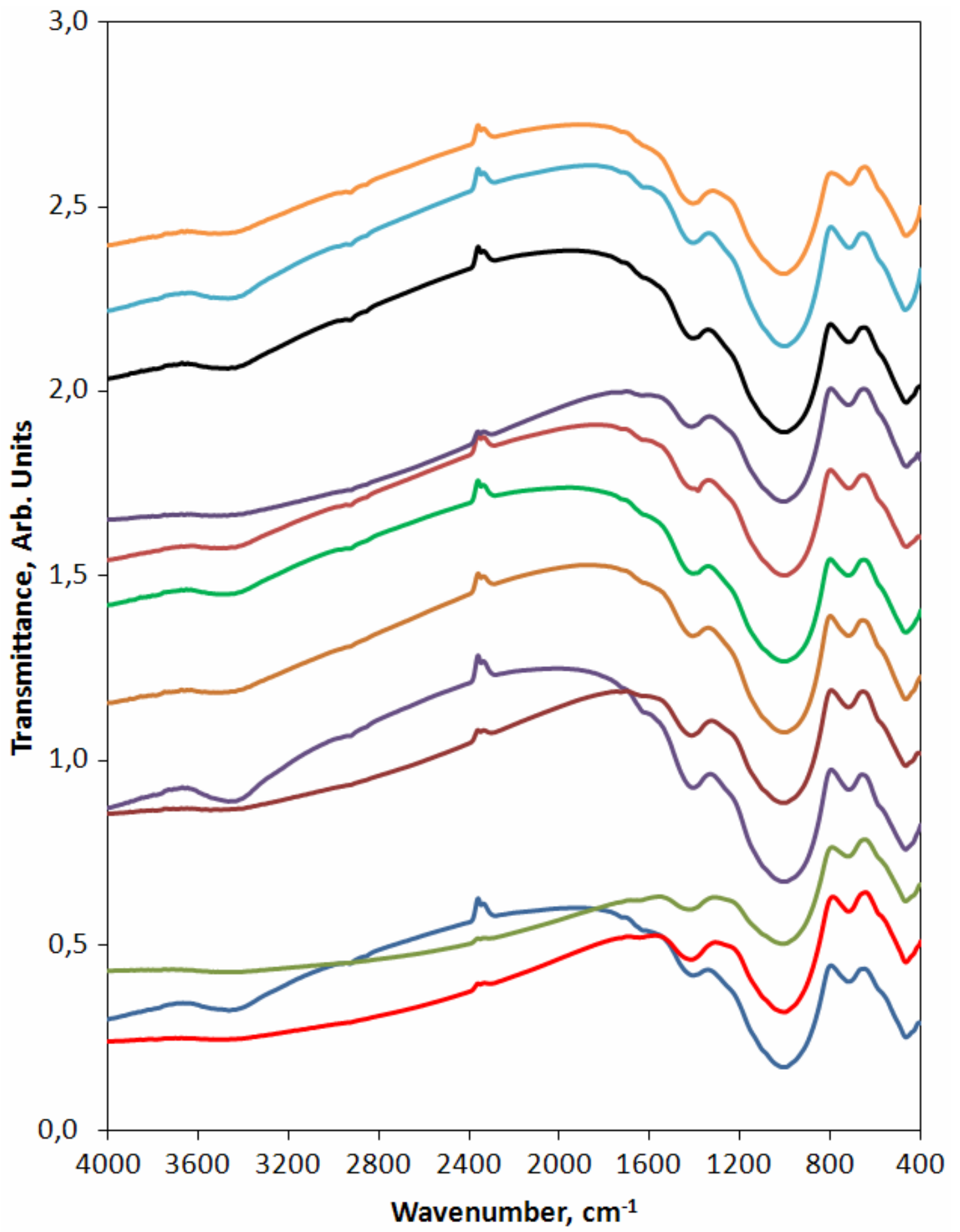

$\begin{array}{lll}\text {-MRF-10-35 } & \text {-MRF-10-36 } & \text {-MRF-10-37 } \\ \text {-MRF-10-38 } & \text {-MRF-10-39 } & \text {-MRF-10-40 } \\ \text {-MRF-10-41 } & \text {-MRF-10-42 } & \text {-MRF-10-43 } \\ \text {-MRF-10-44 } & \text {-MRF-10-45 } & \text {-MRF-10-46 }\end{array}$

Figure 14. IR spectra of the samples within the range of $4000-400 \mathrm{~cm}^{-1}$. 


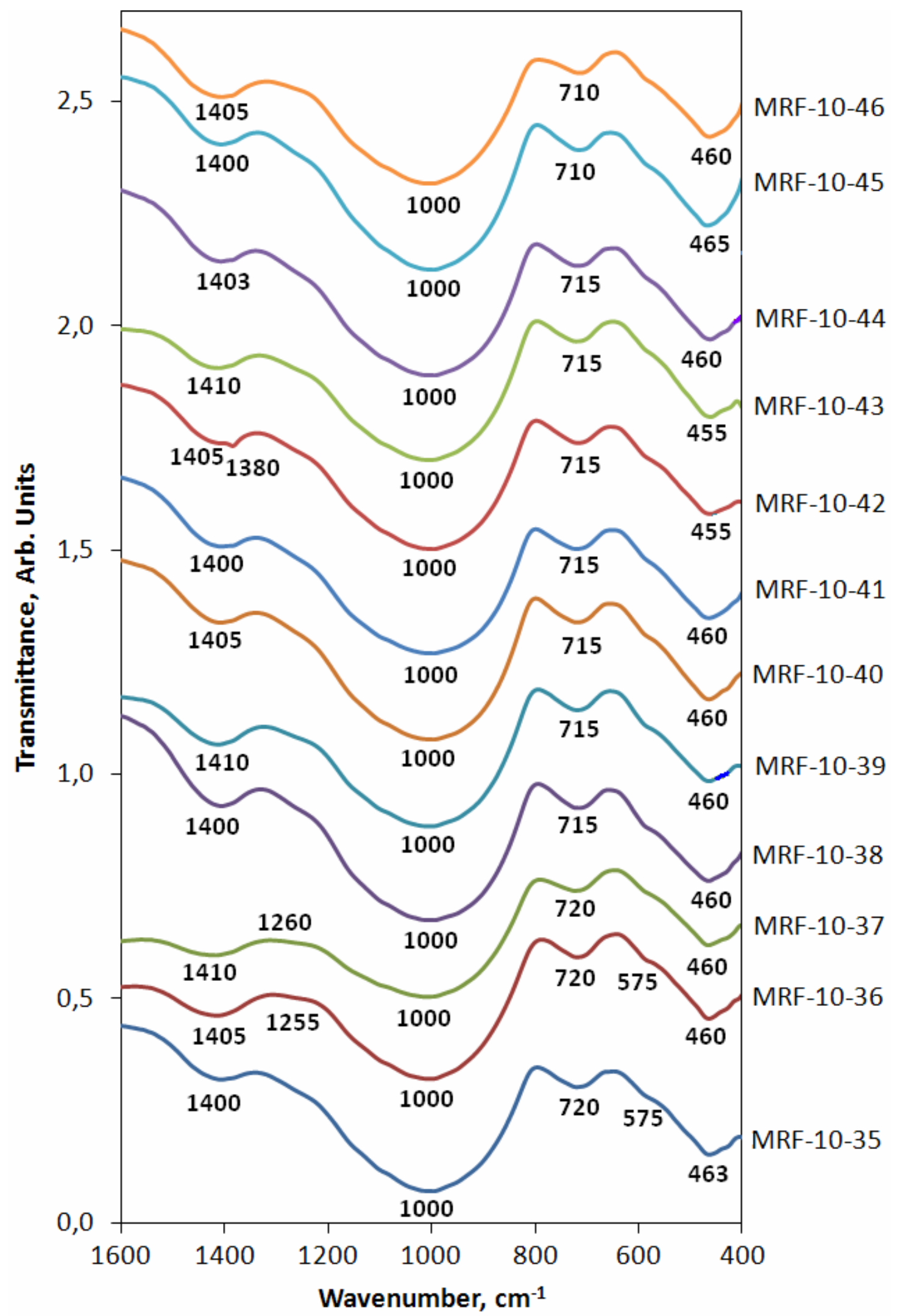

Figure 15. Fragments of IR spectra of the samples within the range of $1600-400 \mathrm{~cm}^{-1}$. 
IR spectra of all the glasses within the range of $4000-1600 \mathrm{~cm}^{-1}$ (Figure 14) consist of the bands due to stretching and bending modes in silicon-oxygen, boron-oxygen, aluminum-oxygen and iron-oxygen (in spectra of glasses A1, B1 and D1 only) structural groups. The wavenumber ranges of $1550-1300 \mathrm{~cm}^{-1}$ and $\sim 1260-1270 \mathrm{~cm}^{-1}$ are typical of vibrations in the boron-oxygen groups with trigonally coordinated boron (boron-oxygen triangles $\mathrm{BO}_{3}$ ) [7]. These bands were attributed as components of twice degenerated asymmetric valence $v_{3} \mathrm{O}-\mathrm{B}-\mathrm{O}$ vibrations (stretching modes). The band with components $\sim 710-730$ and $650-670 \mathrm{~cm}^{-1}$ may be associated with twice degenerated asymmetric deformation $\delta\left(v_{4}\right) \mathrm{O}-\mathrm{B}-\mathrm{O}$ vibrations (bending modes) [7]. Strong absorption in both IR and Raman spectra within the range of $1150-850 \mathrm{~cm}^{-1}$ is caused by asymmetric $v_{3}$ vibrations (stretching modes) in silicon-oxygen units bound to zero $(850-900 \mathrm{~cm}$ $\left.{ }^{1}\right)$, one $\left(\sim 900-950 \mathrm{~cm}^{-1}\right)$, two $\left(\sim 950-1050 \mathrm{~cm}^{-1}\right)$, three $\left(\sim 1050-1100 \mathrm{~cm}^{-1}\right)$ and four $(\sim 1100-1150$ $\left.\mathrm{cm}^{-1}\right)$ neighboring $\mathrm{SiO}_{4}$ tetrahedra $\left(\mathrm{Q}^{0}, \mathrm{Q}^{1}, \mathrm{Q}^{2}, \mathrm{Q}^{3}, \mathrm{Q}^{4}\right.$, respectively) [8] and, in less extent, $\mathrm{BO}_{4}$ tetrahedra $\left(1000-1100 \mathrm{~cm}^{-1}\right)$ [9]. In IR spectra of all the glasses the broad band within the range of $\sim 800-1200 \mathrm{~cm}^{-1}$ is multicomponent due to superposition of vibrations (stretching modes) in $\mathrm{SiO}_{4}$ and $\mathrm{BO}_{4}$ tetrahedra. Stretching modes of $\mathrm{Al}-\mathrm{O}$ bonds in $\mathrm{AlO}_{4}$ tetrahedra and $\mathrm{Fe}-\mathrm{O}$ bonds in $\mathrm{FeO}_{4}$ tetrahedra are positioned at $700-800 \mathrm{~cm}^{-1}$ and $550-650 \mathrm{~cm}^{-1}$, respectively. Bending modes of $\mathrm{Si}-\mathrm{O}-\mathrm{Si}$ bonds in $\mathrm{SiO}_{4}$ tetrahedra are positioned within the range of $350-550 \mathrm{~cm}^{-1}$.

As seen from Figure 14, the bands at 3300-3600 $\mathrm{cm}^{-1}$ and $1620-1650 \mathrm{~cm}^{-1}$ are correlated on intensity and they may be attributed to stretching and bending modes in molecules of absorbed or structurally-bound water [10]. In the spectra of all the glasses the bands due to vibrations in water molecules or $\mathrm{Me}-\mathrm{O}-\mathrm{H}$ bonds have much lower intensity than the bands due to vibration in anionic motif of the glass structure.

The IR spectra of all the glasses within the range of $1600-400 \mathrm{~cm}^{-1}$ are similar (Figure 15). This indicates that all the glasses have similar structure of their anionic motif. As follows from position of major maximum of the strongest band $1200-800 \mathrm{~cm}^{-1}\left(\sim 1000 \mathrm{~cm}^{-1}\right)$ the base of structural network is metasilicate chains and rings where the $\mathrm{Q}^{2}$ units are predominant. Bridging bonds $\mathrm{Si}-\mathrm{O}-\mathrm{Fe}$ and $\mathrm{Si}-\mathrm{O}-\mathrm{Al}$ bonding $\mathrm{SiO}_{4}$ and $\mathrm{FeO}_{4}$ and $\mathrm{AlO}_{4}$ tetrahedra and thus increasing the degree of connectedness of the glass network are positioned within the range of $950-880 \mathrm{~cm}^{-1}$ and may contribute to lower wavenumber edge of the band $1200-800 \mathrm{~cm}^{-1}$. The bans with a maximum at $455-463 \mathrm{~cm}^{-1}$ is due to bending modes in $\mathrm{SiO}_{4}$ tetrahedra and $\mathrm{Si}-\mathrm{O}-\mathrm{Si}$ bonds (in the most extent) and $\mathrm{Si}-\mathrm{O}-\mathrm{Al}$ and $\mathrm{Si}-\mathrm{O}-\mathrm{Fe}$ bonds (in less extent). The band with a maximum at $710-720 \mathrm{~cm}^{-1}$ is due to superposition of symmetric stretching modes in $\mathrm{SiO}_{4}$ tetrahedra and asymmetric stretching modes in $\mathrm{AlO}_{4}$ tetrahedra. Weak band observed as a shoulder at $\sim 575 \mathrm{~cm}^{-1}$ is due to vibrations in $\mathrm{FeO}_{4}$ tetrahedra. Boron in these glasses is predominantly threefold-coordinated and occurs as boron-oxygen triangles. Part of them possibly enters complex borate groups bound with boron-oxygen tetrahedra.

Thus, the structural network is primarily composed of metasilicate chains and rings with embedded $\mathrm{AlO}_{4}$ and $\mathrm{FeO}_{4}$ tetrahedra. Boron-oxygen constituent exists separately.

\section{Raman spectroscopic study}

Raman spectra of the glassy samples are shown on Figure 16. Depolarized spectra are given on Figure 17. Spectra of the samples \#\#39, 40, 44 and 45 differ markedly from the rest spectra. These glasses seem to be higher structured or contain higher amount of crystalline phase (spinel). 


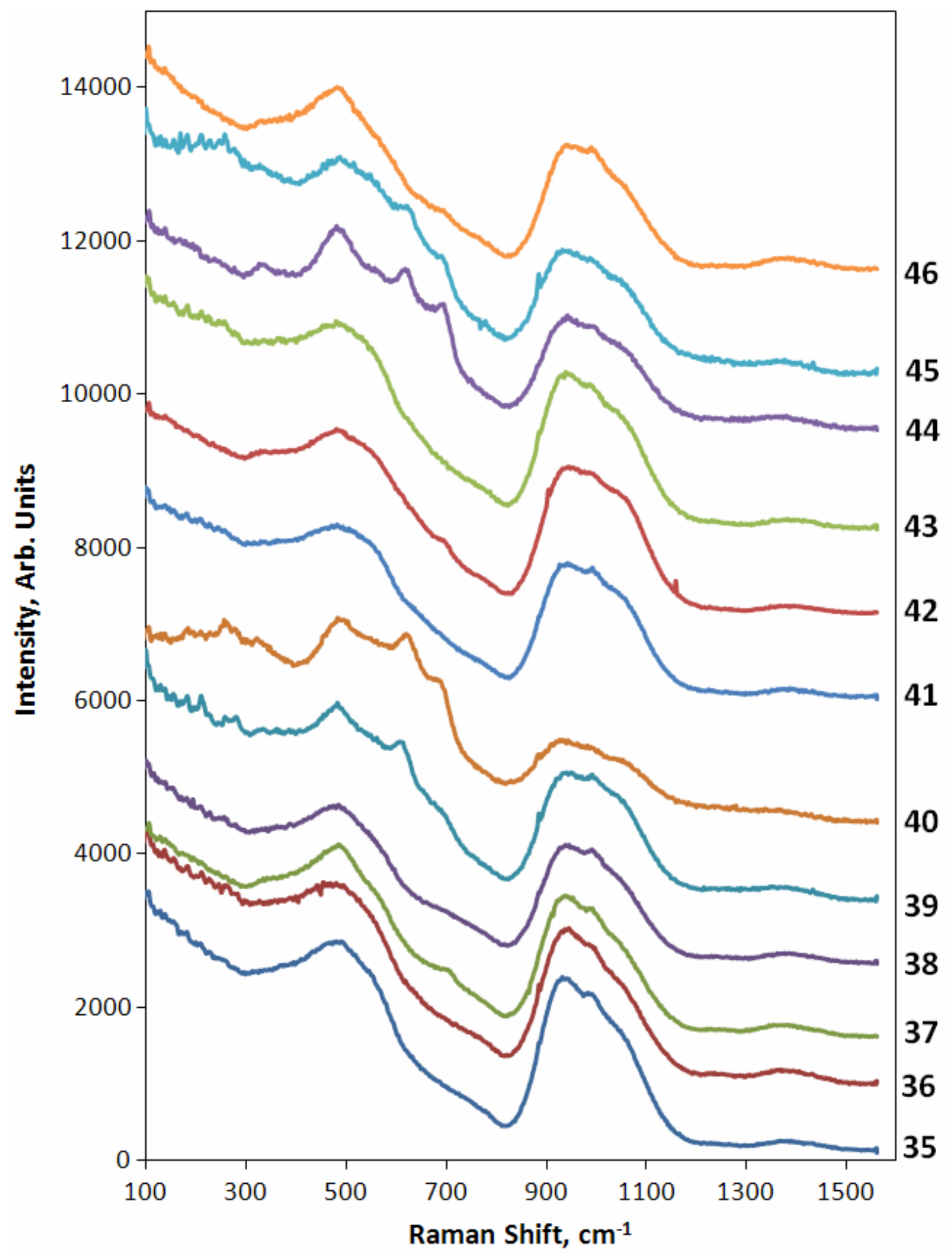

Figure 16. Raman spectra of the samples. 


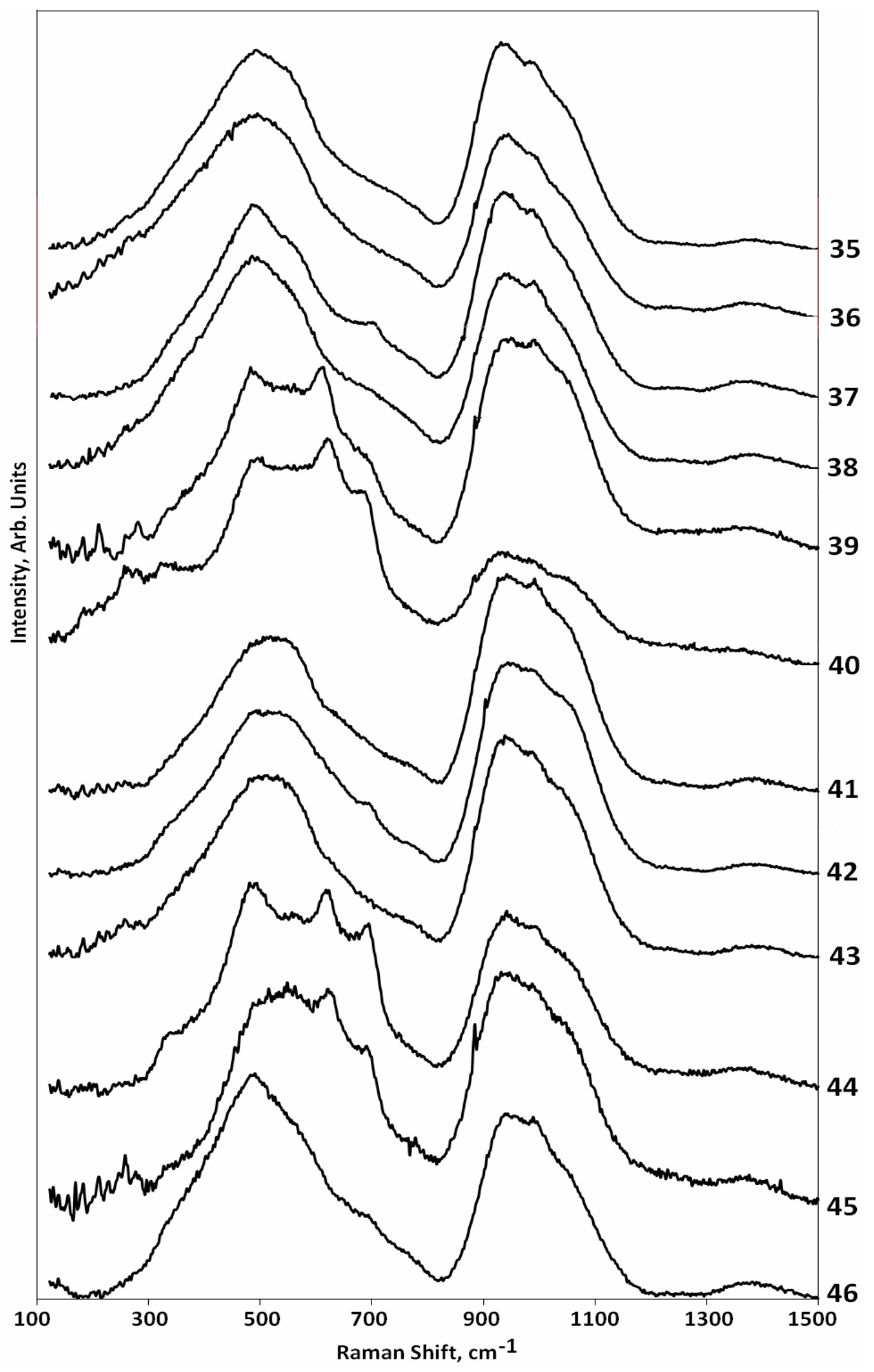

Figure 17. Depolarized Raman spectra of the samples. 
All the spectra consist of the bands within the ranges of $300-600 \mathrm{~cm}^{-1}, 800-1150 \mathrm{~cm}^{-1}$ and weak bands at $650-800 \mathrm{~cm}^{-1}$ and $1200-1300 \mathrm{~cm}^{-1}$ and $1300-1500 \mathrm{~cm}^{-1}$. Like in IR spectra these bands are due to bending and stretching modes in silicon-oxygen network, and vibrations in $\mathrm{AlO}_{4}, \mathrm{FeO}_{4}$ and $\mathrm{BO}_{3}$ units. In the whole Raman spectroscopic data are in a good agreement with IR spectroscopic data but computer fitting allows to distinguishing more details (Figures 18-29).

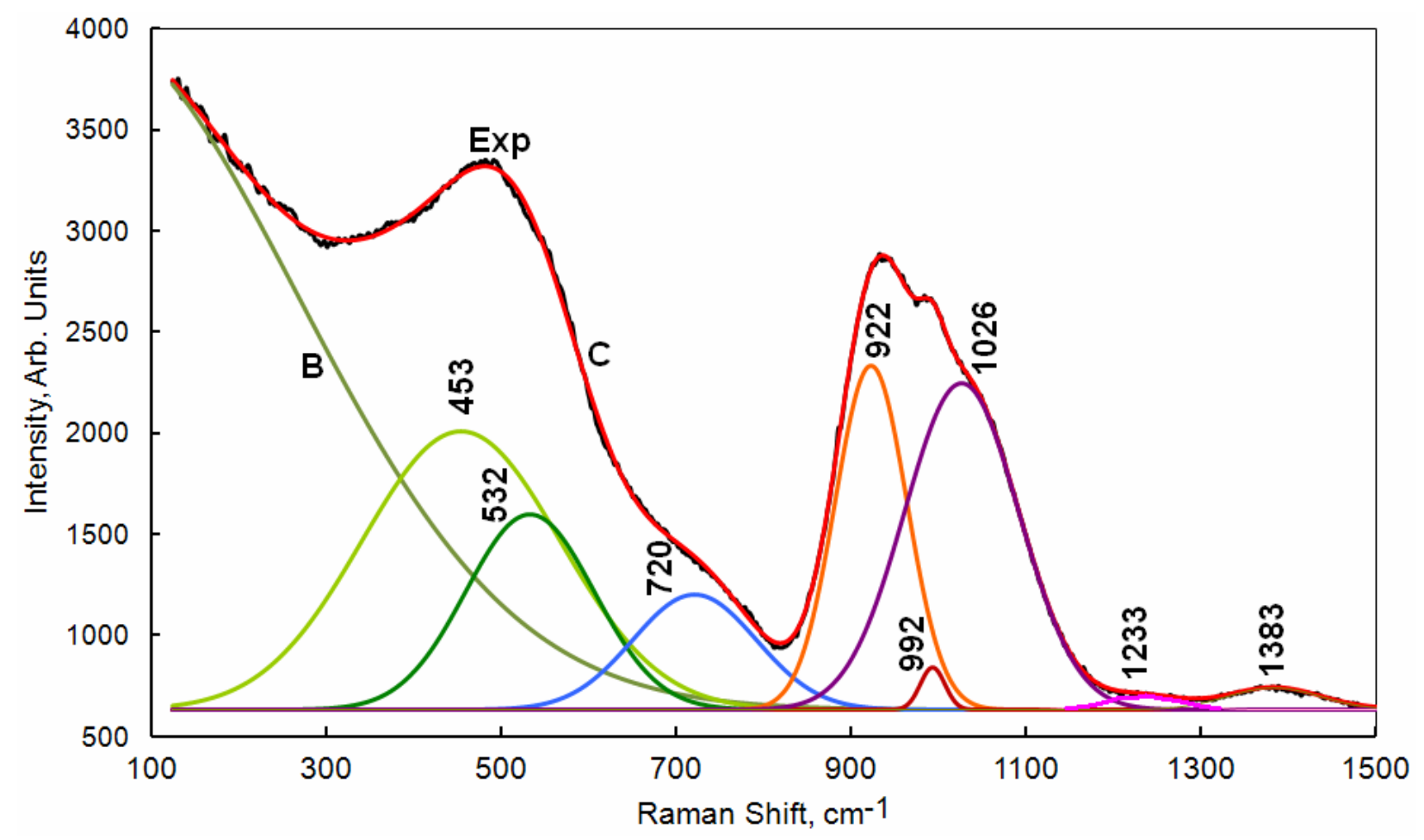

Figure 18. Computer fitting of the Raman spectra of the sample \#35.

In the spectrum of the glassy material \#35 (Figure 18) strong bands with maxima at $453 \mathrm{~cm}^{-1}$, $922 \mathrm{~cm}^{-1}$ and $1026 \mathrm{~cm}^{-1}$ are due to bending and stretching modes in $\mathrm{SiO}_{4}$ tetrahedra and bridging bonds $\mathrm{Si}-\mathrm{O}-\mathrm{Si}$ bonding $\mathrm{SiO}_{4}$ tetrahedra. Some contribution to the band with maximum at 922 $\mathrm{cm}^{-1}$ may be made by vibrations of $\mathrm{Si}-\mathrm{O}-\mathrm{Al}$ and $\mathrm{Si}-\mathrm{O}-\mathrm{Fe}$ bridging bonds. The latter were suggested to be responsible for the band with a maximum at $910 \mathrm{~cm}^{-1}$ observed in Raman spectra of Fe-containing silicate glasses [11]. If so, the contribution of such bonds is rather minor because of low $\mathrm{Fe}_{2} \mathrm{O}_{3}$ content in glass. The band with a maximum at $532 \mathrm{~cm}^{-1}$ may be assigned to bending vibrations of $\mathrm{Si}-\mathrm{O}-\mathrm{Si}\left(v_{4}\right) \mathrm{Si}-\mathrm{O}-\mathrm{Al}$ and $\mathrm{Si}-\mathrm{O}-\mathrm{Fe}$ bridging bonds. The band with a maximum at $720 \mathrm{~cm}^{-1}$ is due probably to bending modes in $\mathrm{AlO}_{4}$ tetrahedra. Weak bands at $1383 \mathrm{~cm}^{-1}$ and $1233 \mathrm{~cm}^{-1}$ are due to vibrations in $\mathrm{BO}_{3}$ units with various degree of polymerization. The band at $1233 \mathrm{~cm}^{-1}$ may be also attributed to stretching vibrations of $\mathrm{B}^{\mathrm{III}}-\mathrm{O}-\mathrm{B}^{\mathrm{IV}}$ bridging bonds. Since glass $\# 35$ has a value of $\psi_{\mathrm{B}}$ factor equal to approximately 2 weak band with a maximum at $992 \mathrm{~cm}^{-1}$ may be assigned to stretching vibrations in $\mathrm{BO}_{4}$ tetrahedra.

Glass \#36 has higher $\mathrm{B}_{2} \mathrm{O}_{3}$ content $\left(8.62 \mathrm{~mol} . \%\right.$ ) and lower $\psi_{\mathrm{B}}$ value than the glass \#35 (Table II). Therefore, fraction of trigonally-coordinated boron in them should be higher. It is seen well 
that intensities of the bands with maxima at $1241 \mathrm{~cm}^{-1}$ and $1376 \mathrm{~cm}^{-1}$ are higher than in the spectrum of the glass \#35 (Figure 19). In the whole the spectra of both glasses are similar and differ slightly only in maxima of the bands.

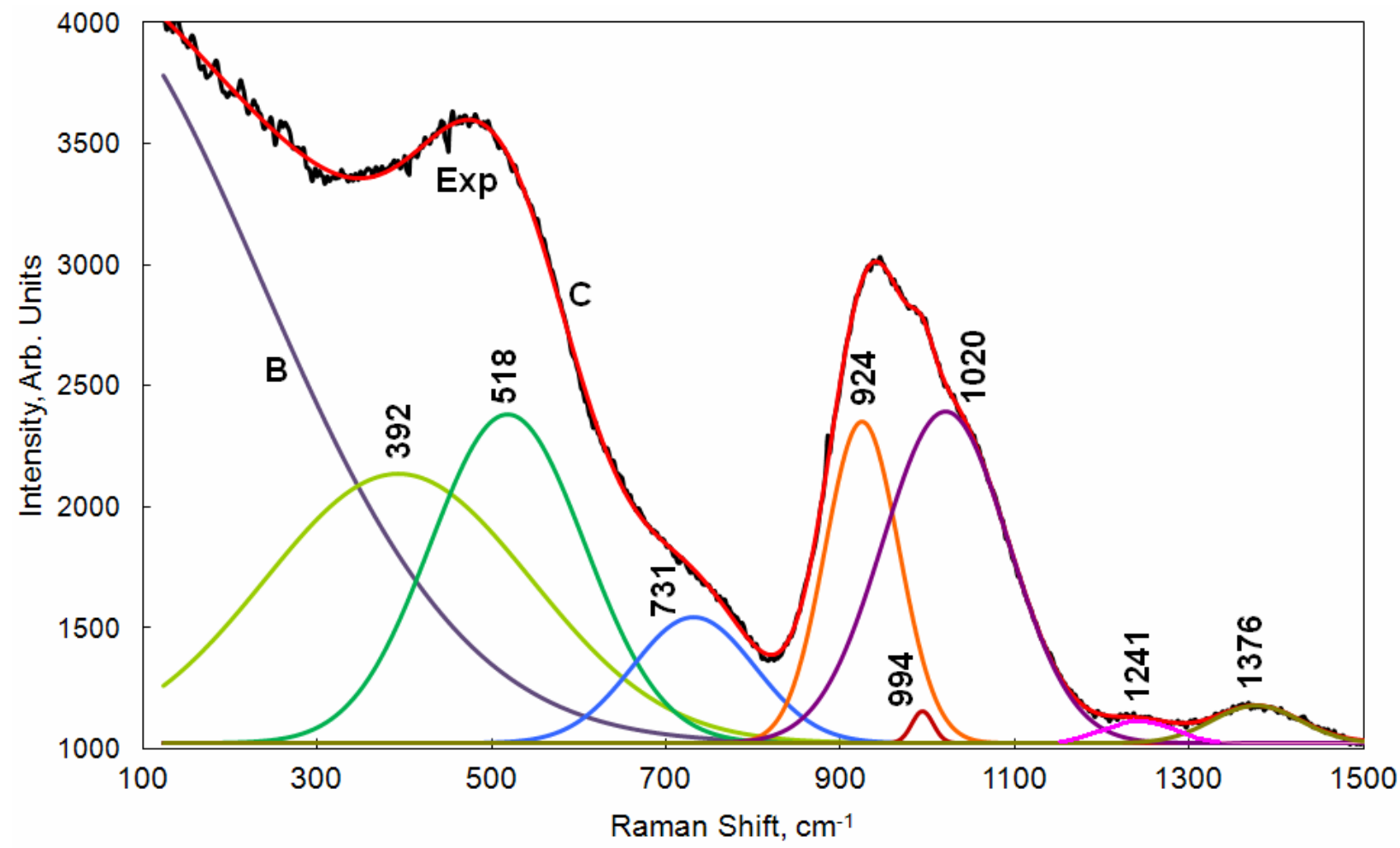

Figure 19. Computer fitting of the Raman spectra of the sample \#36.

The spectrum of the glass \#37 is some more complicated (Figure 20). Except the bands observed in the spectra of the samples \#35 and \#36 (maxima at $503 \mathrm{~cm}^{-1}, 924 \mathrm{~cm}^{-1}, 994 \mathrm{~cm}^{-1}, 1020 \mathrm{~cm}^{-1}$, $1241 \mathrm{~cm}^{-1}$ and $1376 \mathrm{~cm}^{-1}$ ) additional bands with maxima $346 \mathrm{~cm}^{-1}, 486 \mathrm{~cm}^{-1}$ were found. The band at $650-800 \mathrm{~cm}^{-1}$ is split into two components: $700 \mathrm{~cm}^{-1}$ and $771 \mathrm{~cm}^{-1}$. Weak bands at 346 $\mathrm{cm}^{-1}, 486 \mathrm{~cm}^{-1}$ and stronger band with a maximum at $700 \mathrm{~cm}^{-1}$ may be attributed to vibrations in $\mathrm{AlO}_{6}, \mathrm{AlO}_{5}$ and $\mathrm{AlO}_{4}$ polyhedra. The band with a maximum at $771 \mathrm{~cm}^{-1}$ is due probably to symmetric stretching $\left(v_{1}\right)$ modes $\mathrm{in}^{\mathrm{SiO}_{4}}$ tetrahedra.

The spectrum of the glass \#38 (Figure 21) is similar to those of the glasses \#35 (Figure 18) and \#36 (Figure 19). The difference between them is in positions of maxima of the bands. In the spectrum of the glass \#38 they are as follows: $348 \mathrm{~cm}^{-1}, 507 \mathrm{~cm}^{-1}, 714 \mathrm{~cm}^{-1}, 923 \mathrm{~cm}^{-1}, 995 \mathrm{~cm}^{-1}$, $1022 \mathrm{~cm}^{-1}, 1235 \mathrm{~cm}^{-1}$, and $1383 \mathrm{~cm}^{-1}$. If attribution of the bands with maxima at $507 \mathrm{~cm}^{-1}, 714$ $\mathrm{cm}^{-1}, 923 \mathrm{~cm}^{-1}, 1022 \mathrm{~cm}^{-1}, 1235 \mathrm{~cm}^{-1}$, and $1383 \mathrm{~cm}^{-1}$ is rather unambiguous, then assignment of the bands with maxima at $348 \mathrm{~cm}^{-1}$ and $995 \mathrm{~cm}^{-1}$ is indefinitive. As in the spectrum of other glasses the band with a maximum at $995 \mathrm{~cm}^{-1}$ may be due to stretching vibrations in $\mathrm{BO}_{4}$ tetrahedra or $\mathrm{Si}-\mathrm{O}-\mathrm{B}$ bridging bonds. This band has low intensity that is consistent well with low $\mathrm{B}_{2} \mathrm{O}_{3}$ content in glasses. 


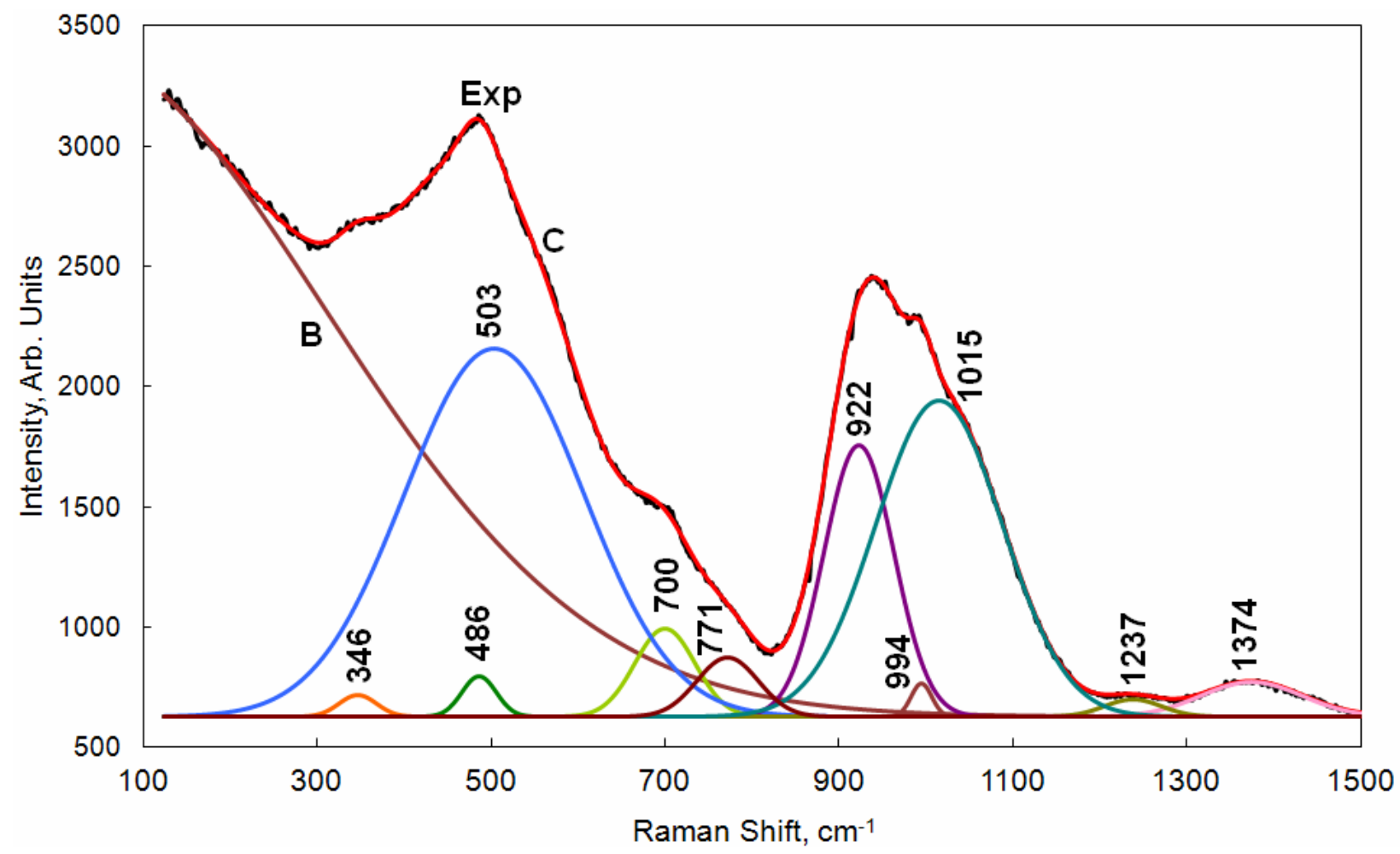

Figure 20. Computer fitting of the Raman spectra of the sample \#37.

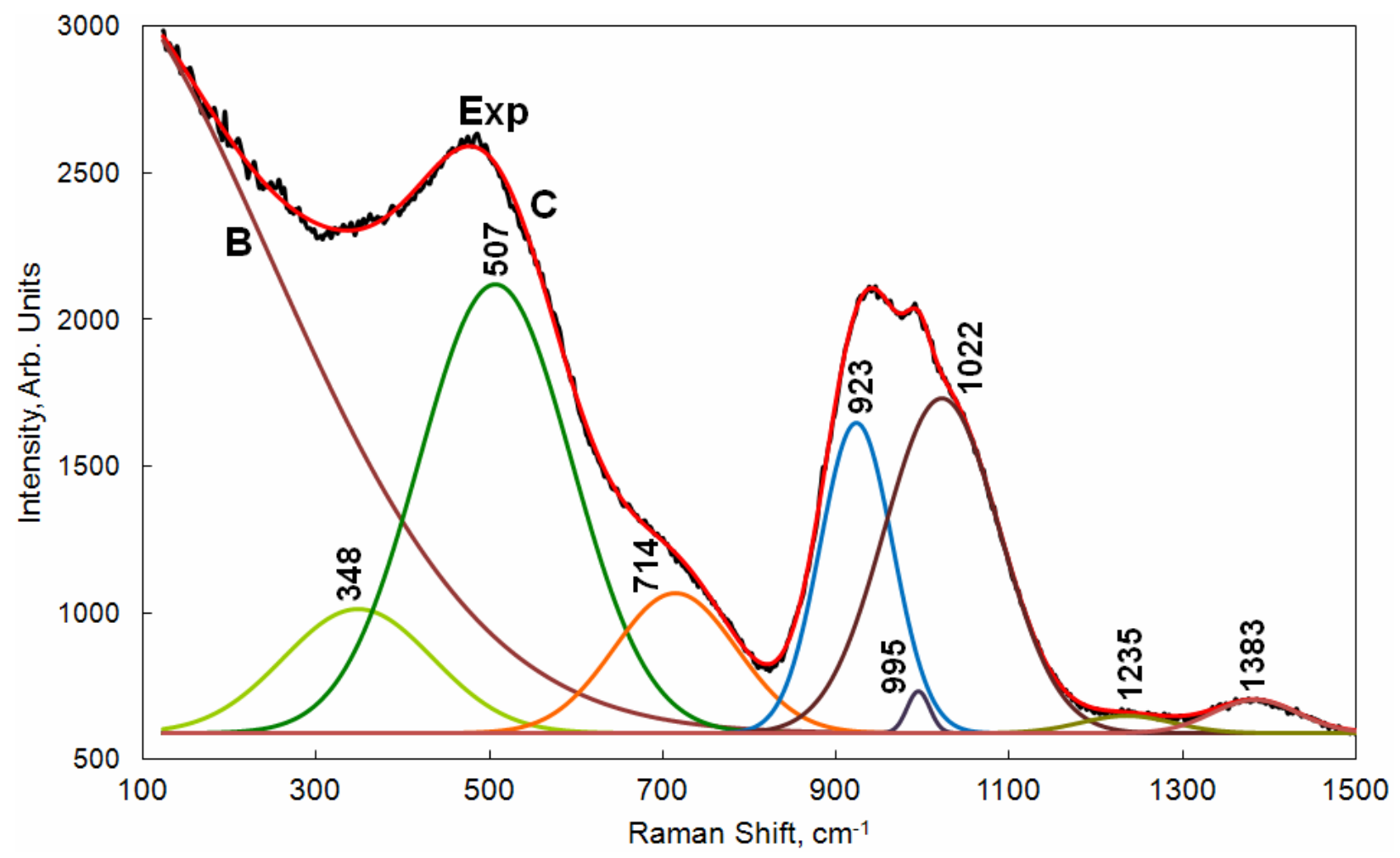

Figure 21. Computer fitting of the Raman spectra of the sample \#38. 
Raman spectrum of the glass \#39 (Figure 22) is markedly different from spectra of previous glasses. Along with the bands observed in spectra of other glasses $\left(539 \mathrm{~cm}^{-1}, 935 \mathrm{~cm}^{-1}, 993 \mathrm{~cm}^{-1}\right.$, $\left.1030 \mathrm{~cm}^{-1}, 1246 \mathrm{~cm}^{-1}, 1386 \mathrm{~cm}^{-1}\right)$ it contains weak bands with maxima at $480 \mathrm{~cm}^{-1}, 613 \mathrm{~cm}^{-1}$, $687 \mathrm{~cm}^{-1}$, and $890 \mathrm{~cm}^{-1}$. The first three bands may be assigned to vibrations in $\mathrm{AlO}_{6}, \mathrm{AlO}_{5}$ and $\mathrm{AlO}_{4}$ polyhedra, whereas the band with a maximum at $890 \mathrm{~cm}^{-1}-$ to stretching vibrations of $\mathrm{Si}-\mathrm{O}-\mathrm{Al}$ bridging bonds.

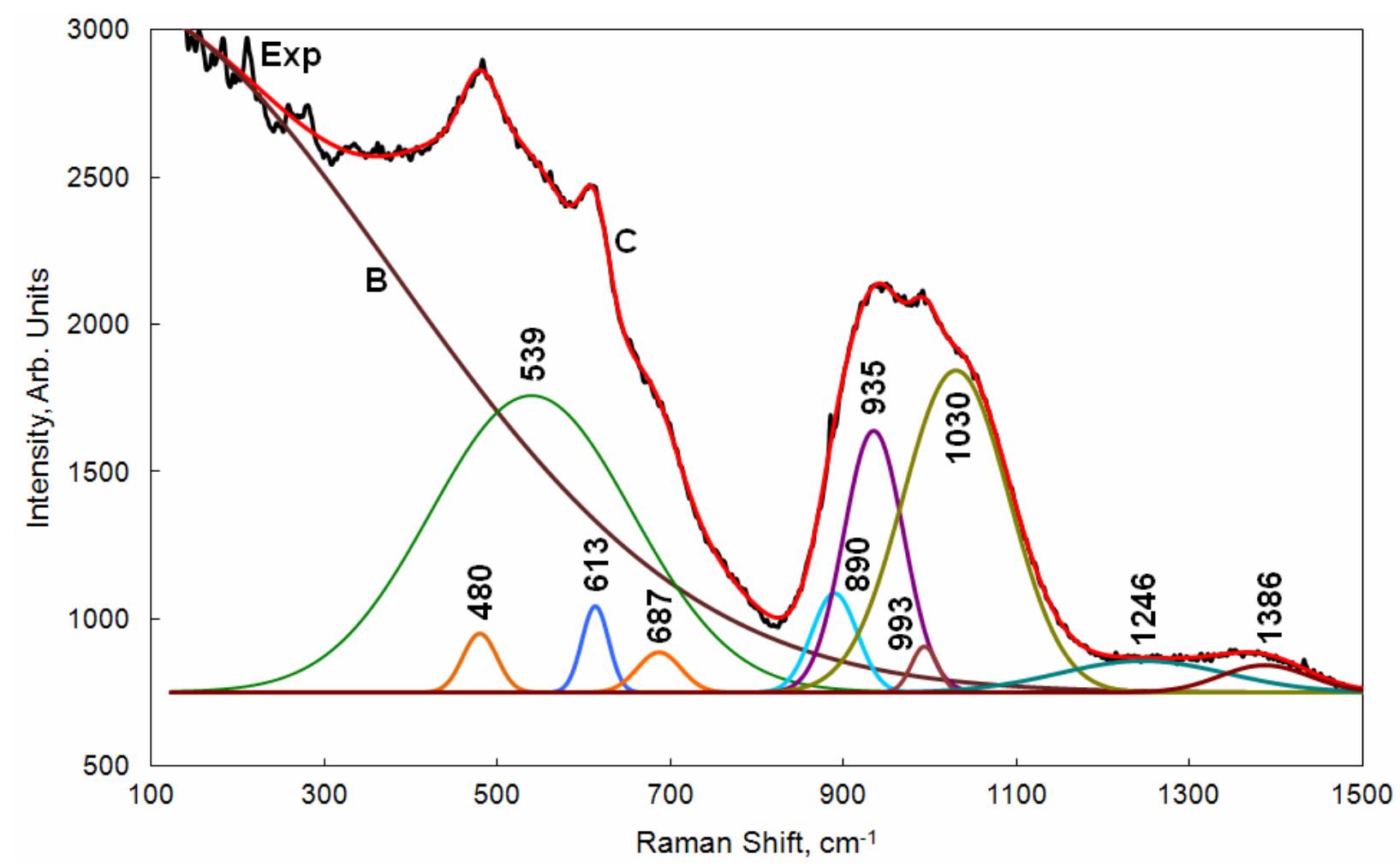

Figure 22. Computer fitting of the Raman spectra of the sample \#39.

Raman spectrum of the glass \#40 consists of numerous bands: strong broad with maxima at 327 $\mathrm{cm}^{-1}, 570 \mathrm{~cm}^{-1}, 751 \mathrm{~cm}^{-1}, 924 \mathrm{~cm}^{-1}, 1045 \mathrm{~cm}^{-1}$, moderate narrow with maxima at $479 \mathrm{~cm}^{-1}, 629$ $\mathrm{cm}^{-1}, 687 \mathrm{~cm}^{-1}$, weak narrow with a maximum at $991 \mathrm{~cm}^{-1}$, and weak broad with maxima at 1202 $\mathrm{cm}^{-1}$ and $1378 \mathrm{~cm}^{-1}$ (Figure 23).

Similarly to the previous spectra the bands with maxima at $570 \mathrm{~cm}^{-1}, 751 \mathrm{~cm}^{-1}, 924 \mathrm{~cm}^{-1}$, and $1045 \mathrm{~cm}^{-1}$ are due to bending and stretching modes in $\mathrm{SiO}_{4}$ tetrahedra and bridging bonds $\mathrm{Si}-\mathrm{O}-\mathrm{Si}, \mathrm{Si}-\mathrm{O}-\mathrm{Al}$ and $\mathrm{Si}-\mathrm{O}-\mathrm{Fe}$; the bands with maxima at $479 \mathrm{~cm}^{-1}, 629 \mathrm{~cm}^{-1}$ and 687 $\mathrm{cm}^{-1}$ are due to vibrations in $\mathrm{AlO}_{6}, \mathrm{AlO}_{5}$ and $\mathrm{AlO}_{4}$ polyhedra, and bands with maxima at $991 \mathrm{~cm}^{-}$ 1 , and weak bands with maxima at $991 \mathrm{~cm}^{-1}, 1202 \mathrm{~cm}^{-1}$ and $1378 \mathrm{~cm}^{-1}$ are due to vibrations in boron-oxygen constituent of glass network.

The spectrum of the glass \#41(Figure 24) within the range of $850-1200 \mathrm{~cm}^{-1}$ is similar to that of glass \#39 (Figure 22). Therefore attribution of the bands may be same. The range lower $850 \mathrm{~cm}^{-1}$ may be interpreted as superposition of strong band due to bending vibrations in $\mathrm{SiO}_{4}$ tetrahedra and bridging bonds $\mathrm{Si}-\mathrm{O}-\mathrm{Si}(\mathrm{Al}, \mathrm{Fe})$ and weak bands due to vibrations in $\mathrm{MeO}_{\mathrm{x}}$ polyhedra. 


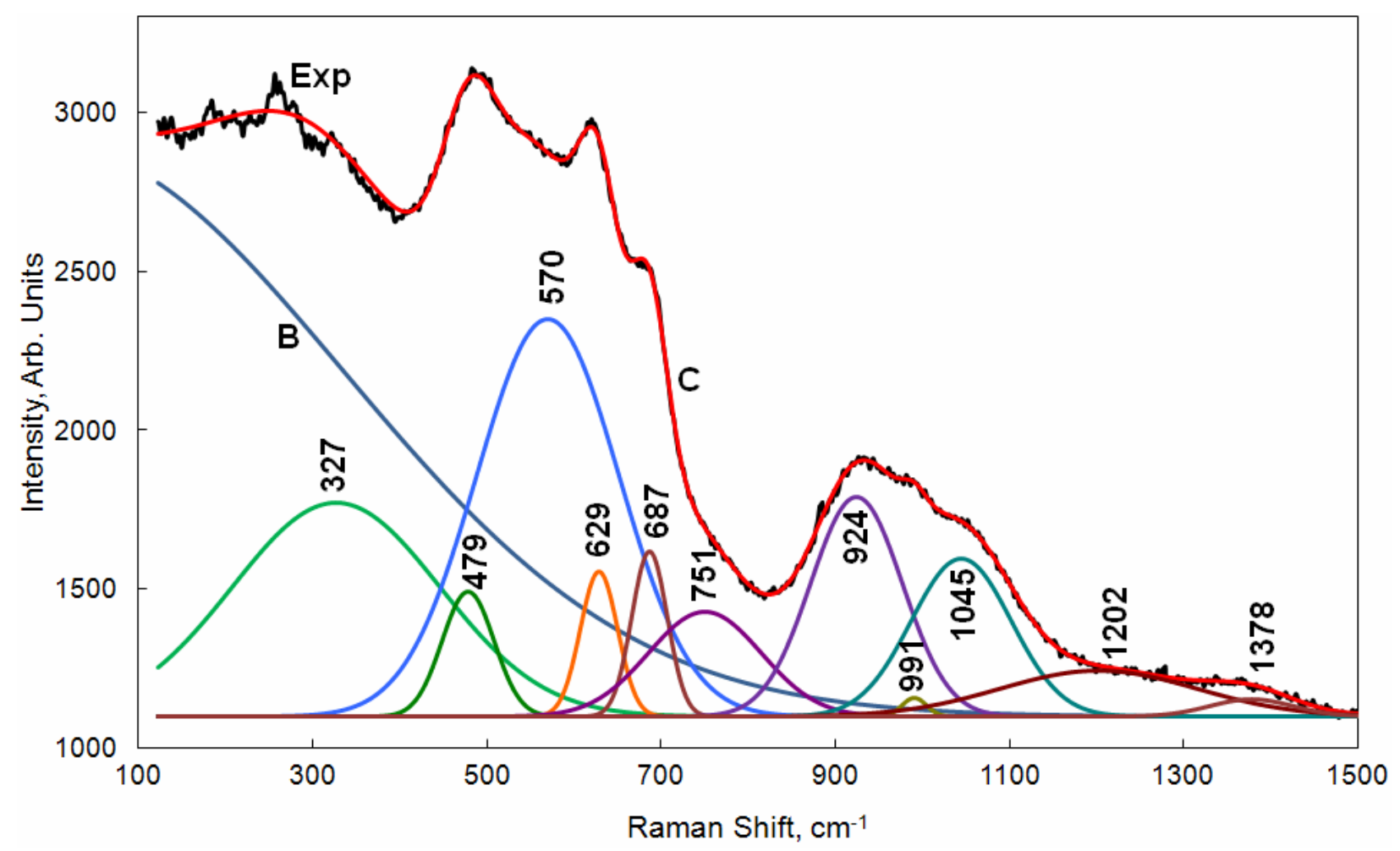

Figure 23. Computer fitting of the Raman spectra of the sample \#40.

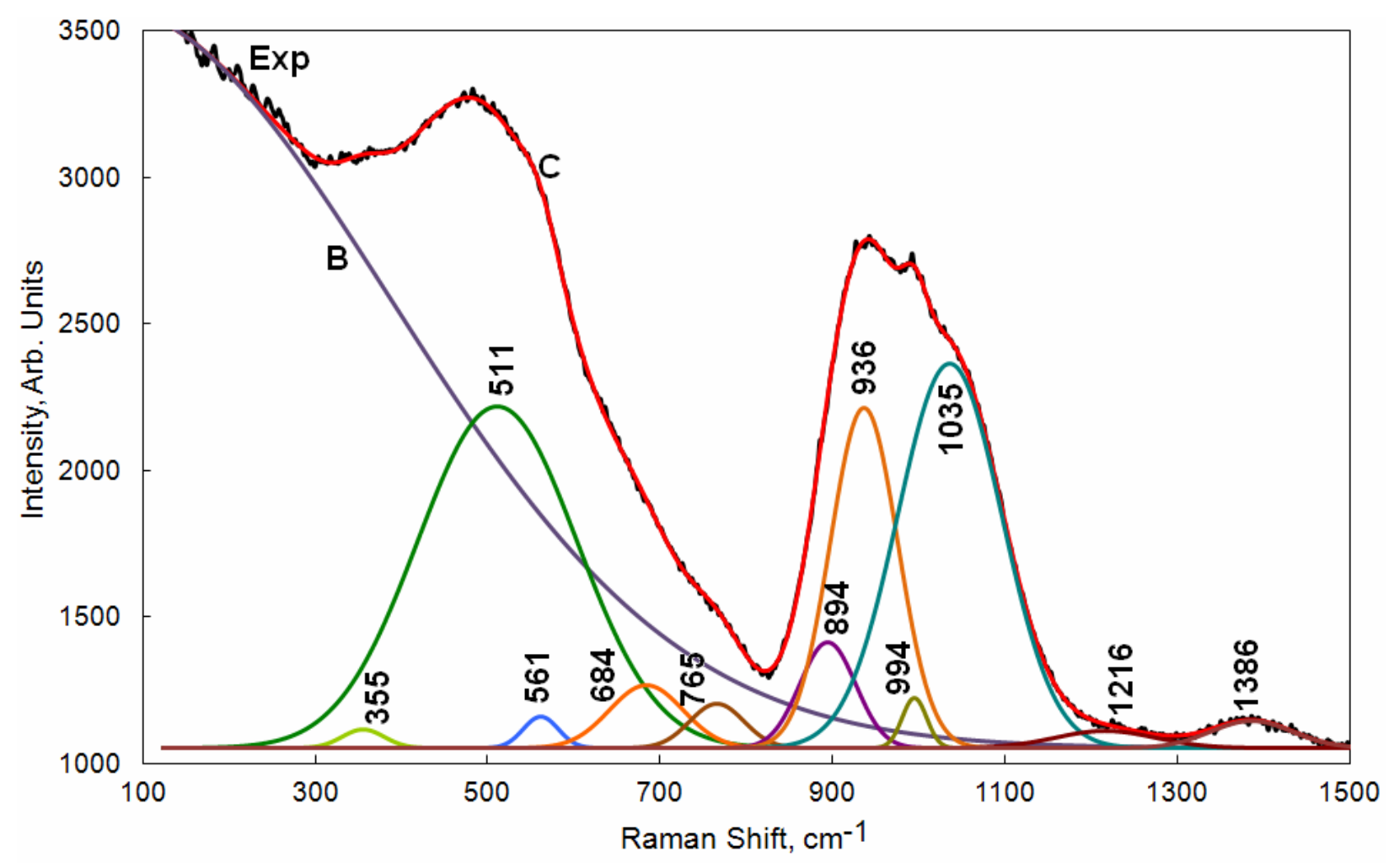

Figure 24. Computer fitting of the Raman spectra of the sample \#41. 
The spectrum of the glasses \#42 (Figure 25), \#43 (Figure 26) and \#48 (Figure 29) like the spectra of other glasses in the same group may be decomposed into the bands due to stretching and bending vibration in silica-oxygen, aluminum-oxygen, iron-oxygen, and boron-oxygen polyhedra.

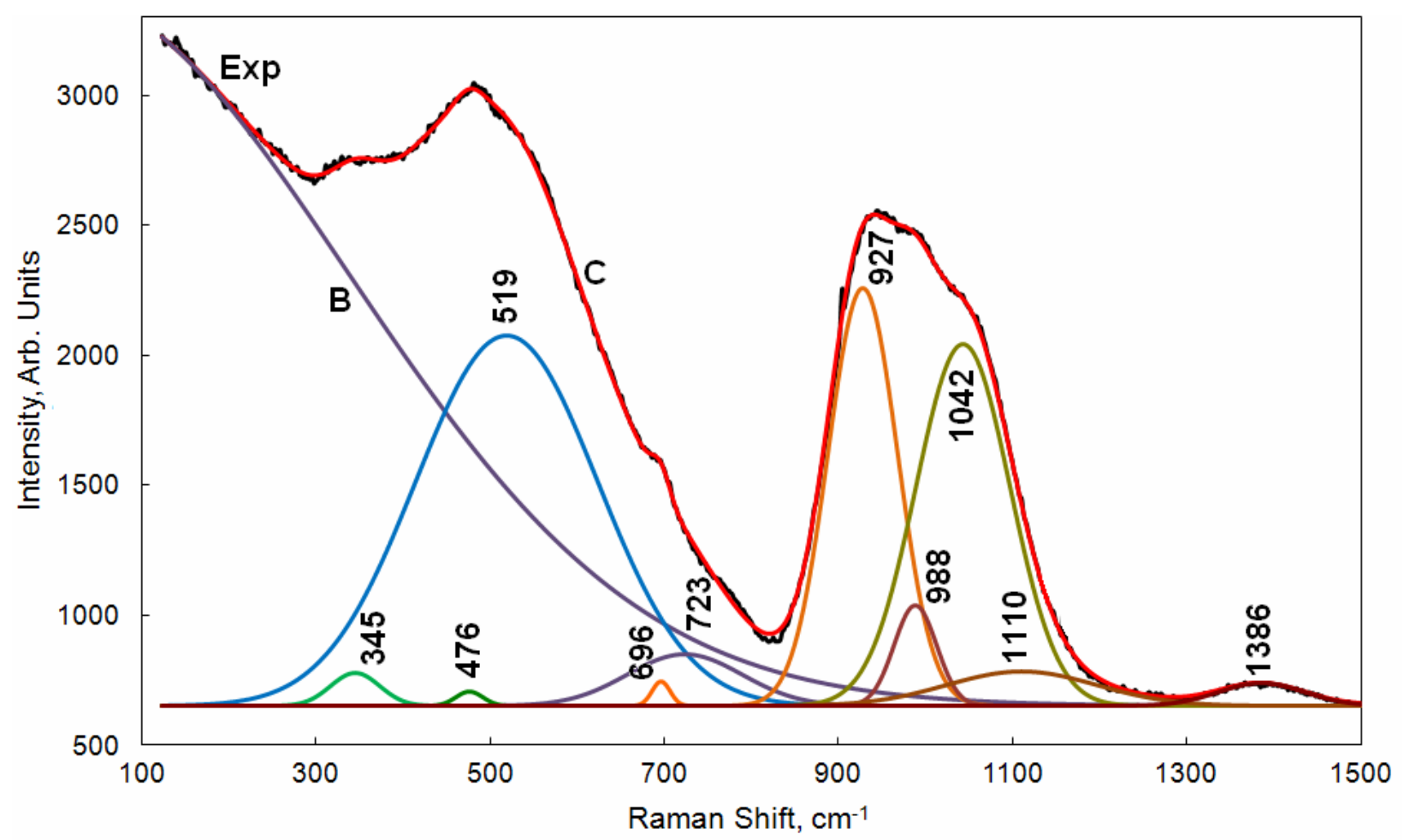

Figure 25. Computer fitting of the Raman spectra of the sample \#42.

A set of the bands obtained by resolving the spectra of the glasses \#39 (Figure 22), \#40 (Figure 23 ), \#44 (Figure 27), and \#45 (Figure 28) within th rang of $850-1200 \mathrm{~cm}^{-1}$ into components is similar to those obtained from the spectra of glasses belonging to different group. The difference is within the range of $300-850 \mathrm{~cm}^{-1}$ where numerous bands are required to achieve good alignment between experimental and fitted spectra.

In the whole, for the spectra of all the glasses within the range of $850-1200 \mathrm{~cm}^{-1}$ the best fit is achieved in suggestion of overlapping of three major components with maxima at $911-936 \mathrm{~cm}^{-1}$, 988-996 $\mathrm{cm}^{-1}$ and $1020-1045 \mathrm{~cm}^{-1}$. For the best fit of spectra of the glasses \#39 and \#41 additional line with a maximum at 890-894 was required. So, it can be concluded that the structure of glasses is composed of metasilicate chains and rings containing incorporated $\mathrm{AlO}_{4}$ and $\mathrm{FeO}_{4}$ as well as minor $\mathrm{BO}_{4}$ tetrahedra. Major $\mathrm{BO}_{4}$ tetrahedra and $\mathrm{BO}_{3}$ triangles form complex borate units and are present as separate constituent.

Computer fitting of the range of $300-850 \mathrm{~cm}^{-1}$ is much more complicated. This range consists of numerous bands due to bending vibrations in silicon-oxygen network with incorporated $\mathrm{MeO}_{4}$ tetrahedra, symmetric stretching vibrations in silicon-oxygen network and stretching vibrations 


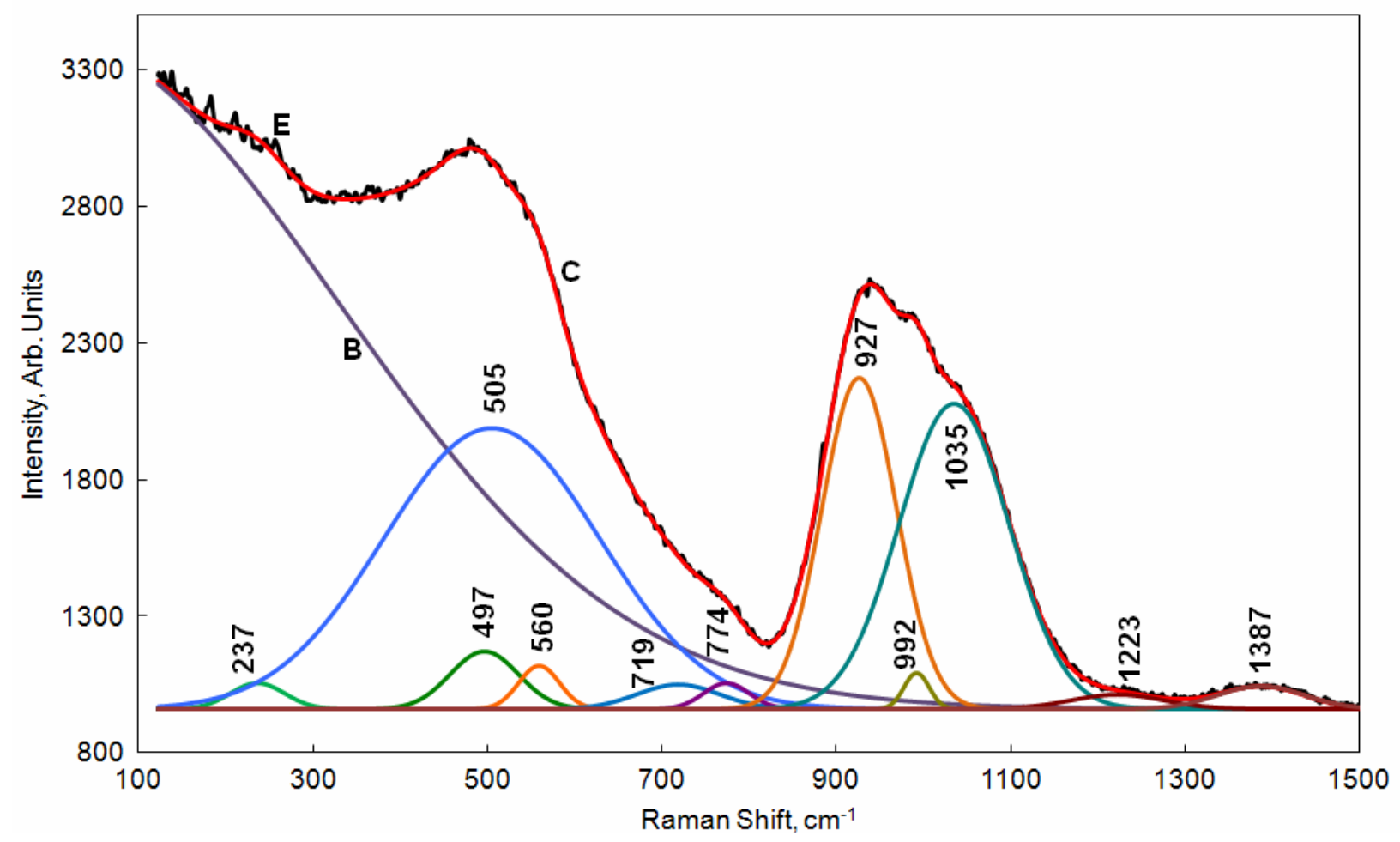

Figure 26. Computer fitting of the Raman spectra of the sample \#43.

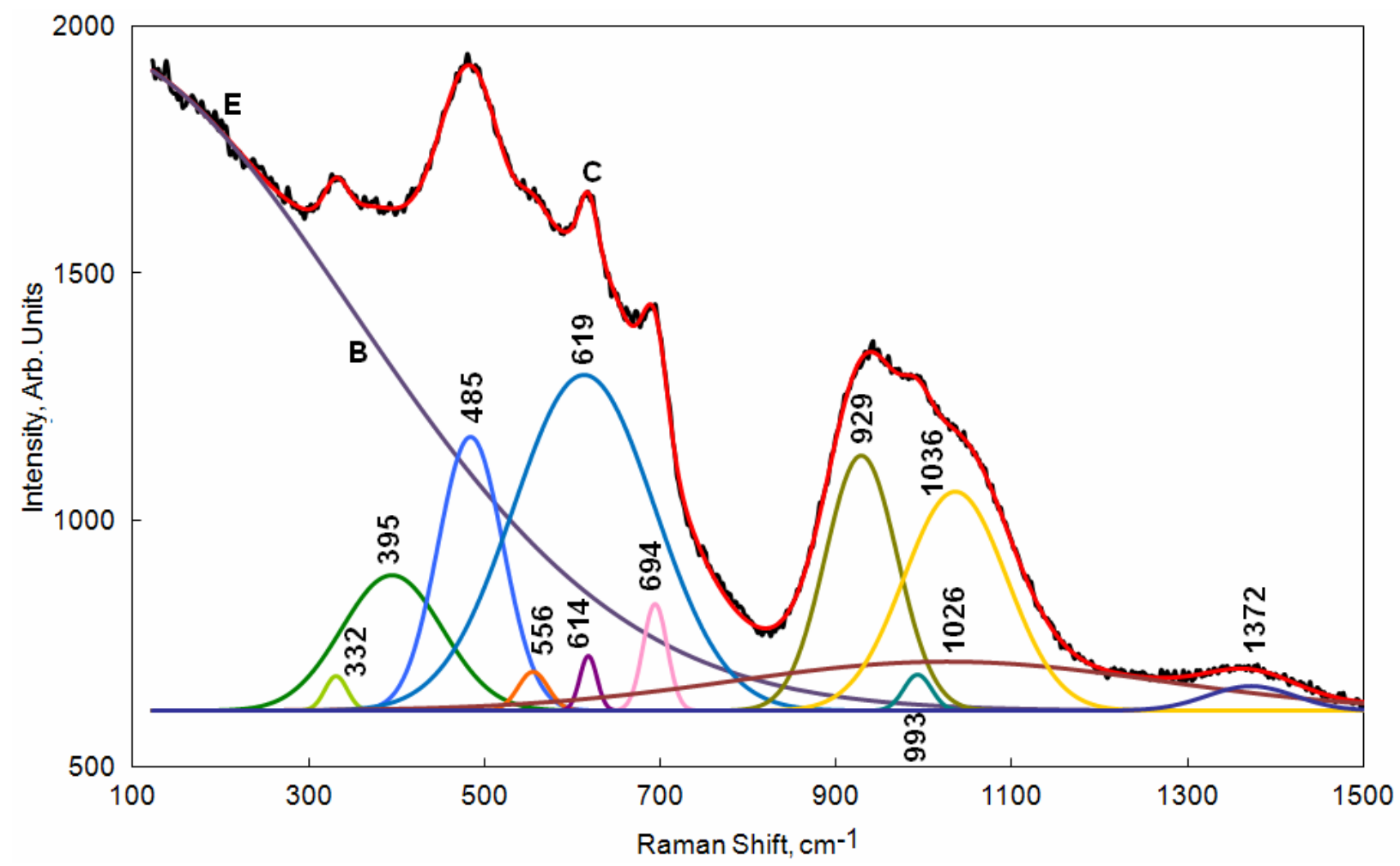

Figure 27. Computer fitting of the Raman spectra of the sample \#44. 


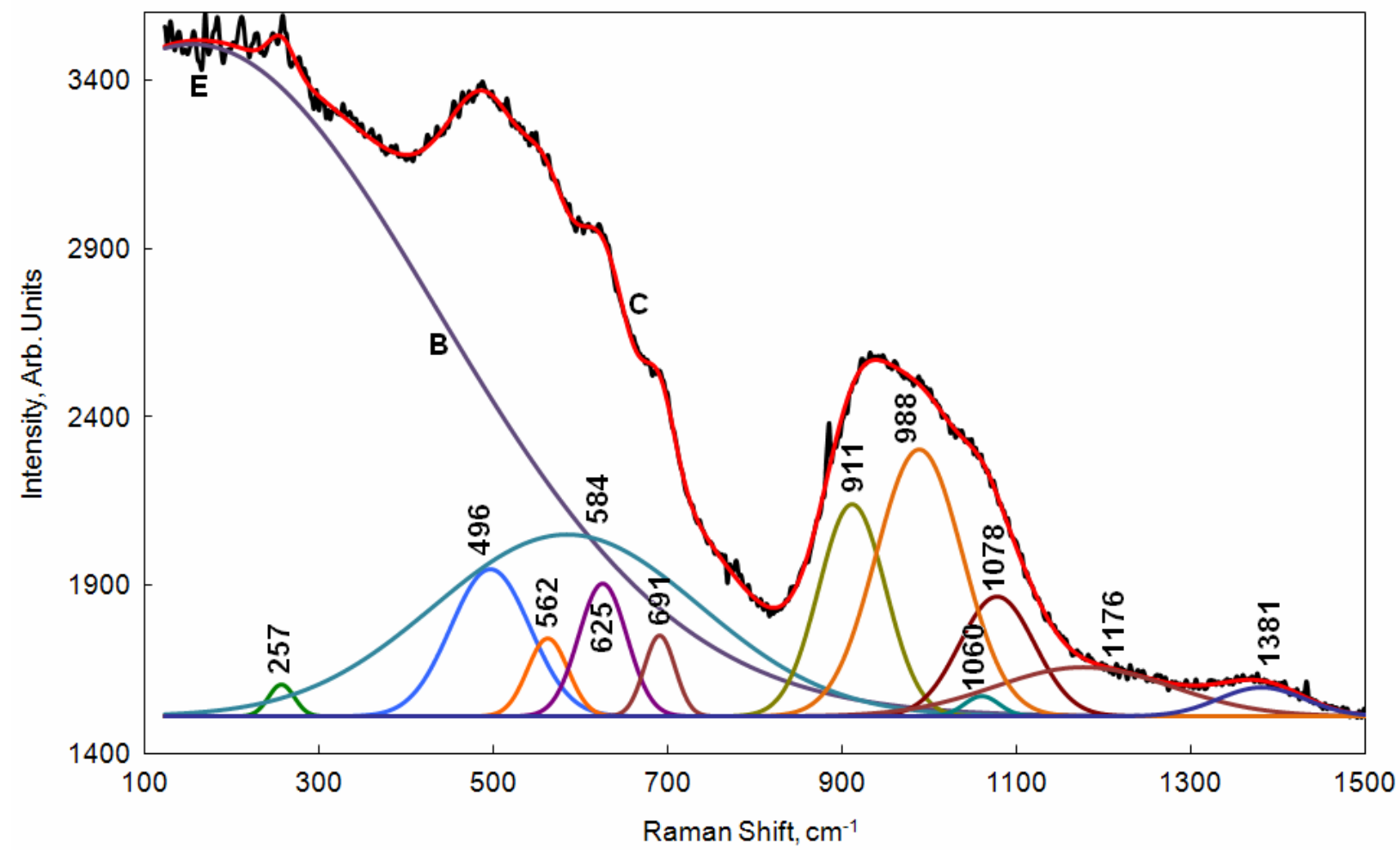

Figure 28. Computer fitting of the Raman spectra of the sample \#45.

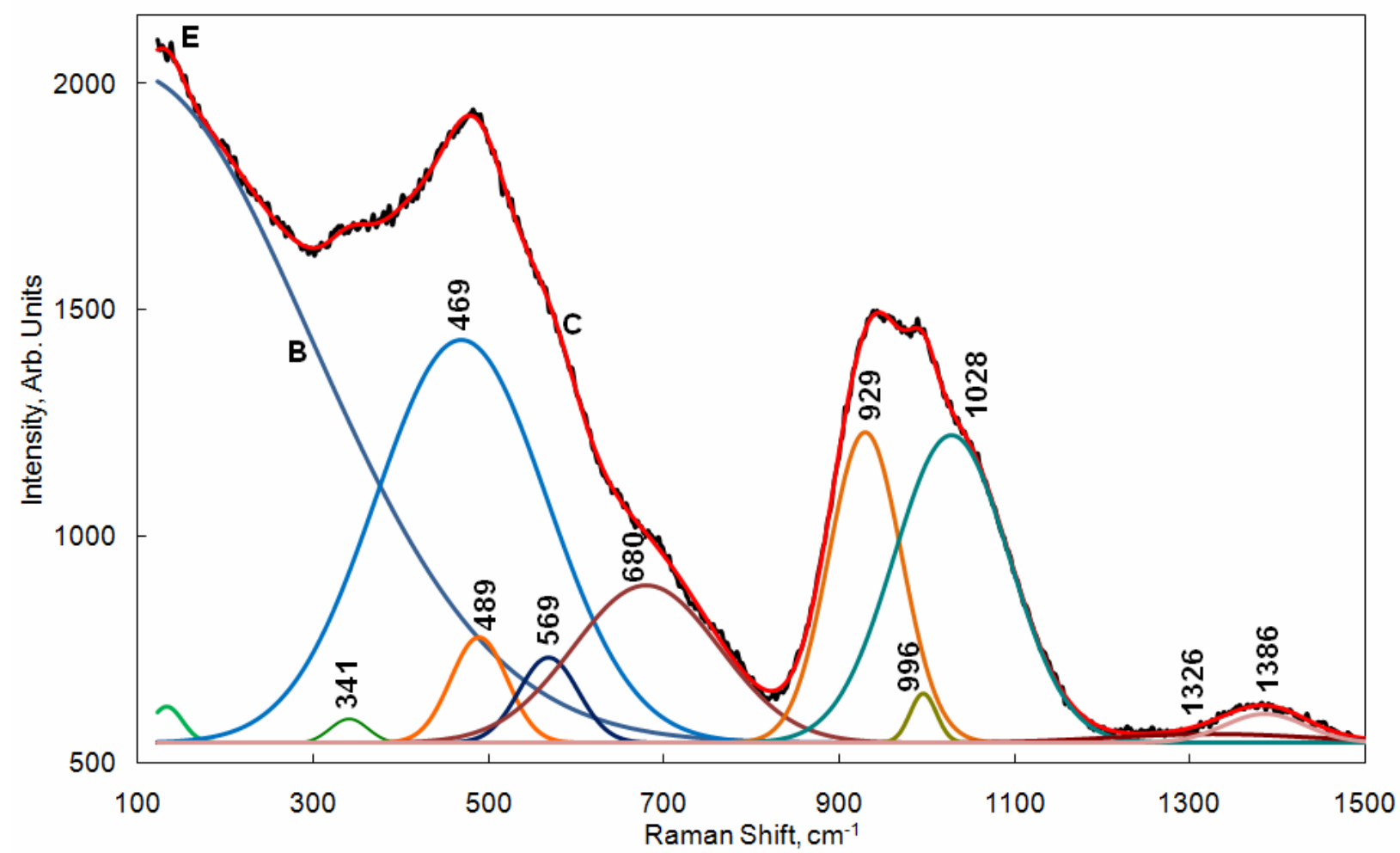

Figure 29. Computer fitting of the Raman spectra of the sample \#46. 
of $\mathrm{Me}-\mathrm{O}$ bonds in $\mathrm{MeO}_{\mathrm{n}}$ polyhedra as well the bands due to stretching and bending vibrations of $\mathrm{Me}-\mathrm{O}$ bonds in spinel. This makes attribution of the bands in this range rather difficult and ambiguous.

Nevertheless some general suggestions concerning attribution of the bands within this range may be done. If to compare Raman spectra of the glasses \#45 (Figure 28) and \#46 (Figure 29) related to two different groups, then we can see some similarity in behavior of the bands: i) occurrence of strong broad band due to bending vibrations of the bonds in silica-oxygen network and bridging bands $\mathrm{Si}-\mathrm{O}-\mathrm{Me}$ bonding $\mathrm{SiO}_{4}$ and $\mathrm{MeO}_{4}$ tetrahedra; ii) occurrence of the bands with maxima at $496 \mathrm{~cm}^{-1}$ or $489 \mathrm{~cm}^{-1}$ and $562 \mathrm{~cm}^{-1}$ or $569 \mathrm{~cm}^{-1}$ (for the glasses \#45 and \#46, respectively). At the same time the spectrum of the glass \#46 contains broad band centered at $680 \mathrm{~cm}^{-1}$ whereas in the spectrum of the glass $\# 45$ weak narrow band centered at $691 \mathrm{~cm}^{-1}$ is present. Moreover the spectrum of the glass \#45 contains an additional narrow band centered at $625 \mathrm{~cm}^{-1}$. If broad bands are due mainly to vibrations in low-symmetry structural units in random glass network, then narrow band are due probably to vibrations in high-symmetry structural units of the spinel structure phase.

Chemical composition of spinel may be represented by general formula $(\mathrm{Mg}, \mathrm{Mn}, \mathrm{Ni}, \mathrm{Cu})^{2+}(\mathrm{Fe}, \mathrm{Al})^{3+} \mathrm{O}_{4}$. Taking into account low $\mathrm{MgO}, \mathrm{NiO}$ and $\mathrm{CuO}$ contents, major contribution to these bands make vibration of $\mathrm{Fe}-\mathrm{O}$ and $\mathrm{Al}-\mathrm{O}$ bonds in $\mathrm{FeO}_{4}$ and $\mathrm{AlO}_{4}$ tetrahedra, and in much less extent, $\mathrm{Mn}-\mathrm{O}$ and $\mathrm{Fe}-\mathrm{O}$ bonds in $\mathrm{MnO}_{6}$ and $\mathrm{FeO}_{6}$ octahedra. Thus, the bands within the range of $300-500 \mathrm{~cm}^{-1}$ may be associated with vibrations of $\mathrm{Mn}-\mathrm{O}$ and $\mathrm{Fe}-\mathrm{O}$ bonds in $\mathrm{MnO}_{6}$ and $\mathrm{FeO}_{6}$ octahedra in the spinel structure. The bands at 550-650 are due mainly to vibrations of $\mathrm{Fe}-\mathrm{O}$ bonds in $\mathrm{FeO}_{4}$ tetrahedra in both spinel and glass structures and, in some extent in $\mathrm{FeO}_{6}$ octahedra. Vibrations of $\mathrm{Al}-\mathrm{O}$ bonds in $\mathrm{AlO}_{4}$ tetrahedra in both spinel and glass are positioned at $650-750 \mathrm{~cm}^{-1}$. For more precise simulation of the spectra within the range of $300-850 \mathrm{~cm}^{-1}$ special studies with the use of model compounds (surrogates) with the known structure are required.

\section{XAS study}

XAS spectrum of Fe K-edge was found to be the same in all the glasses studied (Figure 30). This spectrum corresponds to $\mathrm{Fe}^{3+}$ ions in mixed octahedral and tetrahedral surrounding [12]. EXAFS (Figure 31) and Fourier transform of EXAFS spectrum demonstrate that only first coordination shell is appeared whereas contributions from the second and subsequent shells are negligible. This shows the $\mathrm{Fe}^{3+}$ ions are rather homogeneously distributed in glass and fraction of spinel is minor.

Nevertheless the peak due to the first coordination shell is markedly asymmetric (Figure 32). Results of computer fitting of major peak are given in Table III.

Table III. Fitting of the Fe K Edge EXAFS Spectra of Glasses.

\begin{tabular}{|c|c|c|c|}
\hline Bond & Distance, $\AA$ & Coordination Number & Debye-Waller Factor \\
\hline $\mathrm{Fe}-\mathrm{O}_{1}$ & $1.74 \pm 0.02$ & $1.6 \pm 0.2$ & 0.003 \\
\hline $\mathrm{Fe}-\mathrm{O}_{2}$ & $1.94 \pm 0.02$ & $2.4 \pm 0.2$ & 0.003 \\
\hline $\mathrm{Fe}-\mathrm{O}_{3}$ & $2.07 \pm 0.02$ & $5.9 \pm 0.3$ & 0.004 \\
\hline
\end{tabular}




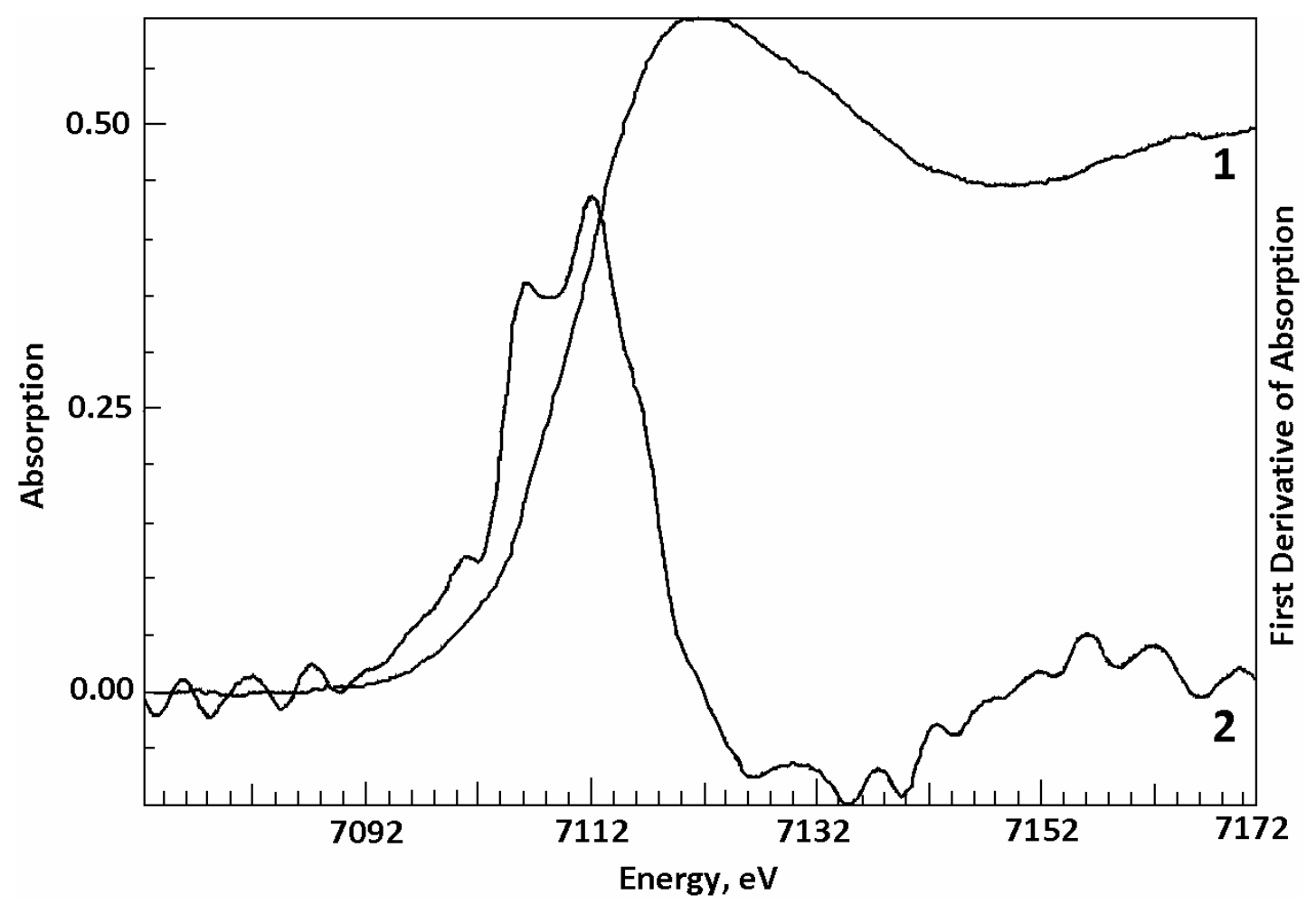

Figure 30. XAS (1) spectra of Fe K-edge and its XANES range (2) of the glasses.

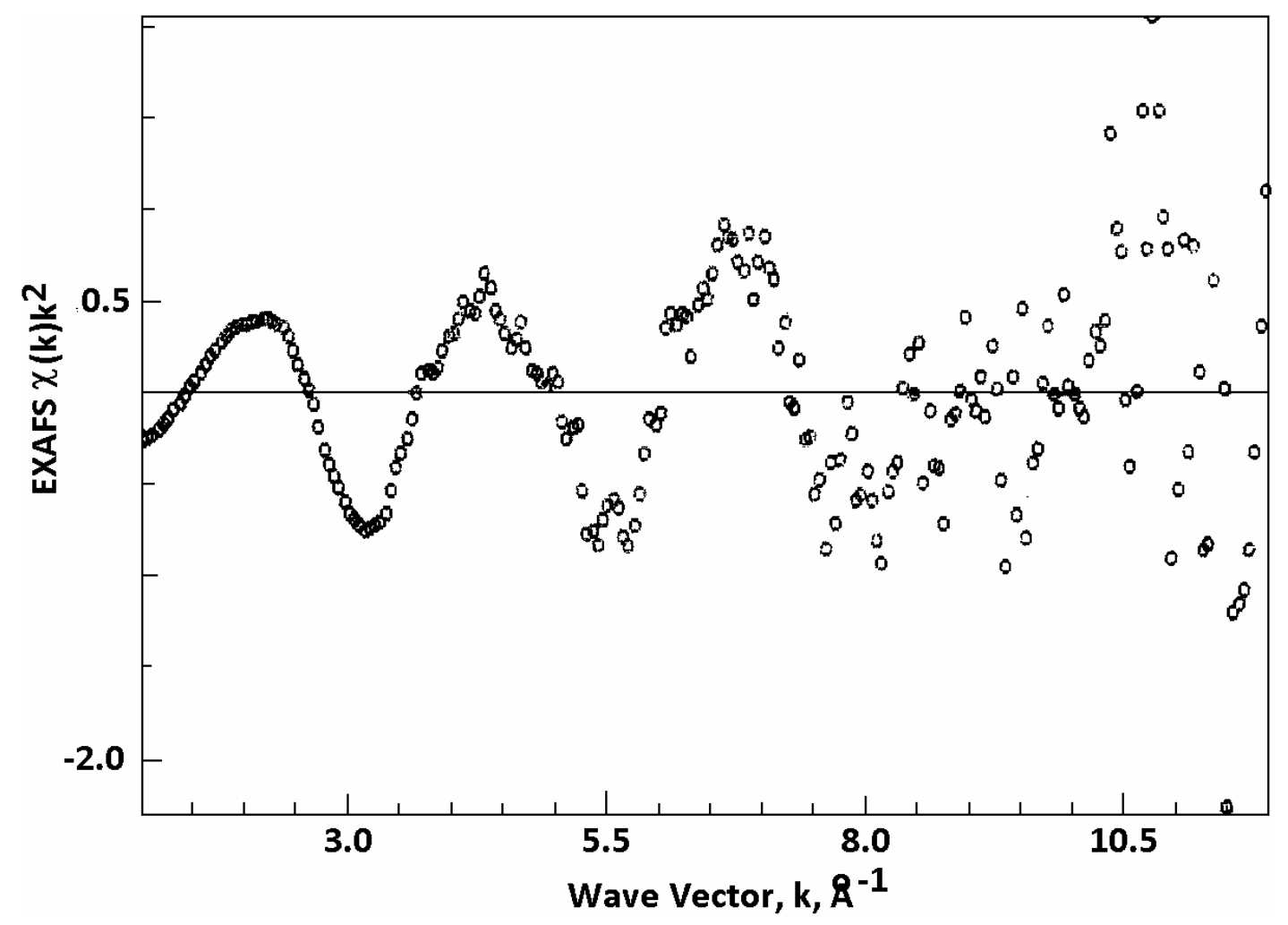

Figure 31. EXAFS of Fe K-edge of glasses. 


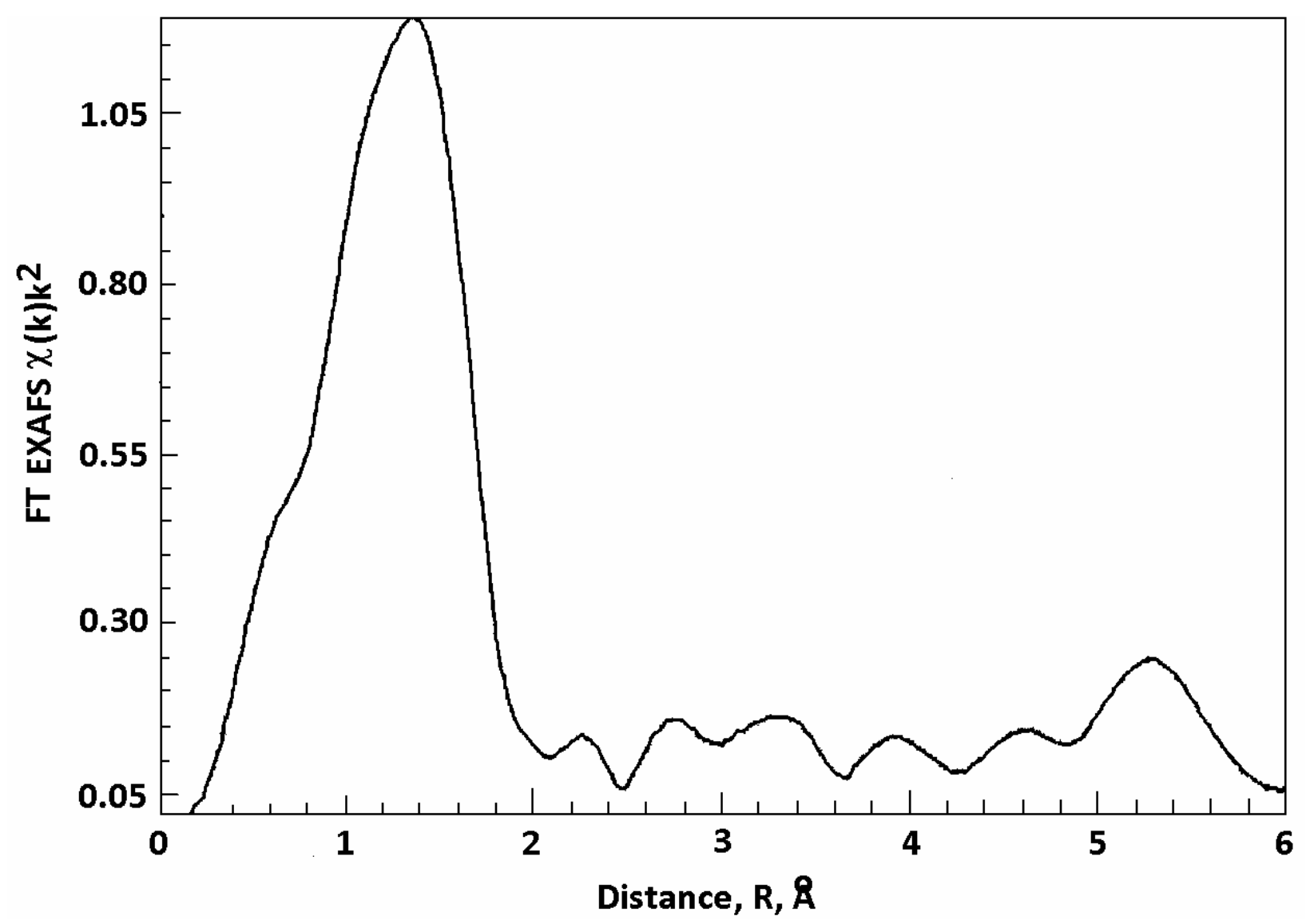

Figure 32. Fourier Transform of EXAFS Fe K-edge spectrum of glasses.

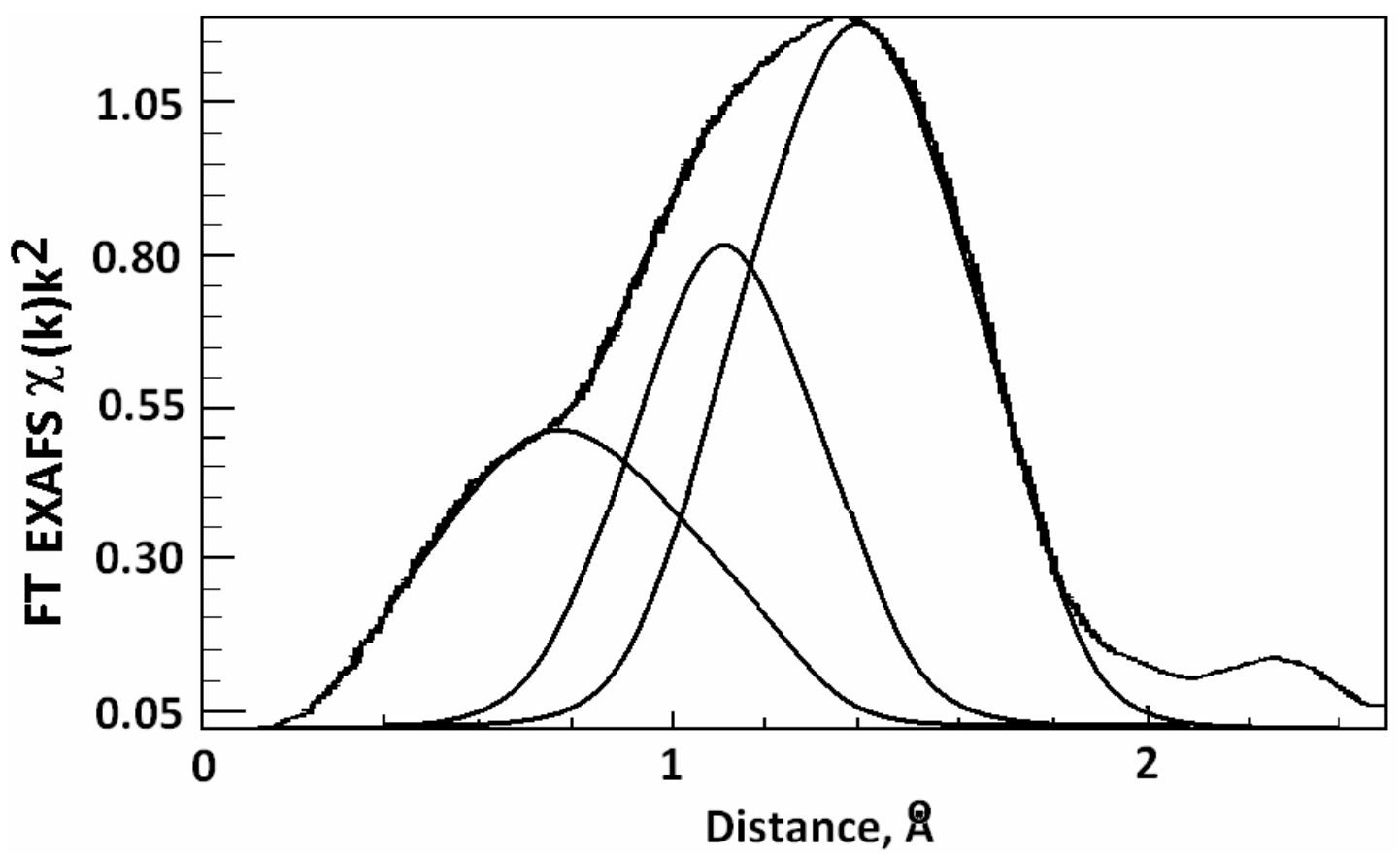

Figure 33. Computer fit of major peak in EXAFS spectrum of Fe K-edge in glasses. 
The first two distances are due to $\mathrm{Fe}-\mathrm{O}$ bonds in distorted tetrahedron. The third $\mathrm{Fe}-\mathrm{O}$ distance is close to that in $\mathrm{FeO}_{6}$ octahedra [13]. Contribution due to $\mathrm{Fe}-\mathrm{O}$ distances in spinel is very low.

\section{CONCLUSIONS}

All the glasses studied are composed of predominant vitreous phase and minor spinel structure phase. Spinel forms both isometric grains and cubic microcrystals $(\sim 1 \mu \mathrm{m})$. Microcrystals are aggregated in bands with variable glass and spinel contents. IR and Raman spectroscopic study the structure of all the glasses are similar and is composed of metasilicate chains and rings containing incorporated $\mathrm{AlO}_{4}$ and $\mathrm{FeO}_{4}$ as well as minor $\mathrm{BO}_{4}$ tetrahedra. $\mathrm{FeO}_{6}$ octahedral units may be also present. In the structure of all the glasses trigonally-coordinated boron dominats over tetragonally-coordinated. At that, major $\mathrm{BO}_{4}$ tetrahedra and $\mathrm{BO}_{3}$ triangles form complex borate units and are present as separate constituent.

As follows from XAS data, iron is predominantly present as $\mathrm{Fe}^{3+}$ ions. Major $\mathrm{Fe}^{3+}$ ions are tetrahedrally-coordimated and built in silicon-oxygen network. Minor $\mathrm{Fe}^{3+}$ ions are octahedrallycoordinated and may be considered as network-modifiers. Contribution due to spinel is negligible.

\section{REFERENCES}

1. A.A. Appen, Chemistry of Glass (Russ.), Khimiya, Leningrad (1974).

2. B. Ravel and M. Newville, J. Synchrotron Radiat. 12 537-541 (2005).

3. A.L. Ankudinov and J.J. Rehr, Phys. Rev. B 56 1712-1716 (1997).

4. H. Funke, A.C. Scheinost and M. Chukalina, Phys. Rev. B, 71, 094110 (2005).

5. H. Funke, M. Chukalina and A.C. Scheinost, J. Synchrotron Radiat. 14, 426-432 (2007).

6. www.esrf.fr/exp facilities/BM20/Software/Wavelets.html.

7. V.A. Kolesova, Glass Phys. Chem. (Russ.) 12 [10] 4-13 (1986).

8. V.N. Anfilogov, V.N. Bykov, and A.A. Osipov, Silicate Melts (Russ.), Nauka, Moscow (2005).

9. I.I. Plyusnina, Infrared Spectra of Minerals (Russ.), MGU, Moscow (1977).

10. K. Nakamoto, Infrared Spectra of Inorganic and Coordination Compounds, John Wiley \& Sons, Inc. New York - London (2009).

11.

12. G.E. Brown, Jr., G.A. Waychunas, C.W. Ponader, W.E. Jackson, and D.A. McKeown, EXAFS and Near Edge Structure IV - J. de Physique. 47 C8, suppl. Au n¹2, C8-661 - C8668 (1986).

13. G. Licheri, G. Paschina, G. Piccaluga, G. Pinna, M. Magini, and G. Cocco, J. Non-Cryst. Solids, 72, 211-220 (1985). 
SRNL-STI-2010-00767

Revision 0 


\section{Distribution:}

S. L. Marra, 773-A

W. R. Wilmarth, 773-A

S. D. Fink, 773-A

C. M. Jantzen, 773-A

A. M. Murray, 773-A

A. P. Fellinger, 773-42A

F. M. Pennebaker, 773-42A

D. A. Crowley, 773-43A

B. J. Giddings, 786-5A

A. B. Barnes, 999-W

C. C. Herman, 999-W

D. K. Peeler, 999-W

K. M. Fox, 999-W

J. E. Occhipinti, 704-S

D. C. Sherburne, 704-S

J. F. Iaukea, 704-30S

T. L. Fellinger, 704-26S 